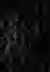

(5)
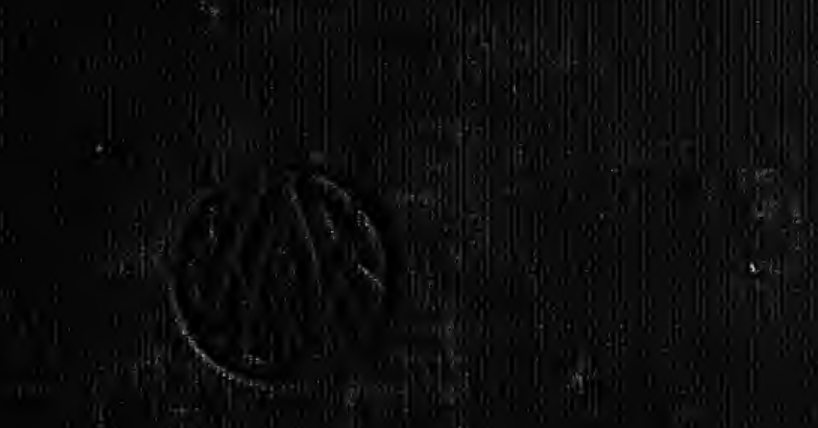

4.

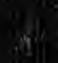

MI

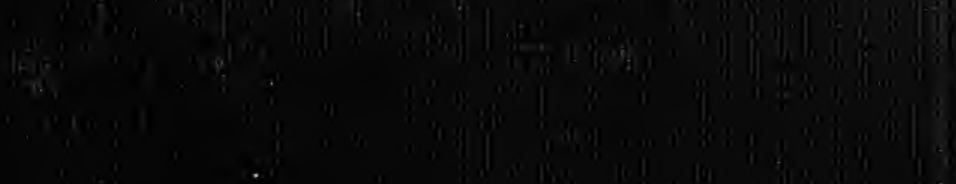




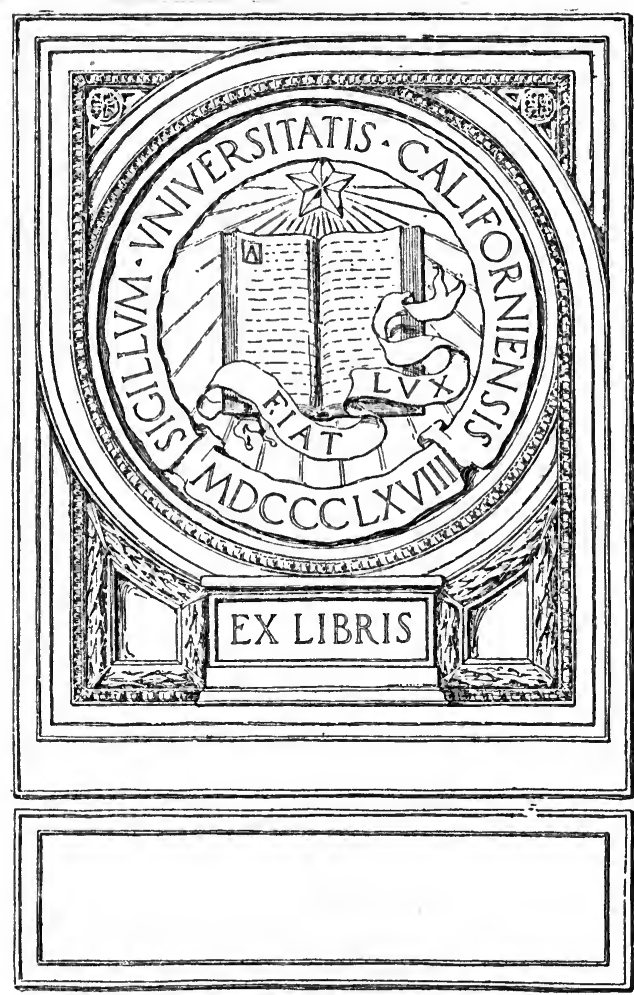






\title{
THE
}

\section{PHYSICAL CHEMISTRY OF THE METALS}

\author{
BY \\ RUDOLPH SCHENCK \\ Professor of Physical Chemistry in the Technischen Hochschule \\ in Aachen
}

\author{
TRANSLATED AND ANNOTATED BY \\ REGINALD SCOTT DEAN \\ Research Metallurgist, American Zinc, Lead and Smelting Co.; \\ St. Louis, Mo.
}

FIRST EDITION

NEW YORK

JOHN WILEY \& SONS, INC.

LONDON: CHAPMAN \& HALL, LIMITED 


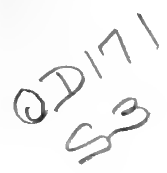

Copyright, I9I9, BY REGINALD S. DEAN

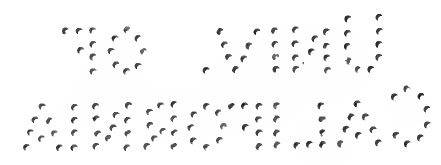

PRESS OF

BRAUNWORTH \& CO. SOOK MANUFACTURERS BROOKLYN, N. $Y$. 


\section{PREFACE}

THERE is perhaps no field where physical chemistry is of more value than in the field of metallurgy and metallography. In the latter field its usefulness has been recognized almost from the first but in the field of metallurgy its application has not been so general. It is hoped that this translation may aid in making the value of chemical dynamics and equilibrium clear to the metallurgist and metallurgical student.

Such additions as have seemed necessary have been incorporated in the text and the numerical data have been revised to agree with the accepted values. I have deemed it advisable not to go into the recent investigations concerning the electron theory since the scope of the work did not seem to warrant an extended treatise on this subject.

The book has been changed from lecture to text-book form and the references shifted from the appendix to the body of the book.

My thanks are due to Mr. A. T. McPherson of the U. S. Bureau of Standards for reading the manuscript as well as for many valuable suggestions. I wish also to thank Dr. Edward Schramm, director of this laboratory, for his encouragement and cooperation in the work of translation.

St. Louis, Mo.

Reginald S, Dean.

March, I9I9. 



\section{PREFACE TO THE GERMAN EDITION}

THIs little book is the outcome of a series of lectures which I delivered in 1907, in the "Technischen Hochschule," at Aachen. Their purpose was to show the engineers of the Rhenish industrial district, before whom they were delivered, the use of chemical statics and to deepen their understanding of smelting operations and metallurgical processes.

I have endeavored, especially, to develop the principles of equilibrium clearly and so far as possible by the use of pertinent examples.

In the systematic survey of such a field new problems naturally arise and there is found in these lectures some heretofore unpublished data bearing on these problems, among which may be mentioned: the equilibrium between the various components of steel, the quantitative determination of amorphous carbon and graphite, and the investigation of the sulfatizing roast.

It has not been possible to consider here, all of the experimental matter relating to the physical chemistry of metals, but all fundamental questions have been treated rather thoroughly.

I wish to thank Dr. P. Goerens, for the preparation of the metallographs and photographs; Dr. Hemplemann, for his assistance in the preparation of the index, and Dr. Ratzbach, for the preparation of the diagrams.

Aachen.

THE AUTHOR.

July, r908. 



\section{CONTENTS}

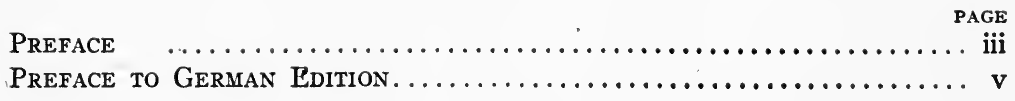

\section{CHAPTER I}

Introduction, Properties of Metals $\ldots \ldots \ldots \ldots \ldots \ldots \ldots \ldots$ I-38

Introduction, I. Form Changes, 3. Vapor Pressure and Volatility, 3. Monatomic State of Metal Vapors, 5. Color of Metal Vapors, 6. Vapor Pressure and the Definition of Melting Point, 7. Melting Points of Metals, 8. Density Change on Melting, 9. Heat of Fusion, 9. Cooling Curves, Io. Polymorphy, II. Analogy of Polymorphic Transition to Melting, 14. Determination of the Transition Point, 14. Explosive Antimony, 17. Enantiotropy and Monotropy, 18. Crystal Growth, 20. Electrical and Optical Properties of Metals, Conductivity, 2I. Faraday's Law, 22. Metallic and Gaseous Conduction, 22. Electron Theory, 23. Law of Wiedemann and Franz, 23. Optical Properties of Metals; Light Reflection and Absorption, 27. Metallic Luster, 28. Electron Concentration of Metals, 30. Temperature Coefficient of Conductivity, 31. Thermo-Electric Force, 32. Passivity in Metals, 34.

\section{CHAPTER II}

Metallic Solutions And Alloys..................... 39-8I

Colloidal Metal Solutions, 39. Dilute Metallic Solutions, 4I. Vapor Pressure of Metallic Solutions, 42. Freezing Point of Alloys, 44. Metals only Partially Miscible in the Liquid State, 46. The Parkes Process, 47. Solidification Curve of Binary Alloys, the System CadmiumZinc, 49. The Pattison Process, 52. Segregation in Alloys, 52. Investigation of Alloy Structure, 53. Solid Solutions, 55. The Heræus Process of Plating Platinum with Gold, 57. Crystallization Diagrams for Metals Forming Solid Solutions, 57. Inter-metallic Compounds, 60. Ternary and Quaternary Alloys, 64. Relations of Mechanical and Physical Properties to Alloy Structure, 68. Bearing Metals, 69. Density of Alloys, 7o. Potential of Alloys, 72. Electrical Resistance of Alloys, 73. Thermo-electric Force of Alloys, 80. 


\section{CHAPTER III}

Alloys of Metals with Carbides, Oxides and Sulfides, Iron and Steel, Mattes, Phase Rule..................... 82-1 38

Compounds with Metallic Properties, 82. The Iron-Carbon Alloys, 83. The Crystallization of the System Iron-Cementite, 85. Perlite and its Transition Products, 93. The Precipitation of Carbon in Iron-Carbon Alloys, 98. The Uses of Additions to Iron and Steel, I04. Alloys of Metals and Oxides; Copper-Copper Oxide, IIo. Silver-Silver Oxide, II3. Alloys of Metals and Sulfides, II4. Lead-Lead Sulfide, I15. Antimony-Antimony Sulfide, II5. Copper Copper Sulfide, i 6 . Silver-Silver Sulfide, I18. IronIron Sulfide, I20. Nickel-Nickel Sulfide, I22. Alloys between Sulfides, I23. Phosphorus and Arsenic Containing Alloys, I25. Silicides of Metals, I3r. The Phase Rule, I33.

\section{CHAPTER IV}

The Metallurgical Reactions, Oxidation and Reduction........ I39-i69

Equilibrium between Metal, Oxide and Oxygen, I40. The Application of the Phase Rule, 140. Oxygen Tension of Oxides, I4I. Oxygen Tension in Atmospheres, r43. The Equilibrium between two Oxides and Oxygen, 145. Direct Decomposition of Oxides by Heat, 148. Reduction by Metals, 149. Reduction by Gaseous Reducing Agents, 149. Reduction by Hydrogen, I50. The Phase Rule, 150. LeChatelier's Principle, 151. The Mass Law, I52. Van't Hoff's Equation, I56. Reduction by Carbon Monoxide, 159 .

\section{CHAPTER V}

Decomposition of Carbon Monoxide, Blast furnace Process.... 170-204.

Catalytic Decomposition of Carbon Monoxide, I 70. Equilibrium between Carbon Monoxide and Iron, 173. The Analysis of Mixtures of Graphite and Amorphous Carbon, 178. The Blast Furnace Process, 180. The Mond Nickel Process, 202. 


\section{THE PHYSICAL CHEMISTRY OF THE METALS}

\section{CHAPTER I \\ INTRODUCTION, PROPERTIES OF METALS}

IT is a well-known fact that the metal industry is based largely on chemical knowledge. The metals were the first chemically defined substances to be recognized, and the first to be obtained by chemical means; it was thus that man acquired the beginning of his hard-earned chemical knowledge.

What a heritage of facts has come to the present day chemist simply through the efforts of the alchemist to change base metals into noble. Interest in the chemistry of metals has never lagged; the mines and the pits of the furnaces were to Berzelius and many other chemists the inspiration to notable new investigations; the application of new agents, particularly the voltaic battery, in the electric decomposition of salts, have brought to light new metals with remarkable properties, for example, sodium, potassium, aluminium, magnesium and many more. The names of Davy, Wöhler, and Winkler recall to our minds what great advances the chemistry of metals has made in the past century. These include the discovery not only of new metals but also of the methods by which mineral substances are recognized and their amounts determined with certainty.

Technical chemists, especially metallurgists, are already convinced of the value of chemical analysis, not only in the investigation of ores, but in the control of processes. Experience has shown that the success or failure of a smelter, may, under 
certain conditions, depend on the reliability of its analyst. The introduction of chemical analysis into smelters was the first great advance toward rational operation.

In the course of the last century the machine industry and the electrical industry have made unheard-of progress; the metallurgical industries, especially that of iron and steel, are now growing into a sphere of new problems. The purchaser demands not only large amounts of material at the lowest possible price, but he also places entirely new and definite demands on the quality of the same. Bridge and machine builders need steel of definite mechanical properties, the electrical industry needs steel of definite magnetic properties, the tool manufacturer, a steel that retains its hardness when hot, ships and machines, needles and pins, wire and sheet, cook stoves and furnaces all are made of iron and each one requires an entirely different material. Iron must play the part of a veritable Proteus to possess all these properties which are often diametrically opposite. It is astounding that one metal is endowed with so great a variation in its properties and it is remarkable that the industries have found a use for this material in each of its notable properties.

The growth of our metal industries is largely due to machine and bridge building, since the carrying out of a large number of these projects required appropriate material and the smelterman was thereby directed to experiments and tests for their production.

Many problems in metallurgy cannot be solved by means of analytical chemistry, since it is often found that material of basically different properties gives identically the same analysis and that extraordinary relations in physical properties are afforded no explanation by the analysis.

Structural chemistry, as developed for organic compounds, also fails to be of value here, and accordingly the only resort was the purely empirical. Every empirical process that we know works uneconomically; a success follows ten failures; every successful advance is costly in experience and money.

All the phases of metallurgy have not yet been placed on a scientific basis, but some of the obscurities have been disposed 
of and progress made in the solution of some of the problems presented by the smelting art. This has been accomplished by means of physical chemistry; especially through chemical mechanics which for metallurgical engineers and technical chemists possesses the same importance that physical mechanics does for bridge and machine builders.

We will now attempt with the examples at hand to present a picture of the manner in which the problems of metallurgy are solved with the help of physical chemistry.

We will not consider the electrochemical relations of the metals as electro-metallurgy has long since left the scientific nursery, gone out into life and proved its worth.

We may not, however, overlook the youngest branch of electrical science, the electron theory of metals, since it explains many of the remarkable physical peculiarities of the metallic state.

\section{Form Changes.}

We must first consider certain physical phenomena which the metals show in common with non-metallic substances but which play an especially important role in the working of the metals. They are the form changes which the metals undergo at high temperatures, the phenomena of vaporization, of melting, and the polymorphic transitions in the solid state. For the present we shall limit ourselves to the pure metals, later taking up solutions and mixtures.

\section{Vapor Pressure and Volatility.}

A number of metals go over easily to the gaseous state. The volatility of mercury is detectable at atmospheric temperatures and cadmium and zinc are obtained by the use of a distillation process. The boiling points of these metals are relatively low. At high temperatures such as can be obtained in the oxy-hydrogen flame, the less volatile metals are vaporized. It is known that silver distils at such temperatures since Stas in his classical investigations on atomic weights purified silver in this way. At the highest temperature of the electric arc there is no metal that does not vaporize. 
Moissan* succeeded with the help of a strong current in boiling and distilling most metals; copper and gold as well as platinum, palladium, iridium, rhodium, ruthenium, and osmium can be vaporized and precipitated again on a cooled metal surface. Of the iron group, manganese is known to be the most volatile, then nickel and then chromium. Iron itself boils with relative difficulty and the boiling points of uranium, molybdenum and tungsten are still higher but they are undoubtedly volatile in an electric arc.

Many metals that are difficultly vaporized at ordinary pressures are easily brought to vaporization and distillation under strongly reduced pressure. Krafft and Kahlbaum $\dagger$ and Roth and Siedler $\ddagger$ have made investigations of this kind. The latter have purified gold, silver, copper, lead, bismuth and antimony by distillation in the highest obtainable vacuum and investigated a series of properties of the metals so purified.

The following table gives the approximate values for the boil. ing points of metals so far as they have been determined. The values are those given by J. Johnston, J. Ind. Eng. Chem. 9, 873 (I9I7), unless otherwise noted.

\begin{tabular}{|c|c|c|c|}
\hline Metal. & $\underset{\text { Degrees C }}{\text { Boiling Point.* }}$ & Metal. & $\underset{\text { Degrees C }}{\text { Boiling Point.* }}$ \\
\hline Cadmium..... & 780 & Chromium......... & 2200 \\
\hline Zinc.............. & 920 & Tin...$\ldots \ldots \ldots$ & 2260 \\
\hline Magnesium.......... & II 20 & Copper............ & 2350 \\
\hline Thallium........ & 1300 & Nickel. ..... & 2400 \\
\hline Bismuth........... & 1440 & Iron........ & 2450 \\
\hline Antimony... & 1440 & Arsenic...... & 610 \\
\hline Lead.......... & 1640 & Platinum $\dagger \ldots \ldots \ldots$ & 3907 \\
\hline Aluminum..... & 1800 & Molybdenum $† \ldots \ldots$ & 3617 \\
\hline Manganese.......... & 1900 & Tungsten $\nmid \ldots . . .$. & 4827 \\
\hline \multirow[t]{2}{*}{ Silver............. } & 2090 & Sodium $\neq \ldots \ldots \ldots \ldots$ & 742 \\
\hline & & Mercury $\ddagger \ldots \ldots \ldots$ & 357.25 \\
\hline
\end{tabular}

* i.e., the temperature at which the vapor pressure is $760 \mathrm{~mm}$. † Langmuir, Phys. Rev. 2, 329 (I9I3).

¥ From Schenck's table.

* Compt. rend., 141, 853: 977 (1905). 142, I89; 425; 673 (1906).

† Ber. 36, 1690 (1903).

Z. anorg. Chem., 29, I77 (I902). 
For volatile substances every temperature corresponds to a definite vapor pressure which increases with rising temperature. The relation between the two has been investigated by Barus and others. The approximate boiling temperatures of metals at various pressures, i.e., the temperature at which their vapor pressure is $10^{-3} \mathrm{~mm}$., etc., is given in the following table taken from Johnston.

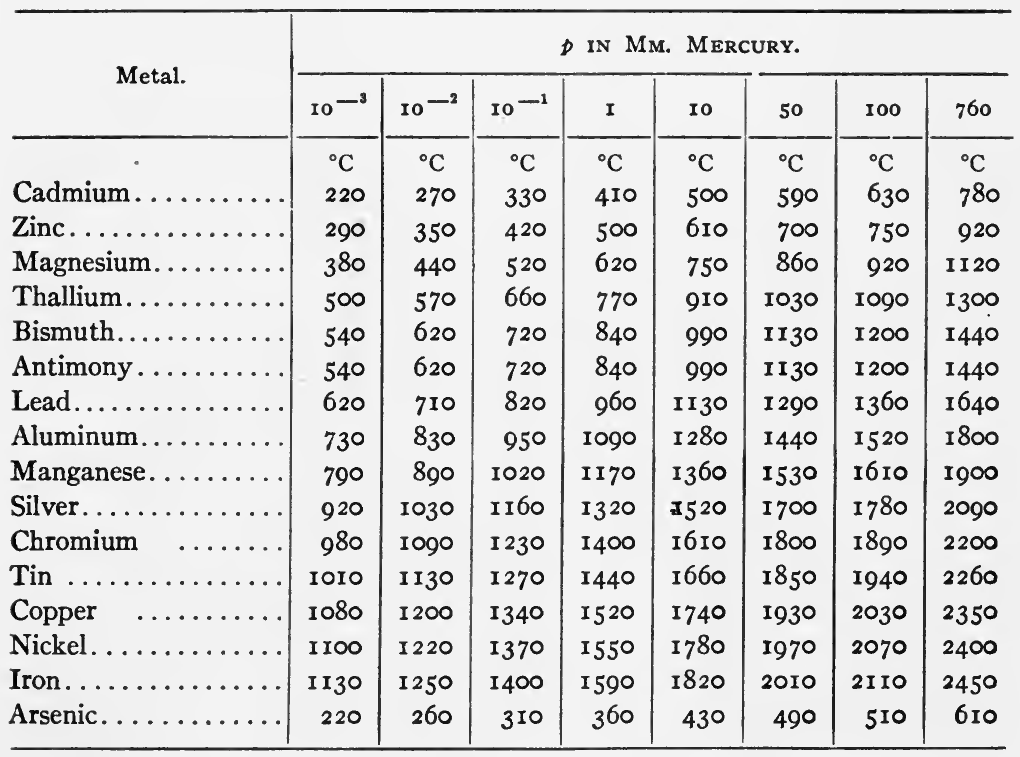

If the relation of the vapor pressure to the temperature for any metal be represented graphically, a curve is obtained which corresponds to the vapor pressure curve of non-metallic substances, for example, water. (Fig. I.)

\section{Monatomic State of Metal Vapors.}

In calculating the molecular weight from the vapor density of metals it is seen that the molecules consist of only one atom, differing in this respect from most other substances. The monatomic state of the vapor has been established not only for the easily vaporized metals, mercury, cadmium and zinc (Victor Meyer) * but also for the difficultly vaporizable metals

* Ber. 12, 1426 (1879). 
bismuth, antimony, lead, and thallium (von Wartenberg.*) The monatomic state is also revealed by another circumstance. Gases have recognizedly two different specific heats. The amount of heat which we must bring into a gas in a closed constant volume to raise it to a higher temperature is smaller than that required to accomplish the heating at constant pressure. In the latter case the gas increases in volume and thereby performs work. It can be deduced from the kinetic theory

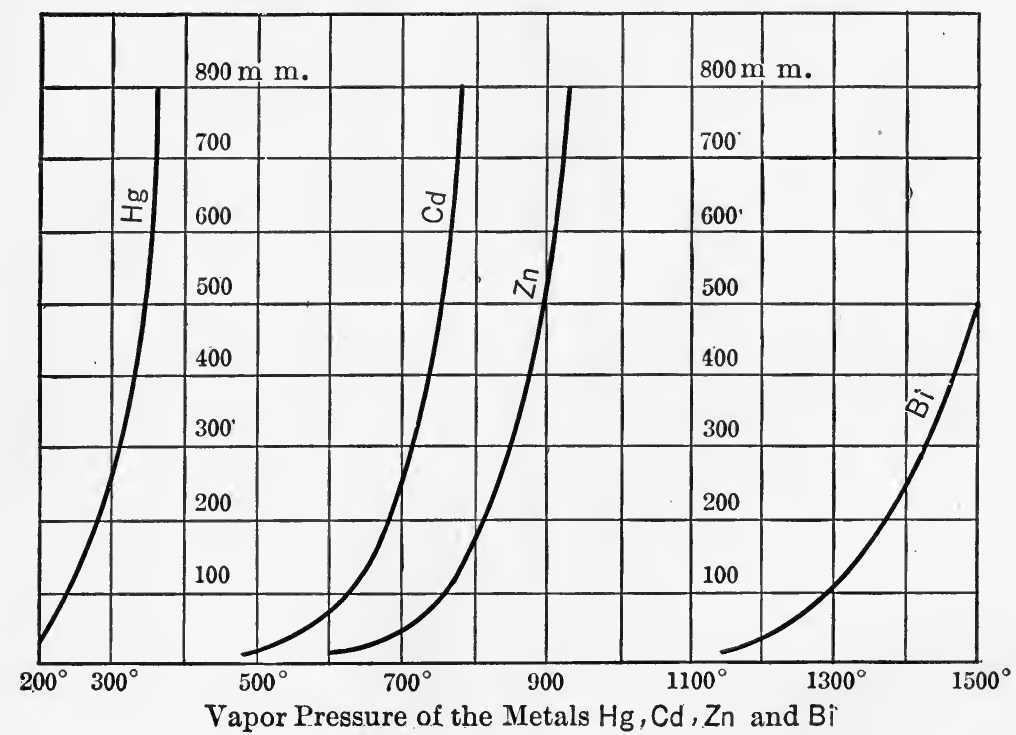

FIG. I.

that for a monatomic gas the ratio of the specific heat at constant pressure to that at constant volume must have a definite value, namely I.667. Kundt and Warburg $\dagger$ found the value I.666 for mercury vapor. Besides the metals only the rare gases of the atmosphere, argon, xenon, helium, krypton, and neon are monatomic. The molecules of all other substances are polyatomic.

\section{Color of Metal Vapors.}

The vapors of the metals often show an intense coloring which is especially easy to observe with potassium vaporized

*Z. anorg. Chem., 56, 320 (1907). † Pogg. Ann., 157, 353 (1878). 
in an atmosphere of hydrogen. The color of the vapor is intensely green. Sodium vapor is blue. It is the powerful absorption of these metal vapors which gives rise to the Frauenhofer lines in the solar spectrum.

\section{Vapor Pressure and the Definition of Melting Point.}

We must ascribe to all substances, the capacity of sending off vapor molecules from their upper surfaces. That we cannot observe them is due to their smallness and the relative insensibility of our methods. Vaporization is not confined to liquids, for solids also vaporize and have a definite vapor tension. For the volatile solid substances as iodine and camphor its magnitude can be readily determined. Substances like benzene and naphthalene whose vapor pressures can be readily measured in both the solid and the liquid state have been investigated and the relation of vapor pressure to temperature established for both states. From this it has been found that each state has a special vapor pressure curve. It is seen from Fig. 2 that these curves must intersect once and the temperature of this intersection is no other than the melting point. The melting point

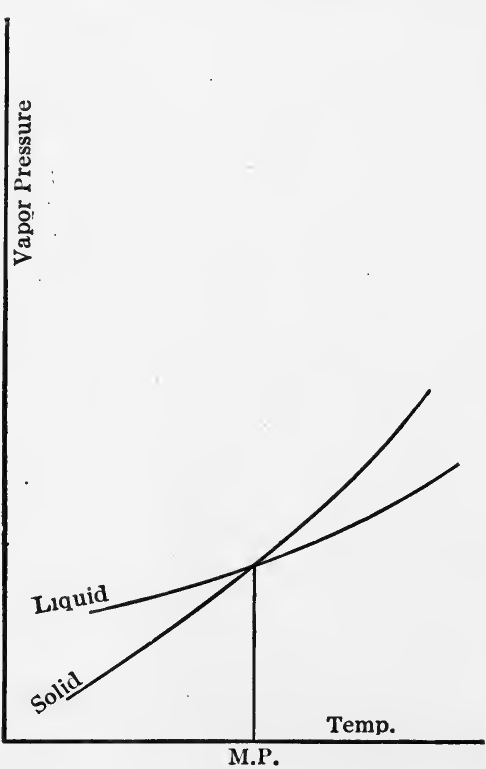

FIG. 2 . of a substance may accordingly be defined as the temperature at which the vapor pressure of the solid substance is equal to that of the liquid. The melting point is an equilibrium point at which solid and liquid can exist together. If heat be added to a substance at its melting point the solid will disappear without change of temperature after which the temperature will rise. If heat be subtracted the liquid will solidify and the temperature will only fall after the entire mass is solid. It is sometimes 
possible, however, to cool a liquid below its melting point without the separation of solid taking place. Such liquids are said to be supercooled. The supercooled liquid has a vapor pressure curve which is a direct continuation of that part of the liquid curve which lies above the melting point. Its vapor pressure is always higher than that of the solid at the same temperature, crystallization is therefore accompanied by a decrease in vapor pressure. Above the melting point the liquid has a lower vapor pressure than the solid would possess if it could be observed there. The transition of liquid into solid, or conversely of solid into liquid always takes place in the direction which results in a decrease of vapor pressure. The state with the lower vapor pressure is always stable, that with the higher always metastable. At the point of equal vapor pressure, that is, the melting point, both states are equally stable and there is no tendency to change.

\section{Melting Points of Metals.}

The melting points vary greatly for different metals. The most recent values are given in the table below.

\begin{tabular}{|c|c|c|c|}
\hline Mercury............ & $\begin{array}{l}{ }^{\circ} \mathrm{C} \\
-38.87\end{array}$ & Barium .......... & $\begin{array}{l}{ }^{\circ} \mathrm{C} \\
850\end{array}$ \\
\hline Cæsium............. & 26 & Germanium........ & $95^{8}$ \\
\hline Gallium............. & 30. I & Silver........... & 960.5 \\
\hline Rubidium.......... & 38 & Gold............. & 1063.0 \\
\hline Potassium.......... & 62.3 & Copper............. & 1083.0 \\
\hline Sodium...$\ldots \ldots \ldots$ & 97.5 & Manganese....... & 1230 \\
\hline Indium...$\ldots \ldots \ldots$ & I55 & Nickel. . . . . . . . . . & $145^{2}$ \\
\hline Lithium............ & I86 & Cobalt............. & 1480 \\
\hline Tin................ & 231.9 & Chromium........... & I6I5 \\
\hline Bismuth............ & 271 & Iron.............. & I 530 \\
\hline Thallium......... & 302 & Palladium.......... & I549 \\
\hline Cadmium......... & 320.9 & 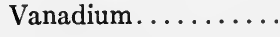 & I 720 \\
\hline Lead............ & 327.4 & Platinum........... & I 755 \\
\hline 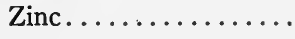 & 419.4 & Titanium........... & I800 \\
\hline Antimony .......... & 630 & Uranium........... & $<1850$ \\
\hline Magnesium......... & 651 & Rhodium........... & I950 \\
\hline Aluminum.......... & 658.7 & Iridium...$\ldots \ldots \ldots$ & 2350 \\
\hline Radium........... & 700 & Ruthenium........ & 2450 \\
\hline Calcium............ & 810 & 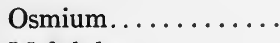 & 2700 \\
\hline Lanthanum........... & 870 & Molybdenum ........ & 2550 \\
\hline Strontium......... & $>\mathrm{Ca}<\mathrm{Ba}$ & Tantalum.......... & 2900 \\
\hline Arsenic............ & $8 \mathrm{I} 7^{*}$ & Tungsten........... & $3540 \dagger$ \\
\hline
\end{tabular}


The values are those adopted by the U. S. Bureau of Standards* except where recent determinations have given more trustworthy figures.

\section{Density Change on Melting.}

The process of melting is accompanied by a sudden change in physical properties. The density is especially to be considered in this connection; its change on melting has been measured for a number of metals as shown in the following table from Landolt, Börnstein and Meyerhoffer, Physikalische Chemische Tabellen. $\dagger$

\begin{tabular}{|c|c|c|c|c|c|c|c|}
\hline \multirow{2}{*}{ Metal. } & \multirow{2}{*}{$\underset{{ }^{\circ} \mathrm{C}}{\text { Temp. }}$} & \multicolumn{2}{|c|}{ Density. } & \multirow{2}{*}{ Metal. } & \multirow{2}{*}{ Temp. } & \multicolumn{2}{|c|}{ Density. } \\
\hline & & Solid. & Liquid. & & & Solid. & Iiquid. \\
\hline Lead...... & 325 & II. .005 & to 045 & Sodium... & 97.6 & 0.9519 & 0.9287 \\
\hline Cadmium.. & 318 & 8.356 & 7.989 & Mercury.. & -38.5 & I4. I93 & 13.6902 \\
\hline Cæsium... & 27 & I. 886 & I. 836 & Bismuth.. & 271 & 9.673 & Io. 004 \\
\hline Potassium. & 62 & $0.85 \mathrm{I}$ & 0.829 & Tin...... & 226 & 7.183 & 6.988 \\
\hline
\end{tabular}

We see from these figures that the volume of the liquid substance is generally greater than that of the solid. There are however exceptions. With bismuth the volume increases on solidification as in the case of water. These phenomena are naturally of great importance in the casting of metals in which case it is necessary to take into consideration the density change on solidification in order to measure rightly the amount necessary to fill the mold so that the cast will give a form of the right dimensions.

\section{Heat of Fusion.}

A definite amount of heat is absorbed in the liquefying of solid substances. The energy content of the liquid is greater than that of the solid and the energy difference is equal to the added

*Chem. Met. Eng. 20, 35 I (I9r9).

$\dagger$ For a discussion of the volume change of melting and transition, see Guertler, J. Inst. Metals, X, 193, I75. Also the following papers: Turner, J. Iron and Steel Inst., I906, I, 48; Turner and Murray, J. Inst. Metals, No. 2, r9o9, II, 98; Ewen and Turner, J. Inst. Metals, No. 2, I9I0, IV, I28; Houghton and Turner, J. Inst. Metals, No. 2, I9I I, VI, I92; Chamberlain, J. Inst. Metals, No. 2, I9I3, X, I93. 
heat of fusion. These values are given in the following table, from Landolt, Börnstein and Meyerhoffer.

\begin{tabular}{|c|c|c|c|c|c|c|c|}
\hline \multirow{2}{*}{ Metal. } & \multirow{2}{*}{$\underset{\substack{\text { Temp. } \\
{ }^{\circ} \mathrm{C}}}{ }$} & \multicolumn{2}{|c|}{ HEAT OF FuSION. } & \multirow{2}{*}{ Metal. } & \multirow{2}{*}{$\begin{array}{c}\text { Temp. } \\
{ }^{\circ} \mathrm{C} \\
\end{array}$} & \multicolumn{2}{|c|}{ HEAT OF FUSION } \\
\hline & & I $\mathrm{Kg}$. & Ig. At. & & & I $\mathrm{Kg}$. & Ig. At. \\
\hline Lead.......... & 326 & $5 \cdot 37$ & I. I & Nickel... & $\cdots \cdots$ & 4.64 & 0.3 \\
\hline Cadmium. & 320 & $13 \cdot 7$ & I. 5 & Palladium & I 500 & 36.3 & 3.8 \\
\hline Iron......... & 1000 & 6.0 & 0.3 & Platinum. & I 779 & 27.2 & $5 \cdot 3$ \\
\hline Gallium..... & I3 & I9.I & 1.3 & Mercury. & $\ldots \ldots$ & 2.82 & 0.6 \\
\hline Potassium. & $5^{8}$ & $x_{5} \cdot 7$ & 0.6 & Silver... . & 999 & $2 \mathrm{I} . \mathrm{I}$ & $2 \cdot 3$ \\
\hline Copper....... & ..... & 43.0 & 2.7 & Bismuth. . & 266 & $\mathrm{I} 2.6$ & 2.6 \\
\hline Sodium.... . & 96 & $3 I .7$ & 0.7 & Zinc.... & $4 \mathrm{I} 5$ & 28.6 & I. 8 \\
\hline & & & & Tin... & 232 & 14.2 & 1.7 \\
\hline
\end{tabular}

\section{Cooling Curves.}

If the melt is allowed to cool slowly and the change of temperature with time observed, it is seen that as long as the mass is liquid there is a regular fall of temperature; as soon as the precipitation of solid begins the temperature remains constant, due to the liberation of the latent heat, and the cooling only proceeds further when the mass has entirely solidified. This can be seen in the following example giving the observed cooling of a mass of molten zinc.

\begin{tabular}{|c|c|c|c|}
\hline $\begin{array}{c}\text { Temperature } \\
\text { Degrees C }\end{array}$ & $\begin{array}{c}\text { Time } \\
\text { Minutes }\end{array}$ & $\begin{array}{c}\text { Temperature } \\
\text { Degrees C }\end{array}$ & $\begin{array}{c}\text { Time } \\
\text { Minutes }\end{array}$ \\
\cline { 1 - 2 } 480 & 0 & 425 & 30 \\
470 & 5 & 419 & 35 \\
461 & 10 & 419 & 40 \\
452 & 15 & 419 & 45 \\
443 & 20 & 415 & 50 \\
434 & 25 & 406 & 55 \\
& & 397 & 602 \\
\hline
\end{tabular}

If these observations be represented graphically, the time as abscissæ and the temperature as ordinates, a cooling curve is obtained, from which the arrest of cooling during solidification is apparent. (Fig. 3.) In many cases the form of cooling or solidification curve is somewhat different. Super-cooling phe- 
nomena frequently occur, that is, the solidification does not begin when the melting point is reached but the temperature of the melt sinks somewhat lower; then when the precipitation of the solid begins, heat is liberated which causes a rise in temperature till the melting point is again reached. This temperature remains steady, as in the first case, until the crystallization process is ended. The form of the cooling curve for this case is shown in Fig. 4.

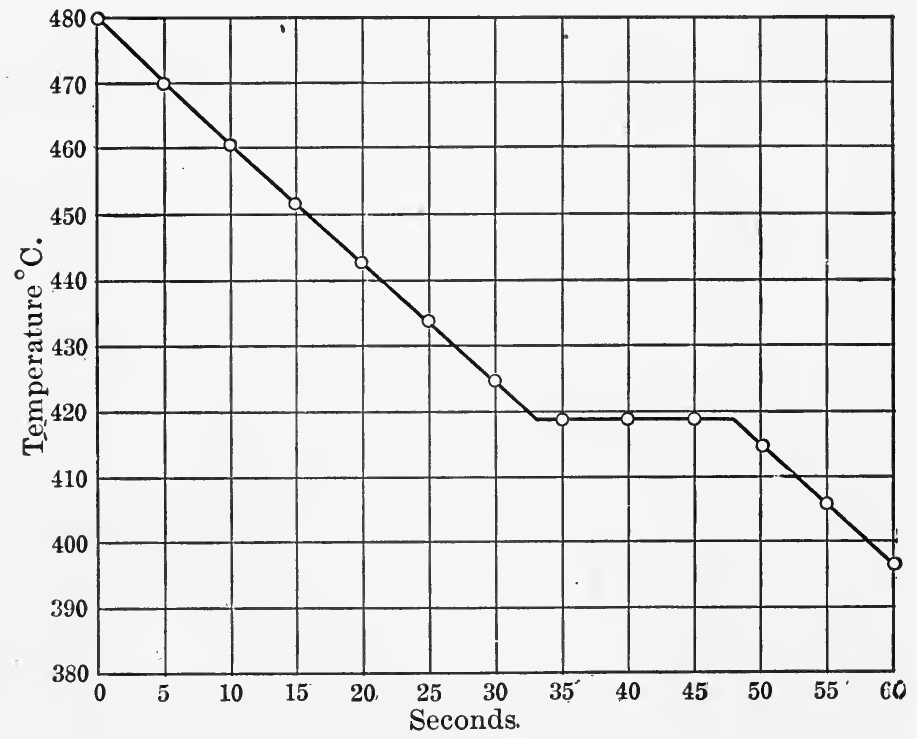

FIG. 3.

In all cases, however where a change of state is involved, the solidification point is marked in the cooling curve,* by means of which we can determine its position. This point has a special meaning in complex systems of mixtures and alloys as we shall see later.

\section{Polymorphy.}

Transitions may take place in the solid state; for example, we know tin as a malleable silver white metal, but a remarkable

* For the methods of determining cooling curves, see Burgess, Bulletin Bureau of Standards, I908, 5, 199; also an excellent chapter in Deschs' "Metallography," p. I23. 
change is sometimes observed, especially in cold regions. In the mass there appear here and there spots of a gray color; the metal falls to a brittle product which occupies a much greater volume than the material out of which it was formed. Due to this volume change there forms at the transition places "Pustules" that fall to pieces by touching. This transformation begins at one spot and travels out from it until it involves the entire vicinity and the metal breaks to a brittle powder. Where this

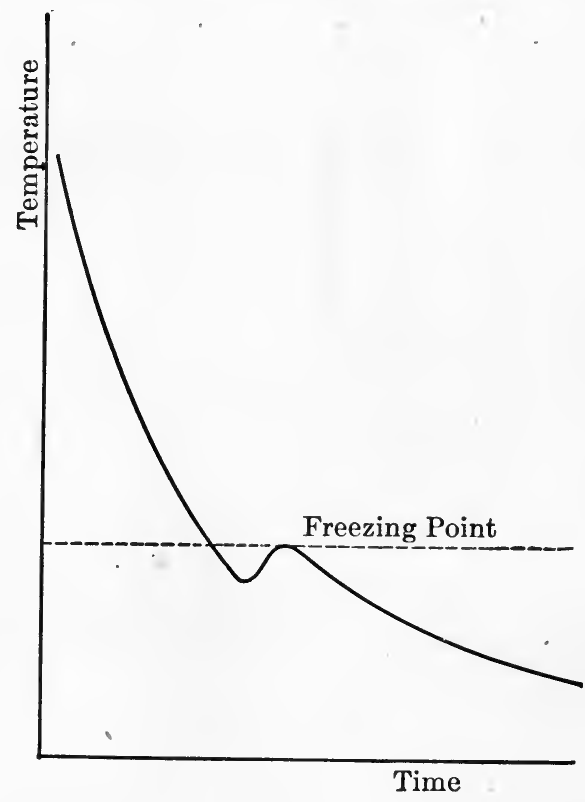

FIG. 4.

phenomenon once shows itself all tin is in danger. If a grain of the transition product be placed on the intact metal the transition is brought on there. The metal is said to be "sick;" it becomes the tin "pest."

This phenomenon was first observed in Russia, where, in a military magazine, a block of tin was found fallen entirely to a powder. The tin pest is also known in Germany; for example, the eaves on the Post building at Rothenberg are infected with it. 
A number of chemists have investigated the tin pest; its complete explanation is due to Schaum* and Cohen. $\dagger$

The chemical analysis of the brittle powder, to which the white tin falls, shows nothing but metallic tin. The tin pest has thus caused no chemical change. It cannot accordingly be considered otherwise than a new allotropic modification of tin, which, because of its gray color is designated as gray tin.

The above-named investigators have now established the reciprocal relations of the two forms of tin. If white tin be powdered by allowing the molten metal to crystallize with strong

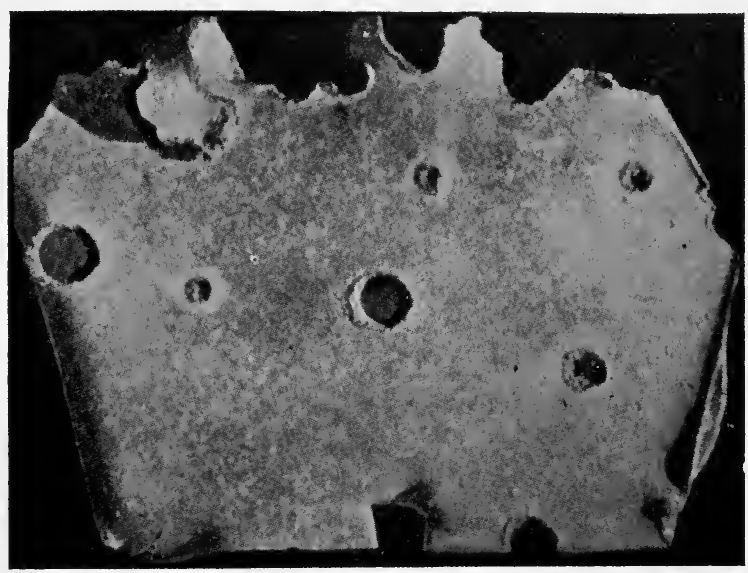

Frg. 5.-Tin Infected with the Tin "Pest."

rubbing in a mortar and this powder mixed with some gray tin and placed in a Dewar vessel for several days at the temperature of solid carbon dioxide and ether, the entire mass changes to gray tin. The reverse change of gray tin into white tin can be accomplished by warming the mass on a water bath.

One may accordingly prepare at will, by simple temperature changes, either the white or the gray modification. The process, as we have seen, is entirely reversible. At low temperatures the gray is the stable form, at high temperatures the white. Between these temperatures there must be a point at which both

*Ann. 308, 30 (1899).

$\nmid$ Z. Physik. Chem., 30, 6or (1899). 
forms are equally stable and are in equilibrium with each other. By experiments on the electro-motive force at various temperatures, of a galvanic cell, formed from the two modifications of tin as electrodes, in a stannous chloride solution as electrolyte, it is possible to determine the position of this equilibrium. At equilibrium the potential difference of the two modifications is nil. At high temperatures the gray modification is the positive pole and the metastable modification, at low temperatures the white. The equilibrium temperature is about $20^{\circ}$. Below this point a transformation occurs to the gray, above it, to the white. The two differ also in their crystalline form, the gray having a columnar structure.

\section{Analogy of Polymorphic Transition to Melting.}

Such a multiplicity of forms or polymorphy in the solid state is also found in other elements, e.g., sulfur, of which there are rhombic and monoclinic forms. For this element the polymorphic transition and its peculiarities have been carefully studied. It has been shown that an extraordinary similarity exists between the process of polymorphic transition and the process of melting and solidification. The equilibrium point which is also designated as a transition point, can be compared in many ways to the melting point. The transition of one modification into the other is accompanied by a change of density that may, in some cases, be very considerable. In the transition of gray to white tin it increases from 5.85 to 7.30. As with melting the transition is accompanied by an absorption of heat. The so-called transition heat is however ordinarily less than the heat of fusion. The two processes differ in only one respect, namely, the low temperature form can frequently be observed above the transition point, while it is not possible to heat a solid substance above its melting point without its going over to a liquid.

\section{Determination of the Transition Point.}

The phenomena of volume change and transition heat can both be used to ascertain the position of the transition point. 
It is of special importance, for example, with iron which has at least three polymorphic modifications sharply separated from each other by two transition points. We have the three forms $\alpha$ iron or ferrite, and $\beta$ and $\gamma$ iron. The transition point $\alpha \rightarrow \beta$ lies at $768^{\circ} \mathrm{C}$., the second $\boldsymbol{\beta} \rightarrow \boldsymbol{\gamma}$ at $898-909^{\circ} \mathrm{C}$. ${ }^{*}$

The cooling curve of iron shows slight arrests at these temperatures which are brought about in precisely the same way as

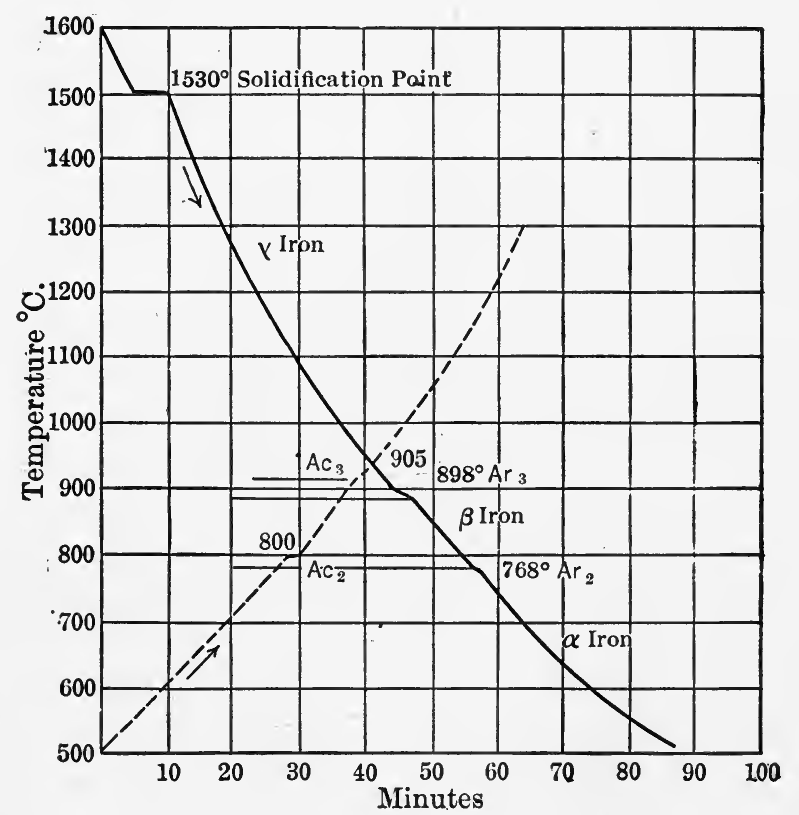

Fig. 6.

the points of arrest due to the solidification of a molten liquid. Fig. 6 shows a cooling curve for pure iron.

The volume change of the transition process is the cause of the re-expansion of iron strips on cooling which has been observed by Kinder. The length change in a strip 90 meters long is about $200 \mathrm{~mm}$. The change of $\gamma$ into $\beta$ iron is accompanied by a volume increase, the $\gamma$ iron being denser than the $\beta$, but the

* Burgess and Crowe, Bur. Standards Bull., 10, 3 r 7 (rgr3). This paper also contains an excellent bibliography on the allotropy of iron. 
change of the latter into the $\alpha$ modification gives again a denser product and a contraction of the piece.*

The $\alpha$ iron possesses the property of magnetism which the other forms do not. This can be easily shown by a simple experiment (Fig. 7). If a small piece of wrought iron be suspended on a wire before a magnet it will naturally be drawn to the magnet, but if it be heated to a white heat, the action of the

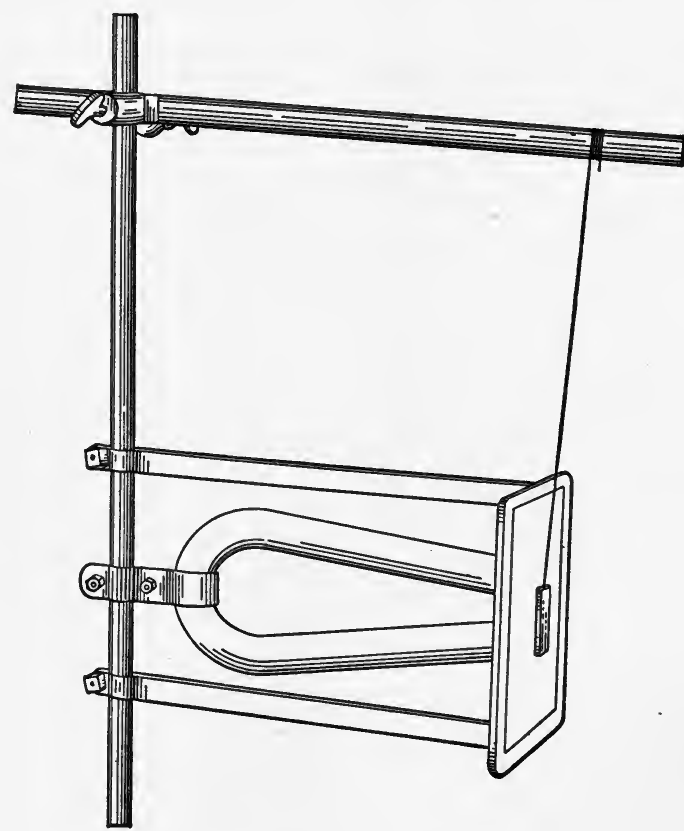

FIG. 7.

magnet ceases. The attraction occurs again on cooling when the temperature has sunk below $768^{\circ} \mathrm{C}$. the transition point for the reaction $\beta \rightarrow \alpha$. Accordingly if the $\beta$ or the $\gamma$ were the stable form at ordinary temperatures our entire electrical industry in

* The volume changes of the iron transitions have been studied by Charpy and Grenet, Bull. Soc. d'Encouragement, 104, 464 (1892); Broniewski, Compt. rend., p. 1983 (1913); Rosenhain and Humphrey, Proc. Roy. Soc., 83, 200 (1909); Le Chatelier, Compt. rend., 129, 279 (1899). 
the form in which we now possess it would be impossible. Dynamo machines and electric motors could not be built if we did not possess a material so strongly magnetic as $\alpha$ iron.

We also encounter polymorphy in other metals. The following table from Guertler* gives the transition points of the elements so far as they have been determined. $\dagger$

\begin{tabular}{|c|c|}
\hline Metal. & Transition Points, ${ }^{\circ} \mathrm{C}$. \\
\hline Iron...$\ldots \ldots \ldots$ & 898,768 \\
\hline Cobalt............ & II59 \\
\hline Nickel. . . . . . . . . & 320 \\
\hline Zinc............. & 360 \\
\hline Aluminum......... & 560 \\
\hline Thallium.......... & 226 \\
\hline Tin............. & I 70, 18 \\
\hline
\end{tabular}

\section{Explosive Antimony.}

The changes which a second form of antimony undergoes are very remarkable and represent another kind of dimorphy. Antimony which has been precipitated electrolytically from an antimony chloride solution on a copper wire as cathode, possesses a smaller density than the ordinary form, namely 5.78 against 6.52 and is also different in appearance, being darker and more lustrous. By touching it with a point an explosion follows, the metal becomes strongly heated and throws off white vapors. The vapor evolution has nothing to do with the transition process, the vapors being chloride which the metal has adsorbed. The ordinary modification under similar conditions also has a tendency to take up the chloride. If a particle loosened from the electrode be rubbed briskly in a mortar a detonation ensues with the evolution of light and heat. The modification transforms explosively and hence is known as explosive anti-

* "Metallographie," Vol. I p. I 2.

$\dagger$ According to Getman, J. Am. Chem. Soc., 39, I806 (I9I 7), cadmium exists in two allotropic modifications, with a transition at $37.5^{\circ} \mathrm{C}$. According to Cohen, J. Am. Chem. Soc., 40, Ir49 (I9r8) there are three modifications of cadmium, one of which is metastable. The transition point of the stable forms is given as approximately $60^{\circ} \mathrm{C}$. 
mony. The explosion also occurs if the metal is heated to $200^{\circ} \mathrm{C}$. Cohen $*$ and his students who have investigated this remarkable substance give an experiment which is designed to show the transition heat. If to $10 \mathrm{gm}$. of the explosive material contained in a thick-walled tube $5 \mathrm{cc}$. of ether be added and the tube

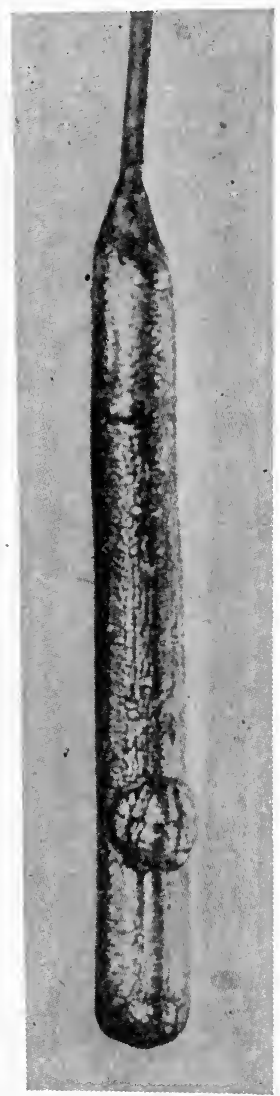

Fig. 8.-Rod of Explosive Antimony. stoppered, by shaking the explosive transformation takes place and the heat liberated vaporizes a considerable quantity of ether and the stopper is blown from the tube with violence. The appearance of explosive antimony is shown in Fig. 8. The transition heat is 20-2I small calories per gram, the product of the transition being ordinary antimony.

\section{Enantiotropy and Monotropy.}

While with tin and iron we can make the transition go in either direction by simple change of temperature, it is not possible to reverse the transition of antimony in this way. The reaction proceeds always in the direction of explosive to ordinary antimony and possesses at no temperature an equilibrium or transition point. The explosive form is at all temperatures metastable. Lehmann has suggested a special name for each of these two cases of dimorphy. He designates the first as enantiotropy, the second monotropy.

The two cases are altogether different as can be readily understood by consulting the vapor pressure diagram. A vapor pressure curve can be determined for every polymorphic modification and equili-

*Z. Physik. Chem., 47, I (I904); 50, 29 I (I904); 52, I29 (I905); Z. Elektrochem., 11, 787 (1905). 
brium between two forms can only exist then where two vaporpressure curves intersect. At this point the two vapor-pressures are equal and there is no tendency to change in either direction.

If a substance is heated sufficiently high, it finally melts, and by super-heating a melting point can be established for metastable modifications. With sulfur, for example, melting points have been determined for the monoclinic as well as for the rhombic variety. If we wish to determine the relative position of the

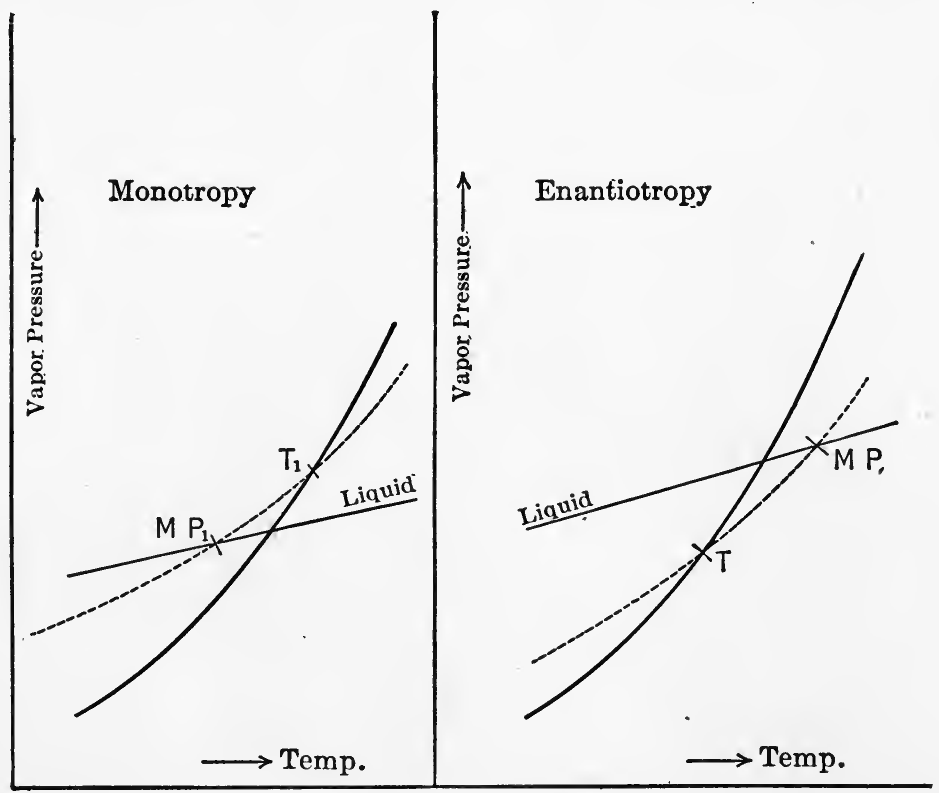

FIG. 9.

transition point and the melting point we must take into account the vapor-pressure curves of the two solids, as well as that of the liquid melt. The curve for the liquid can cut the curves for the solid modifications in two ways, as shown in Fig. 9, either above or below the transition point. The temperature of the intersection is the melting temperature. It can be further concluded from the diagram that the melting point of the stable form with the lower vapor pressure lies at a higher temperature than that of the metastable. If the melting point is above the 
transition point we have the case of enantiotropy. If we neat the low temperature modification gradually we come first to the transition point, by overstepping this the second form appears and finally we reach the melting point. If the melting point is below the transition point we have the case of monotropy. We can therefore not reach the transition point since both forms go over previously to the liquid state. One form must therefore always be metastable and the transition can proceed in only one direction.

\section{Crystal Growth. :}

A structure change can also be observed in iron which is pure or very poor in carbon, if it be heated for a long time at a temperature of $650-700^{\circ} \mathrm{C}$. At this temperature the principal constituent is $\alpha$ iron or ferrite. Under the microscope it is recognized by the polygonal form of the small crystals (see chapter 3 ). Under ordinary conditions a piece of iron which was heated to a high temperature and then cooled, shows a finely crystalline structure. By the above-mentioned thermal treatment, however, a large crystalline structure is obtained, which influences the mechanical properties in an unfavorable way. The material is harder and its solidity is diminished. The large crystals break more easily than the small crystals. (Kinder). This change in structure and properties is not due to a change in modification, but to an enlarging of the single crystals by a gradual recrystallization.

It is a frequently observed fact, that at constant temperature large crystals grow while the smaller ones are consumed. If for example, a crystallized salt, say saltpeter, is allowed to stand under the mother liquor at room temperature, the same relations are shown, the structure of the solid phase becomes largely crystalline. These facts remind one of the growth of a large liquid drop which is found in the vicinity of small drops. According to $\mathrm{W}$. Thomson small drops have a somewhat higher vapor pressure than large drops. Accordingly if the temperature is constant, a distillation takes place from the small drops to the larger ones and there is consequently a growth of the latter. Small 
crystals possess a larger vapor tension and a higher solubility than large ones. The large crystals are accordingly more stable and are formed spontaneously from the smaller ones.

The enlargement of the structure by long-continued heating of iron is, therefore, a special case of this entirely general rule. The process goes on as do all reactions, faster as the temperature increases. The upper temperature limit is formed here by the transition point $\alpha \rightarrow \beta$ iron. If this is exceeded the large $\alpha$ crystals fall to pieces to small $\beta$ crystals so that the structure again becomes finely crystalline.

\section{Electrical and Optical Properties of Metals: Conductivity.}

The previously considered phenomena are of an entirely general nature and are in no way peculiar to the metallic state. There is however a whole series of properties which are characteristic of the metals. The lustrous appearance and the ability to conduct heat and electricity distinguish the metals from all other substances. These properties of the elementary metals appear in a weak degree, in certain metallic compounds especially the sulfides. For an insight into the nature of metals we are indebted to the views of physicists on the nature of electricity, the so-called electron theory.

Electrical conductivity is not characteristic of the metals alone but solutions of acids, bases and salts, as well as molten salts and certain solid oxides, such as constitute the Nernst glower, conduct the electric current. A theory has been developed by which we are able to account for each of these things.

The conduction of electricity by acids, bases and salts dissolved in water has led to the theory that these substances are dissociated in solution into electrically charged split molecules. The products of the dissociation are ions, that is, electrically charged atoms or atom complexes. It follows from the dissociation process that there are as many positive as negative charges, the number of charges which an ion possesses expressing its valence. The positively charged ions migrate to the cathode and are called cathions, while the negative anions go to the anode.

If a solution of an electrolyte be brought between two elec- 
trodes and the circuit closed, the electrodes become charged, one with positive and the other with negative electricity. Under the influence of the charges, motion of the ions to the oppositely charged electrode results. On its arrival the electrically charged particle gives up its charge and becomes electrically neutral. From the silver ion metallic silver results, from the chlorine ion, chlorine gas, etc. The passage of the current, therefore, involves chemical changes, the electrolyte being decomposed at the electrodes.

The transport of electricity through the liquid is accomplished by ions. The displacement of the electrical charges bound to the material particles is greater, the stronger the current. The conductivity is greater the greater the concentration of ions and the smaller the frictional resistance which their motion inside the liquid encounters. The movement of the cathion and the anion in the same electrolyte is generally unequal, and as a result of such migration differences, concentration displacements occur in the vicinity of the electrodes. There is an increase in the concentration at the electrode, of the ion which moves in that direction and a decrease in the concentration of the other ion.

\section{Faraday's Law.}

The amount of the electrode discharges and of substance precipitated depend on the current strength. Faraday has shown that by passing the same current through different cells, the amounts of different substances precipitated are in the ratio of their equivalent weights. Equivalent amounts of ions carry equal amounts of electricity. The gram equivalent carries 96,540 coulombs, a current of I ampere must flow 96,540 seconds or 26.8 hours to precipitate $108 \mathrm{gm}$. of silver, I.OI gm. of hydrogen or 3 I. $8 \mathrm{gm}$. of copper.

\section{Metallic and Gaseous Conduction.}

In the conduction of electricity through metals there is no displacement by the current. The conductor remains absolutely unaltered. In this circumstance the metallic conductors do not stand alone, a similar relation existing in the conduction 
of current by dilute gases under the action of cathode rays and $\beta$ Bequerel rays sent out by radioactive substances. These rays consist of negatively charged electrical particles streaming with great velocity, which can be deflected from their path by electrostatic and electro-magnetic influences. From the magnitude of the electro-static and electro-magnetic deflection both the velocity of the charged particles and their mass, which is the unit of electrical transportation, can be calculated.

\section{Electron Theory.}

For the mass we get a very small value. One gram of substance will transport r. $88 \times 10^{8}$ coulombs. One gram of hydrogen, the lightest of all known substances, carries in the ionic state, 96,540 coulombs. It is calculated therefrom that the equivalent weight of the ray substance is $0.0005 \mathrm{I} 3$. In grams this is the mass of cathode and $\beta$ Bequerel rays which will be associated with 96,540 coulombs. Other phenomena have also been used to determine this magnitude and give about the same value. These carriers of negative charges which are in round numbers 2000 times as light as hydrogen particles, are now generally designated as electrons. It remains to be pointed out that such small carriers of positive charges are not known.

The electrons also cause current conduction inside the metals according to the new view. The electron theory of metals that has been evolved by J. J. Thomson and P. Drude* supposes that within the metal a dissociation is undergone into positive metal ions and negative electrons, and that the negative particles, under the influence of the potential difference attached to the metal, fall to streaming in the same way as the electrolytic ions in an electrolytic cell.

\section{Law of Wiedemann and Franz.}

Wiedemann and Franz have noted a remarkable parallelism between the electrical and heat conductivity of metals. The good conductors of electricity being also good conductors of

* Ann. Physik., 1, 566 (r9o0); 3, 369 (rgoo); 7, 687 (rgo2); 14, 936 (rgo4); Physik. Z., 1, r6r (I900). 
heat and if the ratio of the heat conductivity $K$ to the electrical conductivity $\sigma$ is calculated it is shown that for the same temperature this ratio possesses a large value which varies within narrow limits. This fact is shown in the following table from the experiments of Jaeger and Diesselhorst:*

\begin{tabular}{|c|c|c|c|}
\hline Metal. & $\frac{K}{\sigma}$ for $18^{\circ}$. & $\frac{K}{\sigma}$ for $100^{\circ}$ & $\frac{K}{\sigma 18}: \frac{K}{\sigma 100}$ \\
\hline Aluminum.............. & 636 & 844 & 1.32 \\
\hline Copper............... & 665 & 862 & 1.30 \\
\hline Silver $\ldots \ldots \ldots \ldots \ldots \ldots$ & 686 & $88 \mathrm{I}$ & I. 28 \\
\hline Gold.............. & 727 & 925 & I. 27 \\
\hline Nickel. ............ & 699 & 906 & 1.30 \\
\hline Zinc............. & 672 & 867 & I. 29 \\
\hline 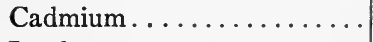 & 706 & 905 & I. 28 \\
\hline 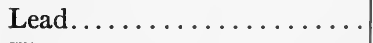 & 715 & 935 & I. $3 \mathbf{I}$ \\
\hline Tin...$\ldots \ldots \ldots \ldots \ldots \ldots$ & 735 & 925 & I. 26 \\
\hline Platinum.............. & 753 & Ior3 & I. 35 \\
\hline Iron..$\ldots \ldots \ldots \ldots \ldots \ldots$ & 802 & ro6I & 1.32 \\
\hline Bismuth............. & 963 & 1067 & 1.12 \\
\hline
\end{tabular}

A theory of these remarkable facts has been brought forward by Drude who explains the parallelism between the two conductivities by the assumption that the electrons cause both the heat and electrical vibrations within the metals. To get a representation of the mechanism of heat conductivity by means of the electrons, he made the bold but successful assumption that the electrons in the metal followed the same diffusion law as the molecules of a gas.

The kinetic theory of gases starts from the assumption that the gas molecules are in a rapid, entirely irregular motion and that the average kinetic energy of the molecules of a gas depends on and is proportional to the absolute temperature. And, further, that the temperature coefficient of kinetic energy possesses the same value for all gases. For the electrons inside the metal Drude postulated that a similar irregular motion also took place and that they possessed a kinetic energy which is equal

*Wissenschaftliche Abhandlungen der Phys. Techn. Reichsanstalt., 3, 269. 
to that of the gas molecules at the same temperature. This assumption requires of the very small mass of the electrons, a very great velocity compared to the gas molecules. If the mass of the electron is placed at about one four-thousandth of that of the hydrogen molecule $\mathrm{H}_{2}$, the velocity of electrons of the same kinetic energy $\left(\frac{1}{2} \mathrm{MV}^{2}\right)$ must be more than 60 times as great as that of the hydrogen molecule, which is recognized as the fastest of material molecules.

The higher the temperature the greater the velocity, and the greater the path which the moving particle describes before collision. The so-called mean free path increases.

The heat interchange in an air column, the upper part of which is warmer than the lower, takes place in the following way: particles from the warmer layers having a higher velocity, advance to the colder and the ascension of the particles exerts an active force, on the particles above, whose energy is increased by the collisions. In an entirely similar way Drude explains the mechanism of the heat conduction in metals which have one end hot and the other end cold.

By the mathematical formulation of these views Drude arrived at the equation, $K=\frac{1}{3} \alpha N l u$ in which the heat conductivity $K$ is set equal to the electron number $N$ multiplied by the mean velocity of the electrons $u$, the mean free path between two collisions $l$ and the temperature coefficient of the active force $\alpha$ that possesses the same value for gas molecules and electrons.

The electrical conductivity is likewise influenced by the irregular movements of free ions. It may not be assumed that the applied electro-motive force transforms the irregular movement into a regular one. It merely causes one dircction of movement of the electrons to be somewhat favored so that a streaming in that direction results. Collisions and direction changes of single ions do not thereby cease. Drude derived for the electrical conductivity the formula

$$
\sigma=\frac{e^{2}}{4 \alpha \top} N l u .
$$

where $e$ is the charge on one electron equivalent. 
By the division of the two equations in a way to eliminate the expression $N l u$ it follows that

$$
\frac{K}{\sigma}=\frac{4}{3}\left(\frac{\alpha}{e}\right)^{2} T
$$

The only variable on the right-hand side of this expression is the temperature. $\alpha$ and $e$ are characteristic constants for the individual metals. This relation is at constant temperature, independent of the nature of the metal. If we know $\alpha$ and $e$ the ratio of the two conductivities can be calculated for a given temperature. The calculation of Reinganum $*$ for $\frac{K}{\sigma}$ at $18^{\circ}$ gives the theoretical value $709.9 \cdot 10^{-8}$.

The law of Wiedemann and Franz that for all metals the relation between heat and electrical conductivity is nearly constant can accordingly be derived from the theory.

The equation admits of a still further test of the basis on which it is built. The conductivity ratio must be proportional to the absolute temperature and must be expressed by

$$
\left(\frac{K}{\sigma}\right)_{t_{2}}:\left(\frac{K}{\sigma}\right)_{t_{1}}=T_{2}: T_{1}
$$

If it be observed at temperatures of $18^{\circ}(T=29 \mathrm{I})$ and $100^{\circ}$ $(T=373)$ the ratio of the conductivity quotients must have a value $\frac{373}{291}=\mathbf{I} .28$, if the actual value be now compared with the theoretically calculated value, there is seen a good agreement. (See table on page 24.)

The hypothesis of the electron theory of metals originated by Drude has accordingly proved itself a valuable research principle.

The magnitude of the electrical conductivity of a metal depends like that of a solution, on two factors, the number of conduction electrons present and the friction which these encounter in their motion through the medium. It is of special

*Ann. Physik., 2, 398 (1900). 
interest to know the electron number or electron concentration in a single metal. The relations which we can derive from the equation connecting the electron number with the mobility will not however accomplish this calculation. It is necessary for this purpose to have a knowledge of further relations between these magnitudes. This leads us to the optical properties of metals.

\section{Optical Properties of Metals: Light Reflection and Absorption.}

The metals are characterized optically by their special kind of luster, the metallic luster. Other substances have also, under certain conditions, a luster similar to the metals. The silver luster of a water surface in the moonlight is known to all. An

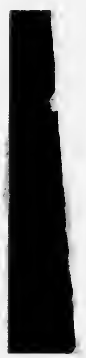

FIG. 10.-Fuchsin Paper.

air blast under water has, if viewed in the proper direction, the appearance of mercury; the same is true of the total reflection prism. In all these cases the cause of the luster is the complete reflection of incident light. Certain organic dyes also show a strong generally colored surface luster. A piece of indigo is lustrous like copper, especially if it has a somewhat polished surface. The crystals of Fuchsin and of methyl violet appear greenish gold. These lusters are also connected with strong reflection of light. (Fig. IO.)

If we dissolve these dyes, and view the sun's spectrum through a layer of this solution, we observe a strong absorption band. The fuchsin solution, for example, allows red and yellow to pass through but not green, this is absorbed and, in place of the green 
part of the spectrum, there is seen a black band. The green light is now accordingly reflected from the solution. It is a general fact that a substance reflects the kind of light for which it possesses an absorption. We see then that light absorption and reflection as well as the luster are all connected.

\section{Metallic Luster.}

Metallic luster is no exception to this rule. In reference to light absorption, the metals exceed all other substances. Only the thinnest metal leaves are transparent. Thin gold leaves allow blue light through while yellow light is strongly absorbed by them and is accordingly especially strongly reflected. For very thin metal layers precipitated on glass, Kundt has measured refraction and absorption for different kinds of light, but this procedure presents very great experimental difficulties. It is not easy to obtain uniform, adherent metal coats a few thousandths of a millimeter thick. Further, the errors of observation in the measurement are relatively large, due to the very sharp prism which must be used.

Therefore Drude made use of another phenomenon to determine the optical constants of metals, their index of refraction $n$ and their absorption coefficient $k$. The metals reflect incident linear polarized light as elliptically polarized. From the magnitude of this displacement there is given the sought values and the reflection constant. The following table contains the constants measured by Drude * and the reflection constant $R$ for a number of different metals for yellow sodium light.

\begin{tabular}{|c|c|c|c|}
\hline Metal. & $R$ Per Cent. & $N . K$. & $N$ \\
\hline 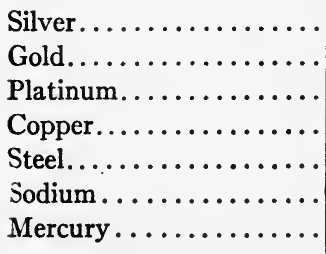 & $\begin{array}{l}95 \cdot 3 \\
85.1 \\
70.1 \\
73.2 \\
58.5 \\
99.7 \\
78.4\end{array}$ & $\begin{array}{l}3.67 \\
2.82 \\
4.26 \\
2.62 \\
3.40 \\
2.61 \\
4.96\end{array}$ & $\begin{array}{l}0.18 \\
0.37 \\
2.06 \\
0.64 \\
2.41 \\
0.005 \\
1.73\end{array}$ \\
\hline
\end{tabular}

*Ann. Physik., 14, 936 (r904). 
The absorption and therewith the reflection constant is very different for different kinds of light and different wave lengths. With copper it is especially large for red, with gold for yellow light.

The light absorption is brought about in a small degree,.especially in the colored metals, by a similar cause as with the aniline dyes. In them the characteristic vibrations reside in the molecules, but the determined equilibrium position of the vibrating electrons agrees with the period of the absorbed light. It can be treated accordingly as an optical resonance phenomenon. With gold, copper, silver and magnesium, the optical relations are determined by such a restricting influence, not by freely moving electrons.

The freely moving conduction electrons possess the greatest influence on the optical properties of metals. To understand this, we must call to mind that, according to the electro-magnetic theory of light, a light wave is no other than a train of electrical waves, that is, a train of periodic changes of electrical force. The action of this periodic electrical force calls forth a displacement of free electrons in the conductor, in the same way as a constantly acting electrical force. The metals are, accordingly, good conductors for the electrical waves, as well as for the constant current.

The quick propagation of the light waves in a medium is, therefore, closely connected with strong light absorption. The velocity of the wave displacement inside of a metal is now, as the electrical conduction, dependent on the number of electrons, and on the frictional resistance, and, therefore, the optical constants of the metals and their reflection constant must stand in close relation to both of these factors. There must be a parallelism between the reflection constant of a metal and its electrical conductivity. In fact, the investigations of Hagen and Rubens * on the reflection of long infra-red light waves yielded so exact a parallelism that it was directly possible to calculate the reflection constant for these waves from the conductivity. The agreement decreases with decreasing wave length.

*Ann. Physik., 11, 873 (r903). 


\section{Electron Concentration of Metals.}

Schuster * has deduced, by the use of the Drude dispersion theory of metals, a relation between these optical properties, the electron number, and the frictional resistance. If we combine this with the above-mentioned relations which connect conductivity, electron number and frictional resistance, we have a means of calculating the unknown magnitudes, electron number and frictional resistance. Unfortunately this way is not feasible since the resistance which the electrons encounter, in streaming, is not proportional to the quickness of oscillation. The friction is, in a large sense, dependent on the vibration number, which, in turn, depends on the wave length; but only for very long wave lengths is an equality between it and the friction of streaming permissible.

Now, Drude has succeeded, by a simplifying assumption, in deriving a relation between the optical constants, index of refraction and coefficient of absorption, and the electron number. In this the frictional resistance is neglected. With the help of this relation and his observations for the wave length $\lambda=0.598 \mu$ (Yellow Na light), he calculated the following electron numbers for the different metals.

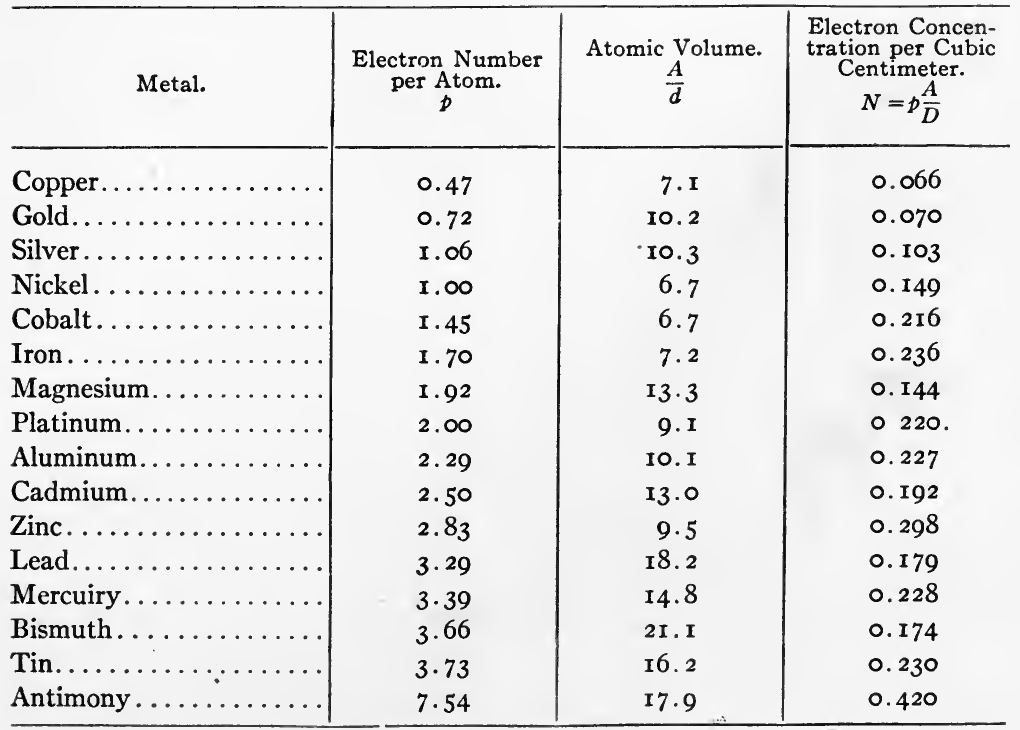

* Phil. Mag., (6), 7, 15I (1904). 
One can come to a conception of the high electron concentration, if it is made clear how many electrons are contained in a liter, by expressing how many times normal the electron solution is with relation to electrons. If we arrange the metals according to the magnitude of this number, we obtain the following table:

\begin{tabular}{|c|c|c|c|c|c|}
\hline Metal. & $\begin{array}{l}\text { Normality } \\
\text { of Electrons, } \\
\text { Times. }\end{array}$ & $\begin{array}{c}\text { Thermo- } \\
\text { electric } \\
\text { Force } a g . \mathrm{Pt} .\end{array}$ & Metal. & $\begin{array}{l}\text { Normality, } \\
\text { Times. }\end{array}$ & $\begin{array}{c}\text { Thermo- } \\
\text { Force. }\end{array}$ \\
\hline Copper.... . & 66 & +0.72 & Cobalt....... & 216 & -0.80 \\
\hline Gold....... & 70 & +0.72 & Platinum..... & 220 & \\
\hline Silver..... . & ro3 & $+0.7 \mathrm{I}$ & Aluminum.... & 227 & +0.40 \\
\hline Magnesium. & I 44 & +0.42 & Mercury..... & 228 & +0.72 \\
\hline Nickel. . . . . & $\mathrm{r} 49$ & -1.62 & Tin......... & 230 & +0.45 . \\
\hline Bismuth... & I 74 & -5.80 & Iron ......... & 236 & $+\mathrm{r} .45$ \\
\hline Lead...... & I 79 & . & Zinc......... & 298 & +0.75 \\
\hline Cadmium. & I92 & +0.85 & Antimony.... & 420 & $+5 . \mathrm{II}$ \\
\hline
\end{tabular}

The electron concentration of metals, is, accordingly, very considerable and their large conductivity is thereby easily understood.

\section{Temperature Coefficient of Conductivity.}

With increasing temperature the conductivity decreases, and indeed by a temperature raise of $\mathrm{I}^{\circ}$ the decrease amounts to practically $\frac{1}{273}$. By what is this change caused? It can be explained by a lowering of the electron concentration or by an increase in frictional resistance with rising temperature. The investigation of optical properties serves to decide this question. The optical constants which have been determined by Roschdestwensky, a pupil of Drude, at the temperatures of solid carbon dioxide and ether and of liquid air, show small differences from those at ordinary temperatures. According to Zeeman, the optical properties of a metal change only slightly by heating to $800^{\circ}$. The electron concentration is accordingly nearly constant throughout a temperature interval of about 1000.

The strong change of the metallic conductivity is then referred to the frictional resistance. The increase of resistance with rising temperature is easily understood, if we recall, that also the internal friction (yiscosity) of a gas increases with in- 
creasing temperature. Now from the kinetic theory of the electrons within the metal, the internal friction must also increase, due to the more frequent collisions that take place with the raised velocity, both between themselves and with the violently vibrating ponderable particles.

The mechanical working of the metal also causes the conductivity to vary within certain limits. The optical properties are not thereby altered, accordingly the electron number remains constant, while the frictional resistance, which the electrons encounter in their motion, changes.

\section{Thermo-electric Force.}

Drude's * calculation of the electron concentration rests on a whole number of hypotheses and special assumptions. There are, however, other magnitudes which stand in a near relation to the electron concentration, especially the thermo-electric force of the metals. These warrant the possibility of making a test of the calculation.

The thermo-electric force caused by the contact of two metals may be considered as the result of electron diffusion. It can be supposed that, at the junction of the two metals, with different electron concentrations, there is a tendency toward equalization of the concentration. However, only an infinitely small amount can actually diffuse into the metal of lower electron concentration. A loss of negative electrons leads to an excess of positively charged particles, and thereby electro-static attraction forces are set up, which swing the escaping electrons back again to their original position. Only a very small potential difference between the metal remains which represents the equilibrium between the diffusion tendency, and the electro-static attraction between the positive particles and the electrons. The diffusion tendency depends on the relation of the electron concentration in the two metals and on the temperature. The potential difference is accordingly greater, the higher the temperature, and the larger the ratio of electron concentrations in the touching

*Ann. Physik., 1, 593 (1900); 14, 948 (I904). 
metals. The relation is exactly the same as with electrolytic diffusion cells.

A thermo-current between the metals can only be brought about if two differently temperatured junctions are present. The negative electrons then flow in the metal with the higher electron concentration from cold to warm and in the other from warm to cold. The metal more concentrated in electrons is the positive pole at the hot junction.

The thermo-electric force of a thermo cell at a temperature difference $\vartheta$ of the two junctions and an electron concentration $N_{1}$ and $N_{2}$ of the two metals is given according to Drude by the equation:

$$
\pi \text { (microvolts) }=\text { I 7I }\left\{\vartheta \log _{e} \frac{N_{1}}{N_{2}}+\frac{\mathrm{I}}{2} \vartheta^{2} \frac{d \log _{e} \frac{N_{1}}{N_{2}}}{d T}\right\} .
$$

We have seen above, that the electron concentration varies only slightly with the temperature; we may, therefore, neglect the second portion of the parenthesis for small temperature differences and obtain a very simple expression.

$$
\pi=\mathrm{I} 7 \mathrm{I} \vartheta \log _{e} \frac{N_{1}}{N_{2}}
$$

If we compare different metal couples at the same temperature difference, in reference to their thermo-electric force, we see that it should be entirely determined by the ratio of their electron concentrations. The order of the metals according to their elctron concentrations must, therefore, agree with the thermoelectric potential series, and it must be possible to calculate the thermo-electric force from the electron concentration. There is only a slight agreement between theory and fact for this latter

\begin{tabular}{|c|c|c|}
\hline \multirow{2}{*}{ Cell. } & \multicolumn{2}{|c|}{$\begin{array}{l}\text { Potential DifFerence For } I^{\circ} \\
\text { TEMPERATURE DifFERENCE. }\end{array}$} \\
\hline & Calculated. & Observed. \\
\hline Bi-Sb.... & $150 \times 10^{-6}$ & 68 to $9 \mathrm{I} \times 10^{-6}$ \\
\hline $\mathrm{Fe}-\mathrm{Co} . . . .$. & $15 \times 10^{-6}$ & $39 \times 10^{-6}$ \\
\hline
\end{tabular}
relation. 
The comparison of the order of electron numbers and position in the thermo-electric potential series is found in the table page $3 \mathrm{r}$. That, in general, variations occur, is explained in that the electron concentrations, calculated from the optical constants, differ by only a slight amount from each other. In all cases, however, where great differences appear in these numbers, the order in both series is nearly the same.

In a general way the method laid down by Drude enables us to orient the metals according to their electron concentration. It cannot, however, be overlooked, that the single metals, especially silver, gold and copper, show very great variation. It is, therefore, certain that the assumptions taken as the basis of calculation were not altogether sound.

Gold and copper being colored metals undergo a selective absorption for certain colors, that is, wave lengths, therefore, not only the free electrons are concerned in the optical phenomena but also vibrations of the bound electrons. Of this resonance phenomenon, however, Drude's equation takes no account. If this correction were made, the electron concentration would certainly stand in better agreement with the thermo-electric data for the given cases.

\section{Passivity in Metals.}

There is still one phenomena which is characteristic of some metals and metallic compounds which we have not so far considered. It is the phenomenon of passivity.

It has long been known that certain metals especially iron were capable of assuming under certain conditions a state of inactivity toward the reagents which normally attack them energetically. Thus if iron be immersed in strong nitric acid it is rendered passive and is no longer dissolved by dilute acids and will not precipitate copper from solution. Numerous explanations have been offered for this phenomenon, but the only one that has received any degree of acceptance is the theory of an oxide coating which was first proposed by Faraday. This theory, however, is open to a large number of objections. A theory of passivity on the basis of Drude's electron theory of metals has 
recently been proposed by Dean * and seems to explain at least the outstanding features of the phenomenon. Taking as a starting point the expression for contact potential which has been derived by Langmuir $\dagger$ where $\phi_{1}$ and $\phi_{2}$ represent the so-called

$$
V_{1}-V_{2}=\phi_{2}-\phi_{1}+\frac{N_{1}}{N_{2}}
$$

electron affinities and $N_{1}$ and $N_{2}$ the electron numbers of the concerned metals. We see that the contact potential depends on $N_{1}$ and $N_{2}$, and the relation only holds if $N_{1}$ and $N_{2}$ represent the electron numbers of the surface layer. If it is possible to maintain a surface of lower electron concentration than the main body of the substance we would have a case of a substance apparently ennobled. Such a surface condition would explain many of the peculiarities of the so-called passive metals.

The production of passivity by oxidizing agents can be explained in this way since oxidation is in effect the removal of electrons. The low photo-electric emission of passive iron as observed by Allen $\ddagger$ is in direct accord with a surface layer lower in electrons.

There remain, however, three things which must be accounted for to make an electron theory of passivity probable (I) the maintenance of an electron deficient surface (2) characteristic occurrence of passivity in the metals of the iron group (3) the effect of magnetism on passivity.

Let us commence by analyzing mathematically the conditions affecting the surface concentration of electrons. If a conductor $A, B$ with difference of potential between $A$ and $B$ moves in a magnetic field of intensity $F$, its velocity normal to $A, B$ will be given by

$$
V=\frac{K V}{\mu F}, \cdot \cdot \cdot \cdot \cdot \cdot \cdot \cdot
$$

where $K$ is a constant and $\mu$ the permeability of the medium. Now, without interfering with our analysis we may replace the

\footnotetext{
.$^{*}$ Am. J. Sci., 47, r23 (r9r9)

$\dagger$ Trans. Am. Electrochem. Soc., p. I44 (Igr6).

$\ddagger$ H. S. Allen, Proc. Roy. Soc., 88, ro (1913).
} 
conductor $A, B$ with a stream of electrons with velocity $\sigma$ in which case $V$ will be given by

$$
V=\frac{K \sigma^{2}}{\mu F} \cdot \cdot \cdot \cdot \cdot \cdot \cdot \cdot \cdot .
$$

Further the ends of $A, B$ may be joined and all the electrons removed but one and Eq. (2) will still hold; we have then our ideal case of one electron moving in its orbit with velocity $\sigma$. Its velocity normal to the plane of its orbit will be given by (2). The irregular motions of electrons within a metal can be resolved into a series of harmonic motions to which this mathematical analysis can be applied. If now we consider the surface of a conductor we find that the electrons on reaching the second medium say air would have a velocity of

$$
V^{\prime}=V \frac{\mu}{\mu^{\prime}}, \quad \cdot \quad \cdot \quad \cdot \quad \cdot \quad \cdot \quad \cdot
$$

where $V$ is the velocity in the conductor and $\mu^{\prime}$ the permeability of the second medium. Electrons whose velocity in the conductor was greater than $V_{e} \frac{\mu^{\prime}}{\mu}$ where $V_{e}$ is the velocity of escape, will, therefore, escape. Considering then a layer at the interface, the number of electrons coming through the lower boundary will be given by

$$
N_{1}=\rho_{1} V
$$

where $\rho$ is the electron density and $V$ the velocity. The number leaving the upper boundary will be given by

$$
N_{2}=\rho_{2} V^{\prime}, \text {. . . . . . }
$$

but $N_{1}=N_{2}$, and hence

$$
\rho_{2}=\rho^{\prime} \frac{\mu^{\prime}}{\mu}
$$

that is, the electron density at the surface is less than that of the interior and is given by (6). This, of course, is only true for paramagnetic metals and the more paramagnetic the substance the greater the passivity which at once explains the tendency to passivation found in the iron group. 
So far we have considered only a constant magnetic field. If we examine Eq. (2) it will be seen that $V$ is inversely proportional to $F$. Hence it is apparent that if a magnetic field be applied to a conductor $V$ will be lowered causing the number of electrons with greater velocities than $V_{e}$ to be smaller and hence the passivity produced by any given set of conditions will be less in a magnetic field than without, or the force necessary to produce a given degree of passivity will be proportional to $F$. However if a conductor be once passivated no effect of changing the magnetic field would be anticipated. This is practically the effect found by Nichols and Franklin* and by Byers and his collaborators. $\dagger$

The phenomenon of passivity is not without meaning in metallurgy particularly as it is connected with contact catalysis which is of importance in the study of the blast furnace. The decomposition of carbon monoxide according to the equation

$$
{ }_{2} \mathrm{CO} \rightleftarrows \mathrm{C}+\mathrm{CO}_{2}
$$

is known to be remarkably accelerated by the presence of iron or nickel.

Let us examine the electron mechanism of this reaction. Carbon monoxide has probably the electron structure $\ddagger$

$$
\mathrm{C}_{+-}^{+-} \mathrm{O}
$$

i.e., the carbon is bivalent. The first process in the mechanism of the reaction,

$$
{ }_{2} \mathrm{CO} \rightarrow \mathrm{CO}_{2}+\mathrm{C}
$$

would be the increase of valence of the carbon, since this is the unsaturated atom. This we may represent

$$
\mathrm{C}_{+-}^{+-} \mathrm{O}-2 \ominus={ }_{+}^{+} \mathrm{C}_{+-}^{+-} \mathrm{O} \text {. }
$$

This process, therefore, requires the addition of two electrons. The purpose of the catalyst is to furnish these. If the catalyst is iron we may write the reaction

$$
\mathrm{C}_{+-}^{+-} \mathrm{O}+\text { iron (passive) }={ }_{+}^{+} \mathrm{C}_{+-}^{+-} \mathrm{O}+\text { iron (active). }
$$

* Nichols and Franklin, Am. J. Sci. (3), 31, 272 (I886); (3) 34, 4I9 (I887).

r Byers and Darrin, J. Am. Chem. Soc., 32, 550, 1910.

$\ddagger$ Hanke and Koessler, J. Am. Chem. Soc., 40, r 726 (1918). 
The next step we may represent

$$
{ }_{+}^{+} \mathrm{C}_{+-}^{+-} \mathrm{O}+\mathrm{C}_{+-}^{+-} \mathrm{O}=\mathrm{O}_{-+}^{-+} \mathrm{C}_{+--}^{+-} \mathrm{O}+\mathrm{C}_{+}^{+}
$$

and finally:

$$
\mathrm{C}_{+}^{+}+\text {iron active }=\mathrm{C}+\text { iron (passive). }
$$

It should of course be pointed out that an electron theory of passivity is only convenient and not necessary in this connection as the same result may be arrived at by means of nonelectronic reaction and the oxide theory of passivity.

Similar explanations may be worked out for the use of catalytic nickel in hydrogenations. In this case it is necessary to start with active metal since the first process in reduction is the addition of electrons. 


\section{CHAPTER II}

\section{METALLIC SOLUTIONS AND ALLOYS}

WE have learned in the first chapter that the metals show nothing exceptional in many of their properties, that the law of vaporization and melting and polymorphic transition is the same as for non-metallic substances.

The same conclusion is reached by the investigation of metallic solutions and alloys, since all the phenomena we can o.bserve with them we have already met in solutions in water and other liquids. That metals can be dissolved is a well-known fact. One needs only to lay a thin gold wire in mercury to be very soon convinced that it is attacked and finally dissolved. The affinity of lead for the noble metals, gold and silver, plays an important role in fire assaying, and everyone who has worked in the laboratory, is familiar with the destruction which takes place when metallic mercury falls into the sewer pipe.

The power of metals to dissolve other metals is not confined to the liquid state alone. Solid alloys are also known, which are homogeneous solutions.

The solvent action of the metals is also extended to certain metallic compounds, especially carbides, oxides and phosphides. Gases can also be dissolved in the metals, particularly hydrogen.

\section{Colloidal Metal Solutions.}

In general the best solvents for the metals are metallic substances. These real solutions must not be confused with the socalled colloidal solutions of metals in water, and organic liquids that have become known in great number, during recent years. Years ago the American chemist, Carey Lea, ${ }^{*}$ succeeded in obtaining brown solutions of metallic silver in water, by reducing ammoniacal silver solutions with organic reducing agents. In a similar way, red solutions of gold may be prepared; if, for

\footnotetext{
* Phil. Mag., (5) 31, 238, 320 (189I).
} 
example, gold chloride solution is reduced with formaldehyde. These colloidal solutions can also be prepared by the method of Bredig * which consists in the electrical dispersion of the metal by arcing under water or other solvent. Such solutions are not permanent but the contents gradually settle to the bottom, as a dark-colored powder. The precipitation is accelerated by adding a little salt or acid to the solution, while small amounts of alkali seem to increase the stability. These colloidal solutions may be considered as extremely fine suspensions of metals. A light beam which falls through such a liquid, is dispersed, and with the help of the ultra-microscope, the diffraction discs of the separate particles can be recognized.

The gold ruby glass and its analogues, with other metals, belong to these colloidal solutions, and it is not inconceivable that the small content of noble metals which is found in certain volcanic rocks is contained as a colloidal solution. Some recent investigations have suggested that the yellow and ruby colors of sphalerite are to be attributed to colloidal iron disulfide. $\dagger$

The experiments of $\mathrm{R}$. Loren $\ddagger$ indicate that the tendency of metals in contact with liquid melts, to disperse into such extremely fine suspensions or fogs is very great. This phenomenon is shown nicely by the following experiment taken from Lorenz.

If a salt, for example, lead chloride, be melted in a reagent tube and a piece of metal, for example, lead, be dropped into it, the metal at first melts to a ball, but after a few seconds it disperses suddenly to a metal fog, spreading rapidly throughout the whole melt and coloring it dark. The melt appears transparent in transmitted light but opalescent or opaque in incident light.

This phenomenon sometimes causes difficulty in the electrolysis of molten salts, fogs forming at the cathode, which wander to the anode, and there enter again into combination (e.g., with the liberated chlorine). The appearance of such fogs is

* Z. Elektrochem., 4, 514, 547 (1898).

$\dagger$ Bull., Mo. Sch. of Mines, 3 (1915).

$\ddagger$ Z. Elektrochem., 13, 582 (1907). 
especially common with cadmium and also with the alkali metals. In the latter case, the electrolyte on cooling, shows an intense blue color, which appears to be due to the mixing of the sodium fog. The blue color of a solution of sodium in liquid ammonia is probably also due to a fine dispersion. Siedentopf * has also shown that the blue color of rock salt is best explained as due to the dispersion of sodium metal through the mass. A real solution of a metal in a non-metallic solvent is entirely abnormal.

\section{Dilute Metallic Solutions.}

A dilute melt, formed by dissolving a small amount of one metal in another, shows all the characteristics of a dilute solution. Particularly characteristic of real solutions is their "dilution tendency" and with it are connected most of the properties of a solution. If solutions of two different concentrations are stratified one over the other, an adjustment takes place; the dissolved substance diffusing from the place of higher concentration to that of lower. The speed with which this diffusion takes place, is of the same order of magnitude as with aqueous solutions. The diffusion constants $k$ for some of the metals are given in the following table. The values are taken from the "Physikalische Chemische Tabellen" of Landolt, Börnstein and Meyerhoffer.

\begin{tabular}{|c|c|c|c|}
\hline Substance. & $\begin{array}{l}\text { Temp. } \\
\text { Deg. }\end{array}$ & $\begin{array}{l}k \mathrm{~cm} . \\
\text { Day. }\end{array}$ & Observer. \\
\hline Lead in mercury ........... & $\ldots$ & I. 37 & G. Meyer \\
\hline Lead in $\operatorname{tin} . \ldots \ldots \ldots \ldots$. & 500 & 3.18 & Roberts-Austin \\
\hline Cadmium in mercury............ & $\ldots \ldots$ & I. 56 & G. Meyer \\
\hline Gold in mercury.............. & II & 0.72 & Roberts-Austin \\
\hline Gold in lead............. & 490 & 3.03 & Roberts-Austin \\
\hline Gold in lead ............. & 500 & 3.19 & Roberts-Austin \\
\hline Gold in bismuth.......... & 500 & $4 \cdot 5^{2}$ & Roberts-Austin \\
\hline Gold in $\operatorname{tin} . . . \ldots \ldots$ & 500 & 4.65 & Roberts-Austin \\
\hline Platinum in lead........ & 490 & I. 69 & Roberts-Austin \\
\hline Rhodium in lead........ & 500 & 3.04 & Roberts-Austin \\
\hline Silver in tin........... & 500 & $4 \cdot 14$ & Roberts-Austin \\
\hline 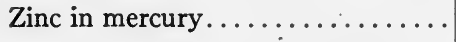 & $\ldots \ldots \ldots$ & 2.09 & G. Meyer \\
\hline
\end{tabular}

* Physik. Z., 6, 320, I9r 5 . 
The diffusion coefficient of normal sulfuric acid is given by Arrhenius as I.I 2 in the units of the table and that of double normal as I.I6 both at $12^{\circ}$.

The dilution tendency can perform work and overcome resistance. It offers an explanation of the osmotic phenomena. If a solution be conceived of, as in a vessel with a semi-permeable bottom and immersed in the pure solvent; the solution could become diluted, since the solvent could be taken in through the semi-permeable membrane. If the solution be placed under pressure, by means of a movable weighted piston, the solvent would be forced out again, and a concentration effected. The dilution tendency will accordingly oppose work, and there must be a counter pressure which the dilution tendency will hold in equilibrium, so that the solvent neither goes in nor comes out of the cell. This equilibrium pressure is designated as the osmotic pressure of the respective solutions. Its magnitude depends on the temperature and the number of dissolved molecules which the space contains, and in fact the osmotic pressure is equal to the pressure which a substance would exert as a gas at the same temperature and molecular concentration.

\section{Vapor Pressure of Metallic Solutions.}

If a solution occurs in contact with the vapor of its solvent the upper surface of the liquid may be considered as a semipermeable membrane, through which the molecules of the solvent, but not of the solute, may pass to the vapor space. Two opposing forces are now to be considered: the tendency of the solvent to evaporate and the tendency of the solution to dilute itself by absorbing solvent molecules from the vapor space. An equilibrium is established between these two forces which act on the vapor, and the pressure corresponding to this equilibrium is the vapor pressure of the solution. The measurable effect of the dilution tendency is the lowering of the vapor pressure of a solution, as compared to the pure solvent. The vapor tension of a dilute solution is always lower than that of the pure solvent. The lowering of the vapor pressure depends as 
does the magnitude of the osmotic pressure, on the molecular concentration and the temperature; it is likewise a function of the dilution tendency. The vapor pressure of the solution being lower than that of the pure solvent, the boiling point, that is, the temperature at which the vapor pressure is equal to atmospheric, is accordingly higher. These relations can be at once recognized, from the graphical representation, as shown in Fig. Ir. The only metallic solutions feasible to study are those with mercury, the lowest boiling of the metals.

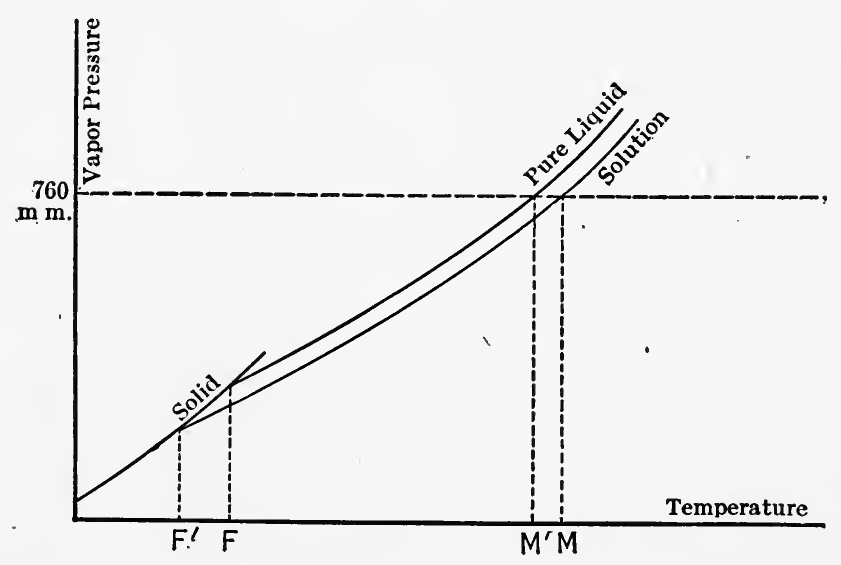

FIG. II.

Investigations on the vapor pressure lowering of dilute amalgams, have been carried out by Sir William Ramsay* for the purpose of determining the molecular weights of the dissolved metals. As we have seen, the vapor pressure lowering is proportional to the number of dissolved molecules. Accordingly if we know the depression for a dissolved substance of known molecular weight, we can calculate the molecular weight of other substances from the vapor pressure depression observed for them. 
The results of Ramsay's observations are given in the following table:

\begin{tabular}{|c|c|c|c|c|c|}
\hline Temp. & $\begin{array}{l}\text { Dissolved } \\
\text { Metal. }\end{array}$ & $\begin{array}{l}\text { No. Atoms } \\
\text { per 100 At. } \\
\text { Hg. }\end{array}$ & $\begin{array}{l}V . P \text {. Lower- } \\
\text { ing in } M m \text {. }\end{array}$ & $\begin{array}{c}\text { Calculated } \\
\text { Molecular } \\
\text { Weight. }\end{array}$ & $\begin{array}{l}\text { Atomic } \\
\text { Weight. }\end{array}$ \\
\hline 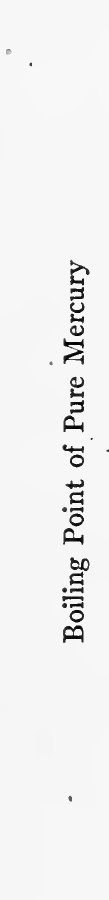 & $\begin{array}{l}\mathrm{Li} \\
\mathrm{Na} \\
\mathrm{K} \\
\mathrm{Ca} \\
\mathrm{Ba} \\
\mathrm{Mg} \\
\mathrm{Zn}\end{array}$ & 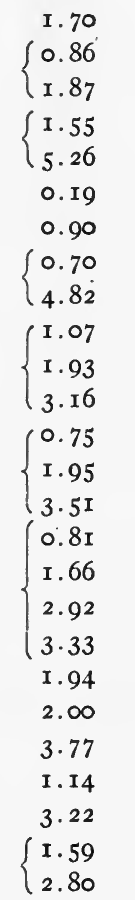 & $\begin{array}{r}\text { I2.9 } \\
6.7 \\
17.9 \\
15.6 \\
49.6 \\
2.9 \\
12.3 \\
5.4 \\
40.6 \\
7.4 \\
15.5 \\
23.6 \\
6.3 \\
16.3 \\
27.4 \\
7.6 \\
13.3 \\
24.6 \\
25.3 \\
14.7 \\
15.4 \\
26.8 \\
8.5 \\
22.8 \\
11.3 \\
19.2\end{array}$ & 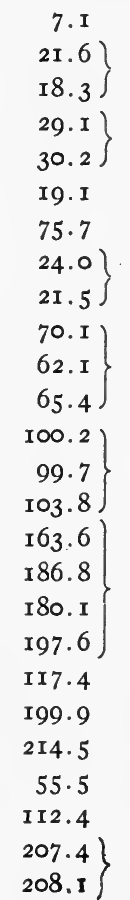 & $\begin{array}{c}\text { II9.0 } \\
206.9 \\
208.0 \\
55.0 \\
107.93 \\
197.2\end{array}$ \\
\hline
\end{tabular}

There are two things to be noted from this table, first, the proportionality between concentration and depression and second, the confirmation of the fact that most of the metal molecules are monatomic, which can also be observed in vapor density determinations.

\section{Freezing Point of Alloys.}

The vapor pressure is also related to the freezing point of solutions. The freezing point of a solution is always lower than that of the pure solvent; it is a recognized fact, for example, that salt water is very much more difficult to freeze than pure 
water. In the first chapter we showed that the freezing point was the intersection of the vapor pressure curve for the solid substance and that for the liquid. Through the addition of the dissolved substance the vapor pressure curve of the liquid is lowered. The vapor pressure of the solid substance is in general uninfluenced by the dissolved substance since the solvent precipitates out in the pure state. The freezing point of a solution is accordingly principally dependent on the vapor pressure curve of the liquid and is hence depressed. The magnitude of the depression depends with the same solvent, on the molecular concentration, precisely as with the lowering of the vapor pressure and the raising of the boiling point.

There is a very great amount of experimental data on the freezing point lowering of metallic solutions. The work of Heycock and Neville* and of Tammann $\dagger$ has been of particular value in this field. The magnitude of the depression which a gram molecule causes, when dissolved in roo grams of solvent, is called the molecular freezing point lowering, and can be calculated from the thermal constants of the solvent, its freezing point (in absolute degrees), and its heat of fusion. The depression is connected with these magnitudes through the following equation which is due to Van'T Hoff,

$$
\Delta=0.02 \frac{T^{2}}{q} .
$$

$T$ is the absolute melting point, $q$ the heat of fusion.

The following table gives these magnitudes for a series of metals:

\begin{tabular}{|c|c|c|c|}
\hline Metal. & $\Delta$. & Metal. & $\Delta$. \\
\hline Antimony.... & I 240 & Silver........ & I 443 \\
\hline Lead........ & 1225 & Bismuth.... & 460 \\
\hline Cadmium.... & 516 & Tin........ & 359 \\
\hline Copper....... & 870 & Zinc............. & $34 \mathrm{I}$ \\
\hline Mercury.... & 390 & & \\
\hline
\end{tabular}

* J. Chem. Soc., 61, 904 (г892); 55, 666 (г889); 57, 376 (г890); 71, 383 (1897); Trans. Roy. Soc., 189, A25 (1897).

† Z. Physik. Chem., 3, 44I (1898). 
Through comparison of these numbers with the observed depression, the molecular weight of the dissolved metal can be determined. Experiments of this nature have also confirmed the fact, that in most cases the metals are monatomic. The data is given in the following table:

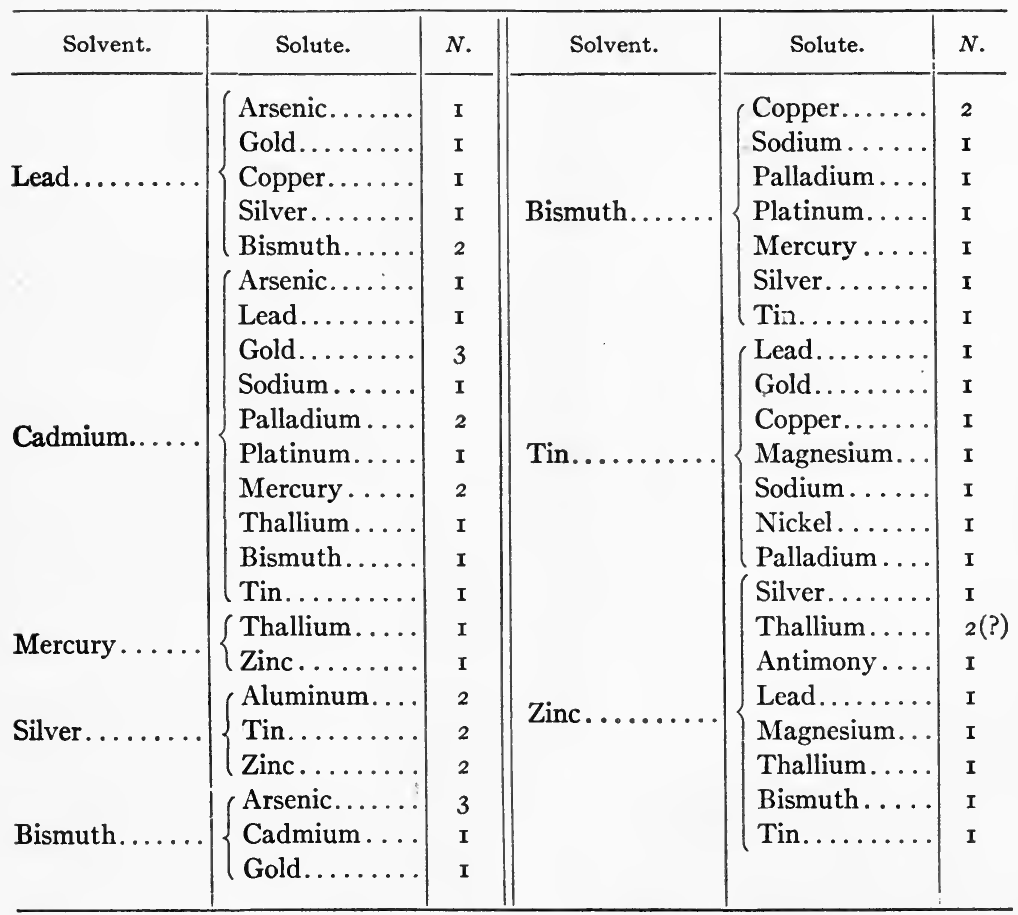

\section{Metals only Partially Miscible in Liquid State.}

The concentrated solutions of metals also show all the phenomena that occur with non-metallic liquids. There are liquid metals that mix with one another in all proportions, for example, lead and tin, and there are those that are only partially miscible, for example, lead and zinc. If, for example, lead and zinc, or zinc and bismuth are melted together, the melt separates into two liquid layers, exactly as in the case of water and ether. The composition of the two layers is different and becomes more nearly equal with rising temperature, finally it becomes identical 
for both layers, and the layers disappear. The temperature of this complete miscibility is called the critical temperature. With a mixture of bismuth and zinc this critical temperature is about $820^{\circ}$, for lead and zinc about $935^{\circ}$. Above these temperatures the miscibility is complete, below it is only partial. In the case of layer formation every temperature corresponds to a definite composition of the two layers. This inter-dependence is represented graphically by a curve with two limbs which intersect at the critical temperature. Outside of this curve is the field for homogenous liquid mixtures; inside a homogenous mixture separates into two liquid layers. The composition of the layers at different temperatures is shown in the following table (according to Spring and Romanoff).*

\begin{tabular}{|c|c|c|c|c|c|c|c|c|}
\hline \multirow{3}{*}{$\begin{array}{l}\text { Temp. } \\
\text { Deg. }\end{array}$} & \multicolumn{4}{|c|}{ Bismuth-Zinc. } & \multicolumn{4}{|c|}{ LEAD-ZINC. } \\
\hline & \multicolumn{2}{|c|}{ Under Layer. } & \multicolumn{2}{|c|}{ Over Layer. } & \multicolumn{2}{|c|}{ Under Layer. } & \multicolumn{2}{|c|}{ Over Layer. } \\
\hline & $\begin{array}{c}\text { Per Cent } \\
\text { Bi. }\end{array}$ & $\begin{array}{c}\text { Per Cent } \\
\text { Zn. }\end{array}$ & $\begin{array}{c}\text { Per Cent } \\
\text { Bi. }\end{array}$ & $\begin{array}{c}\text { Per Cent } \\
\text { Zn. }\end{array}$ & $\begin{array}{l}\text { Per Cent } \\
\text { Pb. }\end{array}$ & $\begin{array}{l}\text { Per Cent } \\
\text { Zn. }\end{array}$ & $\begin{array}{l}\text { Per Cent } \\
\text { Pb. }\end{array}$ & $\begin{array}{c}\text { Per Cent } \\
\text { Zn. }\end{array}$ \\
\hline 266 & 86.0 & $\mathrm{r} 4.0$ & & & & & & \\
\hline 334. & $\ldots \ldots$ & $\ldots$ & $\ldots \ldots$ & $\ldots \ldots$ & 98.8 & I. 2 & & \\
\hline $4 \mathrm{r} 9$ & $\ldots \ldots$ & $\ldots$ & 3.0 & 97.0 & $\ldots \ldots$ & $\ldots \ldots$ & I. 5 & 98.5 \\
\hline 450 & $\ldots \ldots$ & $\ldots \ldots$ & $\ldots \ldots$ & $\ldots \ldots$ & 92.0 & 8.0 & & \\
\hline 475 & 84.0 & r6.o & 5.0 & $95 . \circ$ & 91.0 & 9.0 & 2.0 & 98.0 \\
\hline $5^{14}$ & $\ldots$ & $\ldots \ldots$ & $\ldots \ldots$ & $\ldots \ldots$ & 89.0 & Ir. $\infty$ & 3.0 & 97.0 \\
\hline $5^{84}$ & $80.0^{\circ}$ & 20.0 & 10.0 & 90.0 & 86.0 & 14.0 & 5.0 & 95.0 \\
\hline 650 & 77.0 & 23.0 & $\mathrm{r}_{5} .0$ & 85.0 & 83.0 & $\mathrm{r} 7.0$ & 7.0 & 93.0 \\
\hline 740 & $\ldots$ & $\ldots \ldots$ & $\ldots \ldots$ & $\ldots \ldots$ & 79.0 & 21.0 & 10.0 & 90.0 \\
\hline 750 & 70.0 & 30.0 & 27.0 & 73.0 & & & & \\
\hline 800 & $\ldots \ldots$ & $\ldots \ldots$ & $\ldots \ldots$ & $\ldots \ldots$ & $75 \circ$ & 25.0 & 14.0 & 86.0 \\
\hline 900 & $\cdots$ & $\ldots \ldots$ & $\ldots \ldots$ & $\cdots \cdots$ & 59.0 & 41.0 & $25 \cdot 5$ & $74 \cdot 5$ \\
\hline
\end{tabular}

\section{The Parkes Process.}

An interesting use is made of the partial miscibility of lead and zinc, in the Parkes process for the desilverization of base bullion. A small amount of zinc is added to the molten lead, held at about $500^{\circ}$, and the mixture stirred. A lighter layer collects on the upper surface which contains 97 per cent $\mathrm{Zn}$ and

\footnotetext{
*Z. anorg. Chem., 13, 29 (1897).
} 
3 per cent $\mathrm{Pb}$. In it is found most of the silver originally in the lead. The silver has been extracted from the lead by the zinc. This process reminds one of the shaking out with ether, commonly used in organic chemistry, to extract dissolved substances from water by their solubility in ether. Both processes depend on the fact, that the third substance distributes itself between the layers according to a definite ratio.

The ratio of the concentrations of the dissolved substance is designated as the partition coefficient. This magnitude is

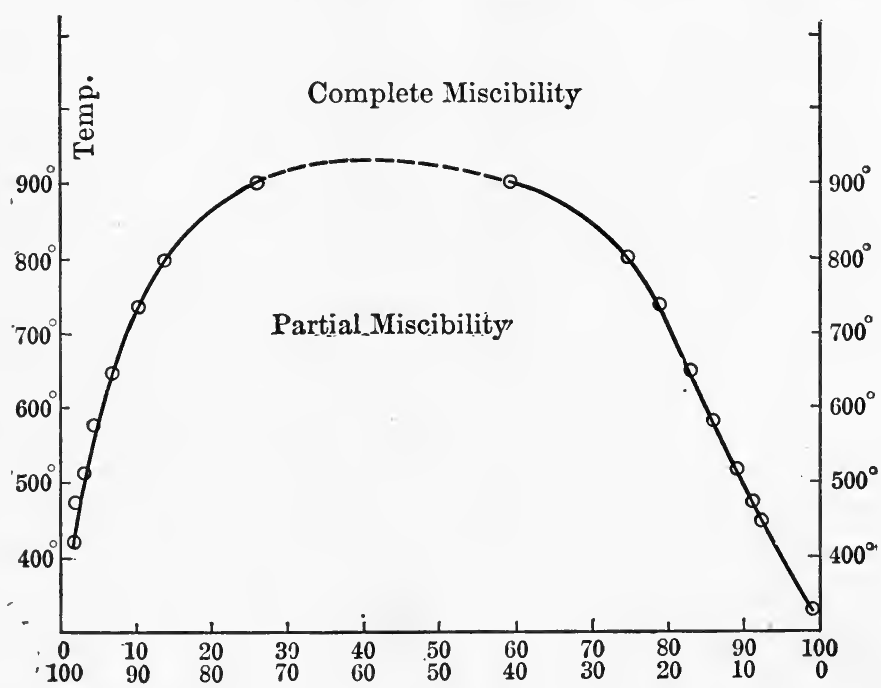

FIG. 12.

large for silver distributed between zinc and lead. The relation is well illustrated by an analagous experiment with iodine water which is shaken with a small amount of ether. On settling the ether is found to cortain the principal amount of the iodine, which can be recognized by its brown color. The iodine water represents the argentiferous lead and ether the added zinc. It can be seen at once that it is not possible to remove the dissolved substance entirely by means of the partition process without repeating the process a number of times. 
Solidification Curve of Binary Alloys, the System Cadmium-Zinc.

On cooling a homogenous melt, there first begins a separation of solid crystals, and finally the entire mass solidifies. We will now study the solidification phenomena of an alloy made up of two metals.

We will first consider the metals zinc and cadmium. The crystallization point of pure zinc is at $4 \mathrm{I} 9.4^{\circ}$. If small amounts of cadmium be added to this metal, the crystallization point will be depressed, according to the above-stated principle, and the further the greater the concentration of the second metal. If

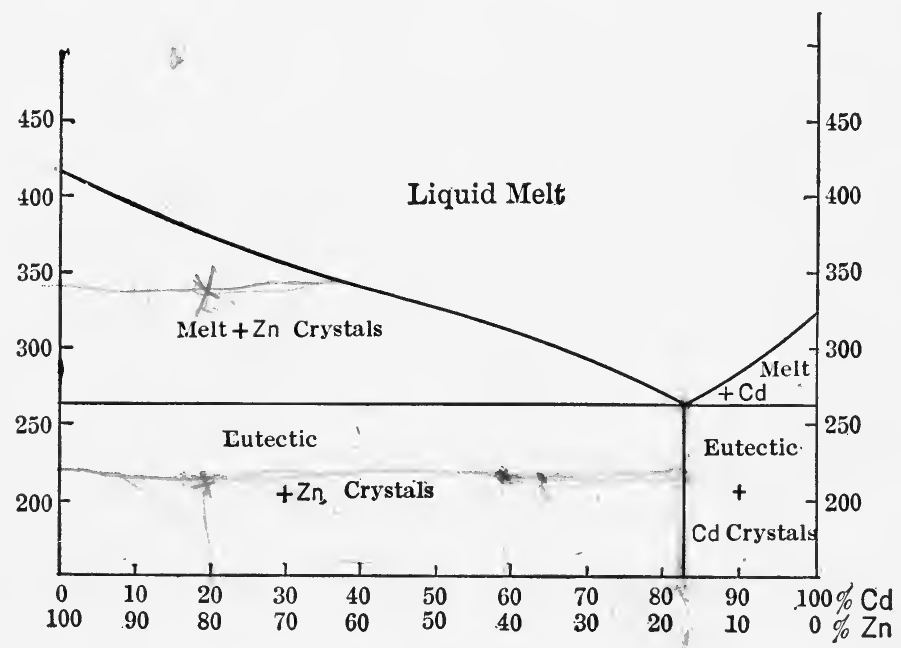

FIG. I3.

now we represent graphically the dependence of the solidification point on the composition of the melt, we obtain a curve which begins at the melting point of the pure substance and gradually sinks. There may be obtained, however, a similar curve by starting with pure cadmium and adding zinc to the melt. The zinc and cadmium crystallize out of the melt in the pure state, no compounds forming, nor mixed crystals separating. This system represents the simplest possible case.

The two curves represent respectively, the equilibrium between liquid zinc-cadmium melt and pure zinc crystals, and the 
equilibrium between the melt and pure cadmium crystals. The two curves intersect at a definite temperature and a definite composition of the melt. At this temperature zinc and cadmium crystallize simultaneously and the melt solidifies completely. This point of complete crystallization is designated as the eutectic point. For the zinc cadmium alloys it is at $264^{\circ}$ and the eutectic alloy contains 26 atomic per cent of zinc (i.e. I 7.35 per cent by weight).

The eutectic temperature is lower than the melting point of either of the components. It is marked by a retardation of the cooling in an entirely similar way to the point of arrest of the

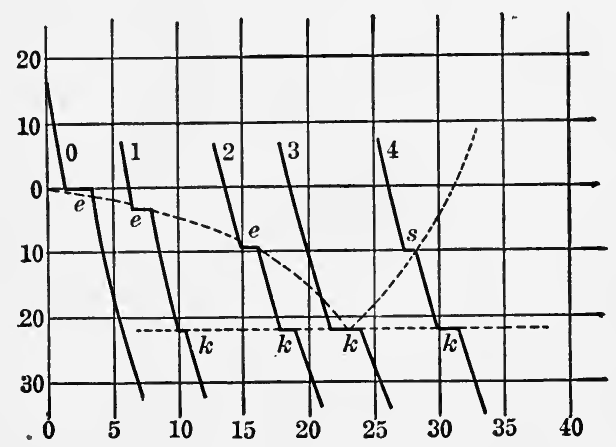

FIG. 14.

pure metals, the temperature remaining steady till the melt is completely solidified to a solid alloy.

The schematic representation of a series of cooling curves for mixtures of the same components (salt and water) but in different proportions is shown in Fig. I4.

Two points of arrest can be recognized in these curves, an upper, which indicates the beginning of the precipitation of a component, its position depending on the composition, and a lower, nameiy, the eutectic point, which has the same position for all compositions of the mixture.

A large number of metal pairs are similar to cadmium and zinc. The position of the eutectic point, the melting point of the alloy components and the composition of the eutectic, are 
however, quite different, as shown by the following table, taken from Roozeboom.*

\begin{tabular}{|c|c|c|c|c|c|c|}
\hline & \multicolumn{4}{|c|}{ COMPONENTS. } & \multicolumn{2}{|c|}{ Eutectic. } \\
\hline & A. & M. $P$. & $B$. & $M . P$. & Temp. & $\begin{array}{c}\text { Conc. } B \\
\text { (Atom- } \\
\text { Per Cent). }\end{array}$ \\
\hline I & $\mathrm{Ag}$ & 960 & $\mathrm{Cu}$ & IO8I & 778 & 40 \\
\hline 2 & $\mathrm{Cd}$ & 320 & $\mathrm{Zn}$ & 418.5 & 264 & 26.5 \\
\hline 3 & $\mathrm{Sn}$ & 232 & $\mathrm{~Pb}$ & 322 & 183 & 23 \\
\hline 4 & Sn & 232 & $\mathrm{Ag}$ & 960 & $22 \mathrm{I}$ & 3.8 \\
\hline 5 & $\mathrm{Zn}$ & 418 & $\mathrm{Al}$ & 654 & $38 I$ & II \\
\hline 6 & $\mathrm{~Pb}$ & 328 & $\mathrm{Ag}$ & .960 & 303 & $4 \cdot 4$ \\
\hline 7 & $\mathrm{Tl}$ & 301 & $\mathrm{Cd}$ & 320 & 203.5 & 27.2 \\
\hline 8 & $\mathrm{Sn}$ & 232 & $\mathrm{Zn}$ & 418.5 & I98 & I6 \\
\hline 9 & $\mathrm{Sn}$ & 232 & $\mathrm{Cd}$ & 320 & I 78 & 3 I. 2 \\
\hline 10 & $\mathrm{Cd}$ & 320 & $\mathrm{~Pb}$ & 322 & 249 & $67 \cdot 3$ \\
\hline II & $\mathrm{Bi}$ & 268 & $\mathrm{Cd}$ & 320 & I 49 & 55.7 \\
\hline I 2 & $\mathrm{Sn}$ & 232 & $\mathrm{Tl}$ & 301 & 170.2 & 31 \\
\hline 13 & $\mathrm{Sn}$ & 232 & $\mathrm{Bi}$ & 268 & I 35 & 42 \\
\hline I4 & $\mathrm{Pb}$ & 322 & $\mathrm{Sb}$ & 632 & 228 & 20.5 \\
\hline I5 & $\mathrm{Bi}$ & 268 & $\mathrm{~Pb}$ & 322 & 125 & 43.8 \\
\hline
\end{tabular}

Still more important than the various relations of the different metals given in the table, are those brought out by the equilibrium curves. Two such pairs are represented in Fig. ${ }^{5}$, the pair $\mathrm{Cu}, \mathrm{Ag}$ and the pair $\mathrm{Ag}, \mathrm{Pb}$. In the first, the eutectic mixture consists of 60 atomic per cent silver and 40 atomic per cent copper and the eutectic temperature is $200^{\circ}$ below the melting point of the lower melting constituent; with the second pair, the difference between the eutectic point

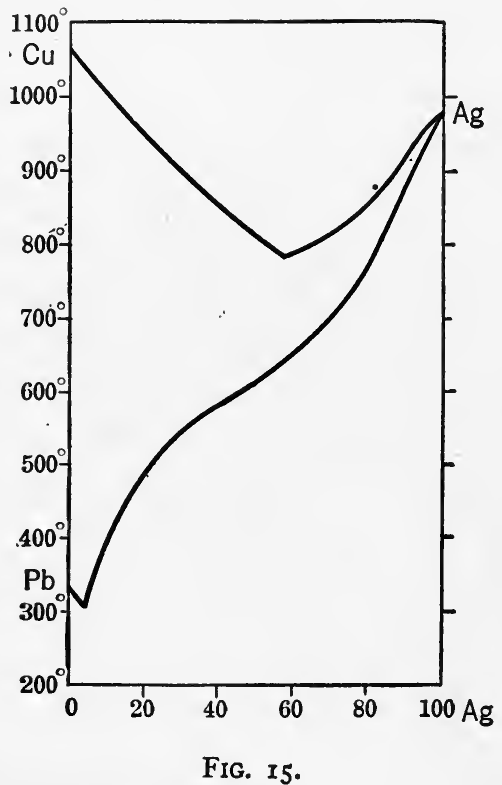

* Heterogene Gleichgewitche, Heft I I, p. I96. 
and the melting point is only $25^{\circ}$ and the silver content of the eutectic melt is very small being only 4.4 atomic per cent or 2.6 per cent by weight.

\section{The Pattison Process.}

These relations are of importance since we have seen that commercial lead is argentiferous. The content, however, is generally small, and before separating the silver and lead by cupelling, it is necessary to enrich the lead in the noble metal. This can be done by the Pattison process, in which the temperature of the molten lead is lowered so far, that a precipitation of the lead takes place, the precipitated crystals consisting of pure lead are skimmed off, the silver remaining in the liquid, and enriching it. It is not possible by this process, to obtain a silver concentration of more than 2.6 per cent. The concentration of the eutectic mixture forms the upper limit and the alloy must not be allowed to cool past the eutectic point, or the whole mass will solidify.

\section{Segregation in Alloys.}

If we consider the zinc-cadmium diagram (Fig. I3), we see that the field is divided by the two curves and the ordinate that passes through the intersection. Between the curves and the abscissa at $264^{\circ}$ is a field inside of which homogenous mixture of the two metals cannot exist. They break up into solid crystals and a melt, the composition of which is expressed by a point on the curve. The crystals which separate, are of one component on one side of the ordinate, through the eutectic point, and of the other component on the other side.

The crystals precipitated from a liquid alloy frequently possess a different specific gravity from the melt, and hence rise to the top or sink to the bottom. If now the alloy be cooled gradually, below the eutectic point, and different layers of the solid alloy examined, it is found that they vary markedly in composition. Above or below there is probably one of the pure components, and in the middle the composition approaches that of the eutectic alloy. This kind of stratification in an alloy is designated as segregation. Such a segregation is impossible if 
the alloy has the composition of the eutectic mixture as this crystallizes uniformly. The crystals of the two components separate simultaneously and are fine and uniformly distributed.

While the eutectic crystallizes finely, the crystals of the excess component have time while swimming in the melt during cooling, to develop fully in all directions. The result is, that, on complete solidification, the alloy consists of large crystals, embedded in finely crystalline eutectic. The number of scattered crystals become less as the total composition of the alloy approaches that of the eutectic.

The diagram (Fig. I3) shows the field in which the solid alloy consists of eutectic with zinc crystals on the one hand and eutectic with cadmium on the other.

\section{Investigation of Alloy Structure.}

Various processes are now employed for the investigation of alloy structure, which has already become important in determining the physical properties of alloys.

We may consider first the method of Heycock and Neville* in which alloys are penetrated by means of $\mathrm{X}$-rays. It is, however, dependent on a condition which is fulfilled by only a few alloys, namely, the components must be very differently transparent to Roentgen rays. The method has proved itself useful with alloys of metals of high atomic weight with those of low atomic weight, since there exists a parallelism between the absorption of X-rays and the atomic weight. The two English metallurgists investigated in this way gold-aluminum and goldsodium alloys. The latter pair has a eutectic temperature of $82^{\circ}$ and the eutectic mixture has a gold content of 3.5 per cent. The radiographs of these alloys is shown in Fig. I6, $a, b, c$.

Radiograph Fig. I $6 a$ shows the structure of a eutectic mixture, Fig. I $6 b$ represents an alloy with excess sodium, the fernlike forms of X-ray transparent crystals which appear light in the positive are easily recognized, as are the opaque, hair-like gold crystals in Fig. I6c. However, in both the latter pictures, the presence of the embedding eutectic is perceived.

$$
\text { *J. Chem. Soc., 73, 714 (I898). }
$$


The microscopic investigation of alloys in reflected light, is useful to a much greater extent. The process has been developed especially by Sorby, Martens, LeChatelier, Heyn, Tammann and

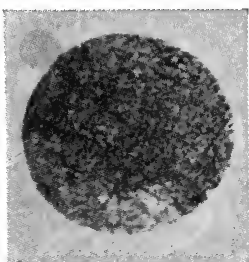

$a$

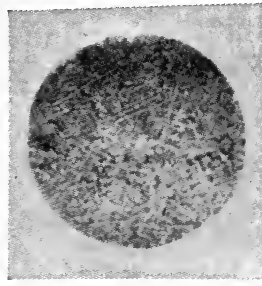

$b$

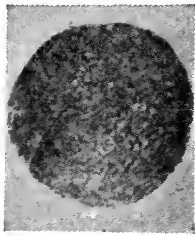

c

Fig. 16.-Radiographs of Au-Na Alloys. (Heycock and Neville.)

others. The alloys are cut, polished and etched, so as to bring a single component into relief. The following pictures show a number of zinc-cadmium alloys so treated.

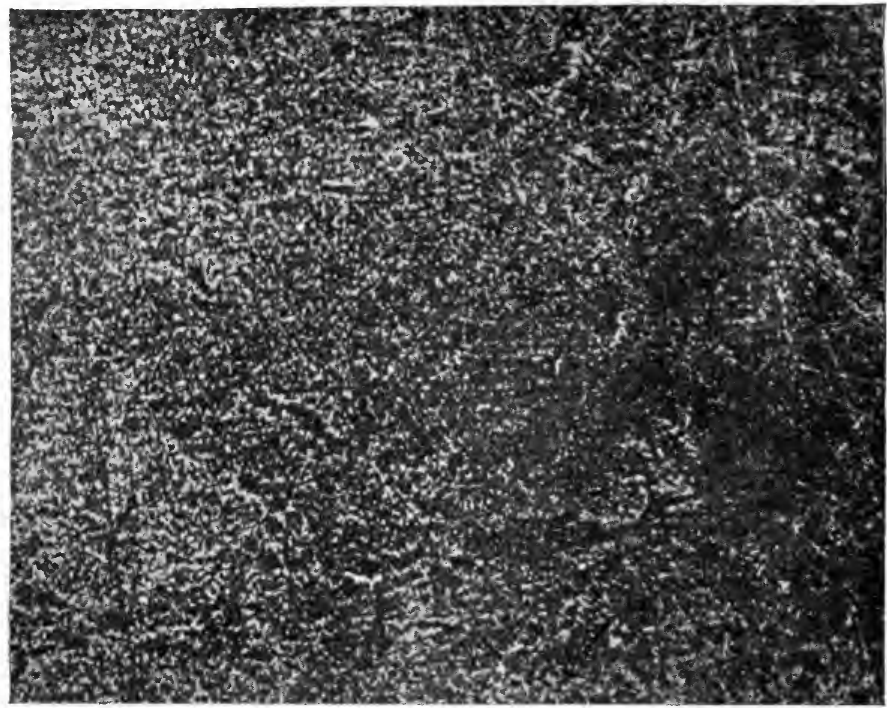

Fig. 1 7.-Zn-Cd Alloy, Eutectic.

Fig. I 7 shows the eutectic alloy with slight enlargement. The light particles are cadmium, the dark zinc. Fig. I8, shows a 
cadmium rich alloy, the bright cadmium stars surrounded by eutectic. Fig ig shows a zinc rich alloy of large feathered zinc needles, in a light ground mass of eutectic.

The structure of the eutectic alloy is only resolvable with strong magnification. Fig. 20 shows in a cadmium zinc alloy, the characteristic appearance of the eutectic structure. It shows clearly, how dark zinc layers and light cadmium layers, alternate with each other. The eutectic structure is a lamellar one.

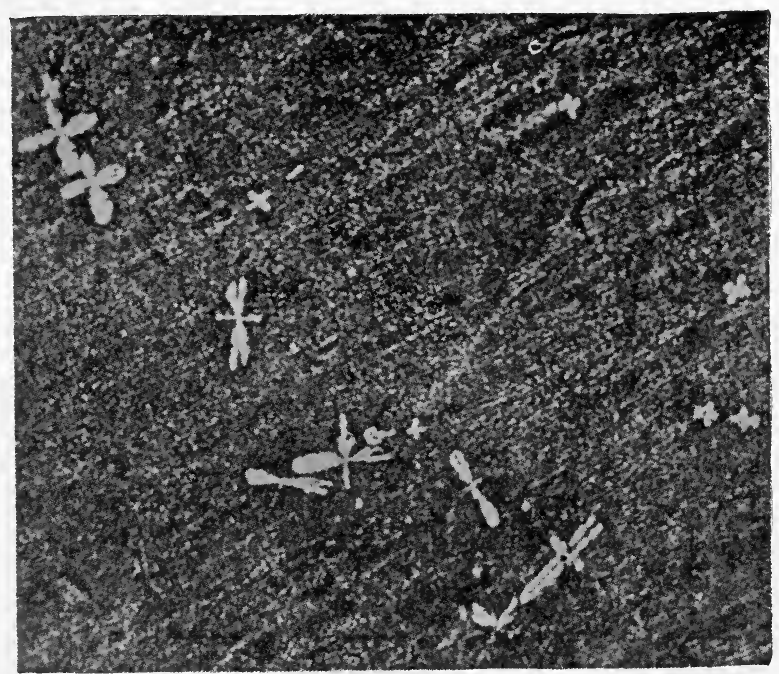

Fig. I8.-Żn-Cd Alloy, Eutectic with Embedded Cadmium Crystals.

\section{Solid Solution.}

In the alloys previously considered, the components precipitate in the pure state. There are, however, a large number of metals between which miscibility in the solid state exists. With these, solid solutions are precipitated from the cooling melt. There are, with solids as with liquids, cases of total and partial miscibility.

Many metals form solid solutions in all proportions, important examples being the coinage alloys, gold-silver and copper- 


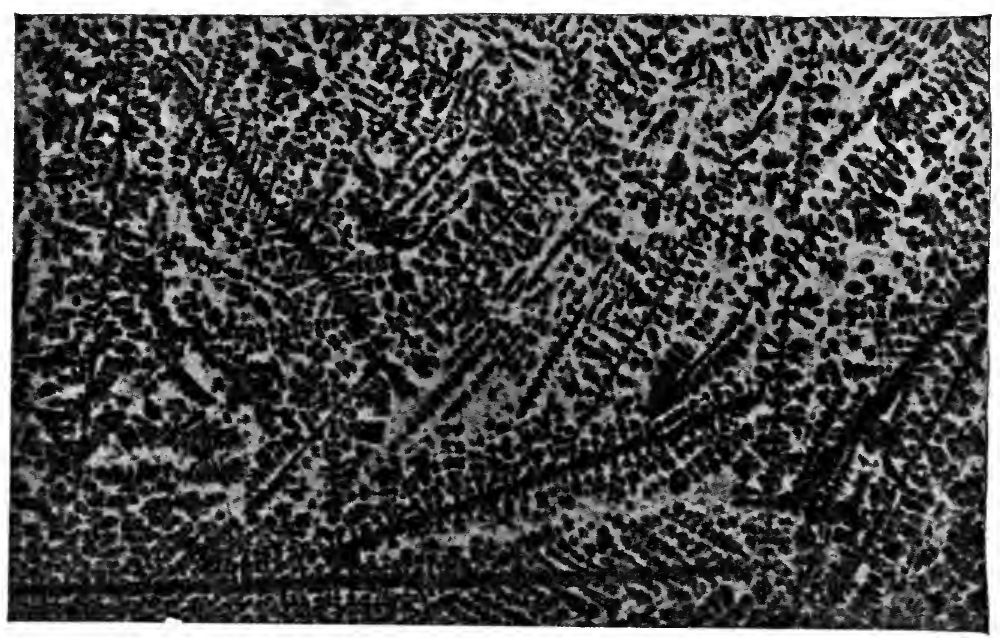

Fig. I9 -Zn-Cd Alloy, Eutectic with Embedded Zinc Crystals.

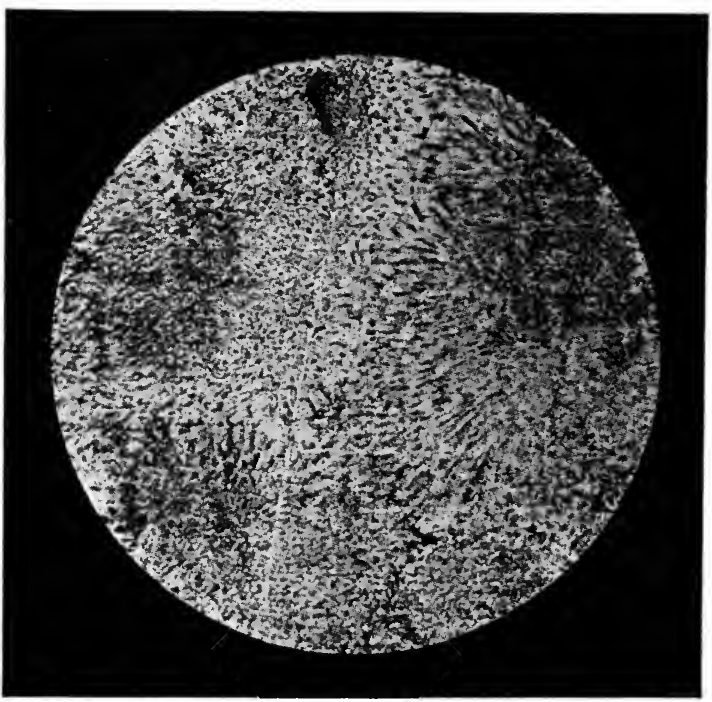

FIg. 20.-Zn-Cd Ailoy, Eutectic Greatıy Enlarged. 
nickel. Tammann * gives a compilation of the single cases in which complete miscibility exists, they are, $\mathrm{Cu}-\mathrm{Mn}, \mathrm{Cu}-\mathrm{Ni}$, $\mathrm{Ag}-\mathrm{Au}, \mathrm{Mg}-\mathrm{Cd}, \mathrm{Bi}-\mathrm{Sb}, \mathrm{Mn}-\mathrm{Fe}, \mathrm{Mn}-\mathrm{Ni}, \mathrm{Mn}-\mathrm{Co}, \mathrm{Fe}-\mathrm{Co}$, $\mathrm{Fe}-\mathrm{Ni}, \mathrm{Ni}-\mathrm{Co}, \mathrm{Pt}-\mathrm{Cu}, \mathrm{Pt}-\mathrm{Au}, \mathrm{B}-\mathrm{Cu}, \mathrm{B}-\mathrm{Ag}, \mathrm{Pd}-\mathrm{Au}, \mathrm{In}-\mathrm{Pb}$.

\section{The Heraus Process of Plating Platinum with Gold.}

Solid solutions are to be considered as true solutions, despite their solid state of aggregation. The phenomena characteristic of solutions can be observed in them, especially the diffusion of a dissolved substance from a place of higher concentration to one of lower. This is shown in the Heraus process of plating platinum with gold, in which a platinum block is heated to the melting point of gold and liquid gold is poured on it. On cooling the two are so solidly united that the combination can be rolled to thin leaves. Further, strong temperature changes do not affect the solidity of the combination, in spite of the very different expansion of the two metals. This process, so valuable practically, is only possible, since gold can diffuse into the solid platinum, and, indeed, with considerable speed, so that the gold does not come into direct contact with the platinum, but there is a continuous transition of gold through solid gold-platinum solutions, the concentration of which diminishes, till finally the pure platinum is reached.

\section{Crystallization Diagrams for Metals Forming Solid Solutions.}

The crystallization diagram of a metal pair of this kind differs very essentially from those already treated. The lack of a eutectic point is characteristic. The form of the curves is shown in Fig. 2I, for the pair Pt-Au, in Fig. 22 for the system $\mathrm{Au}-\mathrm{Ag}$, and in Fig. 23 for the solid solutions of $\mathrm{Bi}-\mathrm{Sb}$.

Figs. 2 I and 22 show the composition of the melt, at the start of the solidification but give no information as to the composition of the solid solutions which separate from the melt. The compositions of the liquid and the solid are, with special exceptions which we will take up later, entirely different.

*Z. anorg. Chem., 53, 447 (1907). 
If we plot the melting temperatures of the solid alloys against their composition, two curves are obtained which, however, coincide with the crystallization curves only at the melting points of the components. Fig. 23 shows the position of the two

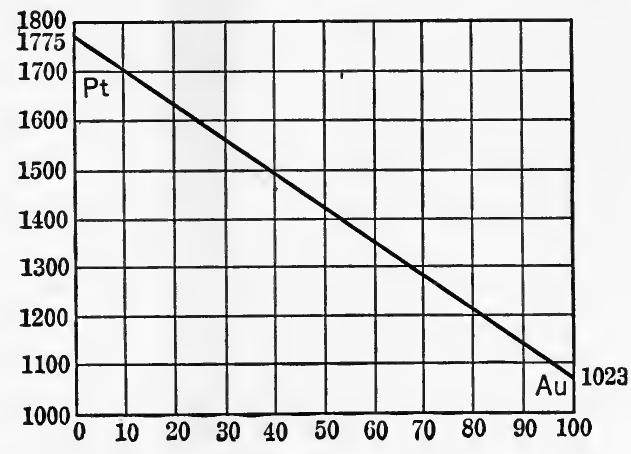

Fig. 2I.

curves for $\mathrm{Bi}-\mathrm{Sb}$ alloys. Curve $\mathrm{Bi}-\mathrm{A}-\mathrm{Sb}$ is the line for the beginning of melting, curve $\mathrm{Bi}-\mathrm{C}-\mathrm{B}-\mathrm{Sb}$ is the line for the beginning of solidification. The two curves enclose a field outside of which solutions in either the liquid and the solid state can exist. In the gap only heterogenous mixtures of solid and liquid solu-

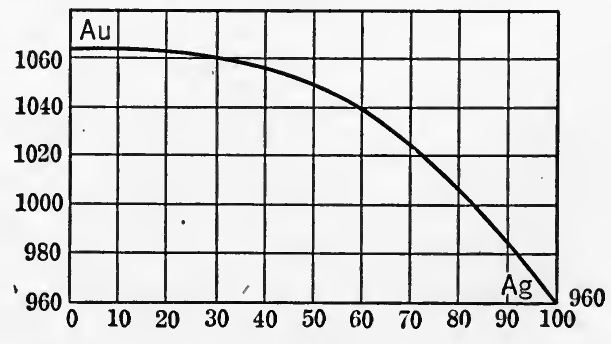

FIG. 22.

tions are possible. As the temperature is lowered the first crystals to precipitate are rich in antimony but as the temperature is lowered the bismuth content grows steadily. The completely solidified alloy is accordingly not homogenous, but consists of a stratification of crystals of different composition. In 
some cases it is possible to make the alloys homogenous, by supplementary heating, at a temperature near the melting point, when an adjustment of the concentration takes place by diffusion. This diffusion is very slow with $\mathrm{Bi}-\mathrm{Sb}$ alloys but with $\mathrm{Au}-\mathrm{Ag}$ and $\mathrm{Au}-\mathrm{Pt}$ alloys the thermal treatment is quite effective.

All alloys whose components are miscible in all proportions do not show the kind of diagram described above, that is, the steady decrease of melting and crystallization points from the melting point of the higher-melting component to that of the lower. Exactly as with solutions of liquids, whose boiling point

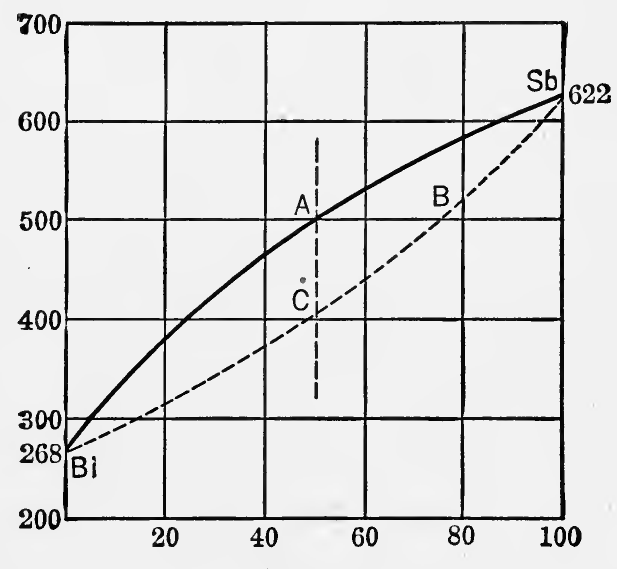

FIG. 23.

is higher or lower than the boiling point of either of the components, there is a mixture which has a maximum or minimum boiling point, so with a solid solution whose melting point is higher or lower than that of the components, there is a mixture of maximum or minimum melting point. The liquid mixture with a maximum or minimum boiling point, boils at a constant temperature, the composition of the vapor being the same as that of the liquid. Similarly, there is no concentration change in the melting of a solid solution of maximum or minimum melting point, the alloy has the same composition in the solid and liquid state. Alloys of this kind are designated as coincident melting. Schematic diagrams of solid solutions with a maximum 
and minimum melting point are shown in Fig. $24 a$ and $b$. Outside of the pure components only the mixture of maximum or minimum boiling point is coincident melting; all the rest melt over a temperature range. With solid solutions of the type $\mathrm{Sb}-\mathrm{Bi}$ there is in general no coincident melting alloy.

The miscibility of the metals, in the solid state, is frequently only partial, for example, in the metal pairs $\mathrm{Cu}-\mathrm{Fe}, \mathrm{Cu}-\mathrm{Pt}$, and others. Tammann has formulated a rule concerning these cases, it is "the metal with the higher melting point, always dis-

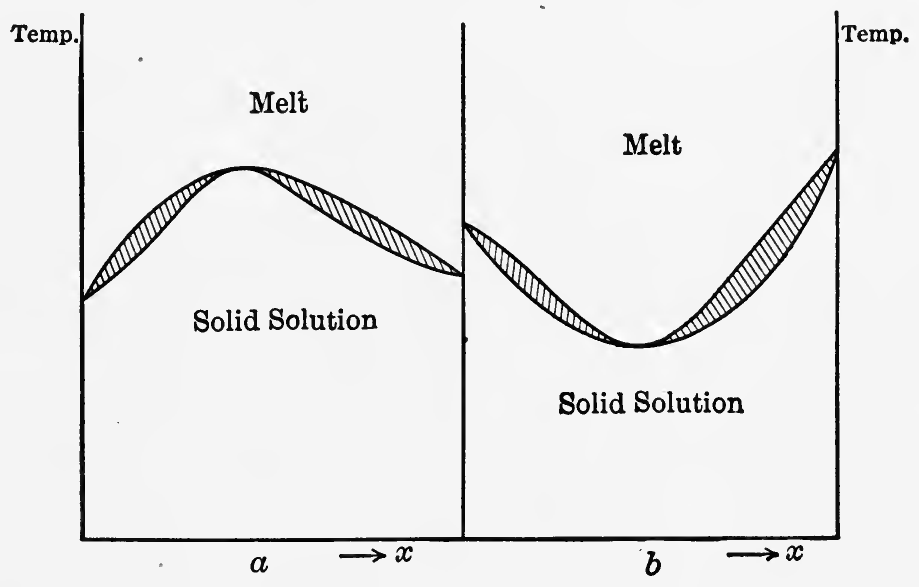

FIG. 24.

solves more of the metal with the lower melting point than vice versa."

The crystallization diagrams of alloys, with partial miscibility of the components, show many different types of phenomena and are best illustrated by examples. The gold-nickel alloys (Fig. 25), which have been studied by Levin, and the cadmium-mercury alloys, which have been studied by Bijl, are such examples. In the first case the occurrence of a eutectic mixture of the two kinds of solid solutions is interesting.

Inter-metallic Compounds.

A whole series of phenomena indicate that chemical reaction takes place when certain metals are melted together. Among 
METALLIC SOLUTIONS AND ALLOYS

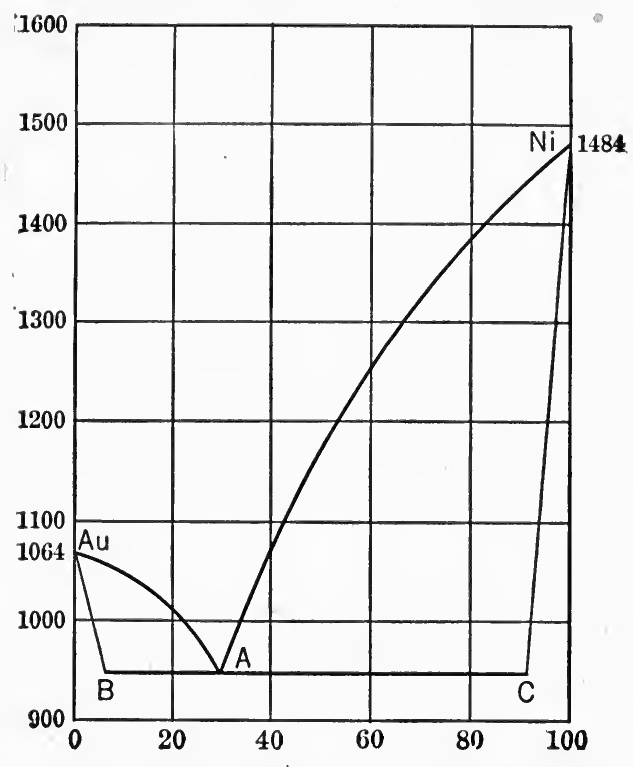

Fig. 25.

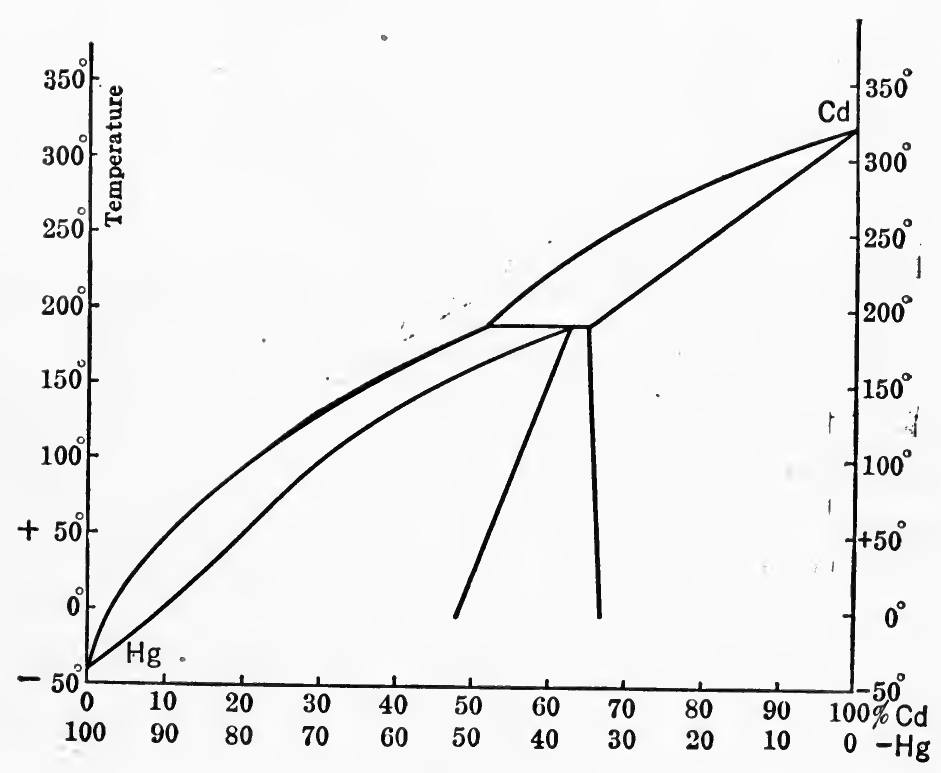

FIG. 26. 
these may be mentioned the strong heat evolution when sodium and hot mercury are mixed and also when copper and zinc are mixed. The large volume difference between alloys and a physical mixture of their components, is best explained by such a compound formation.

Alloys frequently show properties which the components do not possess. The alloys of antimony and manganese, for example, are extraordinary and are well suited to lecture demonstration of the change of components by melting. If a mixture of equal molecular proportions of antimony and manganese are fused, in

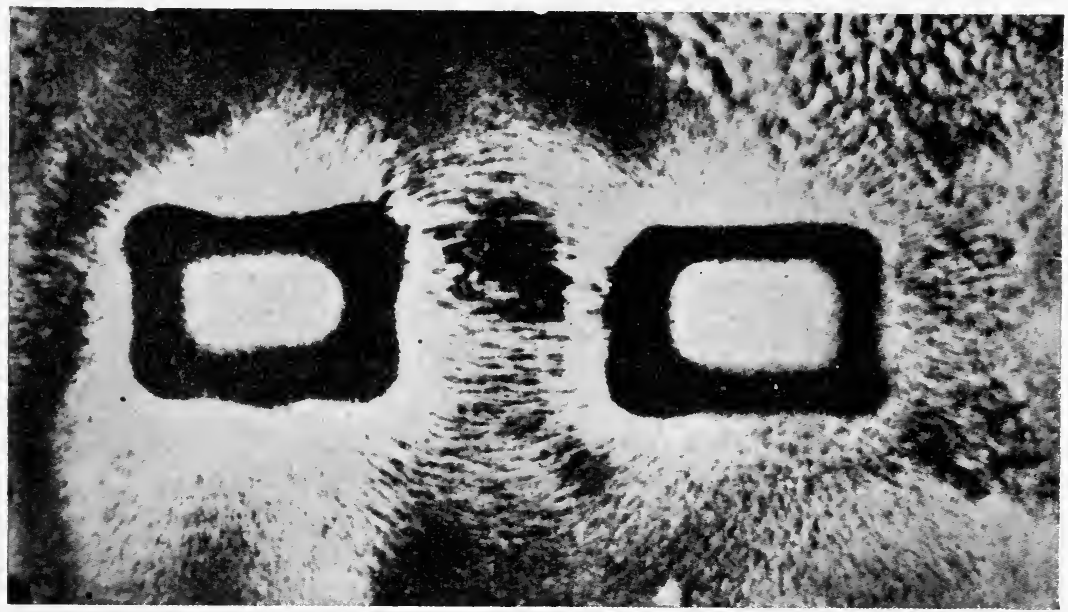

Fig. 27. - Powdered Mn-Sb Alloy in a Magnetic Field.

a hard glass tube, a reaction takes place, and after cooling, the powdered alloy behaves like iron filings, as regards a magnet, it being possible to show the magnetic lines of force by means of it. (See Fig. 27.) Neither manganese nor antimony as elements are magnetic, but manganese compounds frequently are, and in all the magnetic alloys discovered by Heusler* the magnetic character is connected with the presence of manganese compounds; for example, manganese and aluminum.

* Heusler, verh. Deutsch. Physikalisch. Gesselschaft, 1903, 219. Stark \& Haupt, Ibid., I903, 222. Heusler, Z. Angew. Chem., 1904, 260. 
Compounds do not ordinarily occur between metals that stand near each other in the periodic system. (Tammann).* They are, however, no rare occurrence and many metal pairs form several compounds. The existence of the following compounds has been demonstrated: $\mathrm{Cu}_{2} \mathrm{Cd}_{3}, \mathrm{Cu}_{3} \mathrm{Cd}, \mathrm{Cu}_{3} \mathrm{Al}, \mathrm{CuAl}$, $\mathrm{Cu}_{4} \mathrm{Sn}, \mathrm{Cu}_{3} \mathrm{Sn}, \mathrm{CuSn}, \mathrm{Cu}_{3} \mathrm{Sb}, \mathrm{Cu}_{2} \mathrm{Sb}, \mathrm{Ag}_{3} \mathrm{Zn}_{2}, \mathrm{AgZn}, \mathrm{Ag}_{2} \mathrm{Zn}_{3}$, $\mathrm{Ag}_{2} \mathrm{Zn}_{5}, \mathrm{Ag}_{3} \mathrm{Al}, \mathrm{Ag}_{2} \mathrm{Al}, \mathrm{Ag}_{3} \mathrm{Sb}, \mathrm{Au}_{3} \mathrm{Zn}_{5}, \mathrm{AuZn}_{8}, \mathrm{Au}_{2} \mathrm{Zn}, \mathrm{Au}_{4} \mathrm{Cd}_{3}$, $\mathrm{AuCd}_{3}, \mathrm{Au}_{4} \mathrm{Al}, \mathrm{Au}_{5} \mathrm{Al}_{2}, \mathrm{Au}_{2} \mathrm{Al}, \mathrm{AuAl}, \mathrm{AuAl}_{2}, \mathrm{AuSn}, \mathrm{AuSn}_{2}$, $\mathrm{AuSn}_{4}, \mathrm{AuSb}_{2}, \mathrm{Au}_{2} \mathrm{~Pb}, \mathrm{AuPb}_{2}, \mathrm{Na}_{4} \mathrm{Sn}, \mathrm{Na}_{2} \mathrm{Sn}, \mathrm{Na}_{4} \mathrm{Sn}_{3}, \mathrm{NaSn}$,

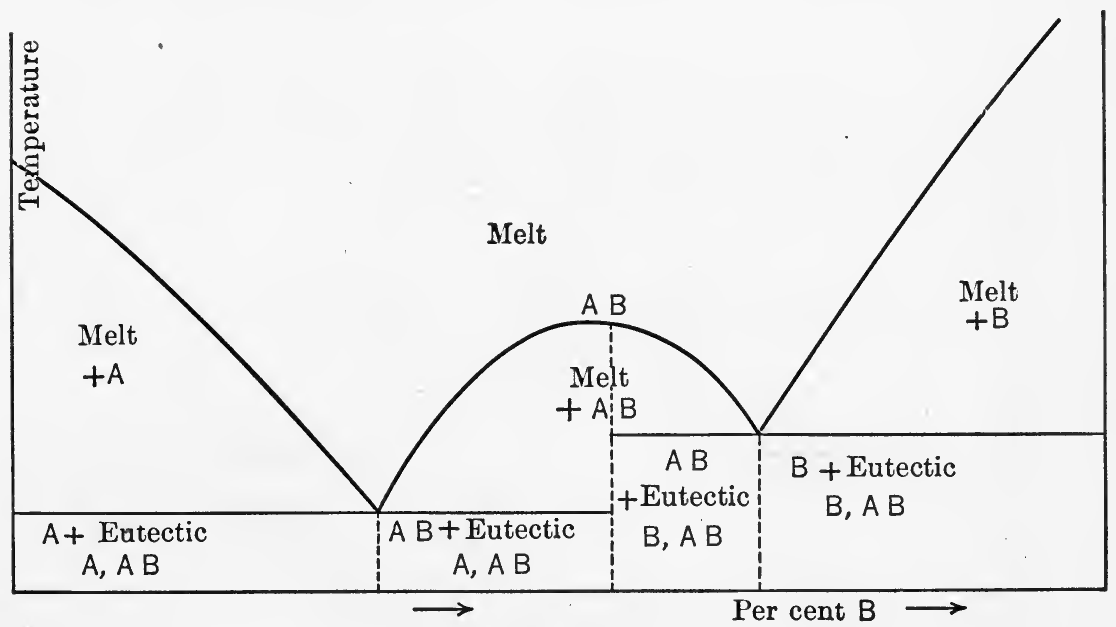

Fig. 28.

$\mathrm{NaSn}_{2}, \mathrm{Na}_{4} \mathrm{~Pb}, \mathrm{Na}_{2} \mathrm{~Pb}, \mathrm{NaPb}, \mathrm{Na}_{2} \mathrm{~Pb}_{5}, \mathrm{Mg}_{2} \mathrm{Sn}, \mathrm{Mg}_{2} \mathrm{~Pb}, \mathrm{SbAl}$, $\mathrm{Sb}_{2} \mathrm{Zn}_{3}, \mathrm{SbZn}, \mathrm{SbNa}_{3}, \mathrm{SbNa}, \mathrm{Mg}_{3} \mathrm{Sb}, \mathrm{BiNa}_{3}, \mathrm{BiNa}, \mathrm{BiMg}_{3}$, $\mathrm{Ni}_{3} \mathrm{Sn}_{2}$.

These compounds can occur as separate structure constituents. They can also form solid solutions with the components, and if several compounds are capable of existence, dissociation and recombination come into consideration. The equilibrium diagram may be very complex, if all these phenomena occur simultaneously with a single metal pair. It is not possible to discuss all known cases here, so we will limit ourselves to the simplest and most typical.

*Z. anorg. Chem., 49, II3 (I 906 ). 
If a stable compound of the two components is formed a diagram like Fig. 28 is obtained. A maximum is seen in the curve which represents the melting point of the compound $A-B$. This melting point is lowered by an excess of $A$ or $B$ and curves are obtained which represent the equilibrium of differently composed melts with the solid compound; these solidification curves intersect on the one hand the crystallization curve of component $A$, and on the other hand, that of component $B$. Two eutectic points and two eutectic mixtures are accordingly possible, for

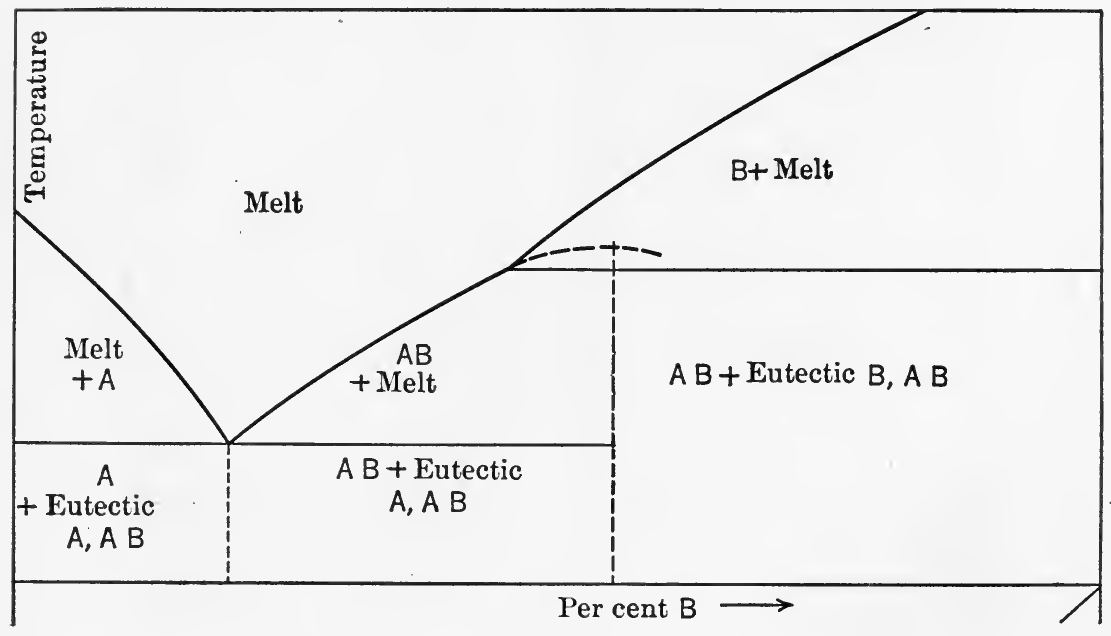

FIG. 29.

an alloy of two components, which form one compound. If the compound $A-B$ decomposes, before it melts, an equilibrium diagram is obtained as shown in Fig. 29. Miscroscopically the existence of two eutectics can be recognized, but only one eutectic point can be observed by the cooling curve method.

The diagram for the occurrence of many compounds is still more complex, but the principles involved are the same as with the cases discussed.

\section{Ternary and Quaternary Alloys.}

In practice, alloys are frequently met which are composed of more than two metals. We shall consider here only the bronzes 
and the bearing metals of which a whole series of different composition have been placed on the market.

The easiest to treat are the three component or ternary alloys containing copper, zinc, antimony, lead and tin. The great number of possible structure components make the study of these complex systems quite difficult. But to give an idea of

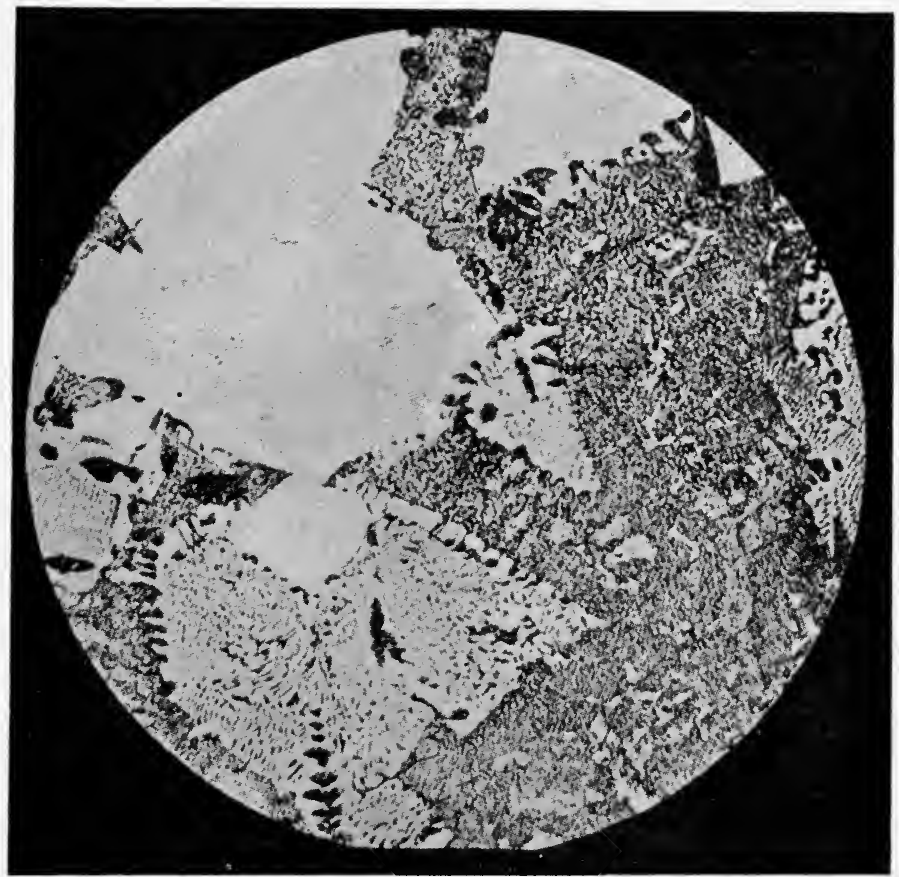

Fig. 30.- Ternary Alloy of $\mathrm{Sn}, \mathrm{Bi}, \mathrm{Pb}$. White Portion Bismuth crystals, Lighter Portion of the Ground Mass, Binary (Bi-Sn) Eutectic, Dark Portion Ternary Eutectic.

the method of attack on ternary systems, the combination of the three metals $\mathrm{Zn}, \mathrm{Bi}, \mathrm{Pb}$, which is not complicated by the formation of solid solutions or compounds, will be considered rather closely. It has been investigated by Charpy.*

We will first consider a metallograph of this kind of alloy (See Fig. 30), the picture shows three different parts, the bright

* Contribution a l'etude des alliages, I2I. 
large surfaces are doubtless the first component to be precipitated and can be considered as $\mathrm{Bi}$. The crystals are embedded in a mass which has the appearance of a eutectic, but this ground mass is not uniform, and light and dark fields can be distinguished from each other in it. The light places are binary eutectic, the dark places ternary eutectic. The binary ( $\mathrm{Bi}, \mathrm{Zn})$ precipitates before the ternary.

A graphical representation of the solidification relations cannot be made in the simple way we have used for binary systems. Representation in a plane is only possible, when the number of variables is two. With more variables a space model must be constructed. We may, however, represent a three-component system at constant temperature. The points no longer form a line but a plane. Of the different possible representations, that of triangular coordinate axes is ordinarily used. The side of an equilateral triangle is divided in the relation $a: b: c$ of the three components, a parallel to the side $A C$ is then drawn through the end point of $a$ and this made equal to $b$. In this way a point $P$ in the interior of the triangle is obtained, which has notable properties. It can easily be proven, that a perpendicular which is dropped from it to the three sides $A B, B C, A C$ are in the same proportion as the coordinates $a: b: c$, and that the sides of the three small equilateral triangles of which $P$ is the mutual vertex are equal to $a: b: c$ respectively. This point adapts itself excellently for the graphic representation of the composition of a mixture of the proportions $a: b: c$. It can be easily seen that the components can be represented by the vertices of the triangle and systems of two components along the triangle sides. (Fig. 3I.) The temperature axis is now erected in a vertical plane, and a three-sided prism is obtained, in which the equilibrium diagram in space is placed. The equilibrium diagrams of the two component systems are now represented on the sides of the prism. In the case of the system $\mathrm{Zn}, \mathrm{Bi}, \mathrm{Pb}$, these are simple pairs of curves with a eutectic point. Experiment shows now that by the addition of a third metal to a binary eutectic, the solidification temperature is lowered. This is true of all the metal pairs and there are three space 
curves, which represent the equilibrium between the melt and the two precipitated metals. The equilibrium of the melt with any one solid metal is represented by a surface. The three space curves intersect in a point, a ternary eutectic point, at which there exists a simultaneous equilibrium between the melt and the three different precipitated metals. The crystallization is complete at the ternary eutectic point.

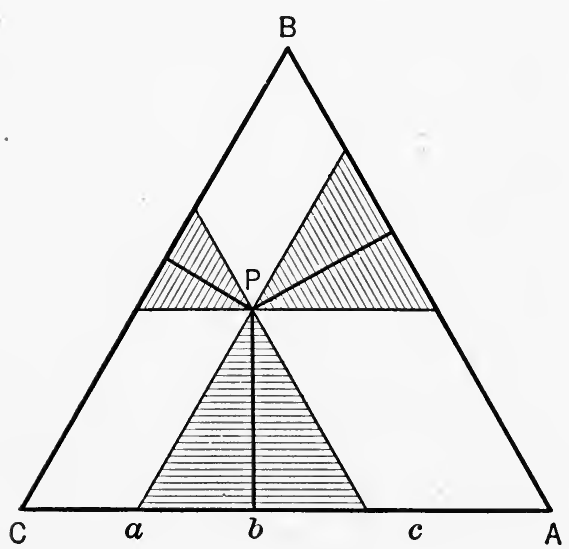

Fig. 3I.

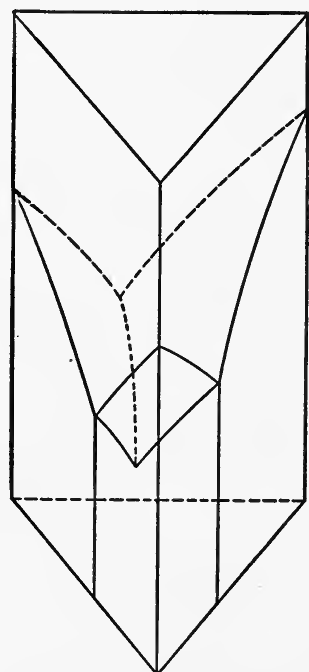

FIG. 32.

The relations between the binary and ternary eutectic points and the composition of the different eutectics are shown in the following table:

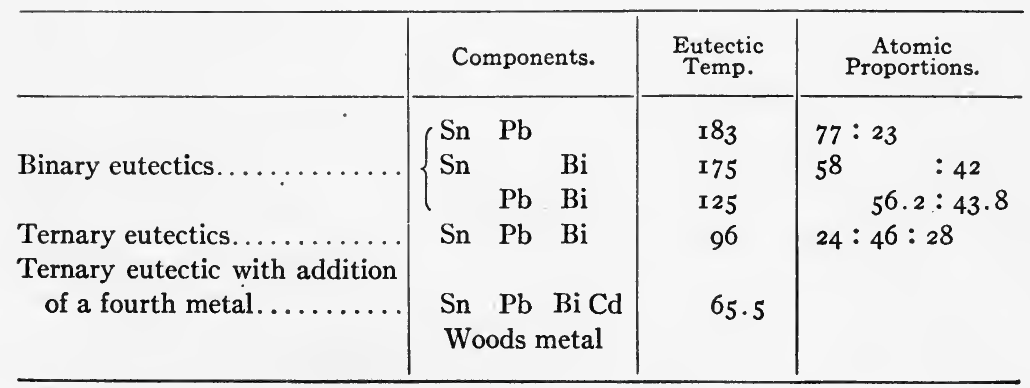


A quick insight into the equilibrium changes in a ternary alloy can be obtained from a projection of the space diagram on the basal plane and connecting the points representing combinations which crystallize at the same temperature. In this way a mul-

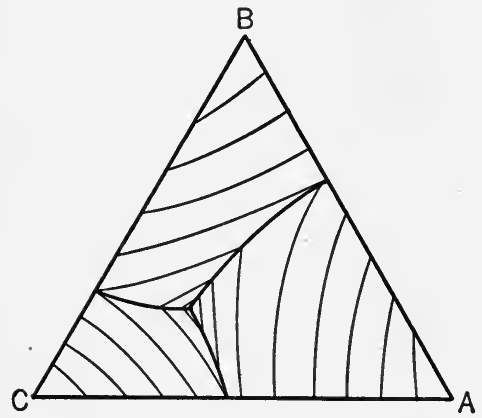

FIG. 33 . titude of isotherms is obtained which show the height above the basal plane, just as the contour lines on topographical maps. Such a projection is shown in Fig. 33 .

The addition of a fourth metal sometimes causes a depression of the melting point below that of the eutectic point of the ternary alloy as, for example, shown for Woods metal in the preceding table. The different low melting alloys are of this type. Some of these alloys melt in hot water as, for example, the metals of Newton, Lichtenberg and Wood and have found practical use in many ways.

\section{Relations of Mechanical and Physical Properties to Alloy Structure.}

The mechanical and physical properties of alloys are dependent on the structure and this fact has given practical importance to metallography for the testing of materials.

It is clear, that an alloy with the most homogenous possible structure, which has the same components as another, containing interstratified large crystals, will excel in tensile and compressive strength. Where the size is important the use of eutectic alloys or alloys that consist of a homogenous solid solution is to be recommended. The elastic limit seems always to be a maximum in the eutectic alloys so far as the few investigations allow a conclusion. (Ssaposhnikow.) It is still premature to make any general statements due to the great difference which the several metals show in their properties.

The question of the relation of hardness to structure.has been 
recently treated by Russian investigators. Ssaposhnikow * and his co-workers have established that with normal alloys of two components the eutectic possesses the maximum hardness. The results with the zinc-cadmium alloys are given in the following table:

\begin{tabular}{|c|c|c|c|c|c|}
\hline $\begin{array}{c}\text { Zinc, } \\
\text { Per Cent. }\end{array}$ & Hardness. & $\begin{array}{l}\text { Ziric, } \\
\text { Per Cent. }\end{array}$ & Hardness. & $\begin{array}{l}\text { Zinc, } \\
\text { Per Cent. }\end{array}$ & Hardness. \\
\hline 0 & I 5.9 & 24.4 & 32.2 & 79.9 & 43.0 \\
\hline ro & $3 \mathrm{I} \cdot 5$ & 30 & 27.2 & 80 & 52.0 \\
\hline 12.5 & 33.0 & 40 & 3 I. 2 & $8 I$ & 46 \\
\hline 17.2 & 36.8 & 50 & 35.0 & 82.2 & 39.0 \\
\hline 17.6 & 38.8 & so & 34.0 & 90 & 39.0 \\
\hline 20 & 34.5 & 70 & 34.5 & 100 & 35.0 \\
\hline
\end{tabular}

The second hardness maximum in the alloy of 80 per cent $\mathrm{Zn}$ is not clearly understood. (The pressure in $\mathrm{Kg} / \mathrm{sq} . \mathrm{cm}$. necessary to press a steel ball of ro $\mathrm{mm}$. diameter into the alloy serves as a measure of the hardness).

Hardness maximums are also shown by alloys of the components $\mathrm{Pb}-\mathrm{Sn}, \mathrm{Al}-\mathrm{Zn}$.

Solid solutions are usually somewhat harder than their components and alloy systems, which are made up of a continuous series of solid solutions usually have a hardness maximum.

\section{Bearing Metals.}

The hardness relations of the structure components play an important role in the so-called bearing metals. The theoretical treatment of this subject is due to Charpy. $\dagger$ A good bearing metal must consist of a plastic ground mass in which hard crystals are embedded in a uniform way. Such a structure offers the best security that the bearing itself will be continually adjusted to the form of the axle without the material becoming attached to the axle. Further there occurs a continual yield of the bearing material, and the abrasion coefficient of it must, therefore, be high so that the bearing is not easily heated. An entirely hard

* Chem. Zentr., I908, I, Ir I.

† Contribution a l'etude des alliages, I 2 I. 
material will not cling to the axle, but it does not give sufficiently to the pressure. All these conditions are met by an alloy of the above-described structure, since by a change of pressure the hard crystals in the yielding mass are immediately pressed out. The structure of a bearing metal is shown in Fig. 34. It represents an alloy of the components $\mathrm{Sn}, \mathrm{Sb}, \mathrm{Pb}$, the bright crystals

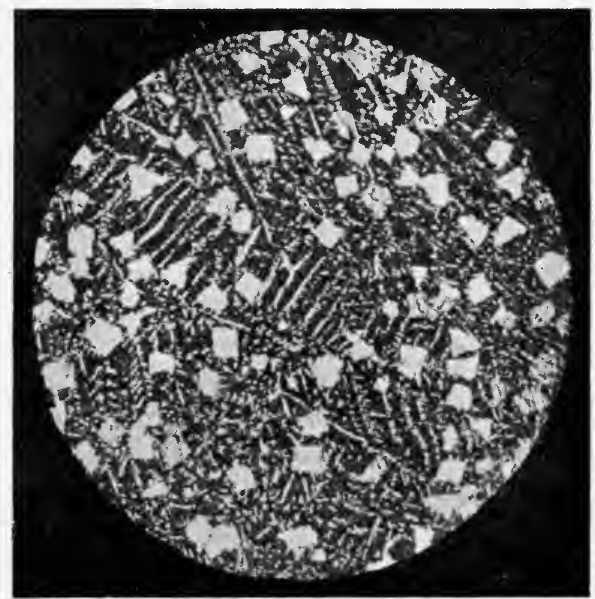

FIG. 34.-Bearing Metal Alloy of Tin, Antimony, and Lead.

are of the compound $\mathrm{SbSn}$ and the dark ground mass is ternary eutectic.

\section{Density of Alloys.}

The relations of certain other constants of alloys to the structure is known with considerable accuracy, viz., the density, the electrical potential and especially the electrical resistance.

In many cases the density of an alloy can be calculated from the density of its components, by the rule of mixtures. The reciprocal value of the density, the specific volume, can be frequently represented, as Maey * has shown, by a linear equation of the form

$$
V_{L}=V_{A}-b \cdot p \cdot B
$$

*Z. Phys. Chem. 38, 299 (rgor). 
Where $V_{L}$ is the specific volume of the alloy, $V_{A}$ that of the component $A, p_{B}$ the percentage of $B$ and $b$ a constant. In the following table are given the values for $V_{A}$ and $b$ which are necessary to calculate $V_{L}$.

\begin{tabular}{|c|c|c|c|c|}
\hline \multicolumn{2}{|c|}{ Components. } & \multirow{2}{*}{$V_{A}$} & \multirow{2}{*}{$b}$. & \multirow{2}{*}{$\begin{array}{l}\text { Kind of } \\
\text { Alloy. }\end{array}$} \\
\hline A. & $B$. & & & \\
\hline Lead............. & Antimony ......... & $0.0879 \mathrm{I}$ & 0.0006106 & $\mathrm{~K}$ \\
\hline Lead............. & Cadmium ......... & 0.08791 & 0.0002763 & $\mathrm{~K}$ \\
\hline Lead........ & Silver............ & 0.08791 & 0.000076 & $\mathrm{~K}$ \\
\hline Lead............. & 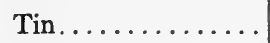 & 0.088 I r & 0.00049 & $\mathrm{~K}$ \\
\hline Cadmium... & 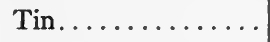 & o. 11554 & 0.0002156 & $\mathrm{~K}$ \\
\hline Gold....... & Copper........... & $0.05 \mathrm{rgr}$ & 0.000605 & $\mathbf{M}(p)$ \\
\hline Gold..... & Silver........... & $0.05 \mathrm{rgr}$ & 0.000605 & $\mathbf{M}(t)$ \\
\hline Gold....... & Tin...$\ldots \ldots \ldots$ & 0.05191 & 0.000852 & \\
\hline Iridium. . . . & Platinum......... & $0.0446 \mathrm{I}$ & $0.0000 \mathrm{rgr}$ & $\mathrm{K}$ \\
\hline Mercury.... & Lead.............. & 0.07368 & $0.000 r_{422}$ & 1 \\
\hline Mercury... & 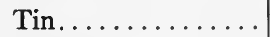 & 0.07366 & 0.0006345 & \\
\hline Silver...... & Copper........... & 0.0948 & 0.000169 & $\mathrm{~K}$ \\
\hline Silver..... & Bismuth...... & 0.0955 & 0.000063 & \\
\hline Bismuth... & Antimony ....... & ०. $1018 \mathrm{r}$ & 0.0004715 & $\mathbf{M}(t)$ \\
\hline Bismuth... & Cadmium ........ & $0.1018 \mathrm{r}$ & $0.000 \mathrm{r} 373$ & $\mathrm{~K}$ \\
\hline Bismuth. . . . & Zinc............ & $0.1018 \mathrm{r}$ & 0.000353 & \\
\hline Tin......... & Antimony ........ & 0.13710 & 0.0001187 & V M \\
\hline Tin............ & Zinc............. & 0.13710 & 0.00004 & $\mathrm{~K}$ \\
\hline
\end{tabular}

$K$ means simultaneous deposition of the two metals, $M$ formation of solid solutions, $t$ total miscibility, $p$ partial miscibility, $V$ formation of compounds.

No volume change occurs in the formation of solid solutions in these alloys. There is, however, a contraction, if the components combine with each other, hence a minimum of specific volume occurs in alloys of $\mathrm{Sb}$ and $\mathrm{Fe}$ and $\mathrm{Cu}$ and $\mathrm{Sn}$ when their composition expresses that of a compound, as $\mathrm{FeSb}$ or $\mathrm{Cu}_{3} \mathrm{Sn}$ (Fig. 35). A large contraction cannot always be explained by the formation of a compound, for example, with tin and silver the minimum volume corresponds to a composition of 29.2 per cent tin and with lead and bismuth the maximum contraction occurs with $40-50$ per cent bismuth while, according to the equilibrium 
diagrams the alloys of this composition must consist of normal conglomerates of their pure components (Roozeboom).

\section{Potential of Alloys.}

Of the electrical magnitudes which are capable of giving an insight into the nature of structure components we shall first consider potential, which has been recently investigated by the Russian investigator Puschin.* He measured the potential difference between the binary alloys and their least noble com-

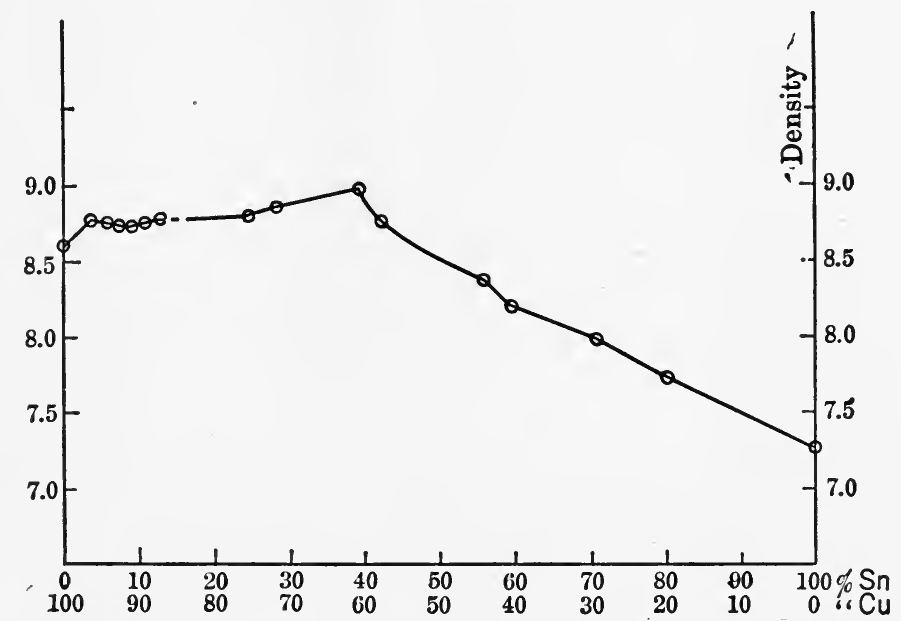

FIG. 35 .

ponents using a salt of the latter as an electrolyte. The following rules have been formulated for the relation of potential to composition.

(I) If the alloy is a conglomerate of components the potential difference is independent of the composition.

(2) With the formation of a continuous series of solid solutions the potential difference rises with increasing content of the noble metal.

(3) With the formation of compounds sudden changes occur in the potential difference.

* Chem. Zentr., I907, I, r724; II, I315, 2026; r908, I, 108. 
Electrical Resistance of Alloys.

The electrical resistance of an alloy frequently shows important imprints of its character and from the relation of the con-

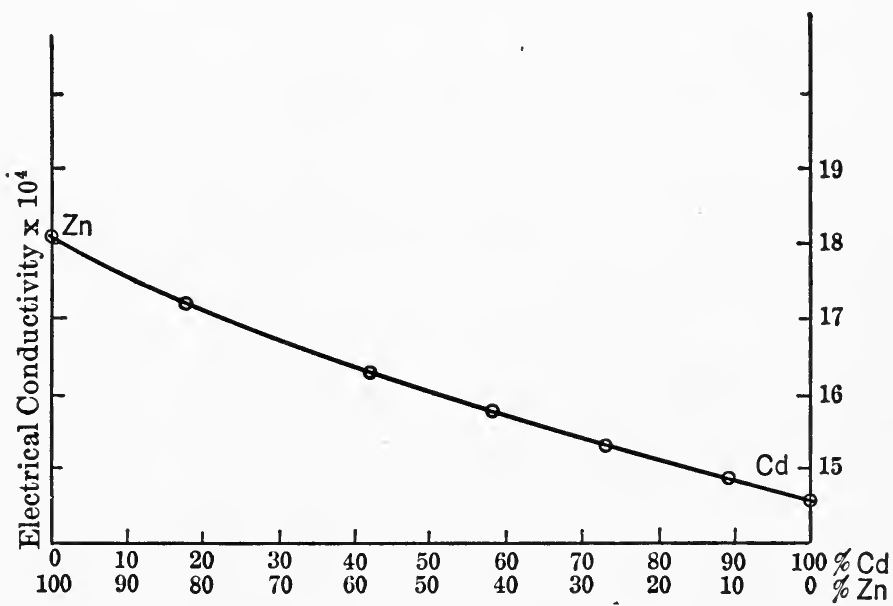

Frg. 35 .

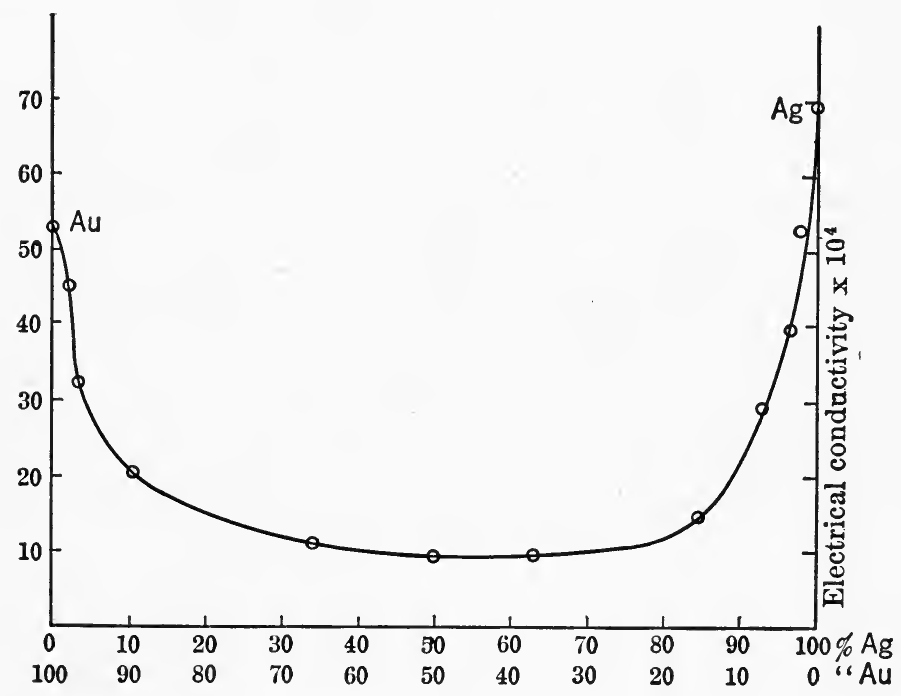

FIg. 37 .

ductivity to the composition, conclusions can frequently be drawn, regarding the structure. 
There is a great deal of experimental material concerning the conductivity of alloys. The investigations of Mathiessen* are of especial value. By comparison of his results with the metallographic investigations of Guertler $\dagger$ and the earlier investigations of LeChatelier $\ddagger$ the following general rules have developed.

(I) Alloys, which are purely mixtures of their components, have a conductivity which is additively made up of the conductivity of their components.

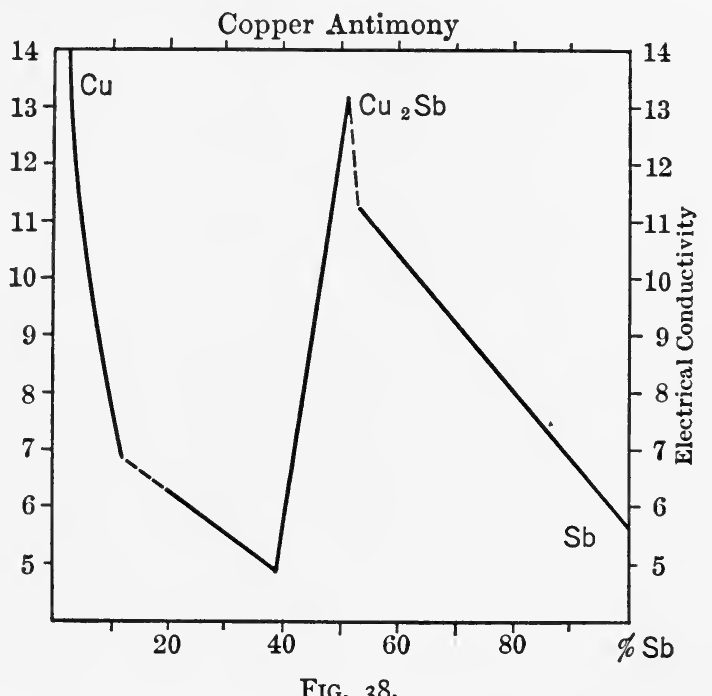

FIG. 38 .

(2) Alloys which consist of solid solutions show an important lowering of conductivity.

(3) The occurrence of compounds can frequently be recognized by the occurrence of peaks in the composition-conductivity diagram.

The alloy of zinc and cadmium is an example of a mixture, (see Fig. 36), while the pair silver, gold is an example of the solid solutions (see Fig. 37). The alloys of copper-antimony show the effect of compound formation (see Fig. 38 ).

* Pogg. Ann., 110, 222 (1860).

$\dagger$ J. Inst. Metals, No. 2, I9II, VI, p. I35.

$\ddagger$ Rev. gen. Sci., 30, June, I895. 
The temperature coefficient of the conductivity shows a similar regularity which has also been noted by Guertler.* With conglomerates, the temperature coefficient is equal to that of the pure metals, and the resistance of all this kind of alloys vanishes as the metals reach absolute zero. The alloys which consist of solid solutions, show in comparison to their components, a very small temperature coefficient, and their resistance does not

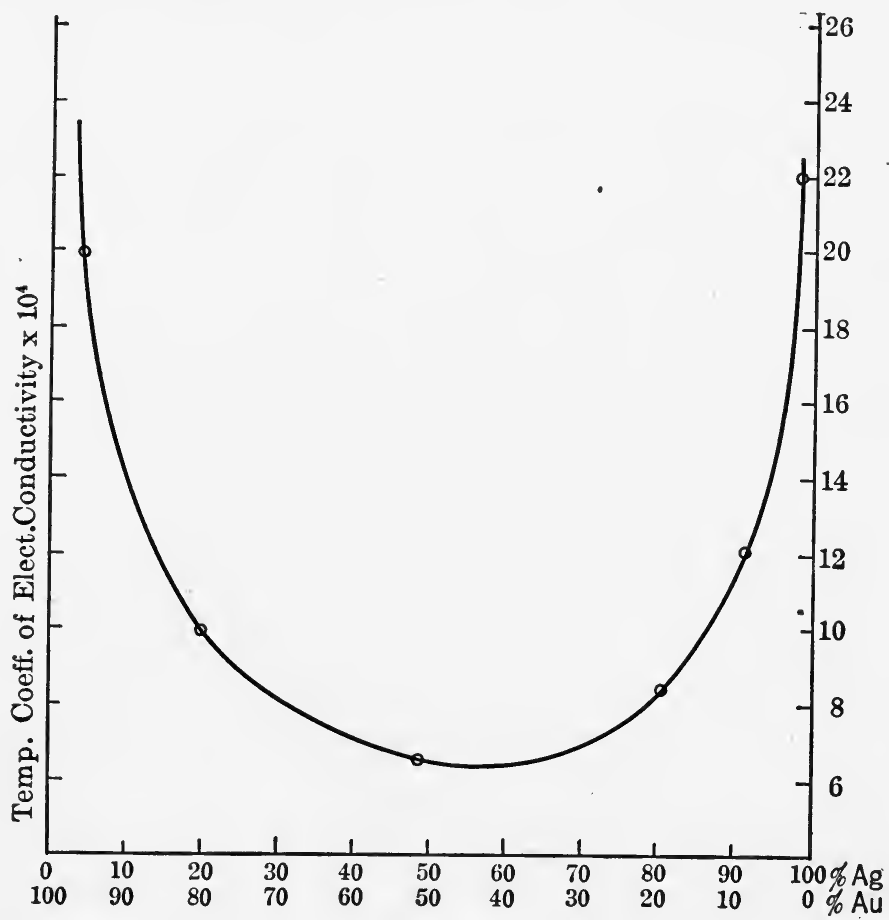

Fig. 39.

vanish at absolute zero. In general there is a proportionality between the conductivity of alloys and their temperature coefficient. The form of the curve expressing the temperature coefficient as a function of the volume composition, has, without exception, the same form as the curve for conductivity. These facts can be recognized by a comparison of Fig. 39 with the earlier figures.

*Z. anorg. Chem., 51, 397 (r9o6); 54, 58 (I907); Z. Elektrochem., 13, 44I (r907). 
The electrical relations of solid solutions are not only of interest for their bearing on metallography, but also for their practical importance. The valuable resistance metals constantan and manganin are solid solutions. We will, therefore, look a little farther into the theoretical problems which they present, and see if we can discover what factors condition the strong influence of small additions of a second metal on the conductivity.

As the following table shows, considerable decrease in the conductivity of metallic copper is caused by the addition of 2 per cent of other material.

\begin{tabular}{|c|c|c|c|}
\hline Copper $+2 \%$ Metal & $\begin{array}{l}\text { Atomic Weight } \\
\text { of addition }\end{array}$ & $\underset{\times 10^{4}}{\text { Electrical Cond. }}$ & $\begin{array}{l}\text { Thermo-electric } \\
\text { force of the dis- } \\
\text { solved metal } \\
\text { against copper. } \\
\text { Temp. diff. roo. } \\
\text { Millivolt }\end{array}$ \\
\hline $\mathrm{Cu}$, pure & $\ldots \ldots \ldots$, & 62.1 & \\
\hline $\mathrm{Ag}$ & 108 & $55 . \mathrm{I}$ & -0.01 \\
\hline $\mathrm{Au}$ & 197.2 & $47 \cdot 5$ & +0.02 \\
\hline $\mathrm{Zn}$ & $65 \cdot 4$ & 45 & +0.03 \\
\hline $\mathrm{Sn}$ & II 8.5 & 26.5 & -0.30 \\
\hline $\mathrm{Ni}$ & $5^{8.5}$ & 26.0 & -2.15 \\
\hline $\mathrm{Al}$ & $27 \cdot I$ & I 7 & -0.32 \\
\hline $\mathrm{Mn}$ & 55 & I 2 & \\
\hline $\mathrm{Fe}$ & 56 & I3 & +r.19 \\
\hline
\end{tabular}

Especially large lowering is obtained with alloys of copper and nickel, whose components are miscible in all proportions, this is shown in diagram 40 and the next table.

\begin{tabular}{|c|c|c|}
\hline Metal & Conductivity $X_{10^{4}}$ & Ratio \\
\hline 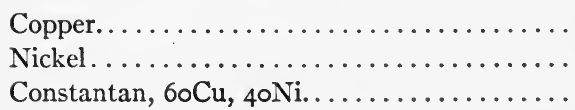 & $\begin{array}{r}57.4 \\
13.39 \\
2.04\end{array}$ & $\begin{array}{l}100 \\
23 \cdot 3 \\
3 \cdot 55\end{array}$ \\
\hline
\end{tabular}

The smallness of the temperature coefficient, is brought out by reference to the next table. It is even possible to obtain an alloy whose resistance is independent of the temperature. This kind of a resistance metal, is of great practical importance, for 
the preparation of precision resistances, as they are uninfluenced by the temperature.

\begin{tabular}{|c|c|c|c|}
\hline Metal & $\begin{array}{l}\text { Temp. Coeff. of } \\
\text { resistance at } 18^{\circ}\end{array}$ & Metal & $\begin{array}{l}\text { Temp. Coeff. of } \\
\text { resistance at } 18^{\circ}\end{array}$ \\
\hline $\mathrm{Cu} 100 \% \ldots \ldots \ldots \ldots$ & +0.00428 & $\mathrm{Au} 100 \% \ldots$ & +0.00368 \\
\hline $\mathrm{Cu} 80 \%, \mathrm{Ni} 20 \% \ldots . .$. & +0.000262 & $\mathrm{Au} 90 \%, \mathrm{Ag} 10 \%$. & +0.00124 \\
\hline $\mathrm{Cu}{ }_{54} \%, \mathrm{Ni}_{46} \%$ & +0.0000 & $\mathrm{Au} 66 \%, \operatorname{Ag} 33 \%$. & +0.00067 \\
\hline $\mathrm{Ni} 100 \% \ldots . .$. & to.00395 & $\mathrm{Ag} 100 \% \ldots .$. & +0.00400 \\
\hline
\end{tabular}

Constantan and manganin which show these valuable properties are solid homogenous solutions.

It is of interest in this connection, that there is also an elementary metal, which possesses an extraordinarily low temperature coefficient, of the same order of magnitude, as that of many alloys, namely, 0.0008 . It is mercury in the liquid state. Liebenow has drawn the conclusion from this, that mercury is a solution, which contains in it a second molecular species. It is assumed for example, that in it outside of the mercury molecules $\mathrm{Hg}$, a second molecule $\mathrm{Hg}_{2}$ is present in equilibrium with the first. In the solid state mercury behaves normally.

The question of the remarkable conductivity lowering of alloys is often raised but it has not been answered in every way. Lord Rayleigh and later Liebenow have attempted to explain the phenomena by the Peltier effect, that is, the thermo-current causes an increase in resistance. However, at the time of the presenting of this theory, we were not so well-informed on the structure relations of alloys, and in the light of our present knowledge it is quite inadequate.

The conductivity lowering can be explained, however, in terms of the electron theory. It is first necessary to find whether the heat conductivity shows a similar lowering for these alloys, and to ascertain whether the law of Wiedemann and Franz holds with certainty. With the $\mathrm{Bi}-\mathrm{Pb}$ and $\mathrm{Bi}-\mathrm{Sn}$ alloys in which the ability to form solid solutions is confined to narrow limits a parallelism has been established between the electrical and heat conductivity (F. A. Schulze).* Compare the following table with Fig. 4I.

* Habilitationschrift, Marburg, 1902. 
From these measurements it follows that the ratio of the two conductivities of the alloys is somewhat greater than for pure metals. The same results have been obtained by differently carried out investigations on the $\mathrm{Ni}-\mathrm{Cu}$ series.

\begin{tabular}{|c|c|c|c|c|c|}
\hline \multirow{2}{*}{ Alloy. } & \multicolumn{2}{|c|}{ Volume, Per Cent. } & \multirow{2}{*}{$\begin{array}{l}\text { Heat Con- } \\
\text { ductivity. } \\
\qquad x\end{array}$} & \multirow{2}{*}{$\begin{array}{l}\text { Electrical } \\
\text { Conduct- } \\
\text { ivity. } \\
\text { I0 }\end{array}$} & \multirow{2}{*}{$\frac{x}{\sigma} \cdot 10-1$} \\
\hline & $B i$ & $\mathrm{~Pb}$ & & & \\
\hline \multirow{5}{*}{ Bismuth-Lead. . } & 100 & $\ldots \ldots$ & 0.019 & 0.830 & 230 \\
\hline & 99.57 & 0.43 & 0.0188 & 0.766 & 245 \\
\hline & 98.44 & I. 56 & 0.0119 & 0.468 & 256 \\
\hline & $97 \cdot 31$ & 2.69 & 0.0117 & 0.444 & 263 \\
\hline & 96.47 & $3 \cdot 53$ & 0.0129 & $0.5 \mathrm{I} 4$ & $25 \mathrm{I}$ \\
\hline \multirow{5}{*}{ Bismuth-Tin. . } & 100 & & 0.0190 & 0.830 & 230 \\
\hline & $99 \cdot 54$ & 0.46 & 0.0140 & 0.595 & 235 \\
\hline & 99.05 & 0.95 & 0.0126 & 0.506 & 248 \\
\hline & $97 \cdot 13$ & 2.87 & 0.0110 & 0.448 & 245 \\
\hline & 90.26 & 9.74 & 0.0126 & 0.488 & $25^{8}$ \\
\hline
\end{tabular}

\begin{tabular}{|c|c|c|}
\hline Metal. & $\frac{x}{\sigma}$ & Observer. \\
\hline $\mathrm{Cu}$, pure... & 665 & Jaeger and Diesselhorst* \\
\hline $\mathrm{Ni}$, pure........ & 669 & Jaeger and Diesselhorst \\
\hline $60 \mathrm{Cu}, 40 \mathrm{Ni} . . . . .$. & I 106 & Jaeger and Diesselhorst \\
\hline $54 \mathrm{Cu}, 46 \mathrm{Ni} \ldots . . \ldots$. & $99 \mathrm{r}$ & Gruneisen $\dagger$ \\
\hline $84 \mathrm{Cu}, 4 \mathrm{Ni}$, I $2 \mathrm{Mn} . .$. & 914 & Jaeger and Diesselhorst \\
\hline
\end{tabular}

* Loc. cit.

t Ann. Phys., 3, 7I (I900).

Copper and nickel are miscible in all proportions and accordingly the curve which represents the relations of the conductivity quotient to the composition possesses a maximum.

The increase of the conductivity quotient shows that the dissolved metal lowers the heat conductivity relatively less than the electrical. How is this fact to be explained? If we take as our basis the Drude electron theory we see that the heat conductivity is concerned with heavier particles than the conduction of electricity. As diffusible particles we have now in these solid solutions, beside the electrons, the dissolved mole- 
cules of the second metal. These will fulfill the requirements for heat conductivity but will not take part in the electrical conductivity. They are to be considered as electrically neutral and undissociated.

Now, however, the electrical conductivity decreases. Such a decrease can, according to our previous considerations, result in two ways; in decreasing the number of electrons or in the

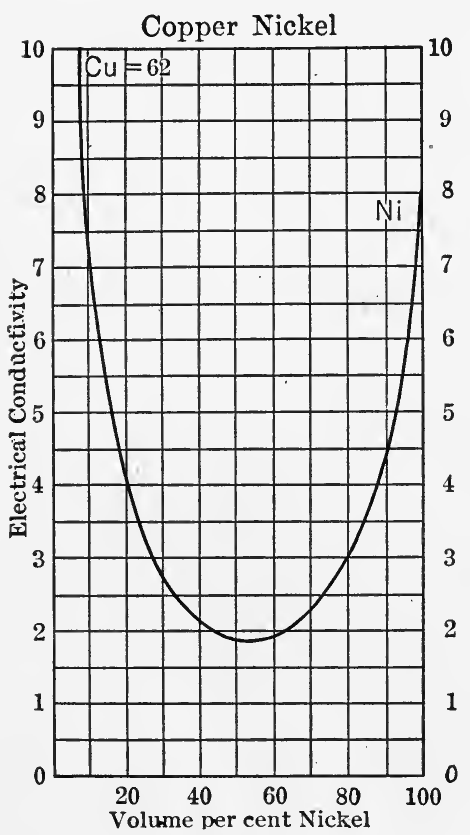

Fig. 40.

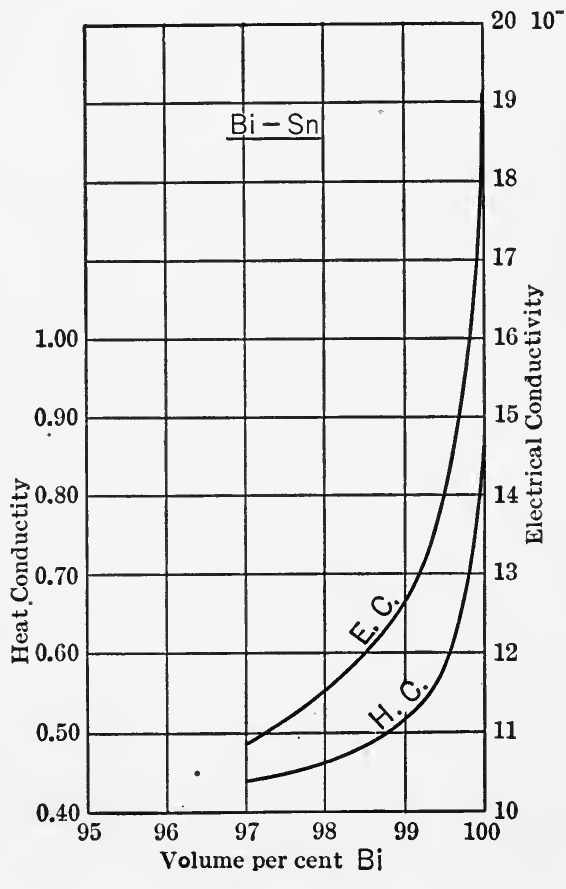

FIG. 4I.

resistance which they encounter in their motion under the influence of the e.m.f. becoming greater due to the increase of internal friction. Electrons and molecules both diffuse in the solid metallic solutions; we have accordingly to do with the diffusion of a mixture. The kinetic theory allows us to draw certain conclusions concerning the friction in a gas mixture, which have been found to agree with the experimental facts. The viscosity of a gas is increased by the addition of a second gas even though the second gas possesses a smaller coefficient than the 
first. (This is true only in certain cases, and is not true in case of oxygen-hydrogen, nitrogen-hydrogen, hydrogen-helium or oxygen-nitrogen, but is true for carbon dioxide-hydrogen and helium-argon). Graham, and later Puluj, both obtained the remarkable, and on first thought improbable, result, that the internal friction of $\mathrm{CO}_{2}$ is not lowered but raised by the addition of a small amount of hydrogen. This increase reaches a maximum with $2 \tau$ per cent $\mathrm{H}_{2}$ and 73 per cent $\mathrm{CO}_{2}$ at room temperature.

Now, if we carry over the kinetic theory to a mixture of electrons and molecules, it follows that the internal friction of the electrons increases with the addition of molecules and, therefore, the electrical conductivity decreases. The lowering of the conductivity can be explained then even if the number of electrons does not decrease.

A decrease of the electron number in the alloys could be ascertained as we have previously seen by a change in the optical properties (compare p. 3I), especially by a lowering of the reflection constant. There is, however, no experimental data on the optical constants of alloys as compared with their components.

\section{Thermo-electric Force of Alloys.}

The comparison of the thermo-electric forces of the alloys and their components gives us a second means, but the experimental material is also scarce in this field. However, there is enough for a preliminary consideration. Jaeger and Diesselhorst have determined the thermo-electric force of constantan and manganin against copper. If one junction is held at $0^{\circ}$ and the other at $100^{\circ}$ there results the following electromotive-force.

$\begin{array}{ll}\text { Constantan-copper } & -3440 \text { micro volts } \\ \text { Manganin copper } & +570 \text { micro volts }\end{array}$

According to Drude the thermo-electric force is connected with the electron number $N$ of the two metals by the equation (v. p. 32).

$$
\pi(\text { micro-volts })=\text { I.7I }\left(T_{2}-T_{1}\right) \log _{e} \frac{N_{c u}}{N_{\text {alloy }}} .
$$


The positive pole at the warm junction is the electron richer metal. It follows, therefore, that manganin has a higher and constantan a lower concentration than copper. From the given results the ratio of the electron numbers is calculated.

$$
\begin{aligned}
& \frac{N_{c u}}{N_{\text {constantan }}}=\text { I.223, } \\
& \frac{N_{c u}}{N_{\text {manganin }}}=0.970
\end{aligned}
$$

If the electron number of copper is now placed arbitrarily at roo it follows that

$$
\begin{aligned}
& N_{c u}: N \text { Constantan }=100: 8 \mathrm{I}, \\
& N_{c u}: N \text { Manganin }=100: 103 .
\end{aligned}
$$

We see, therefore, that the electron concentration of an alloy is not necessarily smaller than that of the pure metals. The ratio of the electrical conductivity between copper and its two alloys is

$$
\begin{aligned}
& \sigma_{c u}: \sigma \text { Constantan }=100: 3.55, \\
& \sigma_{c u}: \sigma \text { Manganin }=100: 4.16 .
\end{aligned}
$$

A comparison of these ratios with the previous ones shows at once that of the two factors which can accomplish a change in conductivity the electron number and the frictional resistance, only the latter really comes into consideration.

To have come to this conclusion shows the value of Drude's kinetic electron theory of metals. 


\section{CHAPTER III}

\section{ALLOYS OF METALS WITH CARBIDES, OXIDES AND SULFIDES. IRON AND STEEL, MATTES, PHASE RULE.}

\section{Compounds with Metallic Properties.}

A series of compounds of metals with non-metals exist which possess certain properties characteristic of metals. The naturally occurring ores, galena, chalcopyrite and pyrite, belong to this series and are colloquially called "Fools Gold." They are characterized by their strong light absorption, their light reflection, and their luster as well as by a metallic conduction of electricity. These metallic properties are not restricted to the sulfides but also occur with certain oxides, phosphides, selenides and carbides.

There are certain regularities in the existence of compounds possessing metallic properties. We do not, for example, meet them in the compounds of the alkali and alkali earth metals, these usually have a salt-like character. The tendency of these metals to go over into the ionic state with water is especially large. With the compounds of these metals with, for example, phosphorus or carbon, there is a decomposition with water, calcium phosphide gives phosphine, calcium carbide, acetylene, leaving a solution of calcium hydroxide. All easily ionizable metals give salt-like or easily decomposable compounds.

The possibility for the occurrence of metal-like compounds is the greatest with metals of small ionizing tendency, especially when the non-metallic part also shows a small tendency to ionization. A chloride of metallic luster is scarcely probable but silver iodide possesses, under certain conditions of lighting, a metallic conductivity. Metallic properties are sometimes met 
in the oxides, as examples may be given here the oxides of the platinum metals as well as copper oxide $\mathrm{Cu}_{2} \mathrm{O}$.

The dependence of the properties on the nature of the metal is best surveyed with the sulfides. The alkaline sulfides have an entirely salt-like character, the sulfides of the heavy metals on the other hand, $\mathrm{PbS}$ and $\mathrm{Ag}_{2} \mathrm{~S}$ are types for the occurrence of metallic properties in metallic compounds. Between these are the sulfides of metals of somewhat greater ionization tendency as, for example, $\mathrm{ZnS}$ which forms crystals which are transparent in thin layers but which are still insoluble in water.

Since compounds of metallic properties do exist, it is not surprising that they are miscible with and soluble in the metals. These alloys of metals with compounds are of great importance in metallurgy. The alloys, for example, of copper with phosphorus and silicon have valuable mechanical properties. The presence of phosphides in iron on the other hand is undesirable since the solidity is adversely influenced. We will now consider the alloys of metals with metallic compounds especially the very important series of iron and carbon or rather iron and iron carbide.

\section{The Iron-carbon Alloys.}

The great influence that a content of carbon exerts on the properties of iron has been known for a long time. The hardness is known to stand in direct relation to it. A chemical investigation of the varieties of iron has shown that the physical properties are not solely determined by the chemical composition and that steels of the same elementary composition frequently show extraordinary differences in properties. That the carbon occurs in different forms can be shown by dissolving the alloys in tilute acid; in some cases the residue is graphite or amorphous carbon and in other cases the alloy dissolves completely in acids, with the evolution of hydrogen containing large amounts of hydrocarbons which shows that the carbon was in the combined form as carbide. With special precautions the carbide, which is more slowly attacked than the iron, may be isolated. The inves- 
tigations of Rathke* and of Foerster $\dagger$ have shown that this carbide, which is designated as cementite, has the formula $\mathrm{Fe}_{3} \mathrm{C}$.

The correct ratio for each of the great variety of properties, which can be obtained by carbon content, can only be determined by a complete knowledge of the solidification process of the mixture and the changes which it undergoes in the solid state. The first attempt to establish an equilibrium diagram for the system iron-carbon was made in the year 1897 by Sir William Roberts-Austin $\ddagger$ on the basis of the studies of Osmond and himself on the crystallization and recalescence points of iron. An essential advance was made in this direction by the work of Bakuis Roozeboom $\S$ in the year r 900 who, simultaneously with LeChatelier, applied the phase rule, as a critical expedient for the investigation of complex systems.

A large number of works treating this subject have appeared in recent years. The works of Heyn $\|$ Stansfield, Benedicks, $\mid$ Wust ${ }^{* *}$ and others have cleared up dark points and removed actual contradictions, but in such a complexity of phenomena there is much that is still unexplained. $\dagger \dagger$

If we consider the two components, iron and carbon, it is seen that both are known in different modifications. The metal solidifies at $1530^{\circ}$ and there are no fewer than three polymorphic iron modifications $\alpha, \beta$, and $\gamma$ iron with the transition points at $768^{\circ}$ and $898^{\circ}$. Graphite and amorphous carbon are the only forms of carbon that occur in these alloys. The transition point between the carbon modifications is not known. It is only known that graphite is the more stable of the two and that the transition takes place only in the sense of amorphous carbon to

*Ann., 260, 333 (r8go).

$\dagger$ Ber., 29, 2991 (1896).

‡Fifth Report of the Alloys Research Committee: Proc. Inst. Mech. Eng., 1899, Vol. 2, 3, 5 .

§ Z. Physik. Chem., 34, 437 (1900).

II Z. Elektrochem., 10, 49I (1904).

T Mettalurgie, 3, 393 (I906).

** Dissertation, Aachen (1900).

t† Recent papers of interest on the iron-carbon diagram are, Carpenter, J. Iron and Steel Inst., No. I, 1913; Benedicks, ibid., No. 2, 1912; Rosenhain and Humphrey, Proc. Roy. Soc., I909, A83, 200. 
graphite. It is not contradictory to this that the former possesses an extraordinary stability at high temperatures. The two elements combine to form a carbide which as we have noted is cementite $\mathrm{Fe}_{3} \mathrm{C}$. The combination is best effected by dissolving the carbon in liquid iron. The condition in such a liquid melt is probably an equilibrium between iron, carbon and carbide. The pure cementite is not a stable form in the solid state in spite of its comparatively great permanence, since it is decomosed by long-continued heating at $1000^{\circ}$ into a solid solution of carbide in iron, and carbon, which appears as temper carbon (amorphous). The dissociation of the carbide into iron and graphite occurs only in the liquid state or in any case only in the vicinity of the melting point (Wust).*

If the cooling and crystallization of a molten iron carbon alloy does not go too slowly the precipitation of elementary carbon is entirely avoided, the total carbon being found in the form of carbide.

If we would now survey the crystallization phenomena of a liquid iron carbon alloy, it is expedient to first consider the metastable systems that result from the quick cooling crystallization and then to treat the solidification with the precipitation of elementary carbon. In this we follow C. Benedicks.

\section{The Crystallization of the System Iron-cementite.}

We will begin with a melt very rich in carbon and allow it to crystallize. It precipitates first cementite needles and the melt becomes rich with the other components as the temperature sinks till finally it reaches the eutectic point at which complete solidification takes place. This eutectic point is at $1130^{\circ}$. The content of the eutectic mixture is represented by 4.2 per cent $\mathrm{C}$. and 62.9 per cent carbide. If the carbon content of the melt is smaller than that of the eutectic alloy the other component crystallizes out first. The precipitation product is, however, not pure iron but saturated solid solution of cementite in iron, and, in fact, in the $\gamma$ modification, which possesses the greatest solvent power for the carbide. This solvent power is not unlim-

* Metallurgie, 3, I (Ig06); ibid., 3, 8 I I (Ig06). 
ited, since the cementite itself will not dissolve iron. This limit of solubility is reached at a carbon content of 2 per cent, that is, a carbide content of 30 per cent. The eutectic of a melt rich in carbon is composed of cementite crystals on the one hand and mixed crystals with 2 per cent carbon on the other.

As is the rule for the precipitation of solid solutions, the composition of the solid solution differs from that of the melt out of which it was precipitated. The solid solutions are poorer in

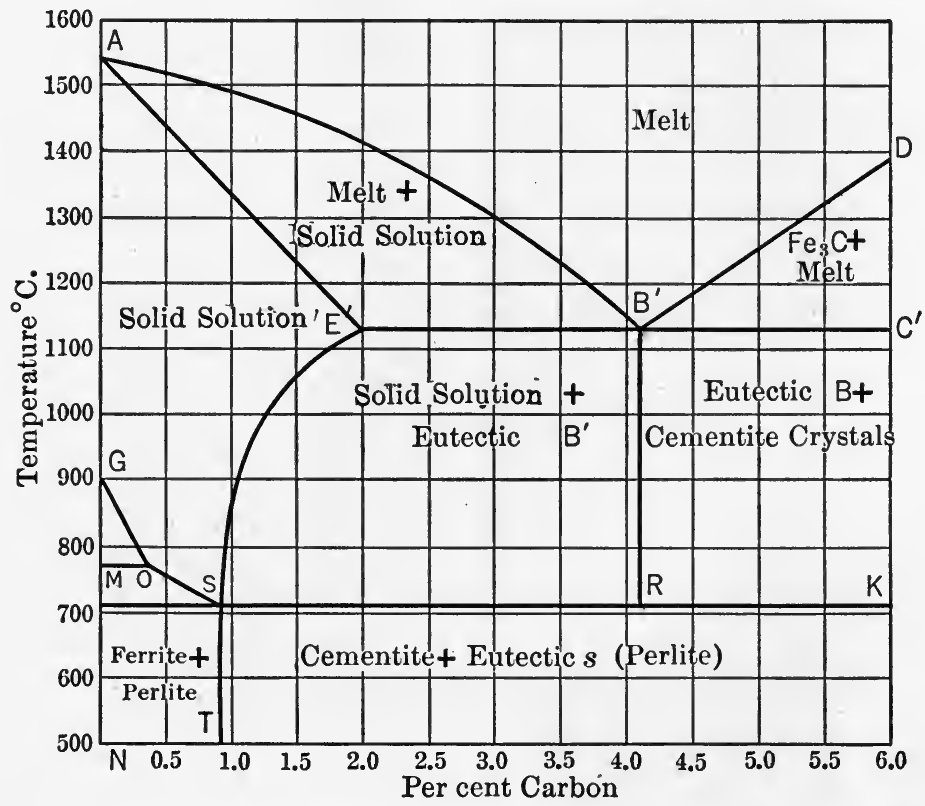

FIG. 42.-Equilibrium Diagram of Iron-cementite Alloys According to Benedicks.

carbon than the liquid mass. The non-coincidence of the crystallization and melting is indicated by the existence of two lines for the precipitation of solid solutions which appear in the equilibrium diagram. (See Fig. 42.)

If there is less than 2 per cent carbon dissolved in the melt the solid solution that precipitates will be rich in metal.

The study of the structure of the alloy which is precipitated out of the liquid melt is facilitated by the fact that the existing 
state at high temperature is fixed by quenching and below a red heat, slight transitions take place. It is, therefore, possible to study all the conditions and changes in structure by metallographic methods.

As an illustration of the method, a number of photographs of the structure of chilled specimens with a content of more than 2 per cent carbon are given here. The structure of a eutectic pig iron is shown in Fig. 43. By resolution through strong mag-

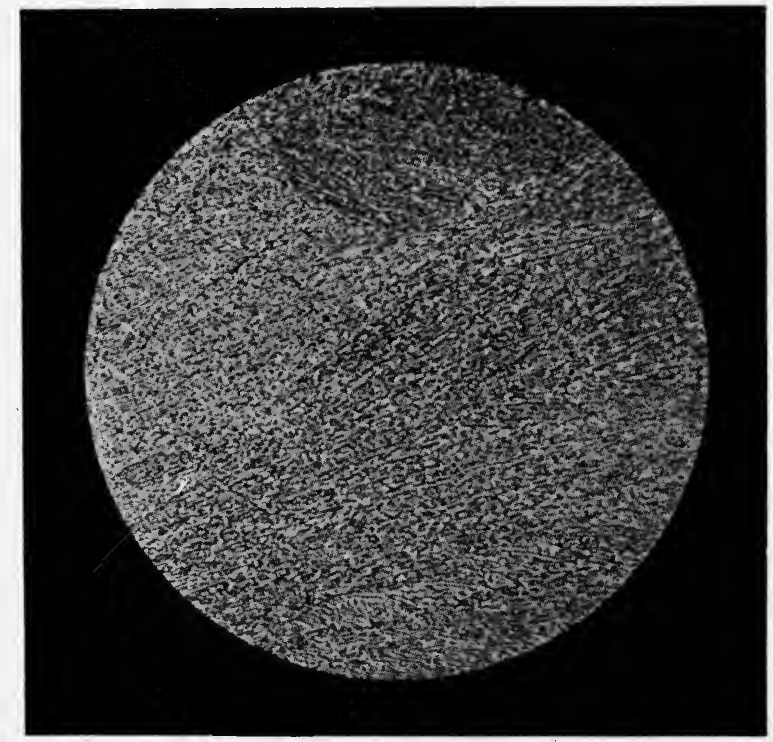

FIG. 43.-Cementite-solid Solution Eutectic (Goerens), Dark Particles solid Solution, Light Cementite.

nification (Fig. 44) it can be seen to consist of bright cementite crystals and a dark component, the finely divided solid solutions.

If we increase the carbon content long, well-formed cementite needles occur, which are embedded in the eutectic (Fig. 45), strongly magnified (Fig. 46).

The primary precipitated solid solutions in the undereutectic alloys show similar figures to ammonium chloride precipitated from water, namely, pine-tree formed crystal skeletons which are unmistakable. They appear in the picture (Fig. 47) 


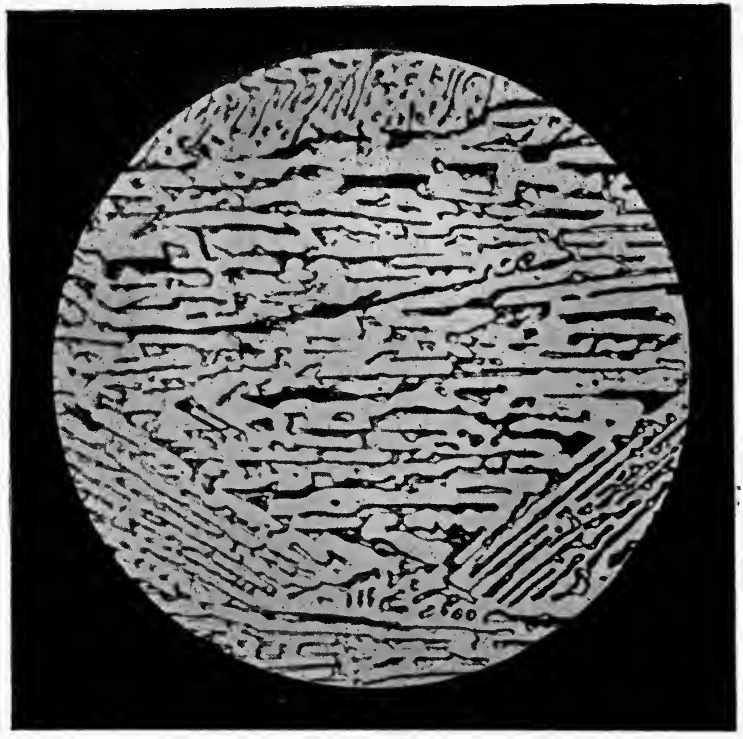

Fig. 44.-Cementite-solid Solution Eutectic Greatly Enlarged (Goerens), Dark Particles Solid Solution, Light Cementite. $\times 75 \circ$.

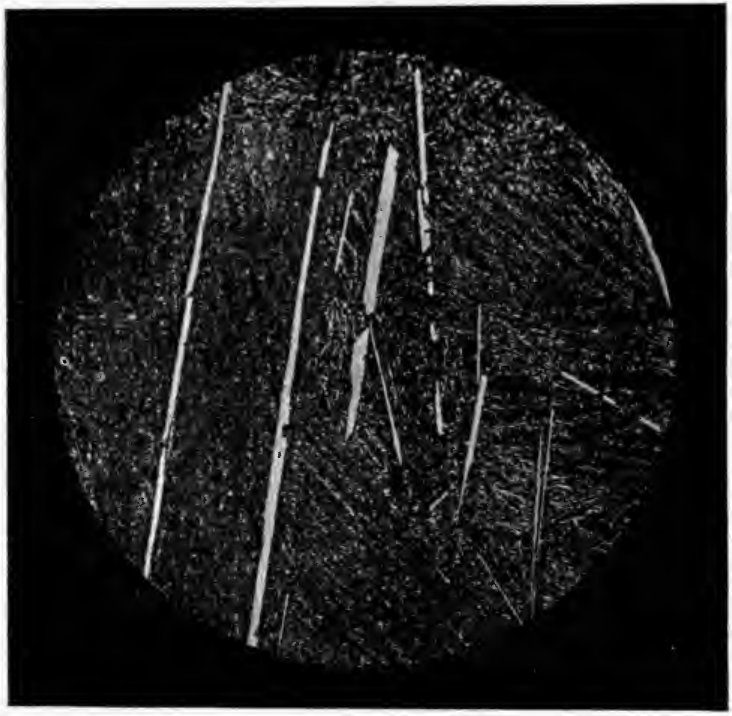

FIG. 45.-Cementite Needles in Cementite-solid Solution Eutectic. $\quad \times_{50}$. 


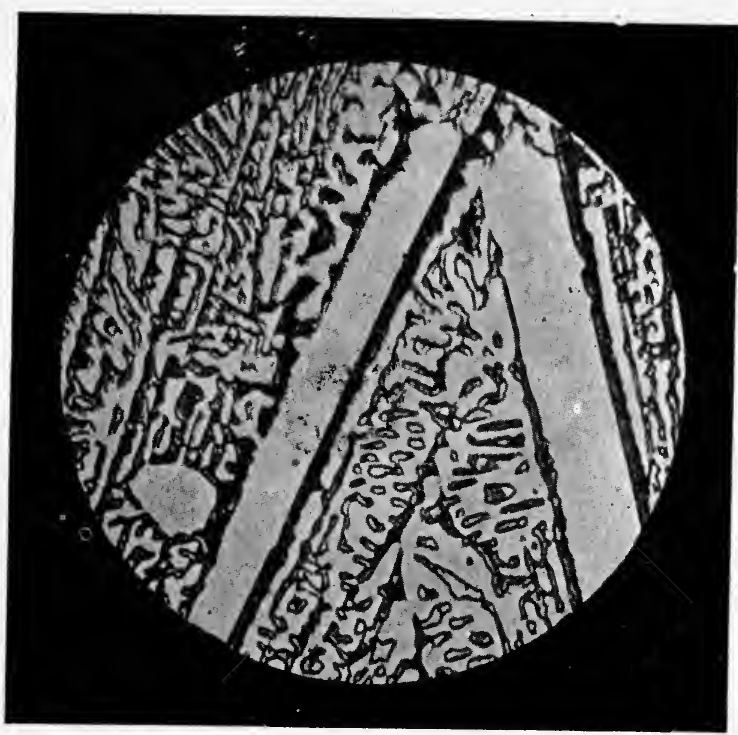

FIG. 46.-Cementite Needles in Eutectic, Greatly Enlarged (Goerens). $\quad \times 750$.

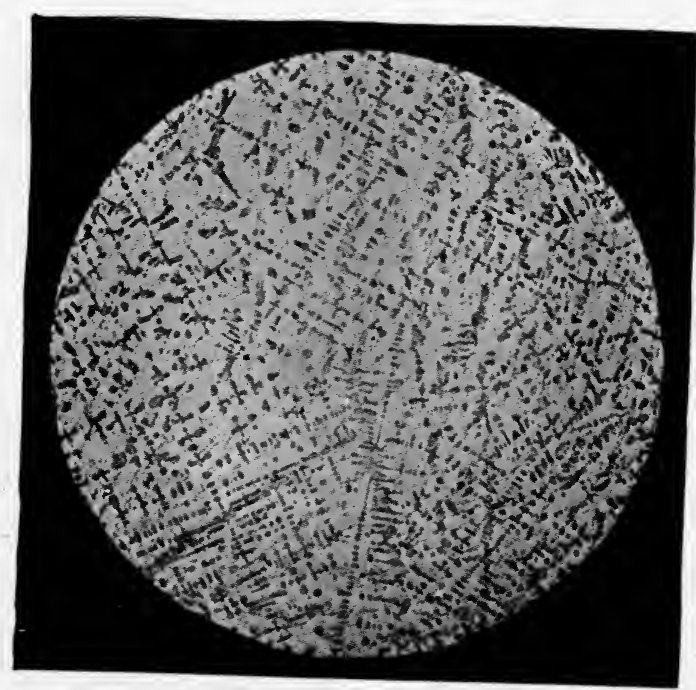

Fig. 47.-Dark Solid Solution Embedded in Cementite-solid Solution Eutectic (Goerens). Xro. 
dark and stratified in a bright eutectic. The details can be seen in the strong enlargement (Fig. 48).

The unsaturated iron-cementite solid solutions, as are observed in chilled steel of less than 2 per cent carbon, do not differentiate themselves so sharply as the previously mentioned structural components (Fig. 49).

The dilute solid solutions, which are the principal component of a hardened steel are designated as martensite. It consists of a

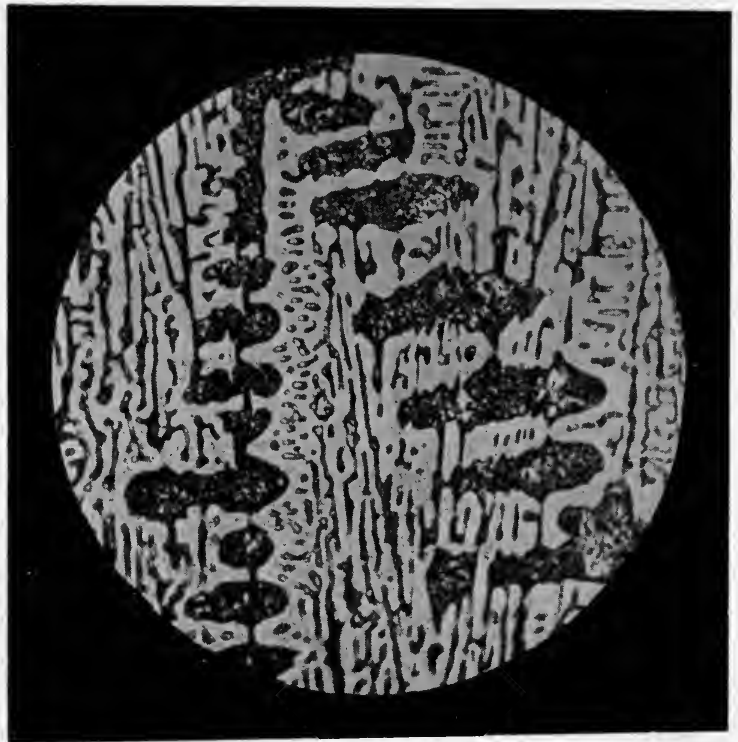

FIG. 48. - Dark Solid Solution, Greatly Enlarged (Goerens). $\quad \times_{750}$

solid solution of cementite in iron, and this solution exactly as in the case of liquids, is capable of separating into its component parts. This segregating phenomena is also expressed in the equilibrium diagram (Fig. 42).

All steels show a point of arrest in their cooling curves at $710^{\circ} \mathrm{C}$. This temperature marks the lower limit for the stable existence of the solid solution; below this temperature it breaks up entirely into a mixture of iron and cementite crystals. This is, therefore, the eutectic temperature of the solid solutions; it. 


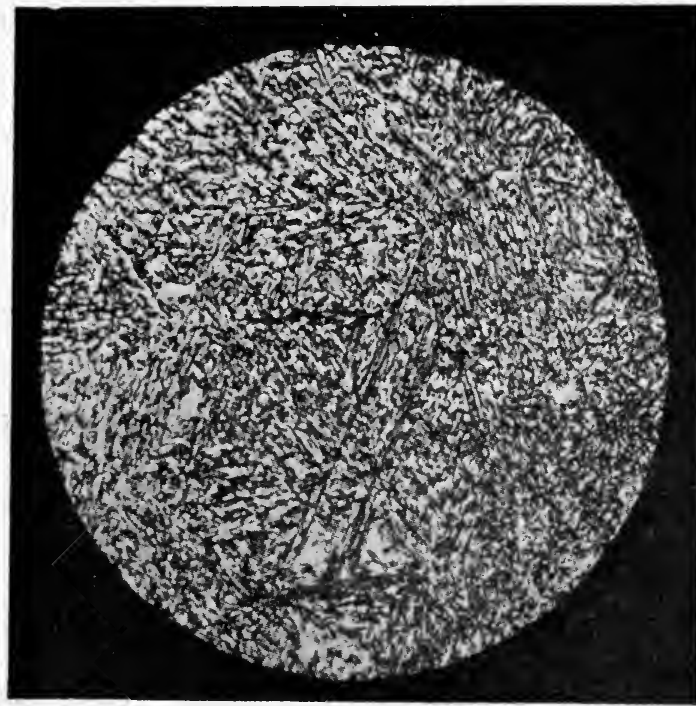

Fig. 49.-Martensite (Goerens).

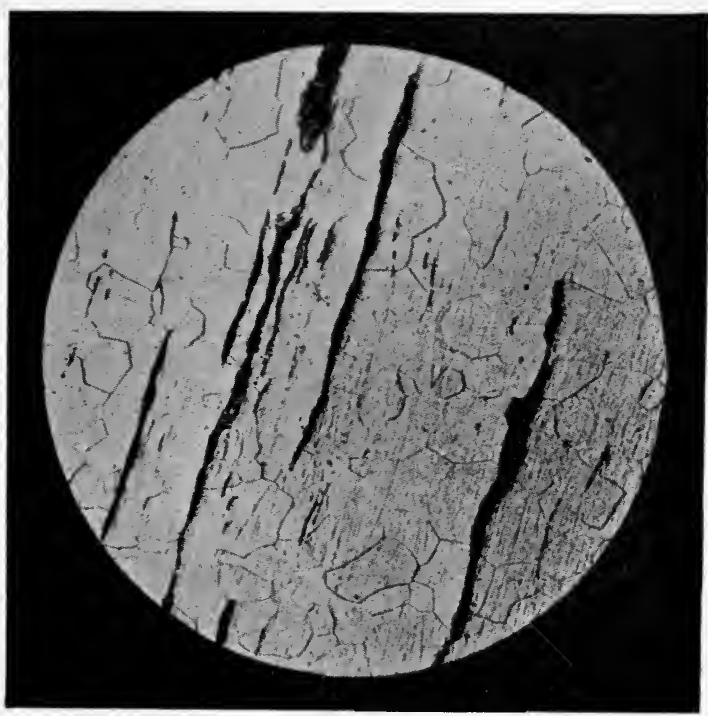

Fig. 50.-Wrought Iron ( $\alpha$-Ferrite) with Embedded Slag Particles (Goerens). $\times_{5}$. 
contains 0.85 per cent carbon corresponding to 12.75 per cent carbide.

The two solubility curves intersect at the eutectic point, exactly as is the case with liquid solutions. One of these curves represents cementite and the other iron. In both cases the solubility decreases with falling temperature. By gradual cooling of suitable concentrations, a precipitation of a component takes place in the solid state before the eutectic temperature is reached,

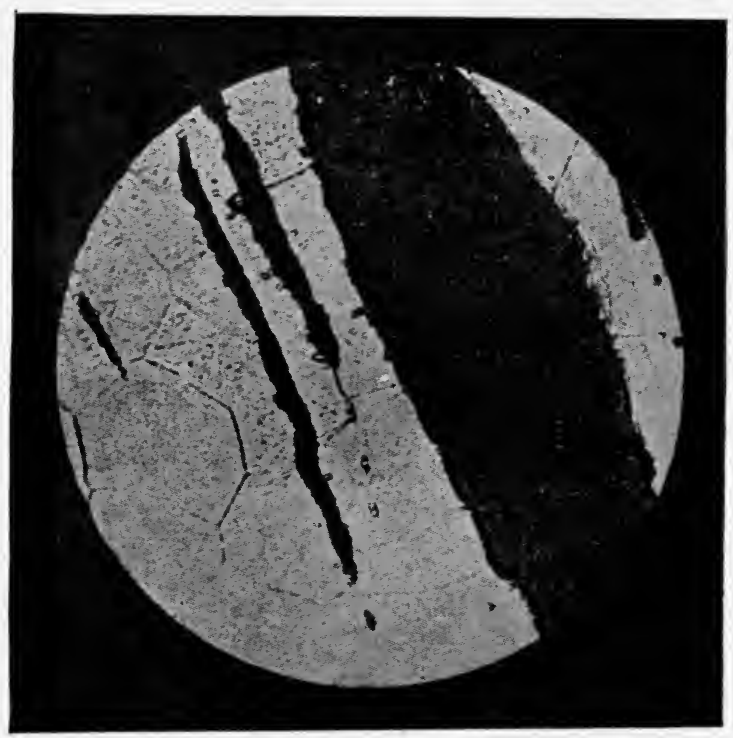

Fig. 51.-Wrought Iron, greatly Enlarged (Slag Particles Dark). (Goerens). $\times 500$.

what that is depends naturally on whether the carbide content of the solution is greater or less than the eutectic. Miscroscopically the over-eutectic steel consists of cementite embedded in the eutectic, the under-eutectic steel of iron crystals, and, indeed, iron crystals in the magnetic form. This structure component is designated as ferrite.

Its appearance is very characteristic. It occurs as the principal constituent in wrought iron poor in carbon and can be recog- 
nized by the polygonal form of its crystals. They are shown in Figs. 50, $5^{\mathrm{I}}$ and $5^{2}$, under different magnifications.

\section{Perlite and its Transition Products.}

The cementite ferrite eutectic has the name perlite. Fig. 53 shows this structural component with strong magnification. The two components are deposited over each other in lamellæ and form a fine net work. The light reflection phenomenon of the lamellæ gives similar effects as mother of pearl. This schillerization is noticeable with the naked eye and this led Sorby to call it the pearl-like component.

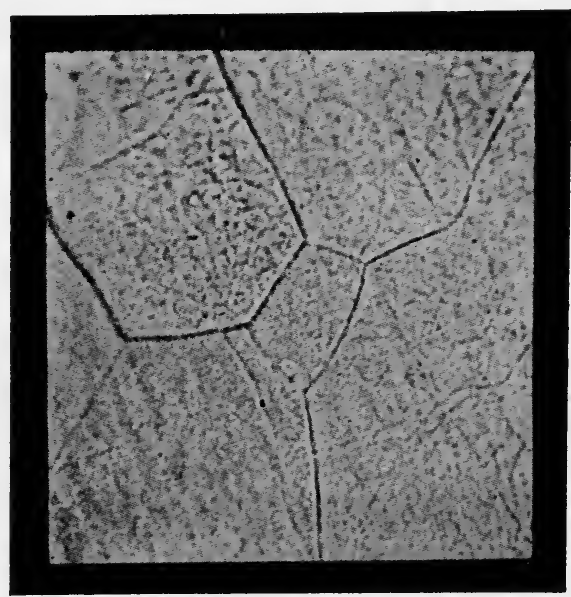

FIG. 52. $-\alpha$-Ferrite (Goerens). $\quad{ }_{5} 00$.

Fig. 54 shows a steel which consists of lamellar perlite in which is embedded ferrite, Fig. 55, with embedded cementite.

The fineness of the perlite lattice is dependent on the duration of heating and the speed of cooling. The interval between the lamellæ is greater, the longer time the piece is subjected to high temperatures. This relation is entirely what would be expected from what we learned in the first chapter of the tendency of ferrite crystals to grow, if they were held for a long time at a temperature between $600-700^{\circ}$. If we treat steel con- 


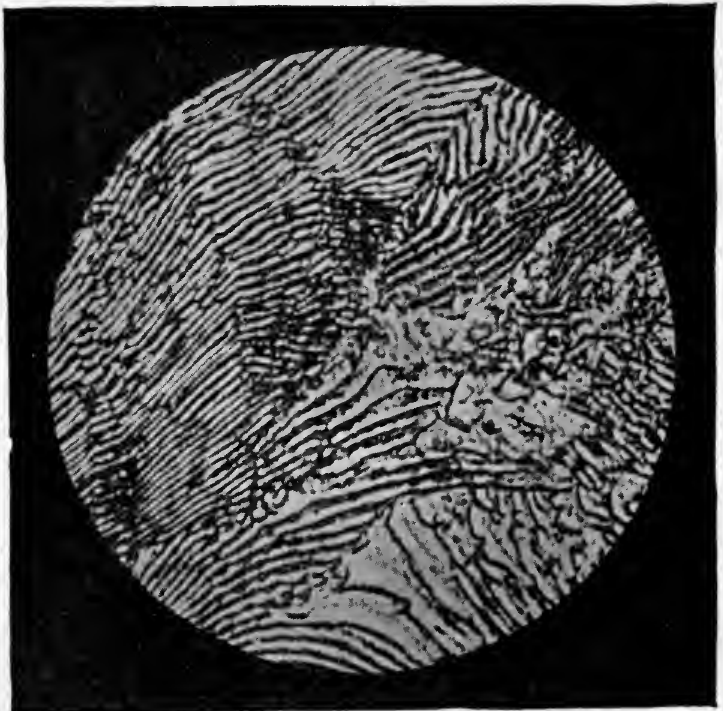

FIG. 53.-Lamellar Perlite. $\times 750$.

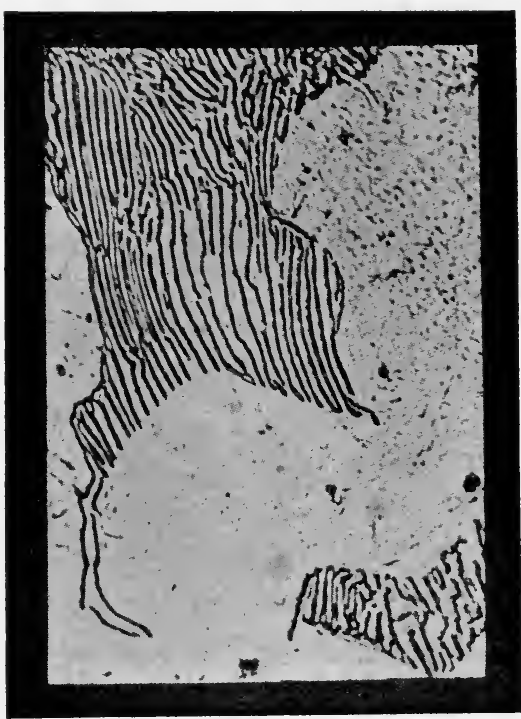

Fig. 54.-Under-eutectic Steel. Lamellar Perlite+Ferrite (Goerens). $\quad \times_{750}$. 
taining perlite in this way the same process goes on. Both the fine ferrite particles and the cementite crystals are enlarged, the latter frequently growing together. In this way the lamellar structure is lost and a crystalline structure replaces it as shown in Fig. 56. The gradual decomposition of the solid solutions and the single phases of the transition process, which finally leaves perlite as the end product can be conveniently studied from the pictures. The products of partial disintegration differ in their relations as regards etching agents and have often been claimed as special structure components and the names austenite, sorbite and troostite given to the various members of the series.

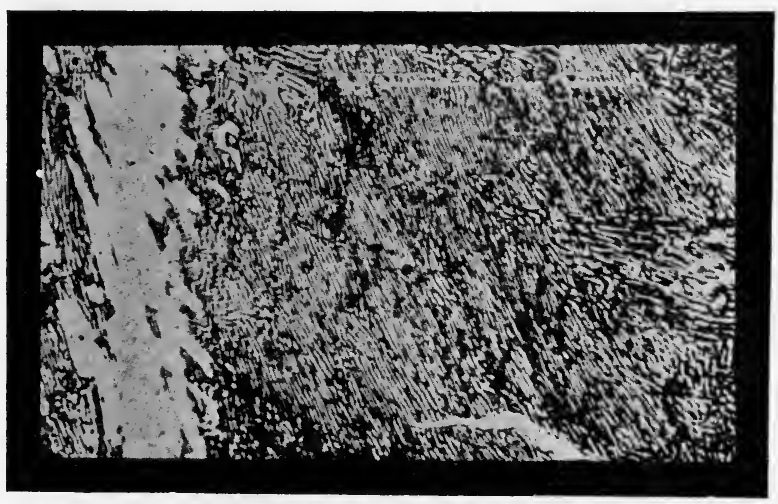

FIg. 55.-Over-eutectic Steel. Lamellar Perlite+Cementite (Goerens). $\quad{ }_{5}$ oo.

It must be remembered, however, that they are not sharply defined or the boundaries between them definite. They have, accordingly, no place in the equilibrium diagram as this represents only equilibrium relations. These members appear in the transition of attacked systems whose further change is made impossible by quenching.

It is well to consider austenite as the solid solution saturated with iron-carbide. If a chilled white pig iron of $3-4$ per cent carbon is annealed cautiously for a short time it changes its action toward the so-called Kurbatoff reagent (a mixture of nitric acid and acetic anhydride in the ratio of 4-100 diluted with a mixture of equal parts of methyl, ethyl and amyl alcohol). 
While the solid solution is not previously attacked by this, part of it shows a dark color after thermal treatment. The colored component has been called troostite. Benedicks* assumes that it consists of cementite and ferrite particles and that these possess ultramicroscopic dimensions and place troostite on a parallel with colloidal solutions.

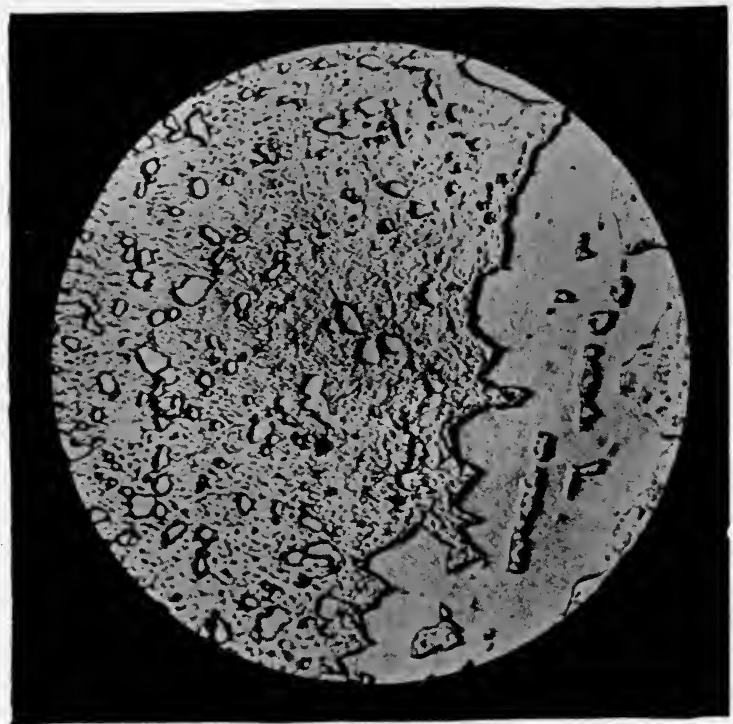

Fig. 56.-Granular Perlite, Cementite Globulites (in Relief), in a Ground Mass of Ferrite (Goerens). $\times_{75}$.

A continuation of the heating causes an enlargement of the structure and we obtain sorbite and, if the lamellar structure is resolvable with the help of the microscope, perlite. Figs. 57 and 58 show pictures of these two intermediate states between the solid solution and perlite.

The steps of the rearrangement are shown in the following equation:

\footnotetext{
Austenite Martensite $\underset{\text { Troostite } \rightarrow \text { Sorbite } \rightarrow \text { lamellar Perlite } \rightarrow \text { Granular }}{\text { Perlite }}$

* Z .Chem. Ind. Kolloide, r9ro p. 290.
} 


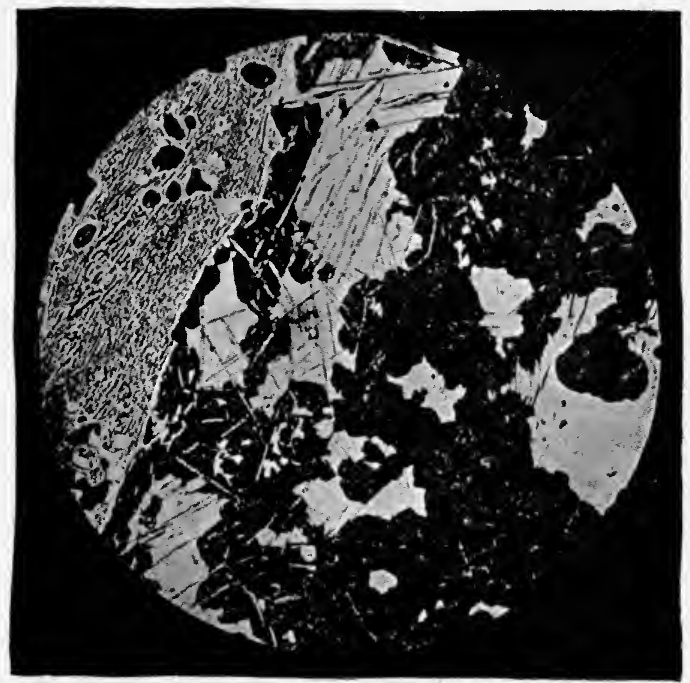

FIG. 57.-Troostite (Black); Austemite (Light), Shot Through with Cementite Needles (Goerens). $\times$ זoo.

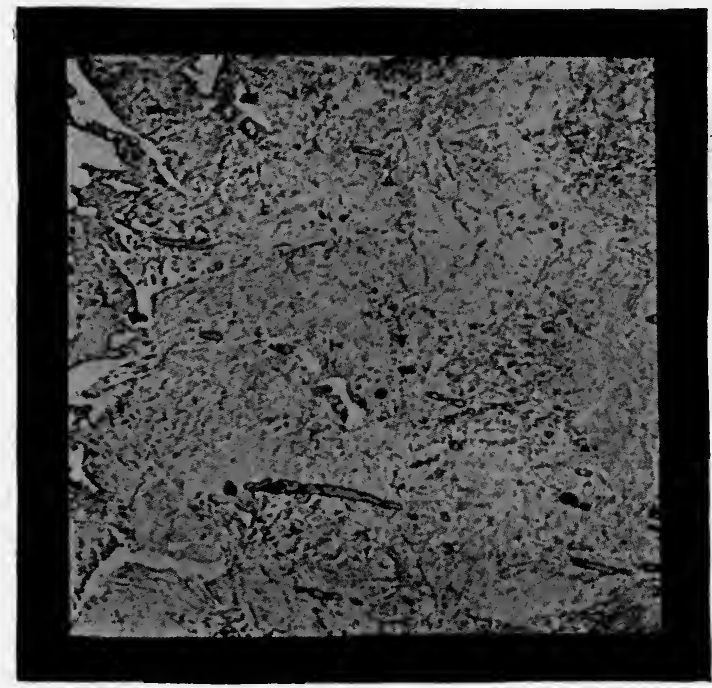

Fig. 58.-Sorbite, Over Light Ferrite (Goerens). $\quad$ × 100. 
If perlite be heated above the eutectic point, $710^{\circ}$, a solid solution of iron and carbide, martensite forms. This structural element may be fixed by quenching and is recognized by its hardness, being the constituent of hardened steels. By heating and slow cooling it separates again into its components and softens. Steel hardened by heating and quenching is accordingly in the metastable state.

\section{The Precipitation of Carbon in Iron Carbon Alloys.}

Under certain conditions, namely slow cooling of the melt or continued heating at high temperature the carbon does not precipitate out of the concentrated melt as cementite but as the stable form, graphite, or, at relatively low temperatures as amorphous carbon; the so-called temper carbon. Due to its small specific gravity it collects at the surface of liquid pig iron, which is held somewhat above its melting point, as in casting practice, and is called "kish." In the slowly solidified gray pig iron it is possible to recognize the graphite leaves with the naked eye.

The equilibrium between carbide, iron and graphite and also that between carbide, iron and temper carbon are unknown. It is certain, however, that amorphous carbon, for example, sugar carbon as well as finely divided graphite dissolves in iron with the formation of carbide. It is the general conception that the total dissolved carbon in the melt is contained as carbide; we may further suppose that an equilibrium is established between this solution and solid carbon, which can be formulated.

$$
\mathrm{Fe}+\mathrm{C} \text { (solid) } \rightleftarrows \mathrm{Fe}_{3} \mathrm{C} \text { (dissolved). }
$$

It is even possible that the equilibrium relations would also hold for the solid iron-carbide solutions.

That this equilibrium has not previously been established is due to the fact that the dissolved carbide especially in not very concentrated solutions is very slowly decomposed. It has, therefore, been impossible up till now to establish the eutectic point for the precipitation of a mixture of graphite and solid solution by cooling experiments. These led always to the eutectic point of the metastable system solid solution cementite. 
The equilibrium relations set forth above do not hold for solid crystallized cementite, this is always labile and its decomposition velocity in the neighborhood of the solidification point of pig iron $\left(1130^{\circ} \mathrm{C}\right.$.) is very considerable. This fact has led a number of authors to assume that the precipitation of graphite must always be preceded by a precipitation of cementite crystals in the melt followed by the irreversible reaction.

$\mathrm{Fe}_{3} \mathrm{C}$ (solid) $\rightarrow$ Graphite +melt.

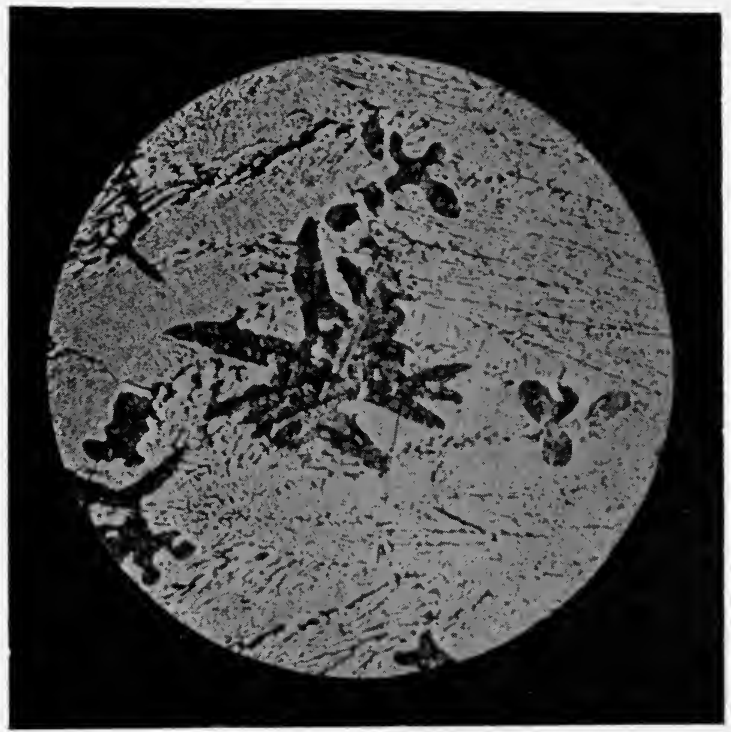

Fig. 59.-Graphite Druse, Surrounded by Light Eutectic (Goerens). $\times_{50}$.

With pig iron of small carbon content this indirect way of decomposition is favored, however, with melts very rich in carbon in which, according to the law of mass action, there must be a very great decomposition velocity the possibility of the direct crystallization of graphite is not rejected.

Since the graphite is stable compared to the cementite, the carbon content of the melt with which the graphite is in equilibrium is smaller than that of the melt out of which the solid cementite crystallizes. These relations must also hold for the solid solutions which are in equilibrium with the graphite. This 
deduction is confirmed by the quenching test of graphite-containing iron-carbon alloys which do not contain foreign substances, especially silicon. The part of the solid solution that is directly in contact with the graphite is always carbon poorer than that at a distance from which the carbon has not separated. In the microphotograph this fact can be at once recognized. In Fig. 59 is seen a light solid solution-cementite eutectic; in the center of this is a dark field consisting of carbon poor iron

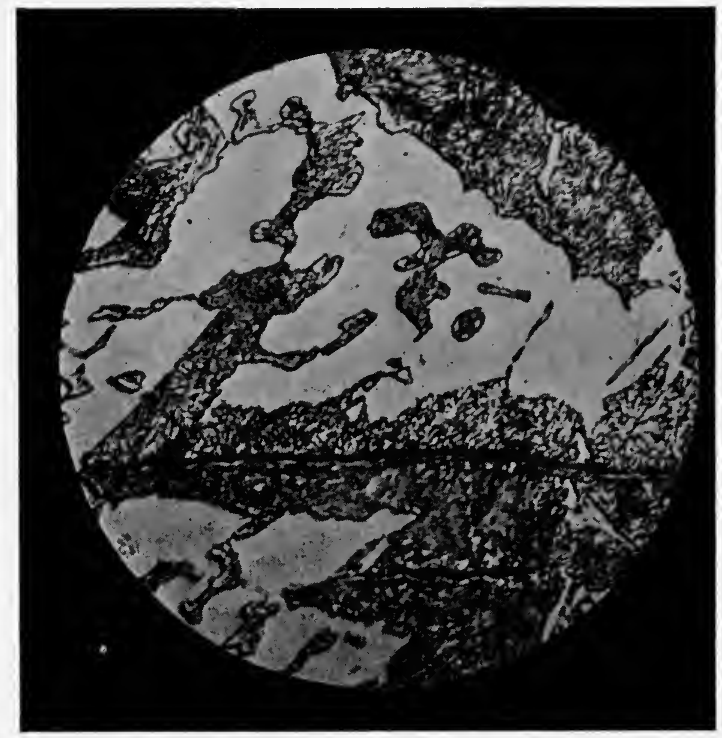

FIG. 60.-Graphite in Eutectic, Strongly Enlarged (Goerens).

inside of which are easily recognized graphite grains. These relations are shown still better and under stronger magnification in Fig. 60.

The necessary experimental material is not extant for the setting up of a complete equilibrium diagram of iron-graphite. A schematic representation must suffice. From our earlier considerations it can be deduced that the curves which express the solubility of graphite in the melt and in the solid solution are deflected to the left as compared to the cementite curve. Also an 
analogous equilibrium line which lies in the space between the graphite and cementite curves is to be given for the amorphous carbon. (Fig. 6I.)

In practice, cases are not met in which the graphite precipitation goes on till the equilibrium is established. Microscopic investigation of all pig iron shows greater or smaller portions with the structure constituents of the metastable

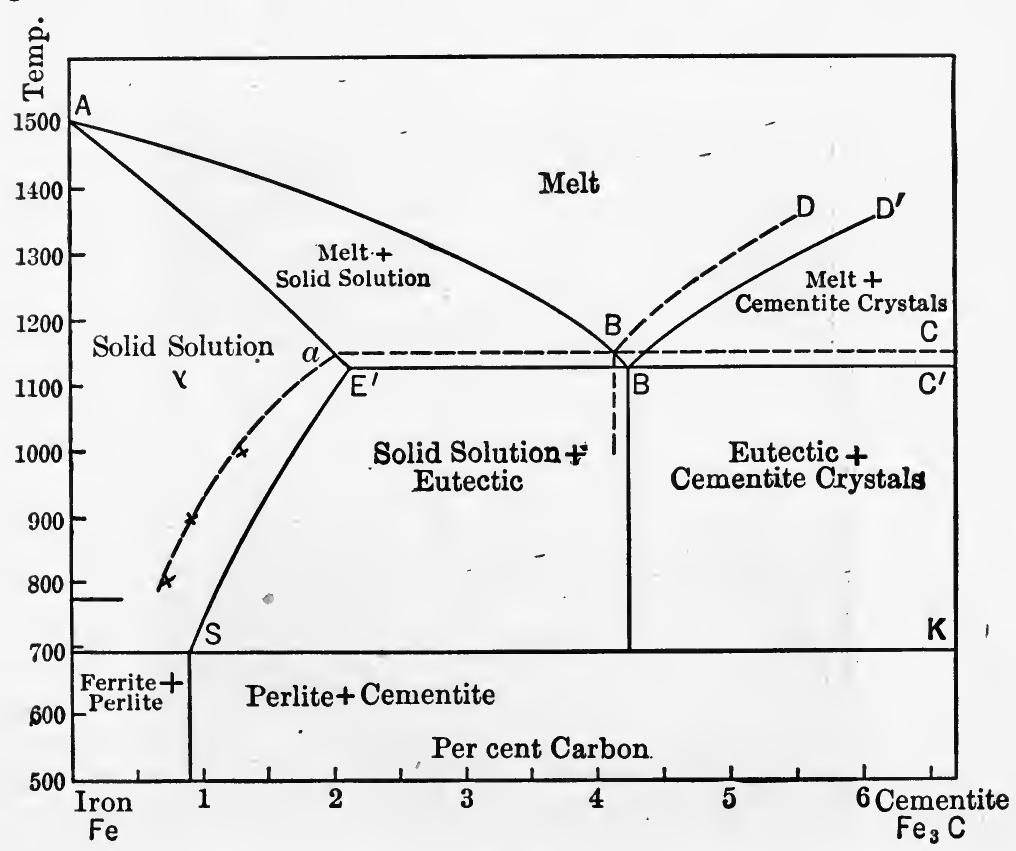

Fig. 6r.

systems. The necessary time for equilibrium is even greater than the duration of cooling of the preparation.

If the gray pig iron is heated for a long time at $1100^{\circ}$ and quenched in ice water there are obtained, as would be expected, graphite and the needle-like martensite as the structural components; unchanged cementite crystals are also often met in such specimens. In single cases troostite and austentite occur. If the cooling is allowed to proceed slowly the specimen shows graphite and cementite embedded in lamellar perlite. These 


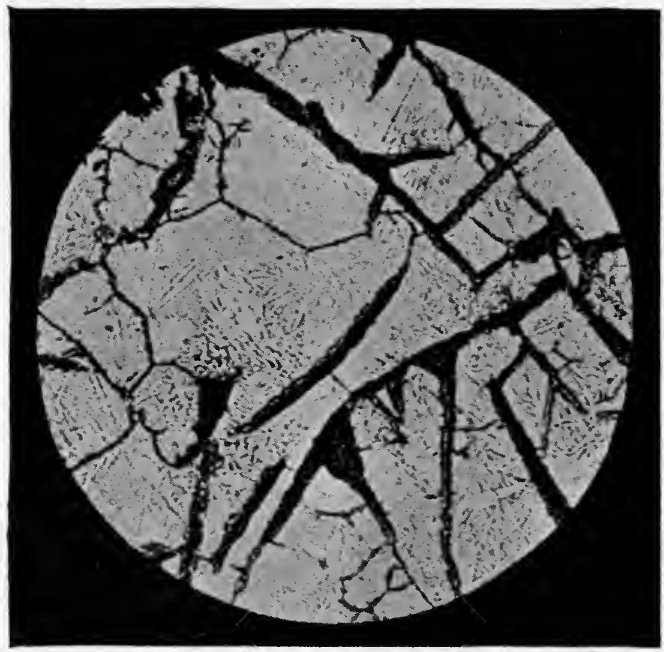

Fig. 62.-Graphite+Martensite (Goerens).

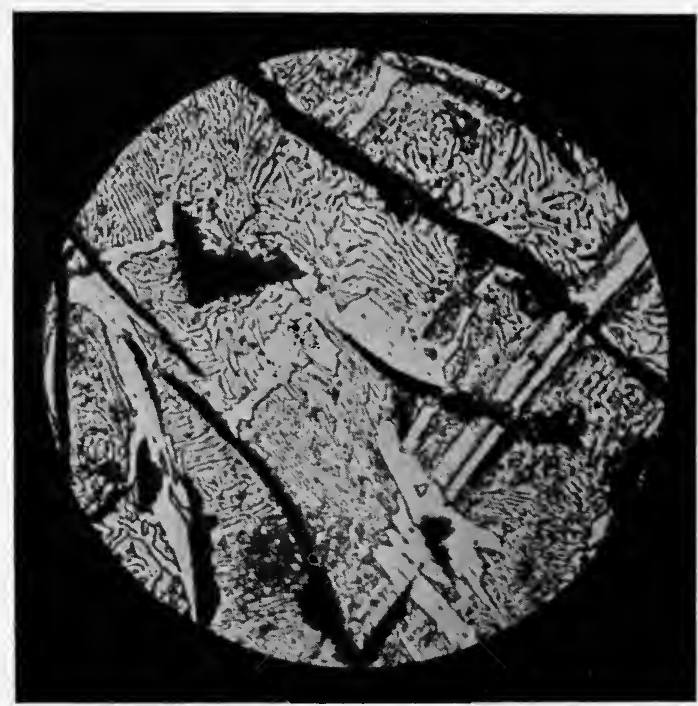

Frg. 63.-Gray Pig Iron; Black Particles of Graphite, Light Cementite Embedded in Lamellar Perlite. A Needle Scratch is on the Surface, which does not Scratch the Hard Cementite. (Goerens). $\times_{500}$. 
are the components that one finds in normal gray pig iron. A micrograph of such a specimen is shown in Fig. 63; to indicate the hardness of the different components a needle scratch is drawn over the surface, showing in the soft perlite as a deep furrow while the hard cementite is entirely uninjured. A picture of gray pig iron with strong graphite precipitation is shown in Fig. 64.

By long-continued heating of white pig iron, the carbon is not obtained as crystal leaves, but in the finely divided state, as the so-called temper carbon, which is probably amorphous.

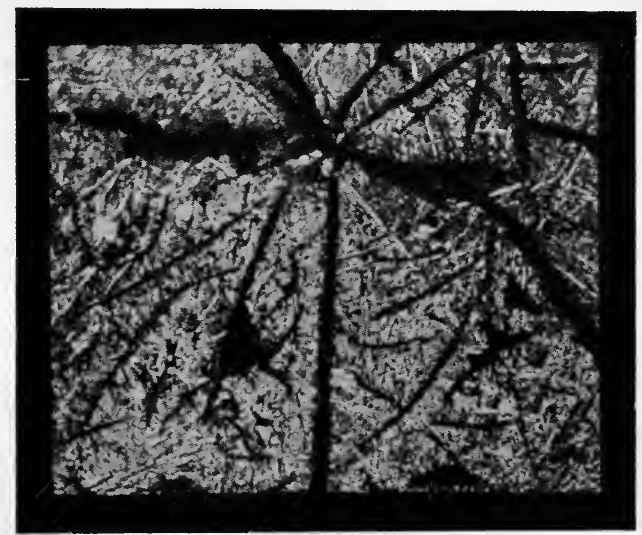

FIG. 64.-Gray Pig Iron; Black Particles of Graphite, Light of Cementite. Ground Mass Lamellar Perlite (Goerens). $\quad{ }_{5} \circ$.

This process has been followed metallographically by Wüst. The pictures of his preparations are given in Figs. 65,66 and 67.

Fig. 65 shows the original material, a white pig iron which has been rather quickly cooled. It consists as can be seen of an intimate mixture of cementite and solid solution which already shows a tendency to decomposition; it is "sorbitic." By heating 50 hours in vacuum at $980^{\circ}$ and slow cooling the structure is totally changed. This can be recognized from Figs. 66 and 67. One obtains black excretions which are surrounded with light halos, embedded in lamellar perlite. The excretions are temper carbon which have surrounded themselves with a circuit of ferrite. It would be interesting to see how a specimen which had 
been heated for a long time and then quenched would be constituted, it would then be shown whether the carbon excretions result equally well from isothermal decomposition of cementite into carbon and solid solution, poor in carbon, or whether these flocks are a secondary condition and a result of the precipitation and the crystallization of ferrite as we have seen in the formation of granular perlite. The practical use of this process in the malleabilizing of cast iron is known to all. At temperatures .

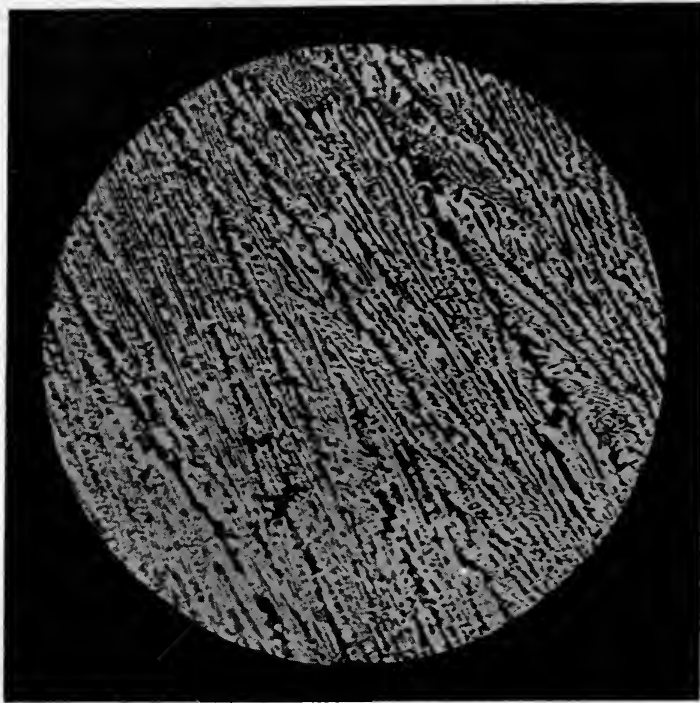

Fig. 65. -White Pig Iron; Cementite (Light) + Sorbite (Dark) (Goerens). ${ }_{55} 00$.

below $700^{\circ}$ the decomposition of cementite into its elements is still unobservable and would require a very long time.

\section{The Use of Additions to Iron and Steel.}

The various kinds of iron and steel which are met in practice are seldom pure iron carbon alloys. Generally they contain still other elements. We shall not consider here such undesirable elements as sulfur and phosphorus which are excluded as far as possible, but only those which are intentionally added. Of these manganese and silicon are especially-important and for the preparation of special steels nickel, chromium, tungsten, molybde- 


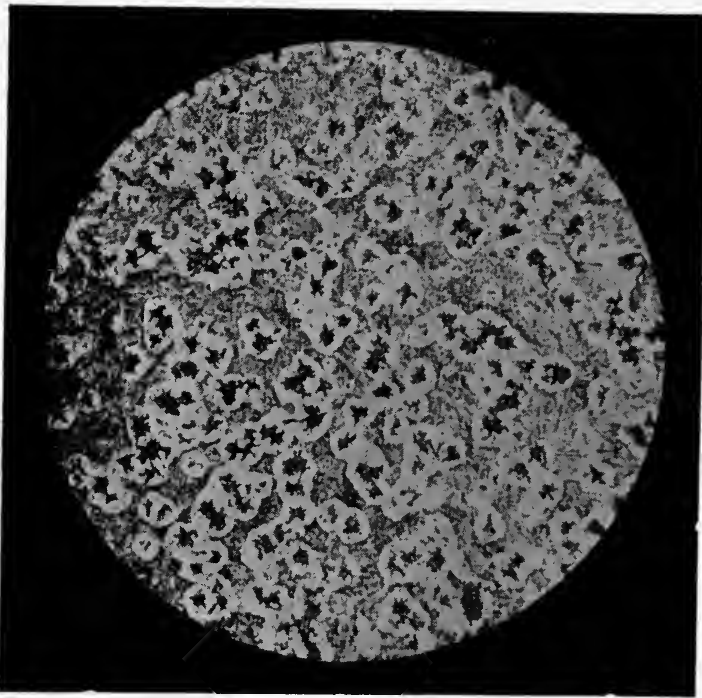

Fig. 66.-Material of Fig. 65 Heated to $900^{\circ}$ and Cooled Slowly. Black Nuclei of Temper Carbon, Surrounded by Light Ferrite; Ground Mass Perlite (Goerens). $\times 50$.

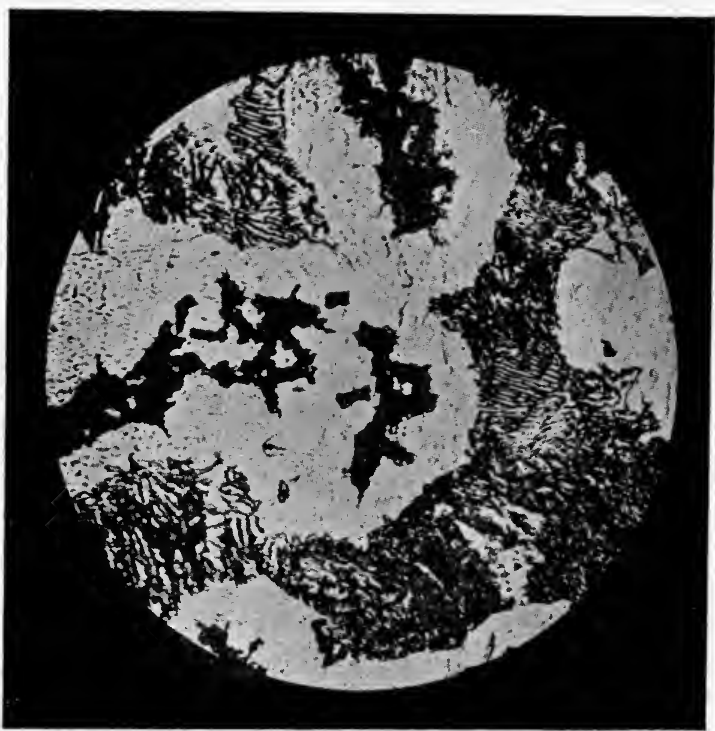

Frg. 67.-Material of Fig. 66 with Great Magnification (Goerens). 
num and vanadium. They all modify the properties of the pure iron carbon alloys.

We will not develop here the space diagrams of these ternary and quaternary alloys but will confine ourselves to a general discussion.

The changes which these substances produce in the properties of iron-carbon alloys can be different in nature. They depend on the fact that either the stability of the carbide is lessened or increased or that the transition temperature and the eutectic point and with them the boundaries of the solid solution fields are displaced. It has been known for a long time that the presence of silicon in iron favored the decomposition of the carbide into its elements; it has even been supposed that the presence of silicon was a necessary preliminary condition for the occurrence of graphite; this, however, has been disproved by the investigations of Wüst on pure iron-carbon alloys which, by sufficiently long heating near the melting point leave graphite. In all the cases considered the presence of this substance in iron decreases the stability of cementite and the solubility of the carbide in liquid iron. Investigations of the lowering of the solubility of carbon in iron by the addition of silicon have been carried out by Petersen.* In carbon saturated silicon containing alloys, which have been heated for a long time at the melting point the content of carbide (cementite+dissolved carbide) decreases with rising temperature as the following table shows:

\begin{tabular}{|c|c|c|c|c|c|}
\hline $\begin{array}{l}\text { Silicon, } \\
\text { Per Cent. }\end{array}$ & $\begin{array}{l}\text { Carbon, } \\
\text { Per Cent. }\end{array}$ & $F . P$. & $\begin{array}{l}\text { Silicon, } \\
\text { Per Cent. }\end{array}$ & $\begin{array}{l}\text { Carbon, } \\
\text { Per Cent. }\end{array}$ & $F . P$. \\
\hline 0 & $4 \cdot 3$ & I I 30 & 3.25 & $3.4 \mathrm{I}$ & 1187 \\
\hline o. 13 & 4.29 & II38 & 3.69 & $3 \cdot 32$ & II97 \\
\hline 0.21 & 4.23 & I I3I & 3.96 & 3.24 & I 205 \\
\hline $0.4 \mathrm{I}$ & $4 \cdot$ II & II 52 & 4.86 & 3.08 & I 210 \\
\hline 0.66 & 4.05 & II 55 & 5.06 & 2.86 & 1215 \\
\hline I. I4 & 3.96 & I I 60 & I 3.54 & I. 94 & I 233 \\
\hline 2.07 & 3.79 & II 85 & 26.93 & 0.87 & I 255 \\
\hline 2.68 & $3 \cdot 5^{6}$ & 1185 & & & \\
\hline
\end{tabular}

* Metallurgie, 3, 8I I (rgo6). 
In contrast to silicon stands manganese which makes the labile carbide stable. This action is easily understood when we think that the manganese cementite $\mathrm{Mn}_{3} \mathrm{C}$, which corresponds to iron cementite $\mathrm{Fe}_{3} \mathrm{C}$ is a stable compound which is not split into its elements and that both cementites are isomorphous and are miscible in all proportions in the solid state. As a general rule, the properties of isomorphous mixtures are made up additively from the properties of their components and hence the small tendency of manganese carbide to decompose into its elements is shared by the iron-carbon alloys containing manganese.

We meet silicon as well as manganese in pig irons. The white pig iron always contains greater or less amounts of manganese while the gray in which the black graphite leaves are easily recognized on a broken surface shows a content of silicon.

These two elements are also not without importance in the iron-carbon alloys poor in carbon. The silicon occurs in the iron, not in the elementary form but in the combined state. Guertler and Tammann, who have established the equilibrium diagram for the binary system iron silicon, found the silicide FeSi and consider the existence of a second silicide $\mathrm{Fe}_{2} \mathrm{Si}$ probable. The latter forms with $\alpha$ ferrite an unbroken series of solid solutions, promotes the occurrence of this structure component and inhibits the polymorphic change as well as the formation of carbide solid solutions. There is also a displacement of the eutectic point toward the side of the higher temperature so that the solid solution field of silicon containing steel is smaller than that of pure carbon steel.

With manganese we have the complete miscibility of the metal with iron on the one hand and the complete miscibility of the corresponding cementite on the other. The presence of manganese causes a lowering of the eutectic point that goes hand in hand with a widening of the solid solution field.

As for the rest of the substances which are added to the ironcarbon alloys in the manufacture of special steels, nickel, chromium, tungsten and molybdenum, their influence on the equilibrium diagram, at least so long as only small percentages of the third component are considered, is entirely similar to that of 
silicon and manganese. At higher concentrations new structure components appear. Nickel which with $\alpha$ iron and with $\gamma$ iron forms solid solutions in all proportions, enlarges the martensite field and not only lowers the eutectic point but also the transition point of the iron modifications. The higher of the two points is lowered in a larger measure than the lower so that finally a direct transition of $\gamma$ solid solution into $\alpha$ solid solution takes place.

Chromium and tungsten which favor the formation of ferrite, form with it solid solutions. The possibility of the occurrence of martensite is not completely destroyed but the perlite eutectic point is raised and the stable $\boldsymbol{\gamma}$ solid solution field lessened.

The entrance of these different metals into the solid solution acts similarly to an increased content of dissolved carbide, that is, the addition increases the hardness. We chance here again on the previously mentioned fact that solid solutions are harder than their components. These special steels, especially nickel steel have the great advantage over the pure carbon steels that in spite of their hardness they are not brittle.

The strong "hysteresis" of the transition phenomena which is characteristic of all ternary and quaternary steels is of practical and theoretical interest. This phenomenon is not entirely missing in the binary system iron-carbon but it is not so strongly marked as in the special steels. In the determination of the transition point and the eutectic point by the survey of the cooling and heating curves it is frequently observed that the transition phenomena do not take place at the same point with falling temperature as with rising temperature (Fig. 6). The alloy can accordingly be under-cooled or overheated before the transition is released; a retardation or hysteresis takes place which, in general, is greater, the greater the amount of the third component. This phenomenon is especially marked with nickel steel where the transition is from $\gamma$ solid solution into $\alpha$ solid solution. The occurrence of this change is especially easy to observe as the $\alpha$ solid solution is magnetic and the $\gamma$ solid solution is non-magnetic. The change can be recognized by the appearance or the disappearance of the magnetism. 
The position of the magnetic transition point on cooling and heating and its relation to the nickel content is given in the following table which is taken from the work of Osmond * who has done the most toward the explanation of these phenomena.

\begin{tabular}{|c|c|c|c|c|c|}
\hline \multicolumn{4}{|c|}{ Composition of the Nickel Steel. } & \multicolumn{2}{|c|}{$\begin{array}{c}\text { Magnetic TRansition } \\
\text { Point. }\end{array}$} \\
\hline c. & Ni. & Si. & $\mathrm{Mn}$. & On Cooling. & On Heating. \\
\hline o. I9 & 0.27 & $0.3 \mathrm{I}$ & 0.79 & 715 & 735 \\
\hline 0.19 & 3.82 & 0.20 & 0.65 & 628 & 710 \\
\hline 0.17 & 7.65 & 0.21 & 0.68 & 530 & 710 \\
\hline 0.23 & $15 \cdot 48$ & 0.24 & 0.93 & 145 & 623 \\
\hline 0.16 & $24 \cdot 75$ & 0.24 & 0.32 & 27 & 540 \\
\hline $0.6 \mathrm{I}$ & 26.20 & 0.24 & 0.46 & $\circ$ & 540 \\
\hline
\end{tabular}

The position of the point is determined not only by the composition, but also by the thermal treatment, which the material has undergone. Osmond's experiments on chrome steel show that the point of arrest on cooling varies considerably with the temperature to which it has been heated. The higher the previous heating the lower is the transition point of solid solution into perlite.

\begin{tabular}{|c|c|}
\hline $\begin{array}{c}\text { Heating Temperature, } \\
\text { Degrees C. }\end{array}$ & $\begin{array}{c}\text { Transition Point on } \\
\text { Cooling, Degrees C. }\end{array}$ \\
\hline 835 & $713-716$ \\
1030 & $682-692$ \\
1220 & $635-643$ \\
1320 & $640-600$ \\
\hline
\end{tabular}

These hysteresis phenomena of steel are not without analogy in other fields. It is a known and often observed fact that a labile modification of a polymorphic substance which is scarcely obtainable with the pure substance may be relatively stable if the substance is impure or if a foreign substance is intentionally added. Heating to a high temperature acts in a like sense. It has been deduced from these facts that at high temperatures,

* Compt. rend., 128, 304 (1898). 
the crystal neuclei which start the occurrence of the stable crystals at low temperatures are destroyed and the more completely the higher the temperature.

The solubility of the solid solution is especially great in quaternary steels, in which two metals are added simultaneously to the carbon-iron alloy. In the chromium tungsten steels, especially if they be exposed before cooling to a very high temperature it is not necessary to quench in order to obtain them hard since there is practically no change to the stable perlite form, the precipitation of cementite out of the solid mass being extraordinarily hindered. This steel also does not lose its hardness by heating to $600^{\circ}$ as does ordinary steel. In order to obtain the perlite structure in a chrome-tungsten steel it is necessary to heat it for a long time due to its very slow transformation which requires at least one hour at a temperature of $700^{\circ}$. This kind of steel is used as a tool steel since it possesses the great advantage that it may become hot during use without losing its hardness. The quaternary steels which remain hard on heating are called " high-speed steels."

There are other metal, metal-compound systems which are of importance in metallurgy and we will study here a few of the systems.

\section{Alloys of Metals and Oxides. Copper-Copper oxide.}

Holborn and Day $\nmid$ always observed lower values for the solidification point of copper in the presence of air than in an indifferent gas atmosphere. The air must, accordingly, form with the liquid metal a soluble product which causes a depression of the copper melting point. This product can be no other than cuprous oxide.

Concerning the solubility of this substance in liquid copper and the solidification phenomena as well as the structure of the solidified melt Heyn* has made a thorough study and has arrived at the important result that the alloys of metals and suboxides differ in no respect from the alloys of metal pairs. The

*E. Heyn, Mittelungen, aus den Konigl. Techn. Versuchsanstalt،, 18, 320 (1900).

$\dagger$ Ann. Phys. 4, 99 (I90I). 
mutual solubility of the two components exists only in the liquid state, a solid conglomerate of the two components exists in the solid state. The typical solidification diagram is obtained with two limbs which cut at the eutectic point (see Fig. 68). The de-

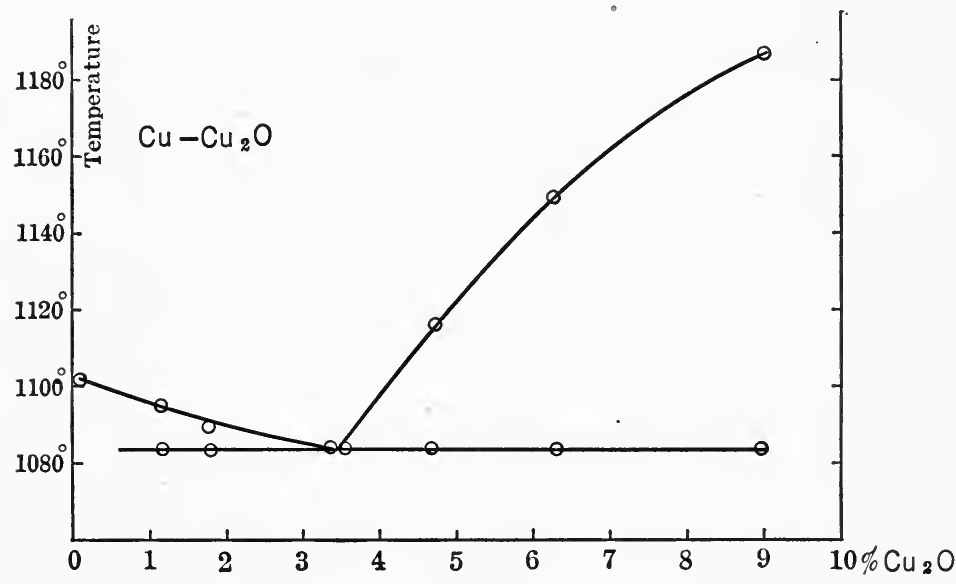

FIG. 68.

pendence of the solidification point on the oxide content is shown in the following table: (The temperatures are probably high).

\begin{tabular}{|c|c|c|}
\hline \multirow{2}{*}{$\begin{array}{c}\text { Content of } \\
\mathrm{Cu}_{2} \mathrm{O} \text {, Per Cent. }\end{array}$} & \multicolumn{2}{|c|}{ Solidification. } \\
\hline & $\begin{array}{c}\text { Begins, } \\
\text { Degrees C. }\end{array}$ & $\begin{array}{c}\text { Ends, } \\
\text { Degrees C. }\end{array}$ \\
\hline 0.08 & IIO2 & . \\
\hline I. I6 & ro95 & 1085 \\
\hline $\mathrm{r} .75$ & 1089 & 1084 \\
\hline $3 \cdot 5$ & 1084 & 1084 \\
\hline $3 \cdot 4$ & 1084 & ro84 \\
\hline $4 \cdot 7$ & III 6 & 1084 \\
\hline 6.3 & II 49 & 1084 \\
\hline 9.0 & I 186 & 1084 \\
\hline
\end{tabular}

The structure of the crystallized copper is shown in the accompanying pictures (Figs. 69-7I). Fig. 69 shows the typical eutectic structure (compare to this Fig. 20). Fig. 70 is a picture of an alloy which is poorer in oxygen; Fig. $7 \mathrm{I}$, one which is richer 
in oxygen than the eutectic. In the first are shown particles of the eutectic embedded between large flakes of metal, in the latter, grainy deposits of oxide in the eutectic. From the amount

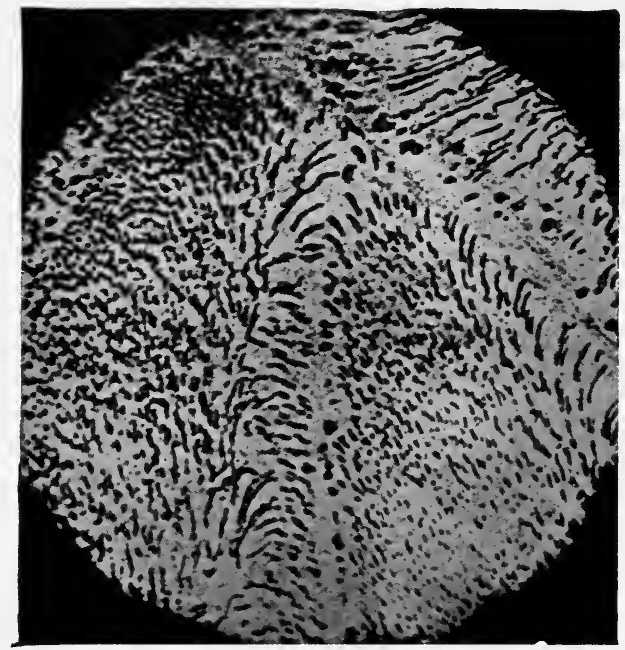

FIG. 69.- $\mathrm{Cu}-\mathrm{Cu}_{2} \mathrm{O}$ Eutectic (Heyn).

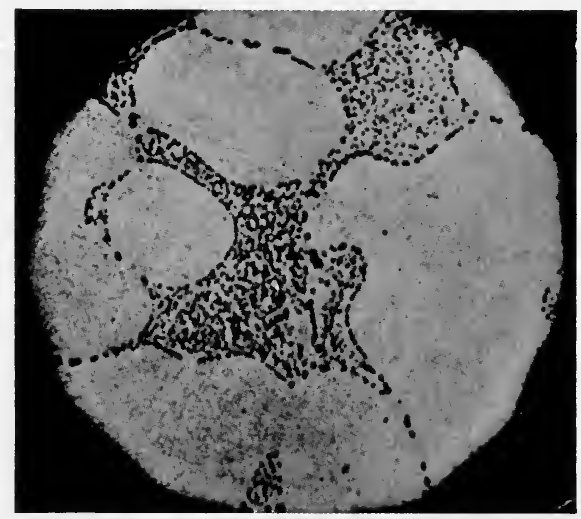

Fig. 70.- $\mathrm{Cu}-\mathrm{Cu}_{2} \mathrm{O}$ Eutectic Scattered Through Metal (Heyn).

of these grains the oxygen content can be approximately ascertained. The metallographic method which is quite simple to use can, in this case, displace the analytical. This method is of 
practical importance since conclusions in regard to the mechanical properties and usability of the copper metal can be drawn from the oxygen content. A high oxide content lowers the malleability of the material very essentially.

\section{Silver-Silver-oxide.}

Liquid silver also dissolves its oxide. It at least takes oxygen from the air which is given up again on solidifying. Since the oxide cannot exist in the free state at the melting point

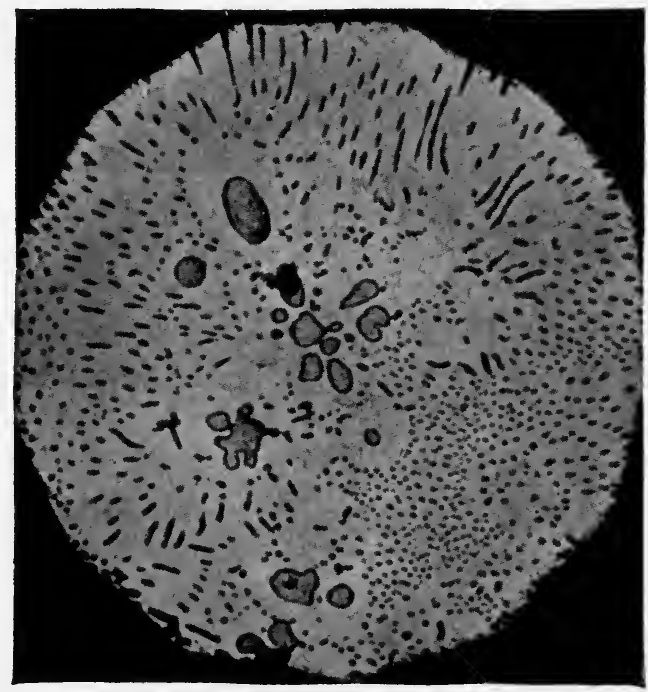

Fig. 7r.-Granules of $\mathrm{Cu}_{2} \mathrm{O}$ in $\mathrm{Cu}_{2} \mathrm{O}-\mathrm{Cu}$ Eutectic (Heyn).

of silver it breaks down into its elements as soon as the concentration in the melt is large, thereby showing the phenomenon of sprouting. The content of dissolved oxide is likewise recognized, in that the melting point of silver determined in the absence of air is higher than that ascertained in the presence of air, the temperatures are $961.5^{\circ}$ and $955^{\circ}$ respectively. (Holborn and Day.)

There are also cases in which the solubility of the oxide in the metal occurs in the solid state, for example, palladium oxide forms a solid solution with palladium metal. 


\section{Alloys of Metals and Sulfides.}

The number of alloys of sulfides with metals is much greater than that of oxides with metals. It also happens that a large number of sulfides show metallic properties and, accordingly, these alloys are in many respects similar to those of elementary metals. Partial and complete miscibility in the solid and liquid state and formation of compounds are known in these alloys as in those of metals.

These systems are also of practical importance. They play, for example, a rôle in the so-called precipitation process, that is, the smelting process by which the metals are precipitated out of their sulfides by decomposition with metallic iron.

\section{Lead-Lead Sulfide.}

We meet in case of lead a slight solubility of the sulfide in the metal. The solidification relations of this solution have been investigated by K. Friedrich and A Leroux.* The crystallization diagram would be entirely normal if the solubility of the sulfide in the neighborhood of the melting point of lead were not so very small. The result is that the eutectic point is very close to the melting point of lead. The dependence of the solidification point on the composition of the melt is given in the following table:

\begin{tabular}{|c|c|c|c|c|c|c|c|}
\hline \multicolumn{2}{|c|}{ Composition. } & \multirow{2}{*}{ F. P. } & \multirow{2}{*}{$\begin{array}{l}\text { Eutectic } \\
\text { Point. }\end{array}$} & \multicolumn{2}{|c|}{ Composition. } & \multirow{2}{*}{ F. P. } & \multirow{2}{*}{$\begin{array}{c}\text { Eutectic } \\
\text { Point. }\end{array}$} \\
\hline PbS. & $\mathrm{Pb}$. & & & PbS. & $\mathrm{Pb}$. & & \\
\hline 100 & $\ldots \ldots$ & $\mathrm{IIO}_{3}$ & $\ldots \ldots$ & 43.0 & 57.0 & 1036 & 328 \\
\hline 94.6 & $5 \cdot 4$ & 1085 & 327 & 38.0 & 62.0 & 1030 & 329 \\
\hline $89 \cdot 3$ & 10. 7 & 1073 & 327 & 33.2 & 66.8 & 1033 & 329 \\
\hline 83.9 & I6.I & 1060 & 327 & 28.3 & 71.7 & IOI 5 & $33 I$ \\
\hline 78.7 & $2 I \cdot 3$ & 1054 & 326 & $23 \cdot 5$ & 76.5 & 998 & 325 \\
\hline $73 \cdot 5$ & 26.5 & 1057 & 326 & 18.7 & $8 r \cdot 3$ & 956 & 325 \\
\hline 68.3 & 31.7 & IO5O & 325 & I 4.0 & 86.0 & $93 I$ & 326 \\
\hline 63.2 & 36.8 & 1047 & 329 & $9 \cdot 3$ & 90.7 & $88 \mathrm{I}$ & 325 \\
\hline 58.1 & $4 I \cdot 9$ & IO4I & 329 & $4 \cdot 7$ & $95 \cdot 4$ & 806 & 326 \\
\hline 53.0 & 47.0 & IO49 & 327 & $\ldots \ldots$ & 100 & $\ldots \ldots$ & 327 \\
\hline 48.0 & $5^{2.0}$ & 1040 & 327 & & & & \\
\hline
\end{tabular}

* Metallurgie, 2, 536 (1905). 
From this and from microphotographs it appears that both components, whether forming solid solutions with one another or compounds, go into sulfides somewhat poorer in sulfur. Fig. 72

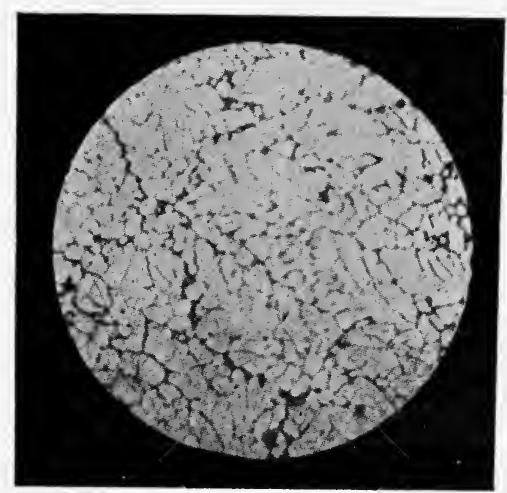

Fig. 72.-Pb-PbS Alloy, 78.7 Per Cent PbS; PbS Light, Metal Dark (Friedrich and Leroux).

shows the metallograph of a sulfide rich (78.7 per cent), Fig. 73 that of a sulfide poor (I8.7 per cent) alloy. The same structure components can be recognized in both.

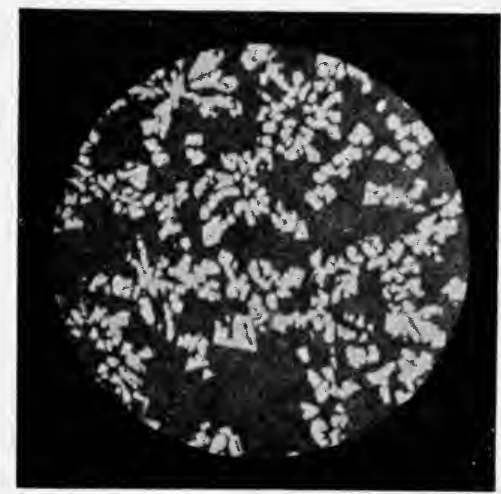

FIG. 73.-Pb-PbS Alloy, I8.7 Per Cent PbS; PbS Light, Metal Dark (Friedrich and Leroux).

\section{Antimony-Antimony Sulfide.}

In the system antimony-antimony sulfide-we meet partial miscibility in the molten state. These relations have been 
somewhat thoroughly investigated by the French investigators Grunchant and Chretien* on the one hand and by Pelabon on the other. They show that the molten sulfide dissolves small amounts of the metal and that thereby the melting point of the solvent is depressed. From the magnitude of this depression the molecular weight of the metal can be ascertained; it is as in most other cases monatomic, the observed value being II 3 as compared to the theoretical I20. The depression constant has the value 790 .

At larger concentrations a separation occurs into two layers of different density, which can be observed up to the boiling point of the metal.

DENSITY OF MIXTURES OF Sb AND $\mathrm{Sb}_{2} \mathrm{~S}_{3}$

\begin{tabular}{|c|c|c|c|c|c|}
\hline Temperature (in degrees).. & I3 & 643 & 698 & II 6 & I 156 \\
\hline 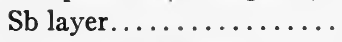 & 6.75 & $\ldots \ldots$ & 6.55 & $\ldots \ldots$ & 6.45 \\
\hline Density, $\mathrm{Sb}_{2} \mathrm{~S}_{3}$ layer..... & 6.43 & 3.85 & $\ldots \ldots$ & 3.82 & \\
\hline
\end{tabular}

The composition of the layers of metal is given in the following table:

\begin{tabular}{|c|c|c|c|c|c|c|c|}
\hline $\begin{array}{c}\text { Temp., } \\
\text { Degrees. }\end{array}$ & $\begin{array}{l}\text { Per Cent. } \\
\text { Sb. }\end{array}$ & $\begin{array}{c}\text { Temp.. } \\
\text { Degrees. }\end{array}$ & $\begin{array}{c}\text { Per Cent } \\
\text { Sb. }\end{array}$ & $\begin{array}{c}\text { Temp., } \\
\text { Degrees. }\end{array}$ & $\begin{array}{l}\text { Per Cent } \\
\text { Sb. }\end{array}$ & $\begin{array}{l}\text { Temp., } \\
\text { Degrees. }\end{array}$ & $\begin{array}{l}\text { Per Cent } \\
\text { Sb. }\end{array}$ \\
\hline 539 & II. 28 & 698 & 16. 5 & 825 & 20.0 & II30 & $21 \cdot 3$ \\
\hline 595 & 13.2 & 702 & I6.0 & 960 & 20.6 & 1167 & 21.2 \\
\hline 640 & 14.34 & $75^{\circ}$ & I 7.96 & 1036 & 21.0 & II 80 & 2 I. I \\
\hline 660 & 15.72 & 800 & 20. I & I 108 & 21.8 & & \\
\hline
\end{tabular}

\section{Copper-Copper Sulfide.}

The relation in the liquid state for alloys of copper with copper sulfide is similar and has been thoroughly investigated by E. Heyn and O. Bauer. $\dagger$ We have here also two melts differing in their density, a metal melt containing sulfide and a sulfide melt containing metal. At $1102^{\circ}$ the composition of the two layers is $\mathrm{Cu}_{2} \mathrm{~S}: \mathrm{Cu}-8: 8 \mathrm{I}$ and $85: \mathrm{I}_{5}$, respectively. There exists accordingly a miscibility gap. The composition has unfortunately not been studied at other temperatures. At the

* Compt. rend., 142, 709 (I906).

$\dagger$ Metallurgie, 3, 73 (1906). 
above-named temperature the two melts begin simultaneously to precipitate copper sulfide. On cooling somewhat, the layer rich in sulfur, disappears and there is obtained only a melt rich in copper, saturated with sulfide whose content is dependent on the temperature. The accompanying crystallization curve arrives finally at the eutectic point where it meets the precipita-

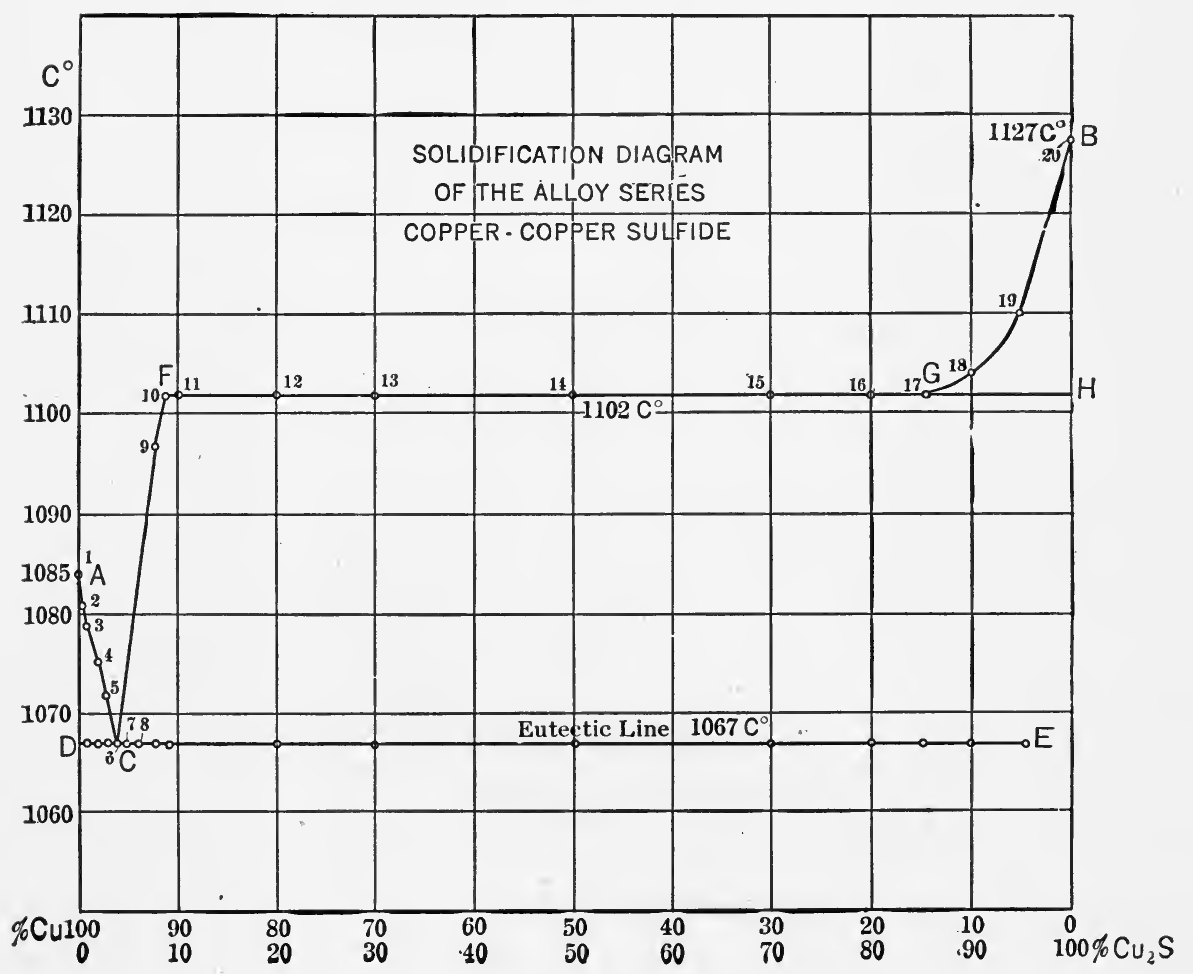

FIG. 74 .

tion curve for the metallic copper. Besides these curves there is between $11022^{\circ}$ and the melting point of the sulfide $\operatorname{II} 27^{\circ}$ still a further curve which represents the precipitation of sulfide from melts rich in sulfur (line $B G$ in Fig. 74). Fig. 74 shows the equilibrium diagram. The eutectic point lies at $1067^{\circ}$. The composition of the eutectic alloy is 3.8 per cent sulfide and 96.2 per cent metal. 
The microscopic structure of the solidified melt is again very characteristic and it is possible exactly as with the presence of oxide to ascertain very small amounts of sulfur in copper in the microscopic way. Heyn and Bauer found amounts that were overlooked by the analytical methods, viz., 0. or per cent sulfide corresponding to 0.002 per cent sulfur as strings of sulfide eutectic. A series of section pictures which represent different parts of the equilibrium diagram are given in Figs. $75-78$.

Fig. 75 shows the eutectic with 3.8 per cent sulfide content (magnification $\operatorname{II}_{7}$ ). Fig. 76 represents an alloy with 0.49 per

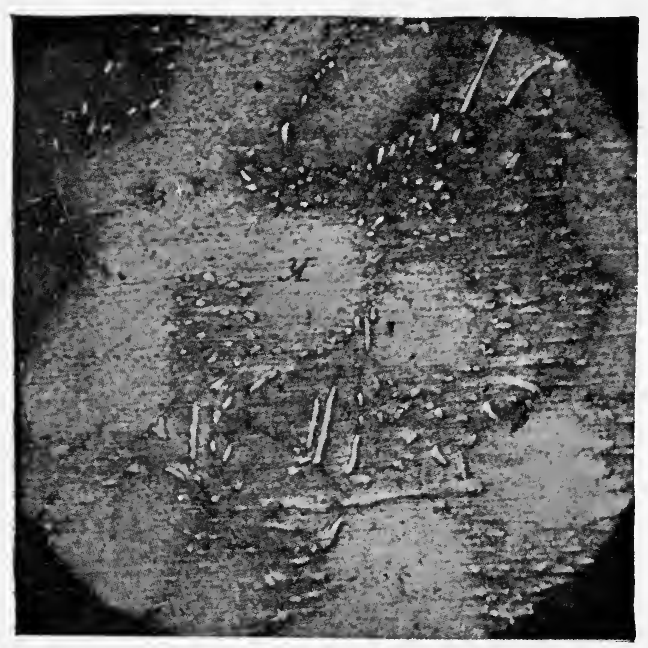

FIg. 75. $-\mathrm{Cu}_{-} \mathrm{Cu}_{2} \mathrm{~S}$ Alloy, Eutectic 3.8 Per Cent $\mathrm{Cu}_{2} \mathrm{~S}$ (Heyn and Bauer). $\times_{\text {II }}$.

cent sulfide (magnification II7.) Fig. 77 represents an alloy with 8 per cent sulfide, the same shows noticeable sulfide crystals (magnification II7.) Fig. 78 shows an alloy of 95 per cent $\mathrm{Cu}_{2} \mathrm{~S}$ with metal inclusions (magnification II 7).

\section{Silver-Silver Sulfide.}

Nearly the same equilibrium diagram as described above is found for the system silver-silver sulfide, which has been investigated by Friedrich and Leroux * the miscibility of the com-

\footnotetext{
* Metallurgie, 3, 36r (I906).
} 


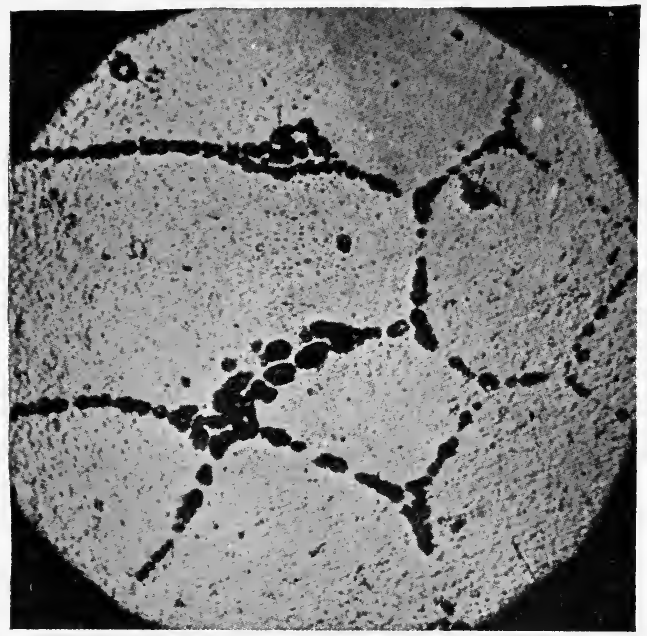

Fig. 76.- $\mathrm{Cu}-\mathrm{Cu}_{2} \mathrm{~S}$; 0.49 Per Cent $\mathrm{Cu}_{2} \mathrm{~S}$; Strings of Eutectic in Ground Mass of Metal (Heyn and Bauer). XII7.

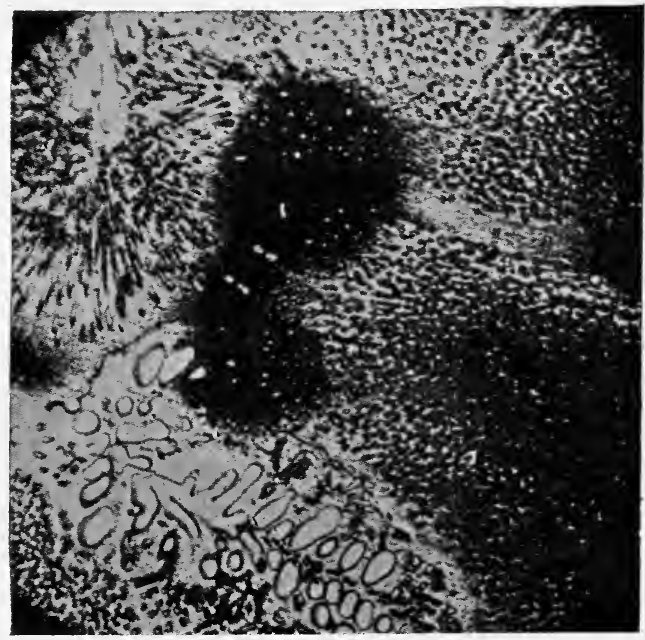

Fig. 77. $-\mathrm{Cu}-\mathrm{Cu}_{2} \mathrm{~S} ; 8$ Per Cent $\mathrm{Cu}_{2} \mathrm{~S}$; Noticeable Sulfide Crystallites (Heyn and Bauer). $\times_{\text {II } 7}$. 
ponents in the liquid state is also limited here. There exists a mixing interval (at $906^{\circ}$ for solutions with a content between I.3 and 97 per cent sulfide). For all mixtures whose composition lies between these limits there exists a constant temperature for the precipitation of metal $\left(906^{\circ}\right)$. Solutions with a content less than $\mathrm{I}_{3}$ per cent show higher crystallization temperatures; the corresponding curve limb has its origin in the melting point of the pure metal. The remaining curve limb, the limb for the precipitation of the sulfide out of the rich melt which starts at the melting point of that compound, $835^{\circ}$ and that for the crystalliza-

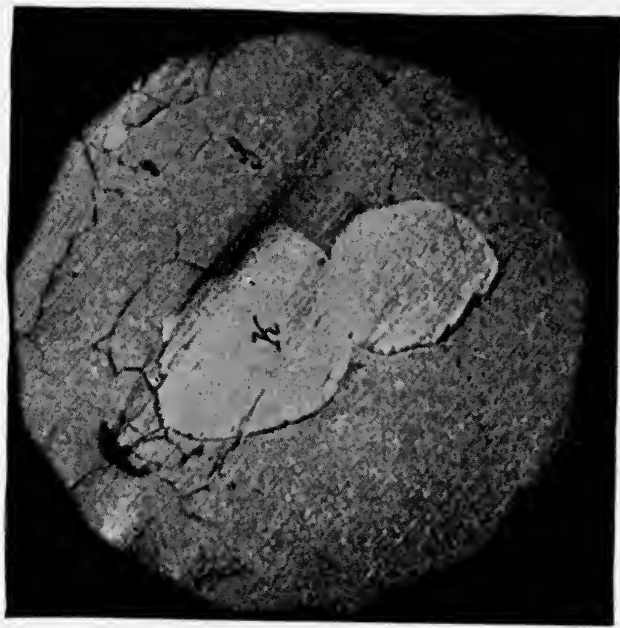

Fig. $78 .--\mathrm{Cu}_{-} \mathrm{Cu}_{2} \mathrm{~S}$; Metal Inclusion $\mathrm{K}$ (Heyn and Bauer). $\mathrm{XII7}$

tion of metal from high percentage melts, which turns off horizontally at $906^{\circ}$, are yet to be observed, only the eutectic temperature at which the two cut is known, namely, $807^{\circ}$. In the cooling curves of the alloys there is shown a still further point of arrest at $175^{\circ}$ at which an allotropic transition of the sulfide occurs.

\section{Iron-Iron Sulfide.}

The partial miscibility between metals and sulfides appears to be the rule; at least we find still others like the systems con- 
sidered. Treitschke and Tammann * found these phenomena also for the mixtures of iron with iron sulfide, since the two liquids are very viscous, layer formation does not take place, but an emulsion of the two melts forms. The mixing gap at $1400^{\circ}$ lies between 20 and 92 per cent metal. The miscibility of the components is also continued in the solid state but is only partial. A solid solution of little sulfide is known in $\gamma$ iron (c) and also of

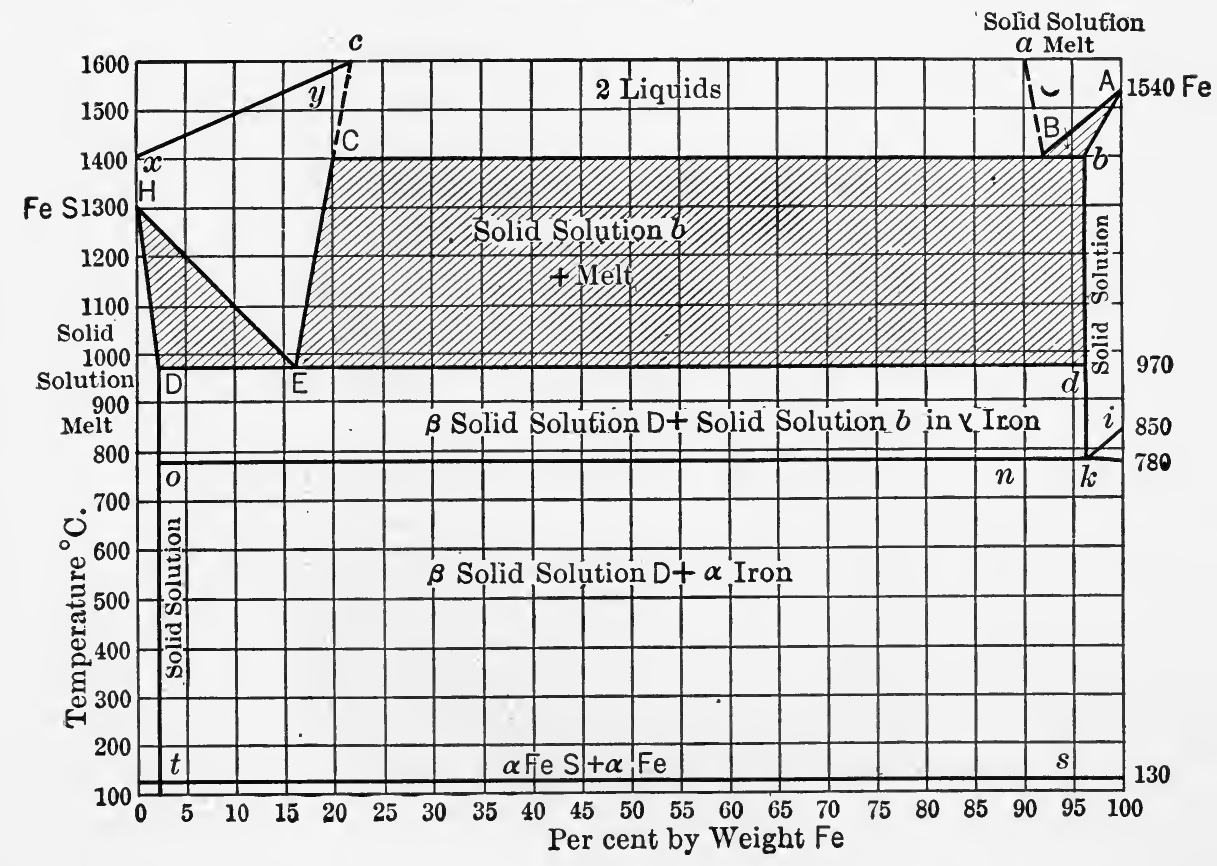

FIG. 79.

iron in $\beta$ sulfide $(D)$. The first separate on cooling with the precipitation of iron (along $i k$ ). Thereby the solid solution is enriched in sulfide up to a content of 4 per cent at $780^{\circ}$, below this temperature it decomposes to a solid mixture of $\alpha$ ferrite and solid solution $D$ which at $128^{\circ}$ undergo an allotropic modification into $\alpha$ sulfide. The complicated equilibrium diagram is shown in Fig. 79.

*Z. anorg. Chem., 49, 320 (rgo6). 


\section{Nickel-Nickel Sulfide.}

The diagram for alloys of nickel and nickel sulfide studied by Bornemann* which is given in Fig. 80 is still more complicated. The only sulfide capable of existence in the molten state has the

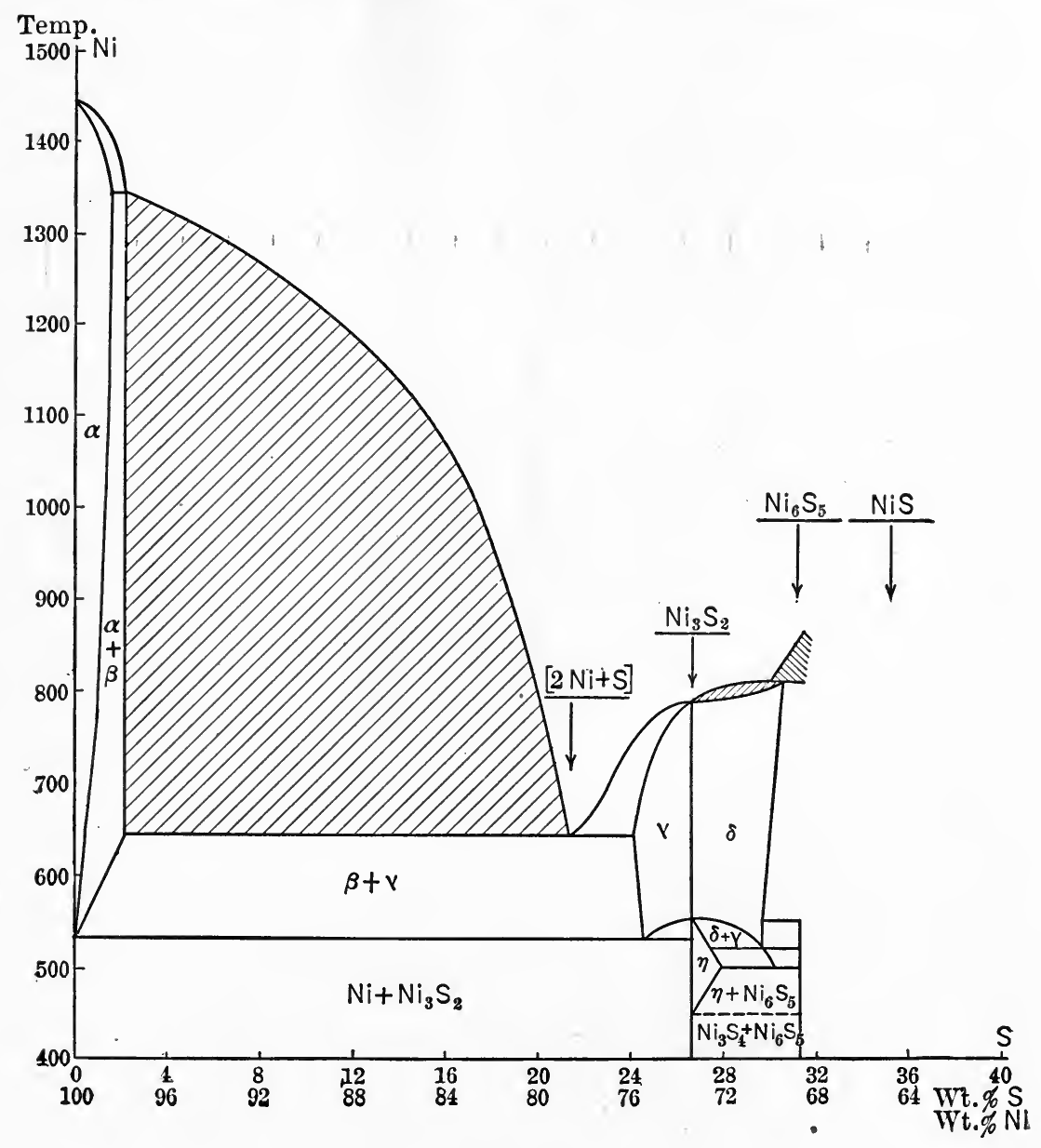

FIG. 80.

composition $\mathrm{Ni}_{3} \mathrm{~S}_{2}$; at low temperatures still further compounds exist namely $\mathrm{NiS}, \mathrm{Ni}_{3} \mathrm{~S}_{4}, \mathrm{NiS}_{2}$ and apparently also $\mathrm{Ni}_{6} \mathrm{~S}_{5}$. As in all nickel containing systems, the tendency to form solid solu-

* Metallurgie, 5, I3 (rgo8). 
tions is very great; there precipitates from the melt principally solid solutions which separate from the melt in a very complex way.

\section{Alloys Between Sulfides.}

In the metallurgy of copper, nickel and lead, there occur as important intermediate products, the so-called mattes, copper matte, lead matte and nickel matte, alloys of the corresponding sulfides with iron sulfide. It is of importance to obtain a picture of their important structural constituents. In many cases compounds occur between the components, in part these are such as occur in nature as ores, we have accordingly before us a field which must arouse the interest of the smelterman to a high degree. Here also metallographic methods give the explanation of the nature and formation of these products.

In most cases the equilibrium diagrams are comparatively simple. Out of the melts, miscible in all proportions the components crystallize on solidification in the pure state. The diagram consists of two curves which cut in a eutectic point. This form we find in all alloys in which lead and zinc sulfide occur as components. The melting points of the components, the position of the eutectic temperature as well as the composition of the eutectic alloy are given in the following table:

\begin{tabular}{|c|c|c|c|c|c|c|}
\hline \multicolumn{2}{|c|}{ Components. } & \multicolumn{2}{|c|}{ Melting Point. } & \multirow{2}{*}{$\begin{array}{c}\text { Eutectic } \\
\text { Tempera- } \\
\text { ture. } \\
\text { Degrees C. }\end{array}$} & \multirow{2}{*}{$\begin{array}{l}\text { Composition } \\
\text { of Eutectic. }\end{array}$} & \multirow{2}{*}{ Observer. } \\
\hline A. & $B$. & $\begin{array}{c}A . \\
\text { Degrees C }\end{array}$ & $\begin{array}{c}B . \\
\text { Degrees C. }\end{array}$ & & & \\
\hline $\mathrm{PbS}$ & $\mathrm{FeS}$ & II 4 & II 87 & 863 & $70 \% \mathrm{~A}$ & \\
\hline $\mathrm{PbS}$ & $\mathrm{AgS}$ & III 4 & 835 & 630 & $77 \% \mathrm{~A}$ & \\
\hline $\mathrm{PbS}$ & $\mathrm{CuS}$ & III 4 & I I 2 I & 535 & $49 \% \mathrm{~A}$ & - \\
\hline $\mathrm{ZnS}$ & $\mathrm{PbS}$ & 1600 & III4 & IO44 & $6 \% \mathrm{~A}$ & K. Friedrich ${ }^{*}$ \\
\hline $\mathrm{ZnS}$ & $\mathrm{AgS}$ & 1600 & 835 & 807 & $3 \% \mathrm{~A}$ & 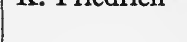 \\
\hline $\mathrm{ZnS}$ & $\mathrm{FeS}$ & 1600 & I I 7 I & II 62 & $5 \% \mathrm{~A}$ & \\
\hline $\mathrm{ZnS}$ & $\mathrm{CuS}$ & 1600 & I I 2 I & $\left.\begin{array}{l}\text { near } \\
\text { II2I }\end{array}\right\}$ & ? & \\
\hline
\end{tabular}

* Metallurgie, 4, 479 (1907); 4, 672 (1907); 5, I14 (1908).

There are also cases in which solid solutions occur between the components; in the system copper sulfide, silver sulfide 
which has been investigated by Friedrich * there appears to be present complete miscibility in the solid state. The solidification curve has a minimum at $677^{\circ}$. The following table shows the dependence of the solidification point on the composition:

\begin{tabular}{|c|c|c|c|c|c|}
\hline \multicolumn{2}{|c|}{ Composition. } & \multirow{2}{*}{ r. P. } & \multicolumn{2}{|c|}{ Composition. } & \multirow{2}{*}{ F. $P$. } \\
\hline $\mathrm{Ag}_{2} \mathrm{~S}$. & $\mathrm{Cu}_{2} \mathrm{~S}$. & & $\mathrm{Ag}_{2} \mathrm{~S}$. & $\mathrm{Cu}_{2} \mathrm{~S}$. & \\
\hline 100 & $\ldots \ldots$ & 835 & 40 & 60 & 791 \\
\hline 90 & IO & 749 & 30 & 70 & 876 \\
\hline 80 & 20 & 698 & 20 & 80 & 945 \\
\hline 70 & 30 & 677 & I0 & 90 & 1050 \\
\hline 60 & 40 & 688 & $\ldots \ldots \ldots$ & 100 & I I $2 I$ \\
\hline 50 & 50 & 719 & & & \\
\hline
\end{tabular}

According to the investigation of $\mathrm{P}$. Röntgen there are a number of compounds which occur between the components of copper matte; those recognizable by a maximum in the solidification diagram are $\left(\mathrm{Cu}_{2} \mathrm{~S}\right)_{3} \cdot \mathrm{FeS}, \mathrm{Cu}_{2} \mathrm{~S} \cdot \mathrm{FeS}$ and probably a third $\left(\mathrm{Cu}_{2} \mathrm{~S}\right)_{2}(\mathrm{FeS})_{5}$; also in the system silver sulfide-antimony sulfide we find a maximum at the places on the diagram which represent the composition of the compounds $\mathrm{Sb}_{2} \mathrm{~S}_{3} \mathrm{Ag}_{2} \mathrm{~S}$ and $\mathrm{Sb}_{2} \mathrm{~S}_{3} \cdot 3 \mathrm{Ag}_{2} \mathrm{~S}$. Both occur naturally, the first as miargyrite, and the last as pyrargyrite or ruby silver ore.

The position of the melting point of the components and compounds (maxima) as well as the co-ordinates of the eutectic point are given for the two systems in the following table:

\begin{tabular}{|c|c|c|c|c|}
\hline $\begin{array}{l}\text { Components and } \\
\text { Compounds. }\end{array}$ & $\begin{array}{l}\text { Melting } \\
\text { Points and } \\
\text { Maxima., } \\
\text { Degrees. }\end{array}$ & $\begin{array}{l}\text { Eutectic } \\
\text { Temp., } \\
\text { Degrees. }\end{array}$ & $\begin{array}{l}\text { Composition of Eutectic } \\
\text { Alloy. }\end{array}$ & Observer. \\
\hline $\begin{array}{l}\mathrm{Cu}_{2} \mathrm{~S} \ldots \ldots \ldots \\
(\mathrm{Cu}, \mathrm{S})_{3} \mathrm{FeS} \ldots \ldots\end{array}$ & $\begin{array}{l}1085 \\
1065\end{array}$ & 995 & $\mathrm{Cu}_{2} \mathrm{~S}, 2 \mathrm{I} .8 \% ; \mathrm{FeS}, 78.2 \%$ & P. Rontgen \\
\hline $\begin{array}{l}\mathrm{Cu}_{2} \mathrm{~S} \mathrm{FeS} \ldots \ldots \\
\left(\mathrm{Cu}_{2} \mathrm{~S}\right)_{2}(\mathrm{FeS})_{5} \ldots\end{array}$ & $\begin{array}{r}1030 \\
980\end{array}$ & 1000 & $\mathrm{Cu}_{2} \mathrm{~S}, 67 \% ; \mathrm{FeS}, 33 \%$ & \\
\hline $\begin{array}{l}\mathrm{FeS} \ldots \ldots \ldots \ldots \ldots \\
\mathrm{Sb}_{2} \mathrm{~S}_{3}\end{array}$ & $\begin{array}{r}\text { II } 33 \\
562\end{array}$ & 895 & $\mathrm{Cu}_{2} \mathrm{~S}, 33 ; \mathrm{FeS}, 67 \%$ & \\
\hline $\mathrm{Sb}_{2} \mathrm{8}_{3}, \mathrm{Ag}_{2} \mathrm{~S} \ldots \ldots$ & 503 & 438 & $\mathrm{Sb}_{2} \mathrm{~S}_{3}, 82.5 \%, \mathrm{Ag}_{2} 8, \mathrm{I} 7.5 \%$ & Pelabon \\
\hline $\mathrm{Sb}_{2} \mathrm{~S}_{3} \cdot{ }_{3} \mathrm{Ag}_{2} \mathrm{~S} \ldots \ldots$ & $\ldots \ldots \ldots$ & 440 & $\mathrm{Sb}_{2} \mathrm{~S}_{3}, 46.3 \% ; \mathrm{Ag}_{2} \mathrm{~S}, 5_{52.7 \%}$ & \\
\hline $\mathrm{Ag}_{2} \mathrm{~S} \ldots \ldots \ldots \ldots$ & 830 & 454 & $\mathrm{Sb}_{2} \mathrm{~S}_{3}, 2 \mathrm{I} \% ; \mathrm{Ag}_{2}, 8.79 \%$ & \\
\hline
\end{tabular}

* Metallurgie, 4, 67r (1907). 
We meet very complex relations in the nickel sulfide-iron sulfide alloys. The equilibrium diagram is given by Bornemann (Fig. 8I). The sulfides $\mathrm{FeS}$ and $\mathrm{Ni}_{3} \mathrm{~S}_{2}$ combine with each other to a compound $(\mathrm{FeS})_{2} \mathrm{Ni}_{3} \mathrm{~S}_{2}$ which is capable of forming solid solutions with the nickel sulfide in all proportions; at low temperatures different transformations go on, the nature of which is not entirely clear. Also the nickel sulfide $\mathrm{Ni}_{2} \mathrm{~S}$ not existent in

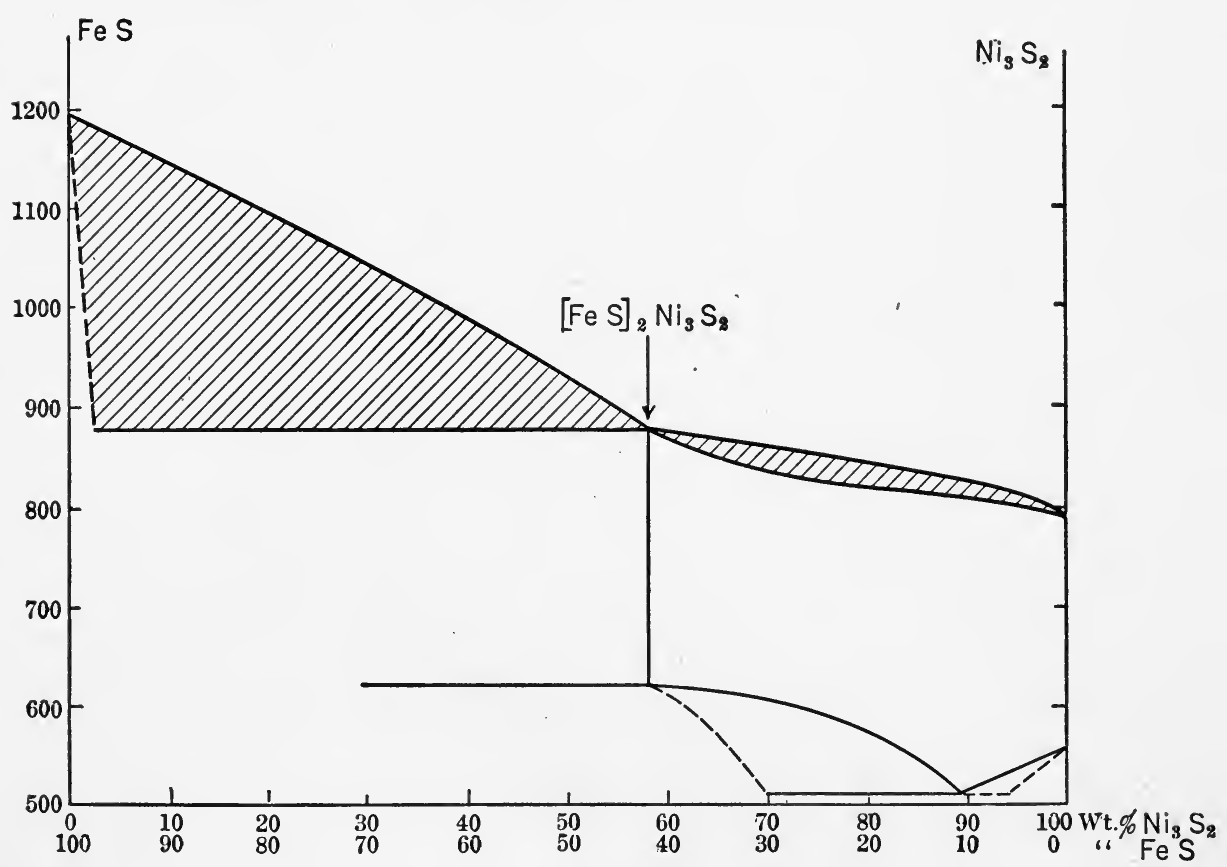

Fig. 8r.

the pure state forms with the iron sulfide a complex compound. Out of the melt crystallizes $(\mathrm{FeS})_{2} \mathrm{Ni}_{2} \mathrm{~S}$ which, on cooling to $575^{\circ}$, splits up into $(\mathrm{FeS})_{3}\left(\mathrm{Ni}_{2} \mathrm{~S}\right)_{2}$ and iron sulfide. At still lower temperatures there forms from the double sulfide with excess of iron sulfide, the further compound $(\mathrm{FeS})_{4} \mathrm{Ni}_{2} \mathrm{~S}$.

\section{Phosphorus and Arsenic Containing Alloys.}

Phosphides may also dissolve in a molten metal and are capable of forming solid solutions to a certain degree in the solid state. 
There is at least the case of copper phosphide $\mathrm{Cu}_{3} \mathrm{P}$ which is soluble up to I.2 per cent in solid copper and also the case of iron phosphide.

The system copper-phosphorus has been investigated by Heyn and Bauer.* Copper phosphide $\mathrm{Cu}_{3} \mathrm{P}$ and phosphide saturated copper crystals are the occurring structure components. The melting point of the pure phosphide lies at $1023^{\circ}$. The eutectic alloy of these components melts at $708^{\circ}$ and contains 8.27 per cent $\mathrm{P}$. Alloys very rich in phosphorus which contain more than I4.I per cent (representing $\mathrm{Cu}_{3} \mathrm{P}$ ) are made up of a solid solution of the above-named phosphide with a second which has the possible composition $\mathrm{Cu}_{5} \mathrm{P}_{2}$.

In the system iron-phosphorus, J. E. Stead $†$ ascertained the occurrence of compounds of composition $\mathrm{Fe}_{3} \mathrm{P}$ and $\mathrm{Fe}_{2} \mathrm{P}$. The alloys of the metal and the phosphide $\mathrm{Fe}_{3} \mathrm{P}$ show in their equilibrium diagram great similarity with those previously mentioned. Solid solutions of iron with phosphide which, as a maximum, contain 1.7 per cent $\mathrm{P}$, that is, 10.9 per cent $\mathrm{Fe}_{3} \mathrm{P}$ also form here.

Alloys rich in phosphide consist of a eutectic of 10.2 per cent phosphorus, in which, with a content of under I0.2 per cent, solid solutions are embedded; with I0.2-I5.6 per cent wellformed rhombic phosphide crystals are embedded. The eutectic itself is a fine mixture of saturated solid solution with phosphide crystals. The pure phosphide $\mathrm{Fe}_{3} \mathrm{P}$ contains I 5.6 per cent phosphorus and melts at $1060^{\circ}$. Under the microscope the single structure constituents can be readily recognized. On this basis we give several microphotographs of the same here (see Figs. 82-85).

Alloys with still higher phosphorous contents consist of the two phosphides $\mathrm{Fe}_{3} \mathrm{P}$ and $\mathrm{Fe}_{2} \mathrm{P}$, which can be easily separated in the powdered state by means of a magnet. The compound poor in phosphorus is magnetic, while the other is not. Concerning the equilibrium diagram in this field no close investigation has been made.

* Metallurgie, 4, 242, 287 (I907).

$\dagger$ J. Iron and Steel Inst., I900, II, 60. 
The smelterman meets arsenic containing alloys* in the working of arsenical ores. By reduction of previously roasted ores one obtains the so-called speiss; alloys of arsenides of dif-

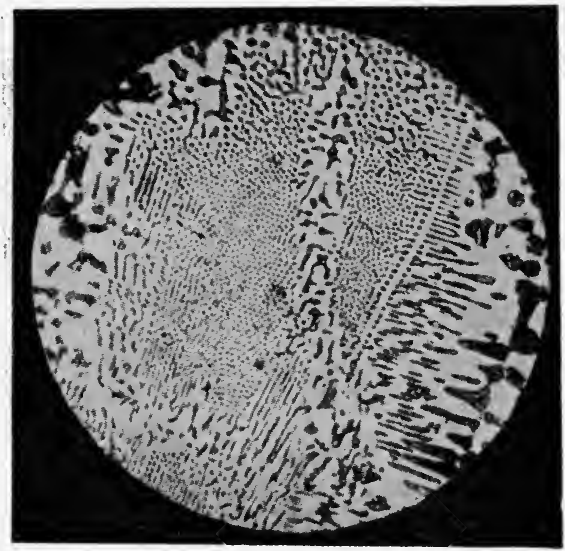

Fig. 82.-Fe-Fe 3 P Alloy; 10.2 Per Cent P; Eutectic (J. E. Stead). $\quad{ }_{35}$.

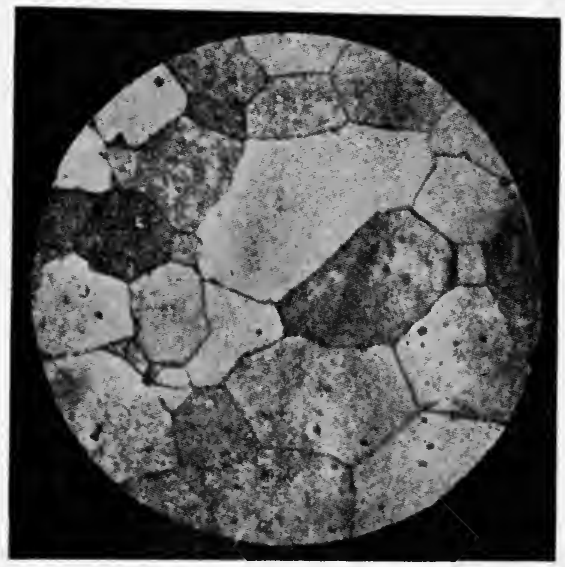

Fig. 83.-Solid Solution of $\mathrm{Fe}$ with $\mathrm{Fe}_{3} \mathrm{P} . \quad$ (J. E. Stead). $\quad \mathrm{X}_{50}$.

ferent metals. The nickel and cobalt speiss that occurs as an intermediate product in the reduction of nickel from arsenical nickel ores is a mixture which consists essentially of iron and

${ }^{*}$ For arsenic alloys in general, see K. Freidrich, Metallurgie, 3, 4I (r9o6); $4,200(1907)$. 
nickel arsenides. To get a glimpse into the constitution of this speiss, K. Friedrich and his co-workers carried out a series of investigations on the alloys of metals with arsenic. They have,

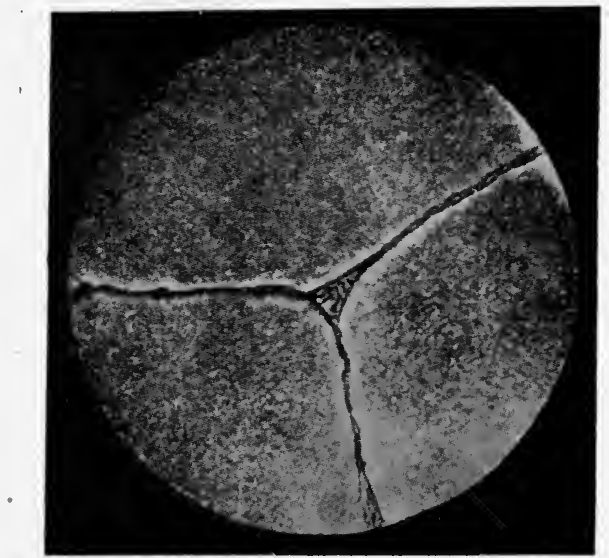

FIg. 84.-Fe-Fe ${ }_{3}$ P Alloy; r.8 Per Cent P; Three Polygonal Solid Solution Crystals, the Interstices are Filled with Eutectic. (J. E. Stead). $\times_{350}$.

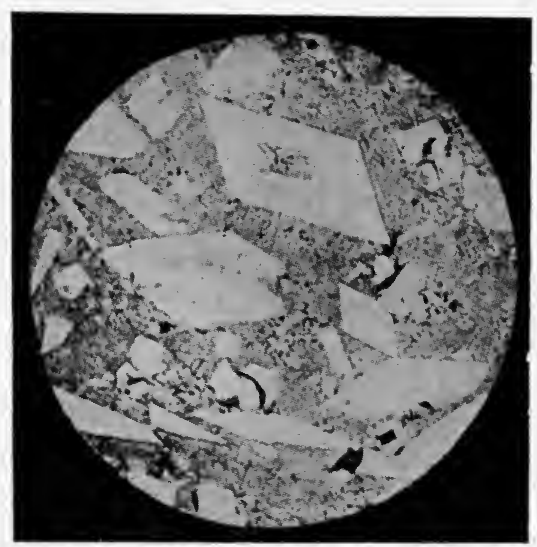

Fig. 85.-Fe-Fe ${ }_{3} \mathrm{P}$ Alloy; Ir.97 Per Cent P; Crystals of $\mathrm{Fe}_{3} \mathrm{P}$ Embedded in Eutectic (J. E. Stead). $\times 60$.

so far as possible, established the crystallization diagram and investigated the solidified mixtures metallographically for their structure constituents, the diagrams can not be completed as 
arsenic is a volatile element and is distilled by high temperatures from quite dilute melts. The nature of the measurements allow the investigation of only those solutions whose vapor pressure is lower than atmospheric.

The relations of the lead arsenic alloys are very simple, both components separating in the pure state. The pictures show distinct arsenic crystals but no compounds. The eutectic temperature is $292^{\circ}$ and the melt contains $2.5-3.0$ per cent arsenic. The eutectic point of the silver alloy, $527^{\circ}$, has been established by the cooling experiments. Compounds as constituents do not have to be considered here and the same is true of the system zinc-arsenic.

Two compounds are formed by melting together arsenic and copper. The melting point, that is, the solidification maximum of one, $\mathrm{Cu}_{3} \mathrm{As}$ lays at $830^{\circ}$, the maximum for the second $\mathrm{Cu}_{5} \mathrm{As}_{2}$ is hidden, since the latter compound changes at $710^{\circ}$, into the first. The eutectic data for the mixture of copper with $\mathrm{Cu}_{3} \mathrm{As}$ is $683^{\circ}$ and an arsenic content of 22 per cent, for the mixture of $\mathrm{Cu}_{5} \mathrm{As}_{2}$ with an unknown arsenic-rich product is $600^{\circ}$ and 47 per cent. In the existence field of the arsenide $\mathrm{Cu}_{5} \mathrm{As}_{2}$ a transition point of $307^{\circ}$ is observed; what change takes place there is not known.

The speiss-formers proper, iron arsenide and nickel arsenide, have been carefully investigated and with them, is known with certainty, the occurrence of compounds on the one hand and of solid solutions on the other. The constitution of these alloys can best be recognized from the equilibrium diagram. (Figs. 86 and 87.)

With iron arsenic (see Fig. 86) five different kinds of crystals are observed inside of the interval 91.6-44 per cent iron. Under this we find with certainty the two arsenides $\mathrm{Fe}_{2} \mathrm{As}_{2}$ and $\mathrm{Fe}_{2} \mathrm{As}$ possibly also FeAs. The solidification point of the last two lay at $919^{\circ}$ and $1030^{\circ}$, respectively. The compound $\mathrm{Fe}_{3} \mathrm{As}_{2}$ does not crystallize directly from the melt but is the product of a transformation which takes place at $800^{\circ}$ and with an arsenic content of 40 to 57 per cent. The nature of the iron rich crystals which precipitate out of the melt at iron-contents between 92 


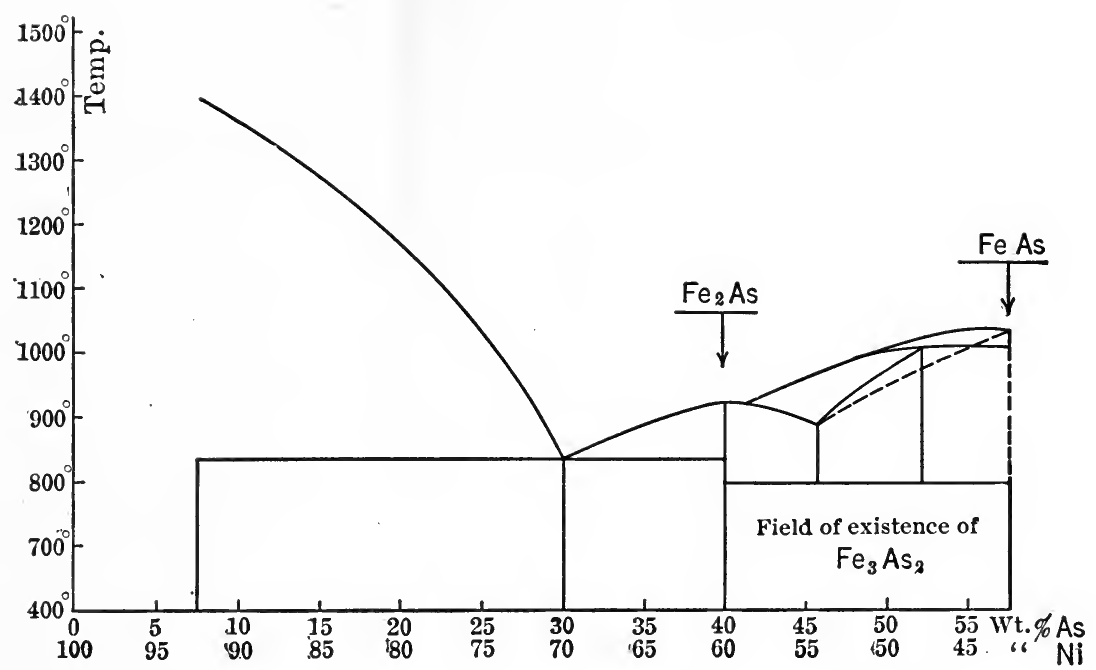

Fig. 86.

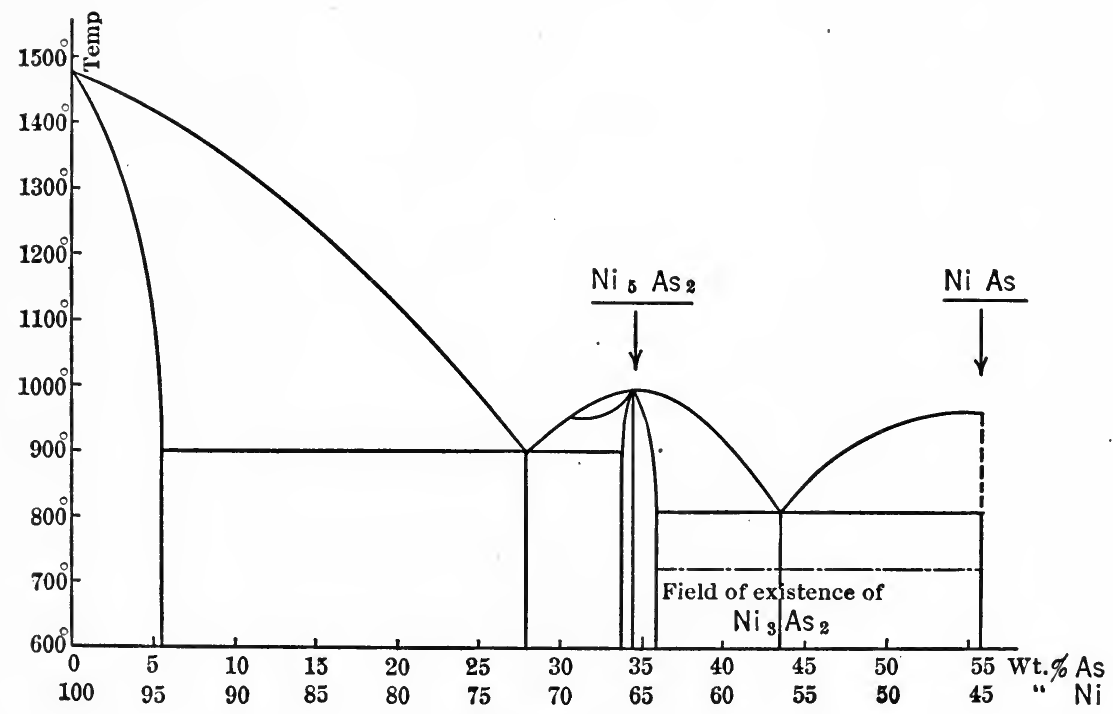

Fig. 87 . 
and 70 per cent is not entirely clear, but they are probably a solid solution of iron and some of its arsenides. By cautious cooling there occurs at $1000^{\circ}$ a transition in which crystals of $\mathrm{FeAs}$ react with the melt with the formation of a kind of crystals of which one conceives either as a further compound $\mathrm{Fe}_{5} \mathrm{As}_{4}$ or as a solid solution. With quick cooling this reaction does not always take place.

With the nickel arsenic alloys (Compare Fig. 87) there is shown the probable existence of the compounds $\mathrm{Ni}_{5} \mathrm{As}_{2}$ and $\mathrm{NiAs}$, also possibly $\mathrm{Ni}_{3} \mathrm{As}_{2}$. The solidification maximum for $\mathrm{Ni}_{5} \mathrm{As}_{2}$ is found at $998^{\circ}$, that for NiAs at $968^{\circ}$. The first of these compounds experiences an allotropic transformation that takes place not far below the melting point. As with all nickel compounds we meet here also the decided tendency for the formation of solid solutions. We observe limited miscibility between $\mathrm{Ni}_{5} \mathrm{As}_{2}$ and metallic nickel with a mixing interval between 5.4 and 33.5 per cent arsenic and also a slight solid solution formation between the two arsenides $\mathrm{Ni}_{5} \mathrm{As}_{2}$ and $\mathrm{NiAs}$; in these the first of the two components is the solvent. The arsenic richer crystallizes out of the melt in the pure state. The compound $\mathrm{Ni}_{3} \mathrm{As}_{2}$ does not form directly out of the liquid melt but owes its existence to a decomposition in the solid state which takes place in the temperature interval $700-750$ degrees.

\section{Silicides of the Metals.}

Concerning the constitution of the metallurgically important silicide systems the investigations of Tammann * and of Rudolphi $\dagger$ have been submitted.

Iron silicon compounds that we have already met in the discussion of special steels, are of the greatest importance; we mentioned there that an iron silicide with a crystallization maximum of $\mathrm{II}_{4} 3^{\circ}$ is known and that the existence of a second $\mathrm{Fe}_{2} \mathrm{Si}$ is probable which forms with iron a continuous series of solid solutions. The crystallization of the pure compound out of the melt can only take place inside of a very limited field of concentration, and accordingly, in the microscopical way is difficult to

* Z. anorg. Chem., 49, 93 (rgo6). $\dagger$ Z. anorg. Chem., 53, 216 (1907). 
recognize. It occurs, however, in a eutectic in which the second component is the silicide FeSi. The formation of this takes place at $1242^{\circ}$ and 34.6 atom-per cent of silicon. The eutectic point for a mixture of silicon and the compound FeSi lies at a concentration of 75 atom-per cent and a temperature of $1240^{\circ}$. The equilibrium diagram (Fig. 88) shows best the relation of the occurring structure components to each other.

Out of the liquid melt of copper and silicon there precipitates, from suitable concentrations, the compound $\mathrm{Cu}_{3} \mathrm{Si}$. The

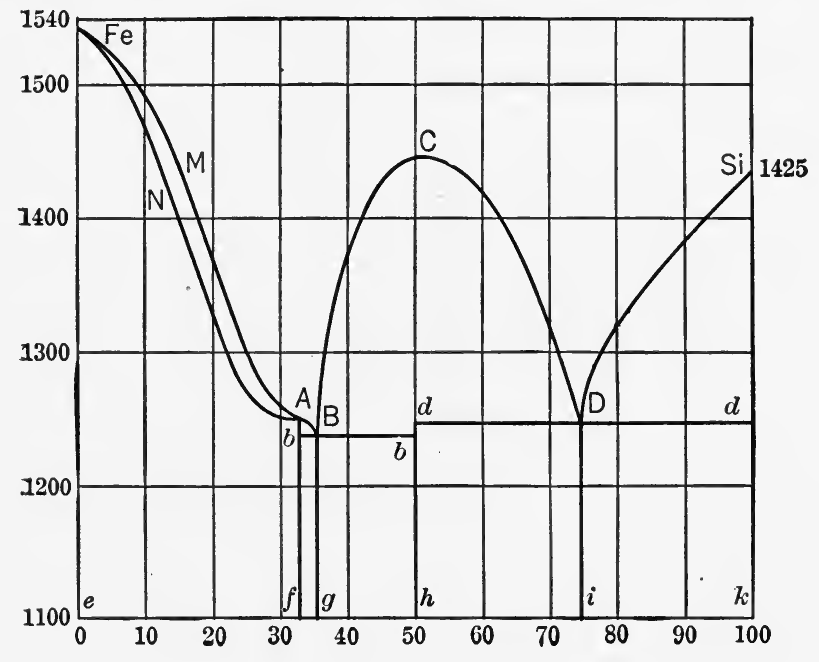

Fig. 88.

melting point of the same lies at $862^{\circ}$ (crystallization maximum). It forms with the metal two series of solid solutions ( $a$ and $b$ ) which merge into each other with the melt at $849^{\circ}$. A eutectic of the solid solution $b$ and $\mathrm{Cu}_{3} \mathrm{Si}$ is met at $820^{\circ}$ and the content of the melt of 9.79 per cent silicon. The eutectic consisting of $\mathrm{Si}$ and $\mathrm{Cu}_{3} \mathrm{Si}$ crystals forms at $8 \mathrm{II}^{\circ}$ and an $\mathrm{Si}$ content of the melt of $17.6 \mathrm{I}$ per cent. In the cooling of the solidified mass reactions take place. Between $780^{\circ}$ and $815^{\circ}$ the solid solution $b$ breaks up into solid solution $a$ and a third kind of solid solution $c$, which in turn goes over at $710^{\circ}$ into a solid solution, and crystals of the composition $\mathrm{Cu}_{19} \mathrm{Si}_{4}$. 
Still more complex-as always in the presence of nickelare the relations of the system nickel-silicon. We meet there, according to the investigations of Guertler and Tammann* the compounds $\mathrm{Ni}_{2} \mathrm{Si}, \mathrm{Ni}_{3} \mathrm{Si}_{2}, \mathrm{NiSi}$ and probably also $\mathrm{Ni}_{2} \mathrm{Si}_{3}$, of these the first forms a solid solution series with the metal with a mixing interval. It is also possible to form such a series with $\mathrm{NiSi}$. The latter compound $\mathrm{Ni}_{2} \mathrm{Si}_{3}$ dissociates into silicon and melt so that its crystallization maximum is concealed, on the other hand it occurs in an $\alpha$ and $\beta$ modification. The silicide $\mathrm{Ni}_{3} \mathrm{Si}_{2}$ results through a change in the solid state. It would be going too far to enumerate all the peculiarities here.

\section{The Phase Rule.}

We will now turn to a general question, after we have learned the large number of single systems and the great multiplicity of phenomena which we can have with alloys of metals with other metals, and of metals with compounds of metallic character, or, finally, with alloys of such among themselves.

We have seen that with our material all different kinds of structural components may appear side by side. We have seen the components as such in the solid state, we see them in compounds with one another, we have learned their capability of forming solid solutions with one another or with the compounds. The elements as well as the compounds are frequently capable of existing in many modifications. A great abundance of phenomena, concerning the liquid melt and the vapor, we have not once mentioned.

We are driven to the question: "Can all the different forms we have met in the complex alloy systems-say in the alloys of nickel and sulfur exist simultaneously side by side or is there a definite limit. The experience which we have had in these considerations has taught us that these are only able to exist under determined external conditions of temperature, composition and pressure. These are the factors which restrict the existence, the appearance and disappearance of all possible forms of matter."

*Z. anorg. Chem., 49, 92 (I906). 
Before we proceed to the answering of the question we will introduce a conception with which we will operate much in the future.

As soon as we allow the melt to solidify the product ceases to be homogenous; we may, as the pictures show, recognize more or less definitely different space divisions. These spaces of the system, distinguished by chemical relations and by the mixture relations of the components are designated by W. Gibbs as phases. He considered, however, separate parts of identical nature as belonging to the same phase. At this place it should be remarked that a solid eutectic which in metallography is considered a single structural component must be regarded as two phases, it consists as one may readily be convinced by strong magnification of an intimate mixture of two different kinds of crystals.

As phases we can take the different kinds of solid components, however, besides these the liquid and vapor are to be considered as such. In a heterogeneous system one can usually have a number of phases together; vapor and liquid, solid crystals and melt, as we have seen are often compatible with each other.

In 1874 , before the development of metallography, the American physicist, Willard Gibbs, derived the rule from general thermodynamics which states, without consideration of the special chemical nature of the heterogenous system, how many phases, as a maximum for a given system, can exist side by side and be in equilibrium with each other. ${ }^{*}$ The number of phases depends on the number of variables present. From this mass of variables we designate the simplest chemical constituents as the components of the system; the different kinds of physical influ. ences to which the system is exposed, also come into consideration as variables. $\dagger$ The latter are rather numerous, we can electrify and magnetize the system, we can light it with different colored light, we can heat it and treat it in different ways mechanically. If we, however, limit the consideration to the action of

* Thermodynamic Studies, Trans. Conn. Acad. i I (I874).

$\dagger$ For detailed applications of the phase rule, see "The Phase Rule," W. D. Bancroft; "The Phase Rule and its Applications," Alexander Findlay. 
temperature and pressure the phase rule of Gibbs can be stated as follows:

The sum of the phases $P$ and the degrees of freedom $F$, which the system possesses are equal to the number of components $N$ increased by 2 , the number of physical variables temperature and pressure.

$$
F+P=N+2 .^{*}
$$

We will now try, by the use of known examples, to make clear the use of the phase rule.

First, we consider a system of one component, the co-existence of the different states of a single substance which does not suffer chemical change; we know that vapor and liquid can exist side by side and the phase rule says that, since the number of phases, is 2 , and the component number is $I$, the system must possess one degree of freedom, that is, we have freely at our disposal one variable, temperature or pressure without thereby endangering the coexistence of the two phases. If we have, at our disposal, the temperature, the pressure is established at which both states can coexist. To every temperature there corresponds an entirely determined equilibrium pressure, the vapor pressure. If we also have at our disposal the pressure one of the two phases disappears, by raising above the vapor pressure, the vapor, by lowering, the liquid. The two are only stable side by side if the exact vapor pressure prevails. If we do not hold the temperature constant and have, at our disposal, the pressure so there appears for every pressure an entirely determined boiling temperature. Vapor pressure and temperature are inseparably con-

* A more complete statement of the phase rule is given by T. W. Richards, J. Am. Chem. Soc., 37, 464 (I9I5). It is as follows: $F=\left(n_{i}+n_{E}\right)-\left(n_{\phi}+n_{r}\right)$, where $F=$ variance, $n_{i}=$ number of individuals, $n_{E}=$ number of physical manifestations of energy brought into play, $n_{\phi}=$ the number of phases, and $n_{r}=$ the number of independent restrictions placed on the system, but not included in the definition of individuals. The individuals of any reacting system are the separate chemical substances, undecomposed in the reactions concerned, which are necessary to construct the system. The number of such individuals to be chosen is the smallest number necessary to construct the system.

It is frequently necessary in metallurgical systems to use this complete statement, otherwise serious errors may result. 
nected. By the position of one magnitude, the other is clearly determined. The relations are precisely the same if we consider the equilibrium conditions between a solid and vapor.

If we place the demand for the simultaneous existence of three phases the liquid, the solid and the vapor so we have according to the phase rule no degrees of freedom, no possibility of controlling freely temperature and pressure, equilibrium, therefore, exists only at a determined temperature - the melting pointand an entirely determined vapor pressure. These demands of the phase rule correspond now in all cases to our experience. If we, for example, would have two polymorphic substances as solid phases side by side and in equilibrium with them vapor that is only possible at a determined transition point. If one recedes from this equilibrium temperature, a phase disappears overstepping the melting point, causes melting of the solid, under cooling solidification of the liquid, raising of the external pressure causes condensation of the vapor. We come again to a twophase system in which every equilibrium temperature corresponds to a determined equilibrium pressure. Also in the system, solid substance-melt that is the case. The pressure represents a determined melting point and we are able by change of the external pressure to accomplish a displacement of the melting point. The mutual relations of the two-phase system can be seen graphically represented above (see Fig. 89). Every twophase system is expressed by a curve, the three-phase system in a point, the intersection point of the three curves, melting and transition points are such triple points, starting points for a curve triplet in the temperature pressure plane.

With two components and two phases simultaneously present, one can change either the temperature or pressure, without the possibility of breaking up coexistence. For $N=2$ and $P=2$ the phase rule gives $F=2$, that is, two degrees of freedom, if we consider the vapor and melt of a mixture of two substances so there corresponds to a temperature not a single vapor pressure but a multiplicity of the same, every displacement of the mixing relations requires also a change of vapor pressure and boiling temperature. 
The establishment of the vapor pressure and the composition of the melt and vapor, results only by the addition of a third phase, it is immaterial whether it be a second liquid as with substances of limited miscibility or whether it be a solid component.

We recall from our wide consideration of the case that all substances send off some vapor in air or vacuum, the vaporization is often very small and escapes direct observation. We will, therefore, in all cases assume the vapor phase as present.

If we have a liquid alloy, for example, of zinc and cadmium, its concentration as well as the pressure and composition of the vapor phase is fixed, if crystals of one or the other component

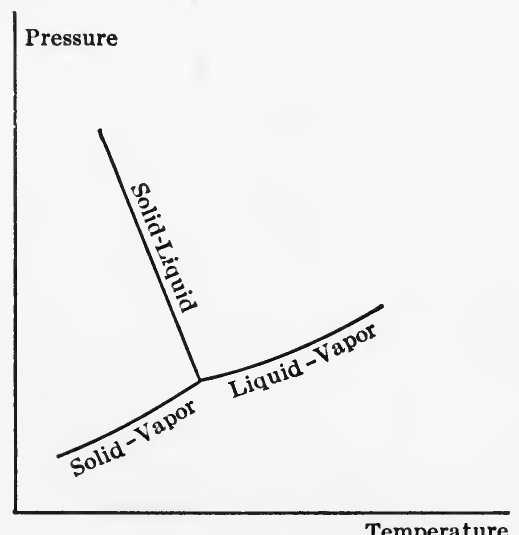

Fig. 89.

precipitate. If we change the temperature the quantitative relations change but the possibility of coexistence of the phases is not endangered. The freedom disappears only if both kinds of crystals are precipitated together from the melt. These are only stable together at a single temperature, the eutectic temperature.

The degree of freedom for complex systems can be deduced at once from the phase rule.

There remains still to mention a much-used and practical nomenclature. Heterogenous systems of one degree of freedom are designated as univariant, of two degrees of freedom as bivari- 
ant, of three trivariant, of more than three multivariant. The system without a degree of freedom is called nonvariant.

What service can the phase rule now render us? It is first of use for the systematizing of different combinations, so that we can orient ourselves, as to the relations of these with respect to temperature and pressure. Concerning the direction of resulting phase displacement as well as concerning the changes which take place in the inside of phases of variable composition-concentration changes in solution and vapor-it allows us to make no predictions.

It is frequently an important criterion, e.g., when it is used to establish whether a complex system that possesses many phases is in equilibrium or whether it is in the labile state. An excellent example of the use of the phase rule in this direction is given us in the above treated system iron-carbon, where we see occurring as the structural components of this two component system, besides the always present gas phase, cementite, graphite, solid solution or cementite graphite and ferrite, over a large temperature interval. The phase rule says at once that theoretically this combination of four phases can only exist at one temperature. Accordingly in the interval of observation one of the present structure components must be labile.

We see therefrom that in the investigation of heterogenous systems one may in many cases take advantage of the use of the phase rule; it is certainly suitable to facilitate the preliminary survey. We must remember, however, that it gives us only the numerical relation between the components present, the phases and the possible freedom. It does not make possible a deeper insight into the chemistry of the system. 


\section{CHAPTER IV}

\section{THE METALLURGICAL REACTIONS-OXIDATION AND REDUCTION}

We have carefully considered in the earlier chapters, the properties of metals, their changes of state, and the phenomena which occur in the mixing of metals with each other and with compounds of metallic character, and we have seen the value of physico-chemical methods in the field of alloys. The usefulness of physical chemistry in problems which concern alike the chemist and the metallurgist is not thereby exhausted. The reactions which are used in the laboratory and in practice for the extraction of metals from their compounds are elucidated if physical chemistry is applied to the investigation of the equilibrium conditions of the substances participating in these reactions.

The metallurgical reactions give to the physical chemist a large number of problems of very great theoretical as well as practical interest, and there is hardly a field in which the study of chemical equilibrium is so advantageously applied. The conditions which permit us to make observations on the equilibrium are here unusually simple since the range of temperature which the metallurgist has at his disposal is very large and, therefore, within it the equilibrium is measurable for many reactions. As the temperatures used are mostly high the customary reaction velocity is usually sufficiently great for the relatively rapid attainment of the equilibrium, accordingly changes of temperature or of pressure and other conditions can be conveniently observed.

Of the reactions which have proved favorable for the application of chemical statics we will treat the oxidation and reduc- 
tion processes, as well as the decomposition of sulfides with oxygen, the so-called roasting processes, rather thoroughly.

\section{Equilibrium Between Metal, Oxide and Oxygen.}

We have now come to the consideration of the oxidation and reduction processes and will try to make clear, as the first example, the relations which exist between the metals, their oxides and gaseous oxygen.

It is a well-known fact that a large number of metals-we designate them as base-are oxidized even at ordinary temperature, and more rapidly on heating, and it is also known on the other hand, that there are oxides which give off oxygen on heating and leave the pure metal as a residue. The experiment of Scheele, to break down $\mathrm{HgO}$ into its elements, belongs to every course of lectures in experimental inorganic chemistry. The reactions between metals, oxides and oxygen, can, accordingly, run in two opposite directions.

The question now arises, are there not also metals, with which depending on the conditions, both directions of the reaction may be observed? The question is to be answered "yes." LeChatelier found, for example, that silver is such a metal and is oxidized at a temperature of $300^{\circ}$ if the oxygen pressure is more than 15 atmospheres; on the other hand the oxide is decomposed, if the pressure is less than Io atmospheres. The oxygen pressure accordingly appears to play an essential rôle.

\section{The Application of the Phase Rule.}

The kind of equilibrium that exists between oxide, metal and gaseous oxygen can be at once deduced from the phase rule. If the metal and oxide exist as separate phases we have in all, with the gas phase, three phases. The system consists of two components, metal and oxygen. The number of degrees of freedom is accordingly $(P=3, N=2)$.

$$
F+P=N+2 ; F+3=4 .
$$

The system is, therefore, univariant. Every temperature corresponds to a definite oxygen pressure. The process of the oxygen 
liberation from oxides, reminds us of the vaporization of a liquid, where we also met a definite gas pressure, depending on the temperature. This pressure is entirely independent of the relative amounts of the two phases.

\section{Oxygen Tensions of Oxides.}

Lewis * has found the following values for the decomposition tension of silver oxide,

\begin{tabular}{l|l|l|l}
\hline Temperature............. & $302^{\circ}$ & $325^{\circ}$ & $445^{\circ}$ \\
Pressure in atmospheres. & 20.5 & 32 & 307 \\
\hline
\end{tabular}

Pelabon $\nmid$ gives considerably smaller values for $\mathrm{HgO}$, as follows:

\begin{tabular}{|l|r|r|}
\hline Temperature...... & $\begin{array}{r}440^{\circ} \\
\text { small }\end{array}$ & $\begin{array}{r}610^{\circ} \\
1240\end{array}$ \\
\hline
\end{tabular}

The number of metal oxides whose oxygen tension is conveniently observable, that is, somewhere between 20 and 800 millimeters, is not large. A complete series of observations on palladium oxide has been made by L. Wöhler. $\ddagger \mathrm{He}$ found the values collected in the following table:

\begin{tabular}{|c|c|c|}
\hline $\begin{array}{c}\text { Temperature in } \\
\text { Degrees. }\end{array}$ & $\begin{array}{c}\text { Oxygen Tension } \\
\text { Solid Phase } \\
\text { PdO, Pd in } \\
\text { mm. .. }\end{array}$ & $\begin{array}{c}\text { Oxygen Terision } \\
\text { Solid Phase, } \\
\text { PdO, Solution of } \\
\text { PdO in Pd, in } \\
\text { mm. }\end{array}$ \\
\hline 756 & 67 & 67 \\
808 & 212 & 239 \\
812 & 230 & $\ldots \ldots \ldots .$. \\
840 & 414 & 483 \\
850 & 5 IO & 566 \\
864 & 634 & 766 \\
\hline
\end{tabular}

In the consideration of this table it appears that the above deduced relation, that every temperature corresponds to a def-

*Z. Physik. Chem., 55, 449 (1906).

† Compt. rend., 128, 825 (1899).

$\ddagger$ Z. Elektrochem., 12, 781 (1906). 
inite pressure, no longer holds. Wöhler observed that the equilibrium pressure depends to a considerable extent on the time during which the metal and oxide are heated together. There occurs in this system a special condition, that the metallic palladium possesses a solvent action on the oxide even in the solid state. The metal phase will contain a more or less large amount of this substance in solution then, depending on the time it is in contact with the oxide or oxygen. If this solvent action did not exist every temperature would correspond to a single oxygen pressure, since, however, this is not true, we must be dealing with a changing composition of the metal phase. The tension rises with rising oxide content and reaches its upper limit, in a saturated solid solution of oxide.

So long as the solution is not saturated the complete equilibrium between the two phases, to which alone the phase rule refers, is still not attained.

If we represent the results of these measurements graphically we obtain for the system with pure metal as solid phase, as well as for every solid solution of given concentration, a curve whose form is similar to the form of the vapor pressure curve (see Fig. 90).

If the external oxygen pressure is higher than the dissociation tension of the oxide, oxidation of the metal takes place, while the direction of the chemical process is the opposite, if the oxygen pressure of the surroundings is less than the tension of the oxide. The curves which represent the dependence of the oxygen tension on the temperature divide the plane of the curve into two fields of reaction. That of higher pressure represents the formation, that of lower pressure the decomposition of the oxide.

High decomposition tension and low decomposition temperatures are found in oxides of noble metals, with which we observe ordinarily only decomposition. In opposition thereto the dissociation tension of the base metals is considerably under the oxygen tension of the atmosphere (about I $50 \mathrm{~mm}$.) so that, only the oxidation process is observed. The tension is generally so small that it can no longer be measured with the help of our ordinary manometer methods. 
We are able however to obtain the order of magnitude of the same indirectly. Nernst has derived a formula by which it is possible to calculate the oxygen tension approximately from the combining heat of the metals. The calculation for oxide of iron has been made by v. Juptner, that for the other heavy metals by W. Stahl.* The following table gives us the essence of the work.

\section{Oxygen Tension in Atmospheres.}

\begin{tabular}{|c|c|c|c|c|c|c|}
\hline $\begin{array}{l}\text { Temper- } \\
\text { ature, } \\
\text { Deg. Abs. }\end{array}$ & $\underset{4 \mathrm{Ag}+\mathrm{O}_{2} .}{\stackrel{2 \mathrm{Ag}_{2} \mathrm{O}}{\rightleftarrows}}$ & $\underset{4}{\stackrel{2}{\stackrel{\mathrm{Cu}^{2} \mathrm{u}_{2} \mathrm{O}}{\rightleftarrows}}}$ & $\underset{2 \mathrm{~Pb}+\mathrm{O}_{2} .}{\stackrel{2 \mathrm{PbO}}{\rightleftarrows}}$ & $\underset{2 \mathrm{Ni}+\mathrm{O}_{2} .}{\stackrel{2 \mathrm{NiO}}{\rightleftarrows}}$ & $\underset{2 \mathrm{Zn}+\mathrm{O}_{2} .}{\stackrel{2 \mathrm{ZnO}}{\rightleftarrows}}$ & $\underset{2 \mathrm{Fe}+\mathrm{O}_{2} .}{\stackrel{2 \mathrm{FeO}}{\rightleftarrows}}$ \\
\hline 300 & $8.4 \times 10^{-5}$ & & & & & \\
\hline 400 & $4.9 \times 10^{-1}$ & & & & & \\
\hline 500 & $24.9 \times 10$ & $.56 \times 10^{-30}$ & $3.1 \times 10^{-38}$ & I. $8 \times 10^{-46}$ & $1.3 \times 10^{-68}$ & \\
\hline 600 & 360.0 & $8.0 \times 10^{-24}$ & $9.4 \times 10^{-31}$ & $1.3 \times 10^{-37}$ & $4.6 \times 10^{-56}$ & $5.1 \times 10^{-42}$ \\
\hline 700 & $\ldots \ldots$ & $1.9 \times 10^{-19}$ & $2.1 \times 10^{-25}$ & $2.8 \times 10^{-31}$ & $4.3 \times 10^{-47}$ & \\
\hline 800 & & $3.6 \times 10^{-16}$ & 6 & I. $7 \times 10^{-26}$ & $2.4 \times 10^{-40}$ & $9 . \mathrm{x} \times \mathrm{ro}^{-30}$ \\
\hline 900 & $\ldots \ldots$ & $1.7 \times 10^{-12}$ & $23.2 \times 10^{-18}$ & $8.7 \times 10^{-23}$ & $4.3 \times 10^{-35}$ & \\
\hline 1000 & . & $1.5 \times 10^{-11}$ & 1 I.IX10-15 & $8.4 \times 10^{-20}$ & $7.1 \times 10^{-31}$ & $2.0 \times 10^{-22}$ \\
\hline 1100 & $\ldots \ldots$ & $7.8 \times 10^{-10}$ & $01.3 \times 10^{-13}$ & $2.3 \times 10^{-17}$ & $2.0 \times 10^{-27}$ & \\
\hline I 200 & $\ldots \ldots$ & $2.0 \times 10^{-8}$ & $7.0 \times 10^{-12}$ & $2.6 \times 10^{-15}$ & $1.5 \times 10^{-24}$ & $1.6 \times 10^{-19}$ \\
\hline 1300 & & $3.3 \times 10^{-7}$ & $2.1 \times 10^{-10}$ & $1.4 \times 10^{-13}$ & $4.3 \times 10^{-22}$ & \\
\hline 1400 & $\ldots$ & $3.6 \times 10^{-6}$ & $3.8 \times 10^{-9}$ & $4.4 \times 10^{-12}$ & $5.4 \times 10^{-20}$ & $5.9 \times 10^{-14}$ \\
\hline 1500 & & $2.8 \times 10^{-6}$ & $4.8 \times 10^{-8}$ & $8.7 \times 10^{-11}$ & $3.6 \times 10^{-18}$ & \\
\hline 1600 & & $1.8 \times 10^{-4}$ & $4.4 \times 10^{-7}$ & $1.2 \times 10^{-9}$ & $1.4 \times 10^{-16}$ & $2.8 \times 10^{-11}$ \\
\hline I 700 & & $8.9 \times 10^{-4}$ & $3.2 \times 10^{-8}$ & 1. $2 \times 10^{-8}$ & $3.7 \times 10^{-15}$ & \\
\hline$r 800$ & & $3.8 \times 10^{-3}$ & $1.8 \times 10^{-5}$ & $9.6 \times 10^{-8}$ & $6.8 \times 10^{-14}$ & $3.3 \times 10^{-9}$ \\
\hline I900 & & I. $4 \times 10^{-1}$ & $8.9 \times 10^{-5}$ & $6.1 \times 10^{-7}$ & $9.1 \times 10^{-13}$ & \\
\hline 2000 & $\ldots \ldots \ldots$ & $4.4 \times 10^{-1}$ & $3.7 \times 10^{-4}$ & $3.3 \times 10^{-6}$ & $9.5 \times 10^{-12}$ & $1.6 \times 10^{-7}$ \\
\hline
\end{tabular}

* These figures for zinc are purely hypothetical, since at temperatures above the boiling point of zinc we do not have two solid phases, and a gas phase giving a univariant system but one solid phase $(\mathrm{ZnO})$ and one gas phase $(\mathrm{Zn}+\mathrm{O})$ which gives us a bivariant system. The same is, of course, true for any volatile metal.

That these calculations do not give accurate, but only approximate values, is shown by a comparison of the calculated pressure, for silver oxide, with that experimentally determined by Lewis.

We may not, however, assume that no oxidation of the metal is possible at oxygen pressures below the tension of the oxide, only

*Metallurgie 4, 682, (1907). 
the formation of the pure oxide phase is impossible. We always get oxidation if the metal has the power to dissolve the oxide, with palladium, for example, of whose oxidation phenomenon we have already learned, a gradual absorption of the gas by the solid metal takes place at small oxygen pressures. A similar property is shown by liquid silver which can take up a considerable amount of oxygen. This property of silver is not without practical importance. Before, however, we consider these phenomena we will orient ourselves, concerning the degrees of

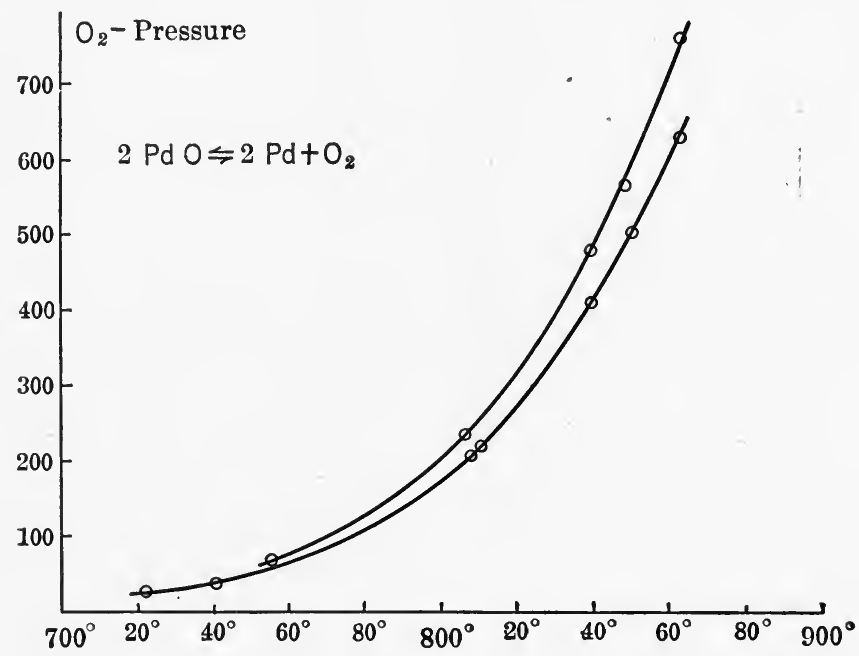

FIG. 90.

freedom of similar systems, which consist of only two phases, the gas and the metal solution. According to the phase rule there are, for a two-component system with the simultaneous presence of two phases, two degrees of freedom, that is, we can vary the temperature and oxygen pressure without one of the two phases disappearing, an increase of oxygen pressure, at constant temperature, causes an increase in the oxide concentration, a lowering of the pressure, a partial decomposition of the dissolved oxide. Every concentration corresponds to a definite oxygen pressure, regardless of whether the solution is a 
solid or a liquid. A very small amount of oxygen is theoretically sufficient to form a small amount of dissolved oxide, even if the metal is a noble one. There is, therefore, no paradox, if we ascribe the absorption of oxygen by metallic silver, to the formation of oxide, even if the silver oxide in the solid state cannot exist at the same temperature, due to its high dissociation tension. The amount of absorbed oxygen is relatively small, always forming very dilute solutions. If we cool below the solidification point, the pure metal precipitates from the solution. The result is that the oxide in the melt, becomes more and more concentrated, thereby raising the oxygen tension of the solution. By quick cooling it rises above atmospheric pressure and the gas breaks with violence through the crystallizing mass. We-say silver "sprouts."

A whole series of metals combine with oxygen in a number of ratios, for example, the different oxides of iron $\mathrm{FeO}, \mathrm{Fe}_{2} \mathrm{O}_{3}$, $\mathrm{Fe}_{3} \mathrm{O}_{4}$, those of manganese $\mathrm{MnO}, \mathrm{Mn}_{3} \mathrm{O}_{4}, \mathrm{Mn}_{2} \mathrm{O}_{3}$, of antimony $\mathrm{Sb}_{2} \mathrm{O}_{3}, \mathrm{Sb}_{2} \mathrm{O}_{4}, \mathrm{Sb}_{2} \mathrm{O}_{5}$, of lead $\mathrm{PbO}$ and $\mathrm{PbO}_{2}$, of copper, $\mathrm{Cu}_{2} \mathrm{O}$ and $\mathrm{CuO}$, as well as many more. For every one of these oxides there exists, if it is in contact with oxygen and its metal, a special temperature tension curve.

\section{The Equilibrium Between Two Oxides and Oxygen.}

In the most cases, we observe, with the escape of oxygen from higher oxides, not the occurrence of the metal, but the formation, first, of the lower oxide. The relations between the two different degrees of oxidation, existing as separate phases, and oxygen, are entirely analogous to those which we studied in the consideration of the system oxide-metal-oxygen. The equilibrium

$$
\mathrm{M}_{n} \mathrm{O}_{x}+\frac{1}{2} y \mathrm{O}_{2} \rightleftarrows \mathrm{M}_{n} \mathrm{O}_{x+y}
$$

corresponds at a given temperature to an entirely definite oxygen pressure.

The decomposition of barium peroxide investigated by LeChatelier * is of practical importance and is convenient for

* Compt. rend., 115, 565 (1892). 
accessible observation. The equilibrium is characterized by the equation

$$
2 \mathrm{BaO}_{2} \rightleftarrows 2 \mathrm{BaO}+\mathrm{O}_{2} \text {. }
$$

The observed dissociation tensions are shown in the following table and Fig. 9r.

\begin{tabular}{c|c||c|c}
\hline $\begin{array}{c}\text { Temperature in } \\
\text { Degrees. }\end{array}$ & $\begin{array}{c}\text { O2-Tension } \\
\text { in Mm. }\end{array}$ & $\begin{array}{c}\text { Temperature in } \\
\text { Degrees. }\end{array}$ & $\begin{array}{c}\text { O}_{2} \text {-Tension } \\
\text { in Mm. }\end{array}$ \\
\hline 525 & 20 & 735 & 260 \\
555 & 25 & 750 & 340 \\
650 & 65 & 775 & 510 \\
670 & 80 & 785 & 620 \\
720 & 210 & 790 & 670 \\
\hline
\end{tabular}

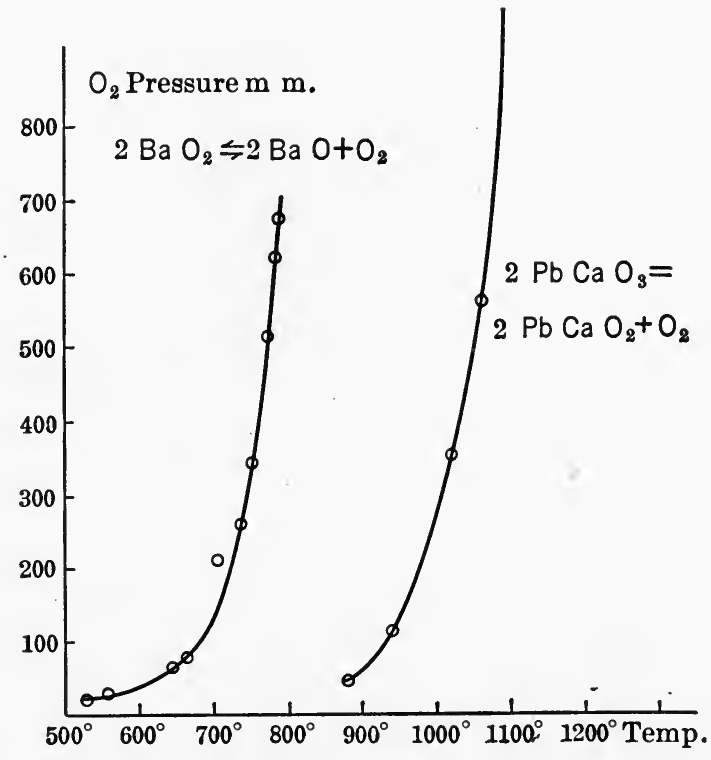

FIG. 9I.

The reversible reaction used for the technical preparation of oxygen is entirely analogous to the above-mentioned case. It is

$$
{ }_{2} \mathrm{Ca} \mathrm{PbO}_{3} \rightleftarrows{ }_{2} \mathrm{Ca} \mathrm{PbO}_{2}+\mathrm{O}_{2} \text {. }
$$

It is treated here as a complex oxide. This, however, does not affect the results. Likewise here, a single temperature corre- 
sponds to an entirely definite oxygen pressure, the measurements for this case have also been made by LeChatelier.*

\begin{tabular}{|c|c|c|c|c|}
\hline & $\begin{array}{l}\text { Temperature } \\
\text { in Degrees. }\end{array}$ & $\begin{array}{l}\mathrm{O}_{2} \text {-Tension } \\
\text { in } \mathrm{Mm} \text {. }\end{array}$ & $\begin{array}{l}\text { Temperature } \\
\text { in Degrees }\end{array}$ & $\begin{array}{c}\mathrm{O}_{2} \text {-Tension } \\
\text { in } \mathrm{Mm} \text {. }\end{array}$ \\
\hline${ }_{2} \mathrm{PbCaO}_{3} \ldots \ldots \ldots$ & 880 & 47 & 1060 & 557 \\
\hline$\rightleftarrows$ & 940 & II 2 & 1070 & 570 \\
\hline$\rightleftarrows$ & 950 & II 7 & I 100 & 940 \\
\hline${ }_{2} \mathrm{PbCaO}_{2}-\mathrm{O}_{2} \ldots \ldots$ & 1020 & 350 & IIIO & 1040 \\
\hline
\end{tabular}

The technical use of this substance is accomplished by heating it at a temperature, where the tension is under that of the partial oxygen pressure of the atmosphere. Under these con-

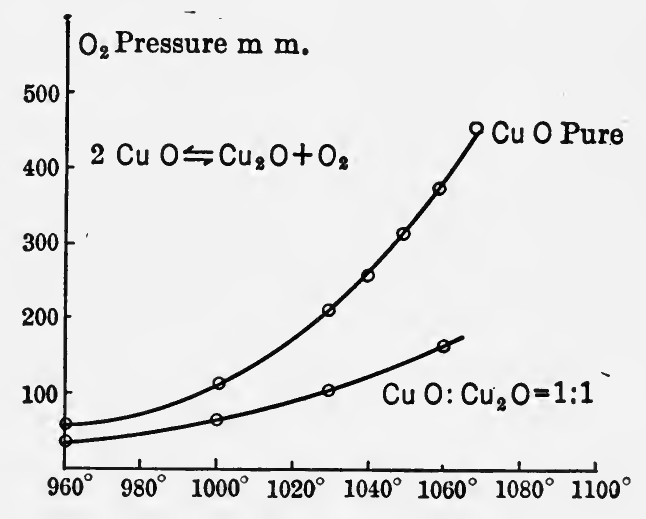

Fig. 92.

ditions the air acts on the lower oxide converting it into the higher. Then the air is shut off and the apparatus connected to an air pump, which considerably lowers the pressure in the reaction vessel. Under the strongly reduced pressure the higher oxide is decomposed and the evolved oxygen is compressed into iron cylinders. We have, accordingly, here, a direct use of the conclusions which one can deduce from chemical statics.

If the two oxides are soluble in one another, whether the solution be solid or liquid, the dissociation pressure is, as in the solution of oxide in metal, dependent not only on the temperature, but on the relative proportions of the two oxides. This case

* Compt. rend., 117, rog (1893). 
occurs with the oxides of copper. A mixture of cupric and cuprous oxides forms at high temperatures a single phase. The dependence of the oxygen pressure of this solution on the temperature and the cuprous oxide concentration has been studied by L. Wöhler.* He found the following values for the reaction:

\begin{tabular}{|c|c|c|}
\hline \multirow{2}{*}{$\begin{array}{l}\text { Temperature } \\
\text { in Degrees. }\end{array}$} & \multicolumn{2}{|c|}{$\mathrm{O}_{2}$-Tension. } \\
\hline & $\begin{array}{l}\text { Nearly Pure } \\
\mathrm{CuO} \text { in } \mathrm{Mm} \text {. }\end{array}$ & $\begin{array}{c}50 \mathrm{CuO},{ }^{50 \mathrm{Cu}_{2} \mathrm{O}} \\
\text { in } \mathrm{Mm} .\end{array}$ \\
\hline 960 & 50 & - $3 I$ \\
\hline 1000 & I 18 & $6_{5}$ \\
\hline roIo & 142 & $\ldots \ldots \ldots \ldots$ \\
\hline 1020 & 174 & $\ldots \ldots \ldots \ldots$ \\
\hline 1030 & 212 & I08 \\
\hline 1040 & $25^{8}$ & $\ldots \ldots \ldots \ldots$ \\
\hline 1050 & $3 I 4$ & $\ldots \ldots \ldots \ldots$ \\
\hline 1060 & 380 & I64 \\
\hline 1070 & $45^{8}$ & $\ldots \ldots \ldots \ldots$ \\
\hline
\end{tabular}

We are now oriented, concerning the different possibilities which we may meet for the systems consisting of oxide, metal and oxygen. These models form the basis for the study of the reduction processes, which we will now consider.

\section{Direct Decomposition of Oxides by Heat.}

It is only possible in a few cases, namely, with the noble metals, gold, platinum, mercury, etc., to obtain the metal from the oxide, simply by the splitting off of the oxygen at high temperature. To accomplish this it is necessary that the oxygen dissociation pressure of the concerned oxide, be greater than the oxygen pressure of the surrounding atmosphere. According to theory it is possible to decompose every oxide in an absolute vacuum. We cannot, however, obtain so complete a vacuum by our present air pumps, as small traces of gas remain in every vacuum no matter how good since the confining liquid, mercury or oil, has a vapor pressure. For the decomposition of nickel and

* Z. Elektrochem., 12, 784 (I906). 
iron oxide at $1000^{\circ}$ (to say nothing of the oxides of less noble metals) vacuua are necessary, according to the preceding table of Stahl, which possess a gas pressure of $10^{-23}$ atmospheres. This is far below the limit of practical attainment and we may dismiss at once all experiments to decompose this kind of oxides direct into their metals.

The so-called reducing agents are generally used to obtain a metal from its oxide. The most important of these are the alkali and alkali earth metals, as well as aluminum and manganese, further the gaseous reducing agents, hydrogen and carbon monoxide, and, first of all, as technically the most important, carbon.

\section{Reduction by Metals.}

The action of the named metals is at once clear. All these metals are base, that is, their affinity for oxygen is extraordinarily great. It is, therefore, extremely tightly bound in the oxides and the dissociation pressure of the same is very small. If now, we have together, an oxide with high oxygen pressure and a strongly reducing metal, it can easily be conceived that the latter would demand the oxygen for itself. The equilibrium of the oxide with the original metal and oxygen, would thereby be immediately destroyed and the decomposition reaction would go on, till all the oxygen had been given to the base metal. All the metals can be used as reducing agents for a given oxide whose oxides possess a lower oxygen tension than the one to be reduced.

This condition is fulfilled in the Goldschmidt process for obtaining chromium and manganese from their oxides by means of aluminum, further, in the iron industry, overblown charges are reduced with ferro-manganese.

\section{Reduction by Gaseous Reducing Agents.}

The reduction of metallic oxides by gaseous reducing agents hydrogen and carbon monoxide, can only be understood by obtaining a wider basis of chemical statics. We have here a favorable opportunity to compare the different methods of working with one another and to learn their range of usefulness. 


\section{Reduction by Hydrogen.}

The reduction of metallic oxides by hydrogen is so well known that I do not need to name a special example. If we designate with $M$ any monovalent metal, the reaction scheme is

$$
\mathrm{M}_{2} \mathrm{O}+\mathrm{H}_{2} \rightleftarrows 2 \mathrm{M}+\mathrm{H}_{2} \mathrm{O} \text {. }
$$

In metallurgy, on the other hand, a process is used by which, with the help of water vapor, easily oxidizable metals, as zinc, are separated from molten nobler metals, as crude lead, which has been desilverized with zinc.

$$
2 \mathrm{M}+\mathrm{H}_{2} \mathrm{O} \rightleftarrows \mathrm{M}_{2} \mathrm{O}+\mathrm{H}_{2} \text {. }
$$

It is readily seen that this is the reverse of the above formulated reduction reaction. We now look again for a metal in which both reaction directions can be observed. It has long been known, that by heating in a current of steam, iron goes over into $\mathrm{Fe}_{3} \mathrm{O}_{4}$ and that, on the other hand, this oxide is reduced by hydrogen to metal. This is accordingly a reversible reaction, which we write

$$
\mathrm{Fe}_{3} \mathrm{O}_{4}+{ }_{4} \mathrm{H}_{2} \rightleftarrows{ }_{3} \mathrm{Fe}+{ }_{4} \mathrm{H}_{2} \mathrm{O} \text {. }
$$

We will now study the conditions which determine whether reduction or oxidation takes place, and will consider for this purpose a system in which all of the substances entering into the double decomposition may be simultaneously present.

\section{The Phase Rule.}

We apply first the phase rule, with which we are already familiar and try with its help to come to a conclusion concerning the nature of our system. Obviously it is to be treated as a system of three components, namely, iron, hydrogen and oxygen which, at the reaction temperature, are divided among the three phases, metal, oxide, and gas (mixture of steam and hydrogen). We conclude, therefrom that we have a bivariant system, that two degrees of freedom are present, and that accordingly we 
can vary the temperature and pressure without the possibility of injuring the coexistence of the three phases.

The phase rule allows us to say nothing concerning the composition of the gas phase.

\section{LeChatelier's Principle.}

If the reaction is allowed to proceed in a closed space and the temperature held constant it is impossible to observe the procedure of the reaction by the change of gas pressure since the number of water molecules resulting from the reaction is exactly the same as the number of hydrogen molecules going into it. Such reactions are independent of external pressure, that is, a pressure change exerts no influence on the composition of the gas phase.

The influence of pressure on chemical systems, as well as the effect of all physical agents, can be arranged in a perfectly general principle, brought forward by LeChatelier, which can be formulated as follows:

"Every external influence arouses in a chemical equilibrium system, opposing forces, which, after the ceasing of the external forces, strive to bring it back to its original condition."

In other words every chemical equilibrium system is in a certain sense to be conceived of as elastic; external pressure may have an influence on the composition, if a change in volume is bound up with the chemical reaction. Raising the pressure displaces the composition so that a decrease of volume must take place, if the pressure ceases, the reaction returns in the reverse sense and halts when the original composition is reached.

Since in the equation

$$
\mathrm{Fe}_{3} \mathrm{O}_{4}+{ }_{4} \mathrm{H}_{2} \rightleftarrows{ }_{3} \mathrm{Fe}+{ }_{4} \mathrm{H}_{2} \mathrm{O},
$$

with the exception of the very small change in the specific volume of the solid phase, which can be entirely neglected, a difference of volume does not exist between the beginning and end condition, a change of pressure can exert no influence on the composition of this system in equilibrium.

The equilibrium between the metal, oxide, and the two gaseous substances depends alone on the composition of the gas 
phase. It is immaterial whether the gas is under a pressure of a few millimeters or many atmospheres.

If the composition deviates from the equilibrium proportions a reaction takes place, with an excess of hydrogen reduction of the oxide with an excess of water vapor oxidation to ferrosoferric oxide. The principle of LeChatelier, accordingly, allows us an important insight into the interesting oxidation and reduction processes.

If we would press still deeper into the conditions of the same so we must consider that beside the hydrogen and the water vapor in the atmosphere there must still be present a very small amount of oxygen, depending on the decomposition tension. It is, in our special case, so small that it escapes detection by the analytical methods, but its assumption gives us a convenient means of investigating the equilibrium conditions.

\section{The Mass Law.}

We can trace back the process of the reduction of the oxide to the burning of hydrogen in oxygen, which is subjected to the special condition, that the partial pressure corresponding to the equilibrium between the gaseous substances hydrogen, oxygen and water vapor is equal to the oxygen tension of the oxide.

The burning of hydrogen is a reversible process; at high temperatures water breaks down into its elements so that we may write the equation

$$
{ }_{2} \mathrm{H}_{2}+\mathrm{O}_{2} \rightleftarrows{ }_{2} \mathrm{H}_{2} \mathrm{O} \text {. }
$$

We meet here a reversible reaction between pure gaseous substances which are all simultaneously present in the homogenous gas phase and are in equilibrium with each other. Reactions in homogenous systems in gases and in solutions are best studied with the aid of the mass law, formulated by the two Norwegian investigators, Guldberg and Waage which declares "The intensity of a chemical action is proportional to the concentration of the reacting molecular species."

If the two substances $A$ and $B$ react with each other with the formation of $D$ according to the equation.

$$
A+B \rightarrow D
$$


and we designate with $C$ the concentration (number of gram molecules per unit of space) and with $K$ a proportionality factor, the intensity of the reaction from left to right will be

$$
I=K \cdot C_{a} \cdot C_{b} .
$$

If we consider a reaction which can also take place in the reverse sense, it follows that the intensity of the reversal will be given by

$$
I^{\prime}=K^{\prime} C_{d} .
$$

The equilibrium condition is, therefore, characterized by the equality of the intensities of the two reaction directions

Therefrom

$$
I=I^{\prime}=K \cdot C_{a} \cdot C_{b}=K^{\prime} C_{a} .
$$

$$
\frac{C_{a} \cdot C_{b}}{C_{d}}=\frac{K^{\prime}}{K}=K .
$$

The fraction on the left side of the equation has at constant temperature in case of equilibrium always the same value $K$. This constant is called the equilibrium constant, or, if the process is looked upon as a dissociation of $D$, dissociation constant.

If we return now to our example we have, for the intensity of the water formation from one molecule of oxygen and two of hydrogen

$$
I=K \cdot \mathrm{Co}_{2} \cdot \mathrm{C}^{2}{ }_{\mathrm{H}_{2}},
$$

for the water dissociation,

$$
I^{\prime}=K^{\prime} \cdot \mathrm{C}^{2} \mathrm{H}_{2} \mathrm{O}
$$

Therefrom the equilibrium constant

$$
K=\frac{\mathrm{Co}_{2}{ }^{\prime} \mathrm{C}^{2} \mathrm{H}_{2}}{\mathrm{C}^{2} \mathrm{H}_{2} \mathrm{O}},
$$

and further that the equilibrium mixture is richer in water vapor the higher the concentration of the oxygen. This conclusion is of importance if we think of our homogeneous system set in equilibrium with metal and metal oxide. By this contact the oxygen is brought to a constant value corresponding to the oxygen tension of the oxide. 
In case of the complete equilibrium with all the substances together, the system must be in equilibrium as regards oxygen and the two other gases and with metal and oxide; we bring now all the constants on one side and obtain

$$
\left(\frac{\mathrm{C}_{\mathrm{H}_{2}}}{\mathrm{C}_{\mathrm{H}_{2} \mathrm{O}}}\right)^{2}=\frac{K}{\mathrm{Co}_{2}} \frac{\mathrm{C}_{\mathrm{H}_{2}}}{\mathrm{C}_{\mathrm{H}_{2} \mathrm{O}}}=\sqrt{\frac{K}{\mathrm{C}_{\mathrm{O}_{2}}}}=\eta .
$$

We see therefrom that for the equilibrium between metal, metal oxide, water vapor and hydrogen, a definite ratio between the two gases is required. This is only true if the metal is always present as a solid or liquid phase; with volatile metals the concentration of the metal vapor also enters into the constant. Since the absolute value of these concentrations and therewith also the pressure under which the gas stands is without meaning, then the ratio $\eta$ can exist under different pressures. We, accordingly, obtain the same result which we had previously deduced with the help of the principle of LeChatelier. Every deviation of the gas composition from the ratio $\eta$ requires reaction, if the ratio is greater than $\eta$ a reduction of the oxide takes place, if it is smaller an oxidation of metal to oxide.

If we represent graphically the conditions for oxidation and reduction in our system, as depending on the pressure and composition of the gas atmosphere at constant temperature, we obtain (see Fig. 93), as limits for the oxidation and reduction fields, the geometrical locus of all gas systems which are in equilibrium with metal and oxide. For all these the abscissa $x$ which gives the number of hydrogen molecules (the sum of the hydrogen and water vapor molecules is equal to I) is defined by the equation

$$
\frac{x}{I-x}=\eta
$$

If $x$ is constant, the curve is parallel to the $p$ axis.

The equilibrium constant $\eta$ is, as we have above deduced,

$$
\eta=\sqrt{\frac{K}{\mathrm{Co}_{2}}}
$$


and is dependent on the dissociation constant of water $K$, and also on the oxygen tension of the oxide. If we compare the value of $\eta$ for different metals, we see that $\eta$ grows with decrease of the decomposition pressure of the oxide, that the amount of hydrogen in the equilibrium ratio for a noble metal need be very small, for a base metal it must be under some conditions extraordinarily large. This agrees with the experimental fact that noble metals are not attacked by water vapor, their oxides

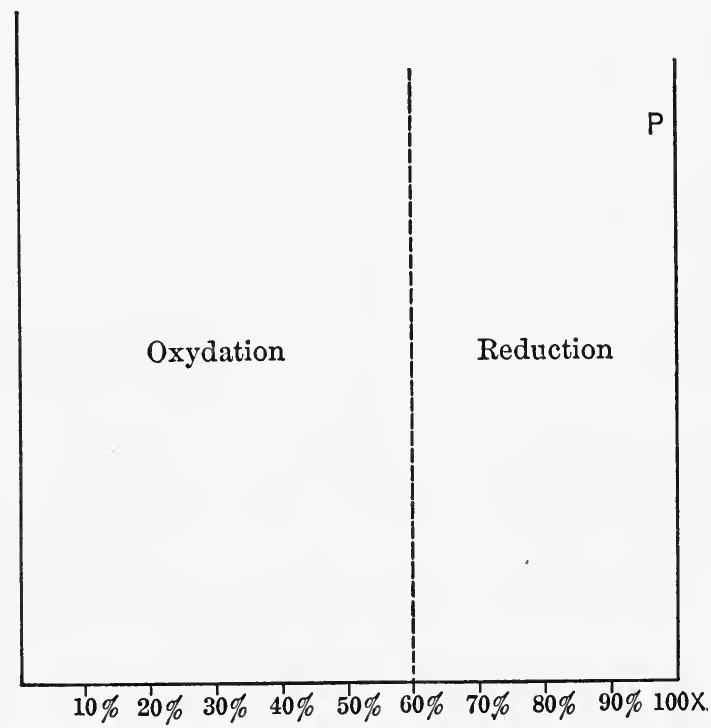

Fig. 93.

are reduced by the smallest addition of hydrogen, and that with base metals the reduction of oxides with hydrogen is difficult.

If more than one oxide is known for a metal, we obtain a number of values for $\eta$ and in the diagram a number of parallels.

Concerning the other magnitude on which the constant $\eta$ depends, the dissociation constant of water vapor, exact experiments have recently been carried out by Nernst and v. Wartenberg.* The dissociation of water vapor is first observable at very high temperature. It is determined by passing the water

*Z. Physik. Chem., 56, 534 (Ig06). 
vapor through a porcelain pipette heated in an electric furnace and measuring the resulting oxy-hydrogen in a fine eudiometer tube.

For temperatures above $1800^{\circ}$ the method worked out by Lowenstein $*$ is used. The water is led through an electrically heated iridium tube, and is partially decomposed into oxyhydrogen gas. The hydrogen partial pressure in the same is measured in by means of an evacuated iridium bulb connected with a manometer and placed in the reaction space. This metal is permeable to hydrogen but not to the other gases, the diffusion into the inside proceeds till the pressure of the hydrogen gas inside the bulb is equal to the partial pressure of the hydrogen from the dissociation of the water vapor. The manometer determines, accordingly, the hydrogen pressure directly. From the experiments the following values have been found. Water vapor at I atmosphere pressure undergoes by heating to the temperature $T$ a decomposition of $X$ per cent.

\begin{tabular}{c|c|c|c}
\hline$T^{\circ} \mathrm{C}$. & $T^{\circ}$ Abs. & $X$ Per Cent. & \multicolumn{1}{|c}{$K}$. \\
\cline { 2 - 3 } II24 & I397 & 0.0073 & $2.312 .10-13$ \\
I207 & I480 & 0.0189 & $3.794 .10-12$ \\
I288 & I56I & 0.034 & $2.094 .10-11$ \\
I882 & 2155 & 1.18 & $6.418 .10-7$ \\
I984 & 2257 & 1.77 & $2.080 .10-6$ \\
\hline
\end{tabular}

The dissociation is dependent on the temperature, and increases with increasing temperature. For low temperatures, the degree of decomposition is so small that one can no longer measure the resulting oxy-hydrogen gas.

\section{Van't Hoff's Equation.}

Thermodynamic methods are used to reckon the equilibrium which cannot be experimentally determined. Van't Hoff has deduced an equation which connects the dissociation constant with the reaction heat and the temperature. It is

$$
Q=R \cdot T^{2} \frac{d \log _{e} K}{d T}
$$

*Z. Physik. Chem., 54, 7I5 (I906). 
if $Q$ is the heat of combustion of the hydrogen. Now, however, the reaction heat is in no way a constant but changes with the temperature. The change is according to thermodynamics equal to the difference between the specific heats of the factors and the products. These latter magnitudes are dependent on the temperature and they have recently been exactly determined by Holborn and Henning who have given the following relation for the molecular heats of the gases concerned (molecular heat $=$ product of the molecular weight and the specific heat at constant volume $\mathrm{C}$ ) for water vapor.

$$
\mathrm{C}_{v}\left(\mathrm{H}_{2} \mathrm{O}\right)=5.62-0.00077^{\mathrm{T}}
$$

The molecular heats of the permanent gases oxygen and hydrogen are equal and

$$
\mathrm{C}_{0}=4.68-0.00026 T \text {. }
$$

From this it follows that the temperature coefficient of the reaction $2 \mathrm{H}_{2}+\mathrm{O}_{2}={ }_{2} \mathrm{H}_{2} \mathrm{O}$ is

$$
\frac{d Q}{d T}={ }_{3} \mathrm{C}_{v}{ }^{\prime}\left(\mathrm{H}_{2} \mathrm{O}_{2}\right)-{ }_{2} \mathrm{C}_{0}\left(\mathrm{H}_{2} \mathrm{O}\right)=2.80-0.00076 T .
$$

The value of the heat of combustion at $100^{\circ}$ and constant volume to form two molecules of water is $Q_{100}=$ II, 500 cal. The temperature function is

$$
Q_{100}=\mathrm{II} 4,380-2.80 T-0.00076 T .
$$

If we substitute this value in the above differential equation and integrate it follows if we replace natural logarithms with Briggsian

$$
\log K^{\prime}=\log K-25,030\left(\frac{\mathrm{I}}{T^{\prime}}-\frac{\mathrm{I}}{T}\right)-\text { I.40 } \log \frac{T^{\prime}}{T}-0.000 \mathrm{I} 6\left(T^{\prime}-T\right) .
$$

If one value of $K$ has been determined experimentally we can, with the help of this equation, arrive at the value of $K$ for every other temperature. From this the per cent of decomposed water vapor $(X)$ can be calculated at every other gas pressure, 
from the mass law; the values given in the following table have been arrived at in this way:

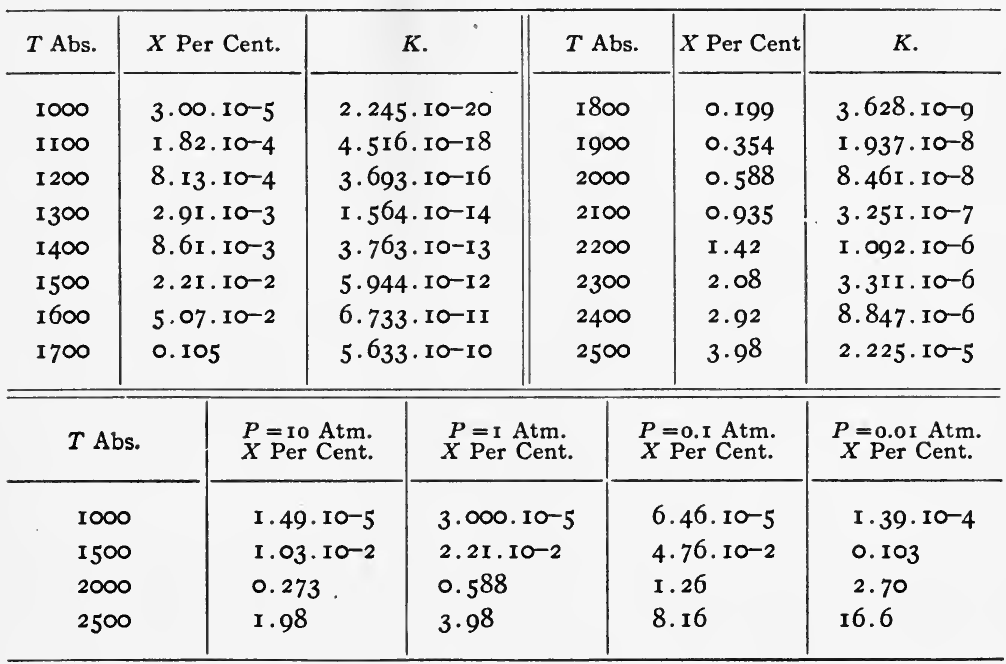

From the differential equation

$$
Q=R \cdot T^{2} \frac{d \log _{e} K}{d T}
$$

it can be at once deduced whether $K$ increases or decreases with rising temperature. If $Q$ is positive, that is, during the dissociation heat is supplied, $K$ increases with increasing temperature. If the process goes on with heat evolution, if heat is given to the surroundings from the system, the differential quotient is negative and $K$ is smaller with rising temperature.

" The equilibrium of a chemical system is displaced by raising the temperature in the sense that the product resulting from heat absorption is favored."

This law can be derived from LeChatelier's principle, since also in thermal relations chemical equilibrium systems are elastic, and by cooling the equilibrium swings back and liberates the amount of heat which has been added.

We are now oriented concerning the constant $K$, for the reaction between hydrogen and oxygen. If we combine it in 
the above-named way with the oxygen dissociation pressure of oxides, we are able to obtain mathematically the equilibrium ratio $\eta$ for all these oxides.

In practice there comes into consideration only the reaction with which we started and to which we now return.

$$
\mathrm{Fe}_{3} \mathrm{O}_{4}+{ }_{4} \mathrm{H}_{2} \rightleftarrows{ }_{3} \mathrm{Fe}+{ }_{4} \mathrm{H}_{2} \mathrm{O}
$$

The equilibrium has been investigated by Deville* and more recently by $\mathrm{G}$. Preuner. $\dagger$ We give in the following table the values which appear to be the nearest correct.

\begin{tabular}{|c|c|c|c|}
\hline $\begin{array}{l}\text { Temperature } \\
\text { in Degrees. }\end{array}$ & $\eta=\frac{\mathrm{CH}_{2} \mathrm{O}}{\mathrm{CH}_{2}}$ & $\mid$ Per Cent $\mathrm{H}_{2} \mid$ & Observer. \\
\hline 200 & $20.4 \mathrm{I}$ & $95 \cdot 3^{2}$ & \multirow{6}{*}{ Deville, Liebig's Ann., 157, 7 I (1872). } \\
\hline 265 & 14.49 & $93 \cdot 5^{6}$ & \\
\hline 360 & 8.405 & 89.39 & \\
\hline 440 & 5.682 & 85.06 & \\
\hline 770 & I. $85^{2}$ & 64.94 & \\
\hline 920 & I. 515 & 60.23 & \\
\hline 900 & I. 449 & 59.27 & \multirow{3}{*}{ Preuner, Physik. Chem., 47, 416 (I904) } \\
\hline 1025 & I. 282 & 56.18 & \\
\hline II 50 & I. 163 & $53 \cdot 76$ & \\
\hline
\end{tabular}

The value of $\eta$ decreases with rising temperature; we may draw the conclusion therefrom that the reduction of $\mathrm{Fe}_{3} \mathrm{O}_{4}$ goes on with heat absorption.

\section{Reduction by Carbon Monoxide.}

The second gaseous reducing agent, carbon-monoxide, plays in practice a still greater rôle than hydrogen. In general there exists between the two reducing gases close agreement in properties. In the treatment of oxides with carbon monoxide we meet a reversible action precisely as in the treatment with hydrogen. This can be represented by the general scheme.

$$
\mathrm{MeO}+\mathrm{CO} \rightleftarrows \mathrm{Me}+\mathrm{CO}_{2} .
$$

This decomposition also takes place without change of volume; the reaction products occupy the same space as the factors. 
The reaction is independent of the pressure of the gas and comes to rest when a definite ratio between carbon monoxide and dioxide exists; which ratio is dependent on the temperature.* This equilibrium ratio

$$
\frac{\mathrm{Cco}}{\mathrm{Cco}_{2}}=\eta=\sqrt{\frac{K^{\prime}}{\mathrm{Co}_{2}}}
$$

is dependent, as the corresponding magnitude for hydrogen, on the oxygen pressure of the oxide to be reduced and the dissociation constant of $\mathrm{CO}_{2}, \mathrm{~K}^{\prime}$, which is defined by the equation

$$
K^{\prime}=\frac{\mathrm{C}^{2} \mathrm{Co} \cdot \mathrm{Co}_{2}}{\mathrm{C}^{2} \mathrm{CO}_{2}}
$$

Then also the combustion of $\mathrm{CO}$ into $\mathrm{CO}_{2}$ is a reversible reaction. Carbon dioxide decomposes at high temperature into $\mathrm{CO}$ and $\mathrm{O}_{2}$. This can be represented by the equation

$$
{ }_{2} \mathrm{CO}+\mathrm{O}_{2} \rightleftarrows{ }_{2} \mathrm{CO}_{2} \text {. }
$$

The equilibrium ratio of this system has been studied by Nernst and v. Wartenberg, by the same method as was described for the dissociation of water vapor. They observed the following

* This again is only true for non-vola tile metals. If we consider, for example, the system

$$
\mathrm{ZnO}+\mathrm{CO} \rightleftarrows \mathrm{Zn}+\mathrm{CO}_{2},
$$

we find that since at temperatures where the reaction goes on, zinc only exists as a vapor, the ratio of $\mathrm{CO}$ to $\mathrm{CO}_{2}$ is therefore not dependent only on the temperature but the equilibrium constant for the system is given by

$$
\frac{\mathrm{Zn} \times \mathrm{CO}_{2}}{\mathrm{CO}}=\mathrm{K} \text {. }
$$

and hence the concentration of zinc vapor must be taken into account. In the various unsatisfactory investigations which have been made of the zinc equilibrium this has not been taken into account. See, for example, the recent paper by Fulton, Bull. Am. Inst. Min. Eng., 140, r375 (I9r8); also the earlier paper of Lencauchez, Mem. Soc. Ing. Civils, 1877, 568; Eng. Min. J., 26, I I (1878). 
decomposition values, $x$-per cent decomposed $\mathrm{CO}_{2}$ at the given temperatures
$T$ abs.
I 300
I 400
I 478
$x$ per cent
0.00414
$0.01-0.02$
$0.029-0.035$

From these values and the thermal data the heat of combustion of $\mathrm{CO}, 6800$ cal. (at constant pressure) the molecular heat of $\mathrm{CO}_{2}$.

$$
\mathrm{Cv}_{\mathrm{CO}_{2}}=5 \cdot 106+0.00334 T+7 \cdot 35 \cdot 10^{-7} T^{2}
$$

and for the permanent gases $\mathrm{CO}$ and $\mathrm{O}_{2}$

$$
\mathrm{C}^{\prime}{ }_{0}=4.68+0.000268 T
$$

the dissociation constant $K$ and the per cent of decomposed gas $x$ for different temperatures and pressures, is calculated in a

\begin{tabular}{|c|c|c|c|c|c|c|}
\hline $\begin{array}{c}T \text { abs. } \\
\text { Degrees. }\end{array}$ & $X$ Per Cent. & \multicolumn{2}{|c|}{$K^{\prime}}$. & $\begin{array}{c}T \text { abs. } \\
\text { Degrees. }\end{array}$ & $X$ Per Cent. & $\begin{array}{c}K \text { Pressure I } \\
\text { Atm. }\end{array}$ \\
\hline 1000 & I. $58 \cdot 10-5$ & \multicolumn{2}{|c|}{$3 \cdot 280.10-21$} & 1800 & 0.507 & $6.016 .10-8$ \\
\hline I 100 & $2 . \infty 0.10-4$ & \multicolumn{2}{|c|}{$5 \cdot 991 \cdot 10-18$} & 1900 & 0.978 & 4. III. IO 7 \\
\hline I 200 & $8.94 \cdot 10-4$ & \multicolumn{2}{|c|}{$4.908 .10-16$} & 2000 & I. 77 & $2 \cdot 335 \cdot 10-6$ \\
\hline 1300 & $3.89 .10-3$ & \multicolumn{2}{|c|}{$3 \cdot 735 \cdot 10-14$} & 2100 & 3.03 & I. 130.10-5 \\
\hline 1400 & $1.38 \cdot 10-2$ & \multicolumn{2}{|c|}{ I. $550.10-12$} & 2200 & 4.88 & $4 \cdot 595 \cdot 10-5$ \\
\hline I 500 & $4.06 .10-2$ & \multicolumn{2}{|c|}{$3.684 \cdot 10-11$} & 2300 & $7 \cdot 55$ & I. $675.10-4$ \\
\hline 1600 & 0.104 & \multicolumn{2}{|c|}{$5.8 \mathrm{I} 3 \cdot 10-10$} & 2400 & II. 3 & $5.631 .10-1$ \\
\hline I 700 & 0.242 & \multicolumn{2}{|c|}{$6.905 \cdot 10-9$} & 2500 & $\mathrm{I}_{5} .8$ & I. $55^{2}$ \\
\hline \multicolumn{2}{|c|}{$\begin{array}{l}T \text { abs. } \\
\text { Degrees }\end{array}$} & Io At. & \multicolumn{2}{|c|}{ I At. } & o.r At. & 0.or At. $=$ Pressui $\mathrm{e}$ \\
\hline \multicolumn{2}{|c|}{1000} & $7 \cdot 31 \cdot 10-6$ & \multicolumn{2}{|c|}{ I. $5^{8}$} & 3.40 & $7 \cdot 3 \mathrm{I}=x \%$ \\
\hline \multicolumn{2}{|c|}{$I_{500}$} & I. 88 & \multicolumn{2}{|c|}{4.06} & 8.72 & 0.188 \\
\hline \multicolumn{2}{|c|}{2000} & $0.8 \mathrm{I} 8$ & \multicolumn{2}{|c|}{ I. 77} & 3.73 & 7.88 \\
\hline \multicolumn{2}{|c|}{2500} & 7.08 & \multicolumn{2}{|c|}{15.8} & 30.7 & 53.0 \\
\hline
\end{tabular}
similar way as for the $\mathrm{H}_{2} \mathrm{O}$ dissociation.

The equilibrium ratio has been determined for the system iron oxide, iron, carbon monoxide, carbon dioxide. The reaction

$$
\mathrm{FeO}+\mathrm{CO} \rightleftarrows \mathrm{Fe}+\mathrm{CO}_{2},
$$


gives the following values:

\begin{tabular}{|c|c|c|c|c|}
\hline $\begin{array}{c}\text { Temperature. } \\
\text { Degrees }\end{array}$ & CO, Per Cent. & $\mathrm{CO}_{2}$, Per Cent. & $\frac{\mathrm{CO}}{\mathrm{CO}_{2}}=\eta$ & Observer. \\
\hline $55^{2}$ & 53.7 & 46.3 & I. 160 & \\
\hline 556 & 53.4 & 46.6 & I. 146 & Schenck, \\
\hline $56 r$ & 53.6 & 46.4 & I. I55 & . \\
\hline 596 & $55 \cdot 5$ & $44 \cdot 5$ & I. 247 & Semiller and \\
\hline 6I9 & 56.8 & 43.2 & I. 3 I 5 & \\
\hline $65 \mathrm{I}$ & 57.9 & $42 . I$ & I. 375 & Falcke \\
\hline 662 & $5^{8.4}$ & 41.6 & I. 404 & \\
\hline
\end{tabular}

The equilibrium constant increases with increasing temperature, that is, the left side of the reaction is favored as the reduction takes place with heat evolution. The reaction

$$
\mathrm{Fe}_{3} \mathrm{O}_{4}+\mathrm{CO} \rightleftarrows{ }_{3} \mathrm{FeO}+\mathrm{CO}_{2},
$$

also has a measureable equilibrium which has been determined by Baur and Glasner.* They found at $58 \mathrm{I}^{\circ}, 4 \mathrm{I} .9$ per cent $\mathrm{CO}$ and 57.4 per cent $\mathrm{CO}_{2}$ corresponding to $\eta=0.72 \mathrm{I}$.

The reversibility of the action of $\mathrm{CO}$ on iron oxide, the oxidation of metal by $\mathrm{CO}_{2}$ is of the greatest importance in the blast furnace process which we shall consider in the next chapter. It gives us the explanation of the remarkable fact that the carbon monoxide used as a reducing agent does not go completely to $\mathrm{CO}_{2}$ but occurs in rich amounts in the exit gases of the blast furnace and becomes a valuable by-product.

We have become familiar with the characteristics of the two gaseous reducing agents $\mathrm{CO}$ and $\mathrm{H}_{2}$. We will find which is the strongest reducing agent. The question is now easily answered since we are familiar with the dissociation ratios of the oxidation products of $\mathrm{H}_{2}$ and $\mathrm{CO}$. The strongest reducing agent is the substance whose oxidation product is the least dissociated, that is, whose dissociation constant possesses the smallest value. In order to make clear the comparative ratios of the two reducing gases we plot the value of $X$ or $K$ for water vapor and carbon dioxide or better their logarithms against temperature, we

* Z. Physik. Chem., 43, 354 (1903). 
obtain two curves (Fig. 94). These cut at a temperature of I I $40^{\circ}$ abs. or $867^{\circ} \mathrm{C}$. Here the $\mathrm{H}_{2} \mathrm{O}$ and $\mathrm{CO}_{2}$ are equally strongly dissociated, hydrogen and $\mathrm{CO}$ are equally strong reducing agents, beneath this temperature the $\mathrm{CO}$ reduces more energetically; above it the reduction is more active with hydrogen.

This, however, does not exhaust what we have to say concerning CO. The gas undergoes, under definite conditions, a charateristic decomposition giving as the products $\mathrm{CO}_{2}$ and solid C. This reaction which was first observed by St. Clair Deville *

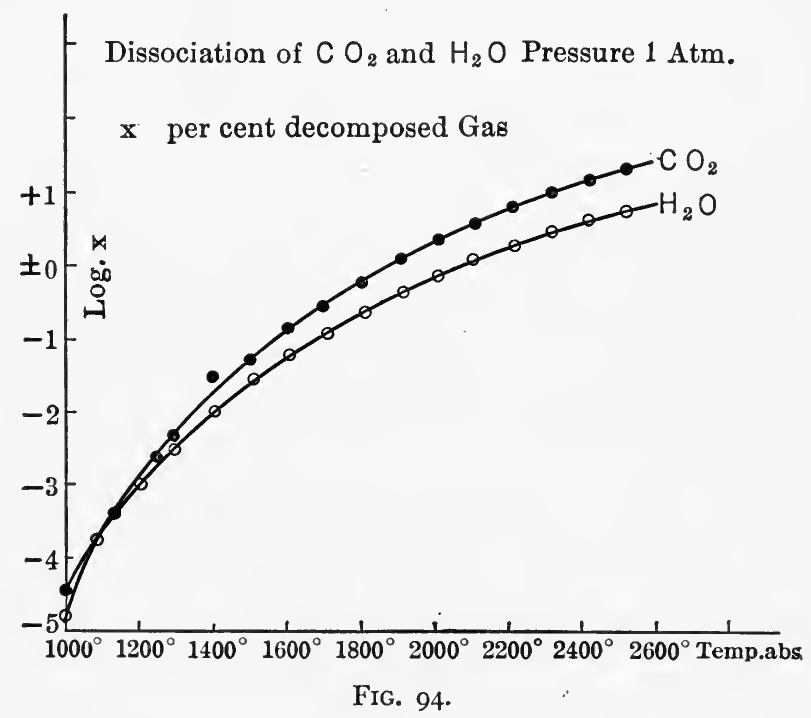

does not proceed alone but requires the presence of certain contact materials. The metals of the iron group $\mathrm{Ni}, \mathrm{Co}, \mathrm{Fe}$ and $\mathrm{Mn}$, are especially active in starting the decomposition process and, indeed, they do this without being thereby changed. Their action is the greater, the greater the surface. We are familiar with the reverse of the above process. The method by which CO is obtained by leading $\mathrm{CO}_{2}$ over glowing $\mathrm{C}$ is a very useful one and plays an important rôle in the formation of producer gas. The reaction

$$
\begin{gathered}
{ }_{2} \mathrm{CO} \rightleftarrows \mathrm{C}+\mathrm{CO}_{2}, \\
\text { * Compt. rend., 59, } 873 \text { (1854). }
\end{gathered}
$$


is accordingly reversible, and runs to completion in neither direction but comes to equilibrium between the concerned substances. Concerning this equilibrium of two components $\mathrm{C}$ and $\mathrm{O}$ divided between two phases the solid $\mathrm{C}$ and the gas mixture, the phase rule says that it possesses a two-degree freedom, that is, the two phases can exist together under different temperatures and pressures.

Concerning the direction in which the composition of the gas is changed by change of pressure, LeChatelier's rule says, through raising the pressure that reaction is favored which goes on with a decrease of volume. It is the decomposition of $\mathrm{CO}$ since two volumes of this gas give one volume of $\mathrm{CO}_{2}$, the simultaneously formed solid substance is neglected in comparison to the gas. The $\mathrm{CO}$ can accordingly be decomposed in the presence of $\mathrm{C}$ at a constant temperature by compressing the gaseous atmosphere. ${ }^{*}$ By lowering the pressure the $\mathrm{CO}_{2}$ acts on the carbon and forms the substance with the greater volume, that is the $\mathrm{CO}$ again (naturally these reactions take place more quickly in the presence of a contact substance). At constant temperature every gas pressure corresponds to an entirely definite ratio of the two gaseous oxides.

The dependence of this ratio on pressure can be determined from the law of mass action. We consider again the reaction in the gas phase and assume that a small immeasurable quantity of carbon vapor is in it. In a similar way as above for the dissociation process, the relations for equilibrium can be developed.

$$
\frac{\mathrm{C}^{2} \mathrm{co}}{\mathrm{Cc} \cdot \mathrm{CcO}_{2}}=\text { Const. }
$$

The concentration of carbon vapor that is in equilibrium with the solid phase is, at constant temperature, a constant magnitude,

* For the effect of pressure on the reaction

$$
{ }_{2} \mathrm{CO} \rightleftarrows \mathrm{C}+\mathrm{CO}_{2},
$$

see Rhead and Wheeler, Trans. Chem. Soc., 97, 218I (1910). These investigators find a very close agreement between the effect of pressure as experimentally determined and as calculated from the mass law. 
depending on the vapor pressure of the carbon. If we combine this constant with the constants on the right side and designate the magnitude obtained by $\zeta$ we obtain as the equilibrium relation for the two oxides of carbon, if they are in contact with solid $\mathrm{C}$ the equation

$$
\zeta=\frac{\mathrm{C}^{2} \mathrm{co}}{\mathrm{CcO}_{2}} .
$$

We will now make the assumption which we have previously employed that the sum of the partial pressures of the two oxides is constant; we set this equal to $I$. If the number of monoxide molecules present is $x$ the dioxide molecules are $\mathrm{I}-x$. If we set the total pressure of the two gases equal to $P$ the partial pressures are $x \cdot P$ and $(\mathrm{I}-x) P$ respectively. The concentrations of the two gases are proportional to these magnitudes. If one substitutes them in the equation it follows:

$$
\zeta=\frac{x^{2}}{\mathrm{I}-x} \cdot P \quad \text { or } \quad P=\zeta \frac{\mathrm{I}-x}{x^{2}} .
$$

These equations give us the relation between the composition of the gas atmosphere ( $x .100$ is the CO per cent) and the pressure under which it stands in case there is equilibrium between the substances present.

In the discussion of the equations it is brought out that $x$ increases with rising values of $P$. The requirements of LeChatelier's principle which we have previously spoken of are accordingly fulfilled. To get a conception of the existing relations we will represent them graphically. The given equation represents a curve of the third degree. Its position is shown in Figs. 95 and $95 a$. Since in our case the abscissa $x$ cannot be greater than I, only that part of the curve with the abscissa between $O$ and $I$ has a real meaning. For later consideration it is well to give here its further extent. In Fig. $95 a$ the real part is drawn. For $x=2$ the curve reaches a minimum, with increasing $x$ it passes through a point of inflection and approaches the abscissa axis asymptotically intersecting it at $x=0$. We have, accordingly, a cubic hyperbola. This form of curve is met with in 
many homogeneous equilibrium systems, for example, in all binary dissociation processes it has considerable importance.

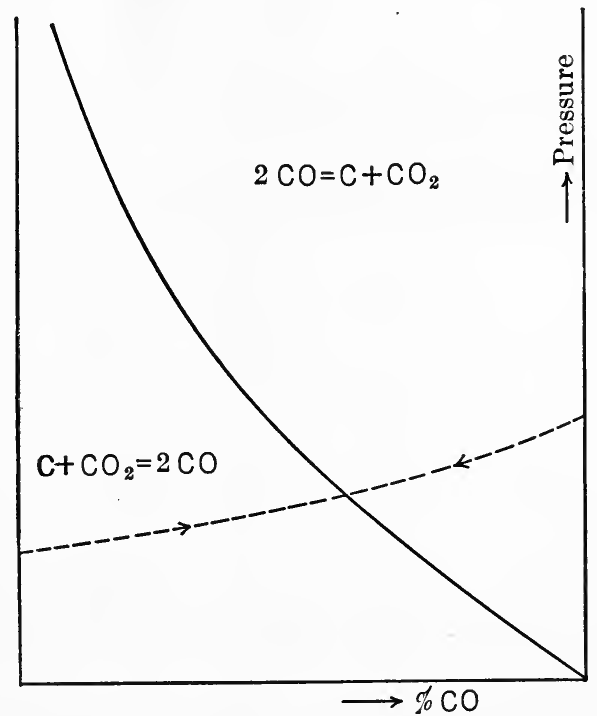

Fig. 95 .

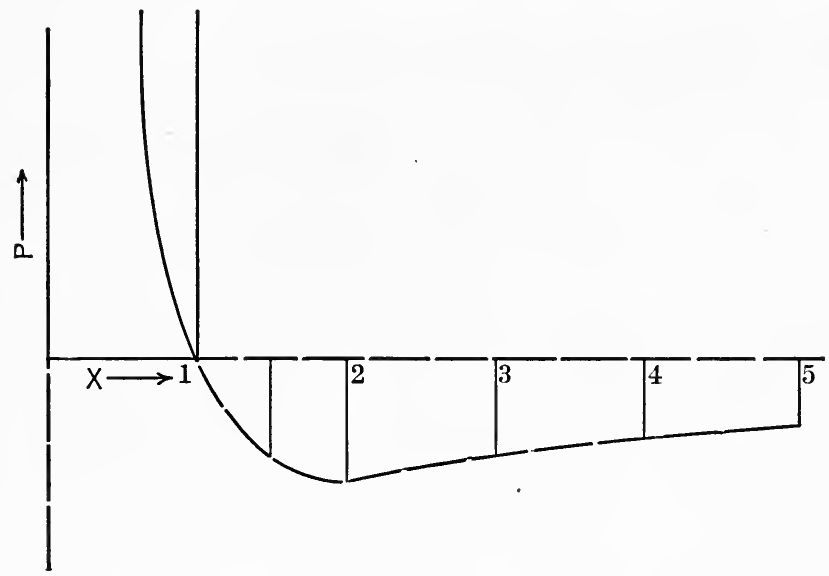

Fig. $95 a$.

The curve which represents the geometrical locus of all possible mixtures of monoxide and dioxide that are in equilibrium with solid carbon, is accordingly an isotherm dividing the field 
(Fig. 95) in two halves. In these, reactions take place, in the right decomposition and in the left formation of $\mathrm{CO}$.

We find in the drawing still another curve (dotted) which begins at the point $x=\mathrm{I}$ and $P=P_{0}$ and terminates at $x=0$ and $P=\frac{P o}{2}$ it is the reaction path of the decomposing of CO, i.e., the series of points through which the decomposing $\mathrm{CO}$ of original pressure $P_{0}$ passes during its decomposition. If we carry the reaction entirely to the end the complete transformation into carbon dioxide is reached when the gas pressure has become half of the original pressure. The form of this reaction path is indicated; the partial pressure of the still present monoxide in the decomposing gas $p$ stands in the following relation to the original pressure $P_{0}$ and the observed total pressure $P$ :

$$
p=P_{0}-2\left(P_{0}-P\right) \Rightarrow 2 P-P_{0},
$$

then the observed difference from the original pressure represents the double difference of the decomposing CO.

Now $p=x \cdot P$ and thence follows

$$
P_{0}=(2-x) P \text {. }
$$

This equation is represented geometrically by a hyperbola. If we consider $P$ as variable we obtain a series of hyperbolas for which $P$ is infinite for the case $x=2$.

The reaction path is also a section of a hyperbola. This usually reaches its end as the equilibrium between the finely divided carbon and its oxides is reached, i.e., in the intersection of the equilibrium curve and the reaction path.

The equilibrium between carbon and its oxides is now, as practical experience in the preparation of generator gas has also shown, strongly dependent on the temperature and at high temperatures very much more monoxide is observed than at low temperatures. From this we draw the conclusion that the formation of carbon monoxide is a process which goes on with heat absorption. Correspondingly heat is evolved in the decomposition of the monoxide, the thermochemistry of the decomposition reaction is expressed by the following equation.

$$
{ }_{2} \mathrm{CO}=\mathrm{C}+\mathrm{CO}_{2}-39,000 \mathrm{cal} \text {. }
$$


there is accordingly a very considerable amount of energy freed in the form of heat.

With increasing temperature the equilibrium constant also increases. Its change with the temperature can be gotten from measurements of Boudouard * on the composition of monoxide dioxide mixtures, that are in equilibrium with carbon at atmospheric pressure and different temperatures. The following table gives the values found from the observations and thermo-

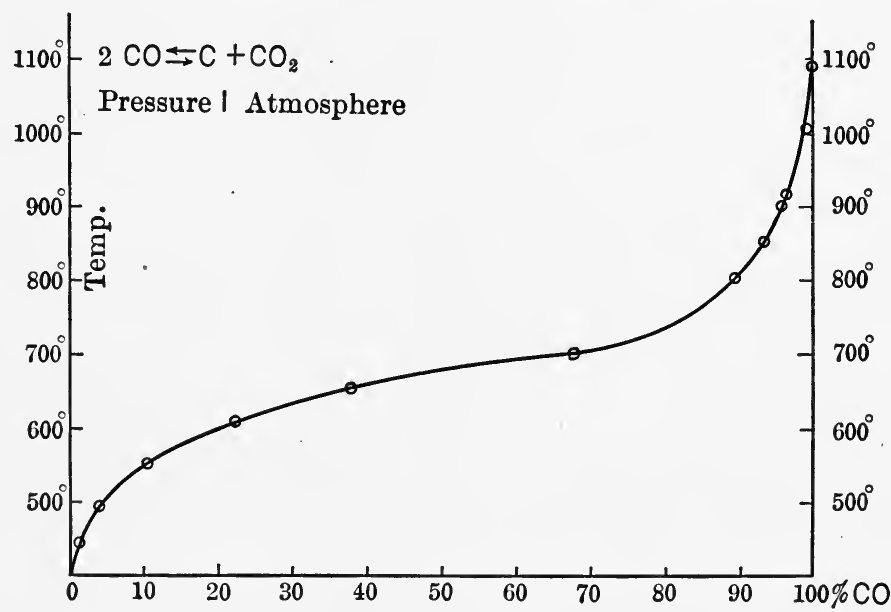

FIG. 96.

dynamic calculations. The dependence on temperature is shown still better by the graphical representation of the results. (Fig. 96)

\begin{tabular}{c|c|c||c|c|c}
\hline $\begin{array}{c}\text { Temperature, } \\
\text { Degrees. }\end{array}$ & Co, Per Cent. & CO $_{2}$ Per Cent. & $\begin{array}{c}\text { Temperature, } \\
\text { Degrees. }\end{array}$ & CO, Per Cent. & CO $_{2}$ Per Cent. \\
\cline { 1 - 2 } 450 & 2 & 98 & 800 & 90 & IO \\
500 & 5 & 95 & 850 & 94 & 6 \\
550 & II & 89 & 900 & 96.5 & 3.5 \\
600 & 23 & 77 & 925 & 97 & 3.0 \\
650 & 39 & 61 & 950 & 98.5 & 1.5 \\
700 & 68 & 32 & 1000 & 99.3 & 0.7 \\
750 & 76 & 24 & 1050 & 99.6 & 0.4 \\
\hline
\end{tabular}

* Ann. Chim. Phys., (7), 24, 5 (rgor).

More recent and accurate measurements of this equilibrium have been made by Rhead and Wheeler, Trans. Chem. Soc., 97, 2181 (1910). For a discussion of the results of these investigators from the standpoint of thermodynamics see Lewis and Randall, J. Am. Chem. Soc., 37, 458(I915). 
The values of $\zeta$ vary still further with the different modifications of carbon. Graphite gives different results from amorphous, wood or sugar carbon, or the modification resulting from the decomposition of the monoxide. The ratio between these equilibrium constants can be determined in a way which we shall consider later. Schenck and Heller* found the following numbers:

\begin{tabular}{|c|c||c|c|}
\hline $\begin{array}{c}\text { Temperature, } \\
\text { Degrees. }\end{array}$ & Graphite. & CO-carbon. & Sugar Carbon. \\
\cline { 1 - 3 } 600 & I & 5 & 5.5 \\
660 & I & 6 & 6.6 \\
\hline
\end{tabular}

It is accordingly not immaterial in the preparation of generator gas whether a graphite like coal is used or an amorphous form, the latter is to be desired since it gives gas richer in a carbon monoxide under the same conditions.

These relations can be at once seen if we recall the development of $\zeta$ with the help of the mass law. We see that the concentration of carbon vapor which is in equilibrium with the carbon enters into these magnitudes. This carbon vapor pressure is different for the different carbon modifications. We can get from this as Smits $\dagger$ has done that the relations between the values of $\zeta$ are the direct relations between the vapor pressures of the different carbon modifications.

We have considered rather fully the relations of carbon monoxide. We must, however, study its peculiarities, its relation to carbon dioxide on the one hand, and to carbon on the other since in all reduction with the help of carbon this oxide occurs as a reaction product and frequently influences the course of the reaction.

$$
\text { * Ber., 38, } 2 \text { 139 (r905). }
$$




\section{CHAPTER V}

\section{DECOMPOSITION OF CARBON MONOXIDE, BLAST- FURNACE PROCESSES}

We have already, in a previous chapter, learned of the remarkable decomposition which carbon monoxide suffers under certain conditions, namely, its decomposition into carbon dioxide and elementary carbon. We have seen that this process can only take place in the presence of contact material and that the finely divided metals of the iron group, nickel, cobalt iron and manganese serve as such. We have also determined the reaction path of the decomposing monoxide and the place at which the decomposition halts.

\section{Catalytic Decomposition of Carbon Monoxide.}

All these theoretical conclusions are confirmed if the decom. position is carried through at a constant temperature, near the boiling point of sulfur, using as a catalyst finely divided nickel or cobalt. Fig. 97 shows the change of pressure with time, of a given amount of carbon monoxide at constant volume, during the decomposition reaction in the presence of nickel and iron. This has been observed by Schenck and Zimmermann in their investigation on the decomposition of carbon monoxide. As is seen, there is a considerable difference in the action of the two metals. With nickel the reaction comes to a standstill, when the equilibrium between carbon and its two gaseous oxides is reached as we should expect from our earlier experiences. The final pressure reached should, therefore, not be under half of the original pressure of the pure carbon monoxide.

To our great astonishment, we meet with iron an entirely different condition, a very large pressure decrease, that we can 
only explain by a transition of the gas into a solid product. Sometimes the final pressure is only a small per cent of the original pressure. If we investigate the contact mass more carefully it is found that along with the precipitation of carbon an oxidation of metallic iron has taken place.

We encounter the paradox, that iron is oxidized by the strong reducing agent, pure carbon monoxide. At first sight this fact appears contrary to all we have learned in the previous lecture.

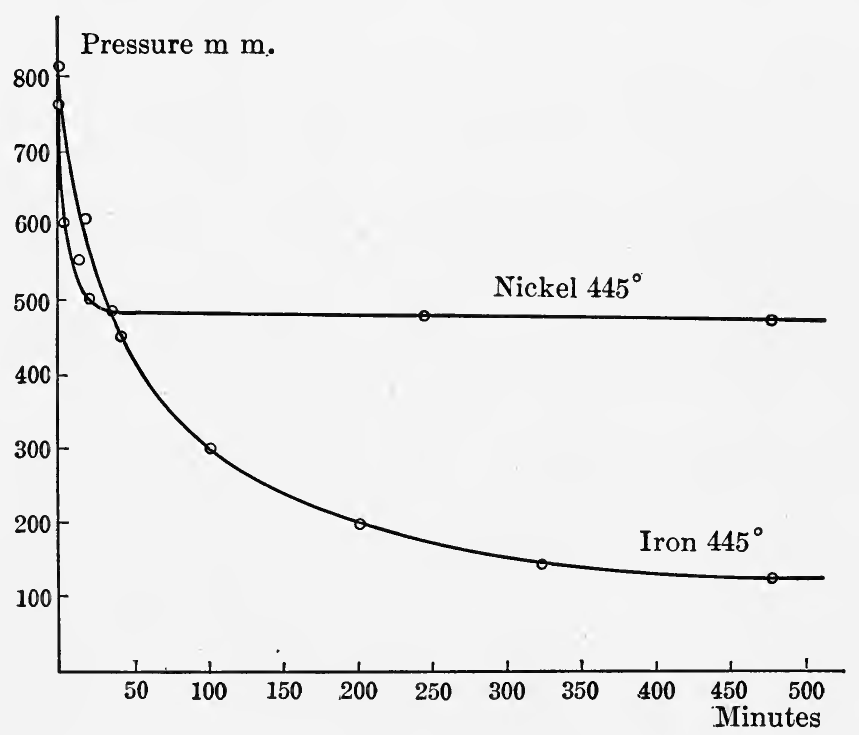

FIG. 97.

The entire problem is apparently thereby complicated since with other original pressures the decomposition goes as in the presence of cobalt and nickel.

The solution of the problem is reached when one thinks that from the decomposition of carbon monoxide, the dioxide results, and that its concentration can, under some conditions, grow so great that the equilibrium ratio of the two gases with iron and iron oxide is exceeded. It then follows that the metal is oxidized with the formation of carbon monoxide, and, on the other hand, this gas decomposes again with the precipitation of carbon. By the alternation of the two processes, oxi- 
dation of the metal and the decomposition of the carbon monoxide, all the carbon as well as all the cxygen can go over to the solid state. The reaction path (see page I33 and Fig. 98), is under these conditions complicated further than with the simple decomposition in the presence of nickel. If we assume the same original pressure and temperature for the reaction in the presence of iron and of nickel then the two hyperbola limbs fall together until the ratio of the two gaseous oxides of carbon has reached a value at which oxidation of the iron results. In the presence of nickel, which is not oxidized, the reaction proceeds along the

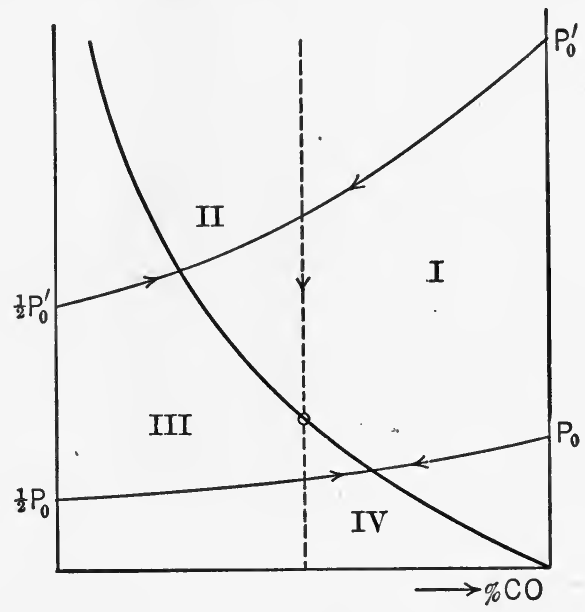

Fig. 98.

hyperbola till the curve is reached which represents the equilibrium between carbon and its oxides. In the presence of iron there is a break in the reaction path, the pressure decreases strongly while the composition of the gases approaches a value at which it is in equilibrium with carbon and with iron and iron oxide. We will see further on, that it depends on the position of this total equilibrium and on the original pressure of the carbon monoxide whether an oxidation of the metal by the gas takes place or whether the metal remains unoxidized and acts as contact material for the decomposition of carbon monoxide into carbon dioxide and solid carbon as nickel does. 


\section{Equilibrium Between Carbon Monoxide and Iron.}

The total equilibrium between iron, iron oxide, carbon and the two gaseous oxides, carbon monoxide and carbon dioxide is represented as an equilibrium of a three-component system (components, carbon, iron and oxygen) with the simultaneous presence of four phases ( $\mathrm{Fe}, \mathrm{FeO}, \mathrm{C}$, gas). According to the phase rule such a system must possess one degree of freedom, the equilibrium is univariant precisely as a vapor pressure. Every temperature corresponds to an entirely definite equilibrium pressure.

We arrive at the same results by the use of the mass law. We have for our case, the equilibrium conditions for two bivariant systems

I.

2.

$$
\begin{aligned}
\mathrm{FeO}+\mathrm{CO} & \rightleftarrows \mathrm{Fe}+\mathrm{CO}_{2}, \\
{ }_{2} \mathrm{CO} & \rightleftarrows \mathrm{C}+\mathrm{CO}_{2} .
\end{aligned}
$$

that must be simultaneously fulfilled. The first may, as we have seen earlier, be expressed by the equation

I.

$$
\frac{x}{\mathrm{I}-x}=\eta
$$

and second by

2.

$$
\frac{x^{2}}{I-x} \cdot P=\zeta
$$

If we eliminate $x$ from these two simultaneous equations we obtain an expression for the total pressure of the two gases $P$ in which this magnitude depends only on the equilibrium constants $\eta$ and $\zeta$

$$
P=\zeta \frac{\mathrm{I}+\eta}{\eta^{2}}
$$

It follows from this so long as $\zeta$ and $\eta$ are constants for a given temperature, that every temperature corresponds to an entirely definite gas pressure, a definite sum for the partial pressures. From Eq. (I) it follows further that also the composition of the gas phase is absolutely fixed.

The facts can be made very plain if we show the equations graphically. 
We have already recognized a parallel to the ordinate axis as a geometrical locus of the equilibrium between metal, oxide and the two gases, and a cubic hyperbola as the geometrical expression of the equilibrium between carbon and its oxides. The two intersect, and at the intersection, the two equilibria are simultaneous, it represents the total equilibrium between metal, metal oxide, carbon and the two gaseous oxides (see Fig. 98). The two equilibrium lines, straight and cubic hyperbola divide the plane of our picture into four fields, in these the following reactions take place:

$$
\begin{aligned}
& \text { Field I. } \quad{ }_{2} \mathrm{CO} \rightarrow \mathrm{C}+\mathrm{CO}_{2} \\
& \mathrm{FeO}+\mathrm{CO} \rightarrow \mathrm{Fe}+\mathrm{CO}_{2} \\
& \text { Field II. } \quad{ }_{2} \mathrm{CO} \rightarrow \mathrm{C}+\mathrm{CO}_{2} \\
& \mathrm{Fe}+\mathrm{CO}_{2} \rightarrow \mathrm{Fe}+\mathrm{CO}
\end{aligned}
$$

Field III. $\mathrm{C}+\mathrm{CO}_{2} \rightarrow{ }_{2} \mathrm{CO}$

$$
\mathrm{Fe}+\mathrm{CO}_{2} \rightarrow \mathrm{Fe}+\mathrm{CO}
$$

Field IV. $\mathrm{C}+\mathrm{CO}_{2} \rightarrow{ }_{2} \mathrm{CO}$

$$
\mathrm{FeO}+\mathrm{CO} \rightarrow \mathrm{Fe}+\mathrm{CO}_{2}
$$

The reduction of iron oxide or generally of oxide to metal accordingly goes on only in fields I and IV. Carbon monoxide can act as a reducing agent inside of both. Solid carbon can only act as a direct reducing agent in field IV. In field II the two substances carbon and oxide, remain together, in field III the carbon gradually disappears without thereby attacking the metal oxide.

Of all points of the $P-X$ diagram the solid phases, metal oxide and carbon, are only present at the point of total equilibrium, the intersection of the curve with the line.

In which way this occurs we have already seen in the consideration of the decomposition of carbon monoxide in the presence of iron. We have there confined ourselves to a special case; we have already mentioned, however, that the decomposition of the pure carbon monoxide in the presence of iron can take place so that no oxidation of metal results. Now we will determine the conditions under which the two forms of carbon monoxide decomposition take place. 
The original pressure of the pure carbon monoxide is decisive for this, on it depends whether the hyperbolic reaction path (see above) lies above or below the intersection of the cubic curve, with the line. We have learned of the first case above, the reaction path meets first the line and suffers a deflection going into field I and field II where oxidation of the metal results. If the hyperbola runs beneath the equilibrium point, so it strikes the decomposition curve first, and with the attainment of the simple carbon equilibrium the reaction comes to rest, since inside of fields I and IV the oxidation of the metal is impossible.

The limiting case between the two is given if the reaction path cuts directly at the point. It can be easily calculated what the original pressure of $\mathrm{CO}$ was when this condition is satisfied. The equation of this hyperbolic reaction path has been derived in the fourth chapter. It is

$$
P_{0}=(2-x) P \text {. }
$$

If we substitute in this equation the ordinates of the total equilibrium, namely,

and

$$
P=\zeta \frac{I+\eta}{\eta^{2}}
$$

$$
x=\frac{\eta}{\mathrm{I}+\eta}
$$

it follows for the limiting case:

$$
P_{0}=\left(2-\frac{\eta}{\mathrm{I}-\eta}\right) \zeta \frac{\mathrm{I}+\eta}{\eta^{2}}=\zeta \frac{2+\eta}{\eta^{2}} .
$$

If the original pressure of the carbon monoxide is greater than this value, the metal is itself finally oxidized, if it is smaller the metal acts only as contact substance.

The position of the equilibrium point and the magnitude of the equilibrium pressure are dependent on the nature of the metal, the carbon modification present and the temperature, since these factors are determinative for the magnitudes $\zeta$ and $\eta$. If we consider now the relations at constant temperature we see that with the same modification of carbon (constant $\zeta$ ) $P$ becomes smaller with increasing $\eta$. 
The less noble the metal is, the smaller will be the equilibrium pressure for the reduction of its oxide with carbon. It is the higher the more noble the metal. Now we understand why the nickel acts only as a contact material toward the carbon monoxide; why it is not, as under certain conditions with iron, oxidized by the decomposing gas.

Nickel is somewhat more noble than iron and we may assume that its equilibrium pressure is many atmospheres, so that under ordinary working conditions the decomposition hyperbola of the carbon monoxide runs far beneath this pressure. Iron is the only metal with which this pressure can be conveniently observed, with the more noble it is so high that it is difficult of measurement and with the less noble it is exceedingly small.

If we consider only one metal (constant $\eta$ ) but different modifications of carbon, the equilibrium pressure is the greatest, with the form with greatest $\zeta$. Accordingly a greater equilibrium pressure corresponds to the equilibrium with amorphous carbon than with graphite.

The magnitudes of the equilibrium pressures, for different forms of carbon are, as can be seen from the equation

$$
P=\zeta \frac{\mathrm{I}+\eta}{\eta^{2}}
$$

directly proportional to the values of $\zeta$.

Both $\eta$ and $\zeta$ are dependent on the temperature and, indeed, they both increase, as we have seen earlier, with rising temperature. Whether $P$ also increases with the temperature, cannot be derived from the equation directly. It depends on the ratio of the temperature coefficients of the two equilibrium constants. Experiment has shown that the pressure increases with the temperature.

For the determination of the equilibrium pressure, several ways are available. We can reach it as we have seen above, if we allow carbon monoxide at a sufficiently high original pressure to react with metallic iron at a given temperature. It is only necessary to follow the pressure decrease and the reaction comes to rest when the equilibrium pressure is reached. We arrive at the same value by gradual heating of the solid phases iron, carbon 
and ferrous oxide, in a previously evacuated tube connected with a manometer.

Investigations concerning these reduction equilibria have been carried out by Schenck and Heller* as well as Schenck, Semiller and Falcke. $\dagger$ Their results are collected in the following table. Besides the pressure values the table gives the composition of the gas phase.

\begin{tabular}{|c|c|c|c|c|c|}
\hline & \multirow{2}{*}{$\begin{array}{l}\text { Temperature } \\
\text { in Degrees. }\end{array}$} & \multirow{2}{*}{$\begin{array}{l}\text { Pressure, } \\
\text { Mm. }\end{array}$} & \multicolumn{2}{|c|}{$\begin{array}{l}\text { CoMposition OF THE } \\
\text { GAS PHASE. }\end{array}$} & \multirow{2}{*}{ Observers. } \\
\hline & & & $\begin{array}{l}\text { CO, } \\
\text { Per Cent. }\end{array}$ & $\begin{array}{l}\mathrm{CO}_{2} \\
\text { Per Cent. }\end{array}$ & \\
\hline $\begin{array}{l}\mathrm{Fe}, \mathrm{FeO}, \mathrm{C} \text { am- } \\
\text { orphous from } \\
\mathrm{CO}\end{array}$ & $\begin{array}{l}455 \\
510 \\
538 \\
55^{2} \\
556 \\
561 \\
562 \\
586 \\
596 \\
616 \\
619 \\
629 \\
643 \\
651 \\
662 \\
670\end{array}$ & $\begin{array}{r}27 \\
43 \\
8 \mathrm{I} \\
130 \\
137 \\
142 \\
177 \\
266 \\
296 \\
401 \\
411 \\
469 \\
561 \\
57 \mathrm{I} \\
662 \\
858\end{array}$ & $\begin{array}{l}53 \cdot 7 \\
53 \cdot 4 \\
53 \cdot 6\end{array}$ & $\begin{array}{l}46.3 \\
46.6 \\
46.4\end{array}$ & $\begin{array}{l}\text { Schenck and } \\
\text { Semiller }\end{array}$ \\
\hline $\begin{array}{l}\mathrm{Fe}, \mathrm{FeO} \text {, sugar } \\
\text { carbon }\end{array}$ & $\begin{array}{l}408 \\
465 \\
560 \\
590 \\
627 \\
649\end{array}$ & $\begin{array}{r}5.6 \\
10.4 \\
161.7 \\
314.5 \\
546.8 \\
750.1\end{array}$ & & & $\begin{array}{l}\text { Schenck and } \\
\text { Heller }\end{array}$ \\
\hline $\begin{array}{l}\mathrm{Fe}, \mathrm{FeO} \text {, graph- } \\
\text { ite }\end{array}$ & $\begin{array}{l}500 \\
536 \\
550 \\
568 \\
582 \\
609 \\
660\end{array}$ & $\begin{array}{r}12.3 \\
27.3 \\
36.8 \\
49.2 \\
69.3 \\
77.5 \\
129.0\end{array}$ & 59.6 & $\cdot$ & $\begin{array}{c}\text { Schenck and } \\
\text { Falcke }\end{array}$ \\
\hline
\end{tabular}

*Ber., 38, 213I (1905).

† Ber., 40, 1708 (1907). 
As carbon modifications, the amorphous carbon resulting from the decomposition of carbon monoxide, sugar carbon, and graphite are used.

It can be seen from the equation, that at the same temperature, differences of pressure due to variation of the carbon modification do not also require differences in gas compositions. These changes influence only the values of $\zeta$ but not that of $\eta$.

Also the reduction of $\mathrm{Fe}_{3} \mathrm{O}_{4}$ to $\mathrm{FeO}$ by means of amorphous carbon has measurable equilibrium pressures which are collected in the following table:

\begin{tabular}{|c|c|c|c|}
\hline Solid Phases. & $\begin{array}{l}\text { Temperature } \\
\text { in Degrees. }\end{array}$ & $\begin{array}{l}\text { Pressure in } \\
\text { Millimeters. }\end{array}$ & Observers. \\
\hline $\mathrm{Fe}_{3} \mathrm{O}_{4}, \mathrm{FeO}, \mathrm{C}$ (amorphous) & $\begin{array}{l}528 \\
535 \\
551 \\
560 \\
568 \\
581\end{array}$ & $\begin{array}{rr} & \text { I } 21 \\
129 \\
\text { about } \\
175 \\
303 \\
\text { about } 430 \\
699\end{array}$ & Schenck and Falcke \\
\hline
\end{tabular}

The Analysis of Mixtures of Graphite and Amorphous Carbon.

We will now put the results of our theoretical and experimental investigations concerning the reduction of iron oxide by carbon to a practical test. We will first consider an analytical problem. The chemist has often been given the problem of determining quantitatively graphite in the presence of amorphous carbon. This problem has been impossible of solution with the previously available methods. Our intimate knowledge of reduction by carbon puts us in a position to arrive at a method which will reach the stated goal. It can be directly deduced from the diagram, which represents the equilibrium between iron and ferrous oxide, as well as the different carbon modifications with the gaseous oxides of carbon at constant temperature.

We show on Fig. 99 beside the vertical line for the iron equilibrium, also the equilibrium isotherm for amorphous and graphitic carbon. We select a suitable temperature of about $75^{\circ}$. From this diagram we arrive at the conditions under which amorphous carbon will be oxidized by ferrous oxide while the graphite will remain unattacked. 
Our earlier considerations (compare page I40 and Fig. 98) show that a transformation of carbon into its gaseous oxides by ferrous oxide is only possible inside field IV as in Fig. 99, field IV for amorphous carbon is considerably greater than the corresponding one of graphite (curve $G=$ graphite, $A=$ amorphous carbon.) The remaining fields are not suitable for our purpose since both forms of carbon react with ferrous oxide. The shaded

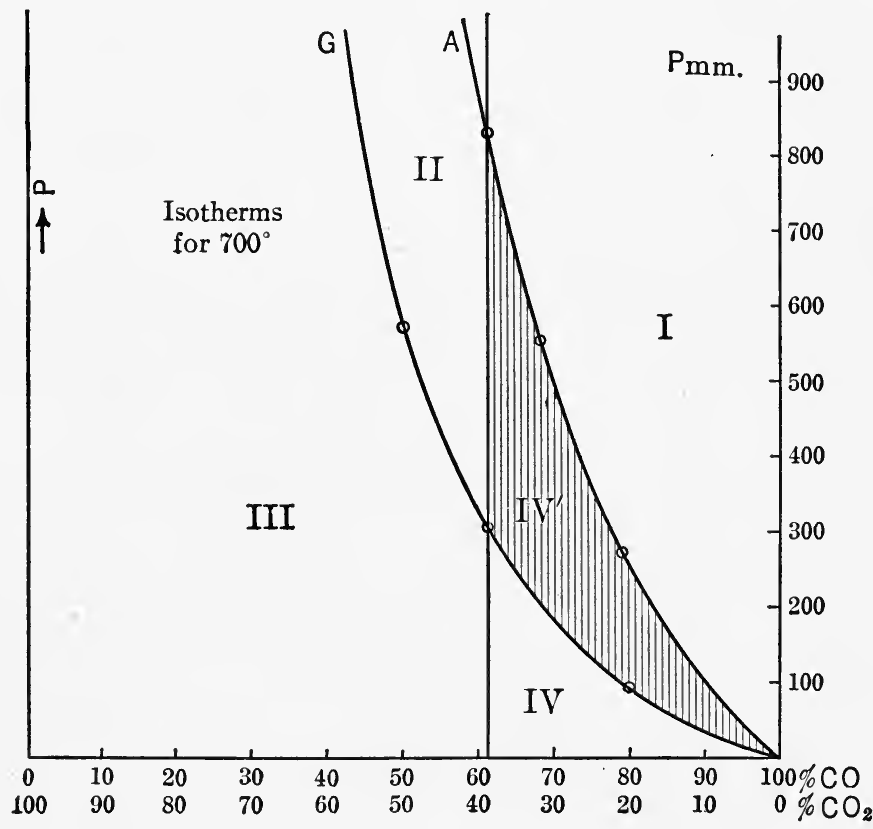

Fig. 99.

field $\left(\mathrm{IV}^{\prime}\right)$ in which only the amorphous carbon is burnt to carbon monoxide is however suitable.

In the practical performance, we mix the sample of mixed carbon forms with ferrous oxide or more conveniently dry ferrous oxalate, which, by heating to $300^{\circ}$ in an indifferent atmosphere, leaves ferrous oxide. If we now heat this mixture in a stream of mixed carbon monoxide, and dioxide, the gas pressure and composition represents a point in field $\mathrm{IV}^{\prime}$, so we have the conditions under which the amorphous carbon is burnt. If we 
choose for the performance a temperature between $700^{\circ}$ and $720^{\circ}$, which can be held sufficiently constant by means of a Heræus resistance furnace, we can work under atmospheric pressure. A convenient composition of the gas mixture is 65 per cent monoxide and 35 per cent dioxide.

\section{The Blast-furnace Process.}

Further, our discussion concerning reduction forms the basis for the theory of our most important technical process, the ironblast furnace. As we all know the blast furnace consists of a shaft of double conical form in which the iron ore to be reduced is interlayed with carbon and slag-forming material in the upper cone. The under bowl sets with its narrow part in the " frame," in which the supply for the hot blast, the so-called " tuyeres," are built in.

The pit still beneath forms the hearth in which the blast furnace products, liquid pig iron and above this the slag settle, the latter flows continuously through a side opening, while the metal is drawn from time to time.

The process with which we are concerned takes place between the tuyeres and the throat. In front of the tuyeres the carbon is burnt by the oxygen of the air and as a result of the preheating of the air there is a very high temperature of combustion, which is above $1100^{\circ}$, the combustion product is accordingly nearly pure carbon monoxide since the gas mixture, which is in equilibrium with carbon at this high temperature and the lowest possible pressure, of the combustion product contains only traces of dioxide.

As at the ordinary pressure of $750 \mathrm{~mm}$. the partial pressure of the oxygen is $150 \mathrm{~mm}$. and since the two volumes result from one volume of oxygen the pressure maximum is $\frac{1}{3}$ atmosphere (two volumes $\mathrm{CO}-4$ volumes nitrogen) i.e., $250 \mathrm{~mm}$. The sum of the partial pressures of $\mathrm{CO}_{2}$ and $\mathrm{CO}$ cannot exceed this pressure and, as a rule, it remains under this value.

The gases containing $\mathrm{CO}$ come up from below and encounter the solid charge which melts in the hot zone and is displaced by fresh material from above. On their way the hot gases give up 
their temperature and finally enter into reaction with the heated ore and carbon. We obtain thus a temperature gradient inside of the furnace from below to above.

At the throat of the furnace the gases still have a temperature of $400-500^{\circ}$. In this upper zone chemical reactions do not take place but the moisture which the charge contains is vaporized and so a drying of the solid material results. With sinking into the hot sphere the reduction begins, first, that of the higher oxides to ferrous oxide, then that of ferrous oxide to metal. This is cemented by a further action of the carbon monoxide and carbon. Somewhat below the tuyeres the temperature finally becomes so high that both the iron and the slag melt. This liquid mass collects in the hearth and the task of blast furnace, namely the preparation of pig iron, is finished.

The problem is to conduct the process so that the single processès which go on from oxidized ore to the iron carbon alloys, take place smoothly and without disturbance. The right temperature and the right composition of the gas stream are of the greatest importance to reach this goal.

Before we go into the possible disturbances we will turn to an important by-product of the blast furnace, the throat gases. Still at the beginning of the Igth century the gases were simply allowed to escape from the throat, it was, however noticed that they contained a large amount of burnable substance which, if allowed to go to waste, meant the loss of large heat values. In I836, Fabre du Faure sought to remedy this disadvantage and by the use of the throat gas, for regenerators, brought the blast furnace process to a rational form. At this time the demands on iron due to the introduction of railroads and steam machines and interest in cheap prices for the raw materials was growing steadily, and caused everything necessary for economic production of the pig iron to be energetically considered, and occasioned also in I836 the Kurfurstliche Hessische Bergdirektion zu Kassel, to put to the professor of chemistry at Marburg, Robert Bunsen, the problem of making a close investigation of the blast-furnace process.

The title of his communication on the results of his research 
in Poggendorffs Annalen, "Concerning the gaseous products of the blast furnace and its use as burning material," betrayed at once from which side he attacked the problem. It was on this occasion that he worked out his well-known methods of gas analysis which he used for the study of the composition of the blast-furnace gases. He confirmed their high $\mathrm{CO}$ content and calculated that under certain conditions up to three-fourths of the carbon used was lost if the gases were allowed to escape unused, into the atmosphere.

The amount of combustible constituents is in fact large and the following small table gives the average composition of the blast-furnace gases:

Nitrogen.............. 54-66 per cent

Carbon Dioxide........... 7-19

Carbon Monoxide........... 2I-3I

Hydrogen............... I -6

Hydrocarbons............. o- 6

The technic has made use of this knowledge and the gases are led out and used in the rational way. In part, they are burnt in the Cowper apparatus and so warm the blast which the furnace receives through the tuyeres and in part they are used to heat steam boilers. Later experience has taught that their energy content is best used, if they are purified and mixed with air in gas engines. The useful effect is here much greater than by the use in connection with boiler and steam engines. Blast-furnace gas motors of very large dimensions are now used. They furnish the mechanical energy for the operation of steel and rolling mills, as well as drive dynamos and furnish light and power for a wide circle of our industrial operations. The exploitation of this original by-product has been of the greatest technical importance.

Yet before we had progressed so far, the question was frequently asked whether it was possible to use the strongly reducing gas for further reduction of ore. Large means have been used to lengthen the layer of ore through which the gas passed. Blast furnaces have even been built 30 meters high; however, no matter how high they were the $\mathrm{CO}$ content of the throat gases was not 
appreciably reduced. This negative result of costly experiments cannot be wondered at by one conversant with chemical equilibrium, he knows that the reduction of iron is a reversible reaction, he knows that by the action of $\mathrm{FeO}$ on $\mathrm{CO}$ a certain amount of the gas must remain over and that the remainder does not come into consideration in the least for the preparation of iron. However, this scientific knowledge is unfortunately younger than the troubles concerning the utilization of blastfurnace gases.

The cooler is the zone in which the gases arrive the higher rises the content of carbon dioxide. This is not alone due to the reduction; the same phenomena would be observed if the ore in the furnace were entirely lacking. The influence of the temperature on the composition of the gases is due to its effect on the equilibrium of carbon monoxide with carbon. With decreasing temperature the carbon monoxide formed at the tuyeres, breaks down more and more into dioxide and finely divided carbon. The presence of metallic iron greatly favors this reaction. The attainment of the theoretical equilibrium is, however, only partial, due to the great velocity of the gas stream. Therefore, the blast-furnace gases are always richer in carbon monoxide than corresponds to the equilibrium ratio and the zone temperature. Since the temperature at which reduced iron is in contact with the gas, is quite high, and the pressure of the total equilibrium between metal, oxide, carbon and the gases corresponding to these temperatures is over $\frac{1}{3}$ atmosphere, we may, accordingly, designate the field of the equilibrium diagram that represents the pressure and the composition of the blast-furnace gases. According to the above laid-down rules only field I comes into consideration and, indeed, only that part in which the pressure is smaller than the pressure of the total equilibrium. We recognize therefrom that the reduction in the blast furnace is essentially by means of $\mathrm{CO}$.

Under certain conditions, for example, as a result of stoppages in the blast supply, the region in which the ore is reduced to metal may be cooled to a temperature of $500^{\circ}$ or still lower. At this temperature the pressure of the total equilibrium is less 
than the sum of the partial pressure of monoxide and dioxide, the composition of the gases then represents a point in field II. Oxidation of the metal takes place and simultaneous precipitation of finely divided carbon, which stops the furnace. The approach of danger may be learned from the increase of $\mathrm{CO}_{2}$ in the throat gases. The lowest temperature at which reduced metal may be in contact with the furnace gases, without reoxidation of iron taking place, is that at which the pressure of the total equilibrium is equal to the sum of the partial pressure of the carbon monoxide and dioxide in the gases. If we take this sum as $200 \mathrm{~mm}$., the temperature above which no difficulty will ensue is $570^{\circ}$. Beside the reduction, there takes place in the furnace, the cementing of the iron, which is a very important process for the smooth operation of the blast furnace. As we have seen in an earlier lecture the melting point of the iron-cementite is very much lower than that of pure iron. This fact has the important practical consequence, that one can operate a furnace, in which pig iron is to be melted, at a much lower temperature than one in which pure iron is to be melted. This temperature difference is nearly $400^{\circ}$, a condition which is very essential for the permanence of the furnace material.

Concerning the conditions for the cementing of iron by carbon monoxide we will supplement the experiments by means of theoretical calculation. We are limited for experimental material to an investigation of the question at temperatures up to $700^{\circ}$, below this the formation of solid solutions of iron and carbide does not occur, the results of these experiments give us only a general schematic picture of the run of cementation at higher temperatures and with solid solution formation.

In laboratory investigations concerning the action of $\mathrm{CO}$ on metallic iron, it has frequently been observed that if the amount of carbon monoxide present is large compared to the amount of iron, that there are entirely different and much lower equilibrium pressures than under the same conditions of temperature and original pressure with relatively smaller amounts of gas and larger amounts of metal. The former pressure value is near that which represents the equilibrium between iron, $\mathrm{FeO}$, graphite and 
the gases and its origination is explained by the transition of labile amorphous carbon into the stable graphite.

On the basis of our earlier experiences we have a means of testing this explanation for its correctness. If the difference of the two pressures is conditional on the carbon modifications, there must be at constant temperature, the same ratio of carbon monoxide and carbon dioxide, the monoxide content of gas must vary accordingly between 53 per cent and 60 per cent (see table p. I43). To our astonishment the content proves to be much higher, between 85 and 90 per cent. The difference of the two equilibrium systems can not accordingly be conditioned by the difference in the carbon modifications.

Another possible explanation is that, in the place of $\mathrm{FeO}$, another more difficultly reducible oxide has been formed, but there is no other evidence of this. The only logical assumption is that a change takes place in the iron phase. Since by the action of carbon monoxide on metallic iron, there takes place first.a transformation of the upper surface into cementite $\left(\mathrm{Fe}_{3} \mathrm{C}\right)$, according to the equation

$$
{ }_{3} \mathrm{Fe}+{ }_{2} \mathrm{CO}=\mathrm{Fe}_{3} \mathrm{C}+\mathrm{CO}_{2},
$$

and this carbide is oxidized by further decomposition of the $\mathrm{CO}$, as we have earlier seen with the metal, till finally there results a total equilibrium between cementite, ferrous oxide, amorphous carbon and the gas mixture. The observation data follow:

\begin{tabular}{|c|c|c|c|c|}
\hline \multirow{2}{*}{$\begin{array}{c}\text { Tempera- } \\
\text { ture, } \\
\text { Degrees. }\end{array}$} & \multirow{2}{*}{$\begin{array}{c}\text { Pressure, } \\
\text { Millimeters. }\end{array}$} & \multicolumn{2}{|c|}{ Composition of Gas. } & \multirow[b]{2}{*}{ Observers. } \\
\hline & & $\begin{array}{l}\mathrm{CO} \\
\text { Per Cent. }\end{array}$ & $\begin{array}{l}\mathrm{CO}_{2}, \\
\text { Per Cent. }\end{array}$ & \\
\hline 468 & 10.3 & 0.0 & 0.0 & \multirow{10}{*}{$\begin{array}{l}\text { Schenck, Heller, Semiller, and } \\
\text { Falcke. } \\
\text {. }\end{array}$} \\
\hline 540 & 30.0 & $\cdots \cdots$ & $\cdots \cdots$ & \\
\hline 600 & 65.0 & - $\cdots \cdots$ & $\cdots \cdots \cdots$ & \\
\hline $\begin{array}{l}364 \\
672\end{array}$ & $\begin{array}{l}82.9 \\
13 I\end{array}$ & $\begin{array}{c}\cdots \ldots \\
86.0\end{array}$ & $\begin{array}{c}14.0 \\
14.0\end{array}$ & \\
\hline 691 & 195 & & & \\
\hline 722 & 298 & 87.5 & I 2.5 & \\
\hline 734 & $34 \mathrm{I}$ & 88.0 & 12.0 & \\
\hline 735 & 344 & 88.3 & II.7 & \\
\hline 774 & 562 & 89.5 & 10.5 & \\
\hline 779 & 657 & & & \\
\hline
\end{tabular}


The iron carbide is accordingly considerably more easily oxidized than the metal.

If the dependence of the pressure on the temperature is shown graphically, a curve is obtained exactly as with the reduction of ferrous oxide by the different modifications of carbon. In order to represent the comparative relations of this univariant system, the composition of the gas phase must be considered, that is, a space model must be used with the coordinates $T$, temperature, $P$, pressure and $x$, composition. In

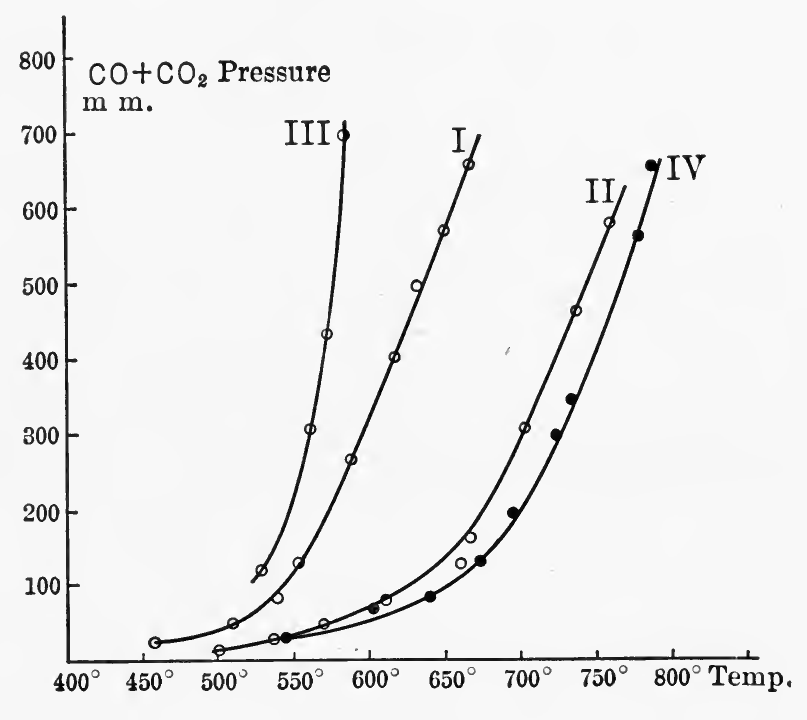

Fig. 100.

this the equilibria are represented by space curves. If we project these space curves on the three coordinate planes, we obtain Figs. I00 and Ior.

From these observation data the conditions can be deduced, under which iron carbide is formed from metallic iron. We have even determined a series of space curves which represent the many equilibria of the four-phase system. If we consider a single isotherm in this space diagram, the intersections of the single space curves are marked as points. 
Concerning the 4-phase systems ( $\mathrm{Fe}, \mathrm{FeO}, \mathrm{C}$ (amorphous) $\mathrm{CO}$, $\left.\mathrm{CO}_{2}\right)\left(\mathrm{Fe}, \mathrm{FeO}\right.$ graphite, $\left.\mathrm{CO}, \mathrm{CO}_{2}\right)$ and $\mathrm{Fe}_{3} \mathrm{O}_{4}, \mathrm{FeO}, \mathrm{C}$ (amorphous) $\mathrm{CO}, \mathrm{CO}_{2}$ ) we have earlier seen that these points can be conceived of as intersections of the curves of bivariant equilibrium systems. The same holds naturally also for the new systems $\left(\mathrm{Fe}_{3} \mathrm{C}, \mathrm{FeO}, \mathrm{C}\right.$ (amorphous) $\mathrm{CO}, \mathrm{CO}_{2}$ ). We think of these four phases as conditioned on the simultaneous existence of the equilibria

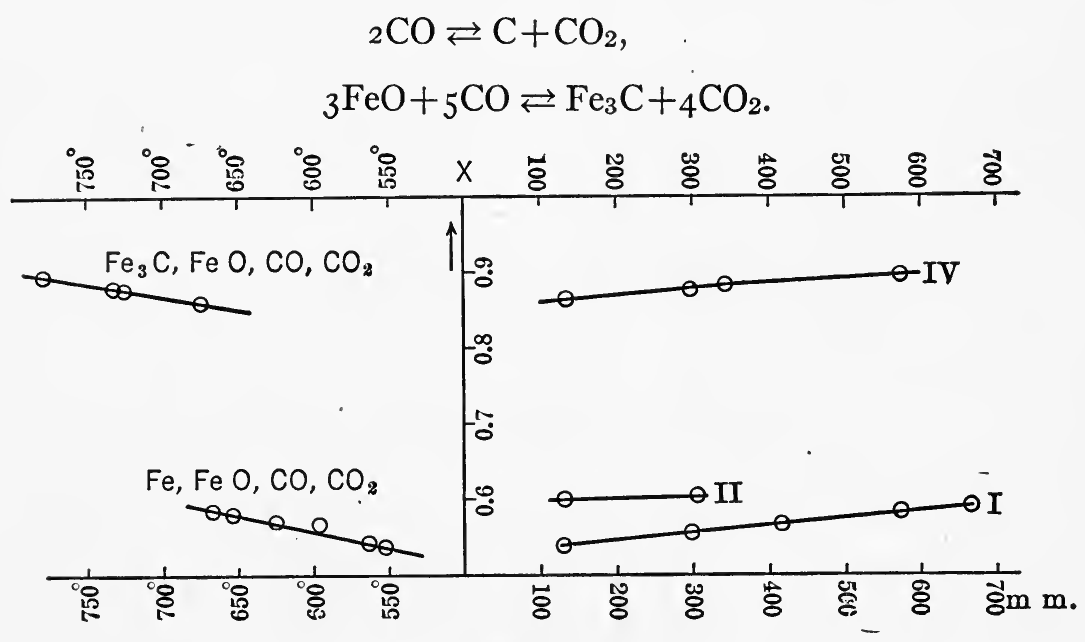

Fig. IOI.

The conditions for the first

$$
\zeta=\frac{x^{2}}{(1-x)^{\prime}} \cdot P .
$$

We already know, for the second mass law gives the constant

$$
\vartheta=\frac{x^{5}}{(1-x)^{4}} P \text {. }
$$

The graphic representation for the first equation is the cubic hyperbola with which we are familiar, the second equation is represented by a similar curve of a higher order, which, beside the starting point $(P=O, x=\mathrm{I})$ cuts the carbon curve in still a second point. 
The coordinates of this intersection can be deduced, in a very simple way, from the two equations which must be simultaneously fulfilled. The division of the second by the first gives

$$
\frac{x}{I-x}=\sqrt[3]{\frac{\vartheta}{\zeta}} \quad \text { or } \quad x=\frac{\sqrt[3]{\frac{\vartheta}{\zeta}}}{I+\sqrt[3]{\frac{\vartheta}{\zeta}}}
$$

From this and from the first it follows:

$$
P=\zeta \frac{\mathrm{I}+\sqrt[3]{\frac{\vartheta}{\zeta}}}{\sqrt[3]{\left(\frac{\vartheta}{\zeta}\right)^{2}}}
$$

From the isotherm, in which we represent, beside the two above treated curves, still the vertical straight lines for the equilibriurn:

$$
\mathrm{FeO}+\mathrm{CO} \rightleftarrows \mathrm{Fe}+\mathrm{CO}_{2},
$$

with the equation,

$$
\frac{x}{I-x}=\eta
$$

we see that the new curve (see Fig. 102) in its lower part is strongly curved and above it is a straight line nearly normal to the $x$ axis. Its tendency toward the left is only small, neverless it causes an intersection of this curve of higher order with the equilibrium line for the system $\left(\mathrm{Fe}, \mathrm{FeO}, \mathrm{CO}, \mathrm{CO}_{2}\right)$ at high values of $P$. (Compare here Fig. I03). At the intersection the two equations

$$
\frac{x}{\mathrm{I}-x}=\eta \quad \text { and } \quad \frac{x^{5}}{(\mathrm{I}-x)^{4}} \cdot P=\vartheta
$$

are simultaneously fulfilled; from these the coordinates of the intersection follow:

$$
x=\frac{\eta}{\mathrm{I}-\eta}, \text { and } P=\vartheta \frac{\mathrm{I}+\eta}{\eta^{5}} .
$$


This point represents a new univariant equilibrium not previously treated and not directly observable, between the four phases, $\mathrm{Fe}, \mathrm{FeO}, \mathrm{Fe}_{3} \mathrm{C}$, and gas. We may represent it by the symbol

$$
\mathrm{FeO}+\mathrm{Fe}_{3} \mathrm{C} \rightleftarrows{ }_{4} \mathrm{Fe}+\mathrm{CO} .
$$

The corresponding equilibrium pressure cannot be directly measured, but we are able to calculate it from the equilibrium

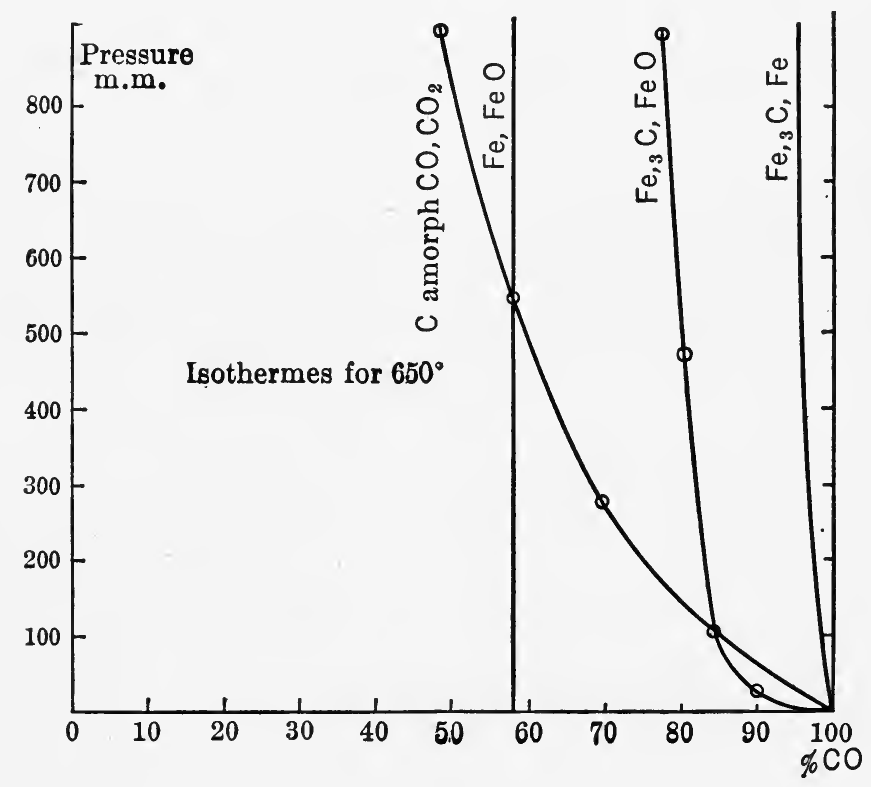

FIG. 102.

pressure of the systems we can observe. The calculation gives for the temperatures 650 and $700^{\circ}$, the values

$$
P_{650^{\circ}}=51.92 \mathrm{~atm} . ; P_{700^{\circ}}=166.3 \mathrm{~atm} \text {. }
$$

The composition of the gases is naturally the same as in the reduction of $\mathrm{FeO}$, by carbon monoxide, forming metal and carbon dioxide as the calculated points already belong to the equilibrium lines for this reaction system. Accordingly $X_{650^{\circ}}=$ $0.5^{8}$ and $X_{700^{\circ}}=0.60$. 
The calculation of this not directly observable equilibrium is not as it might appear idle play. The coordinates found in

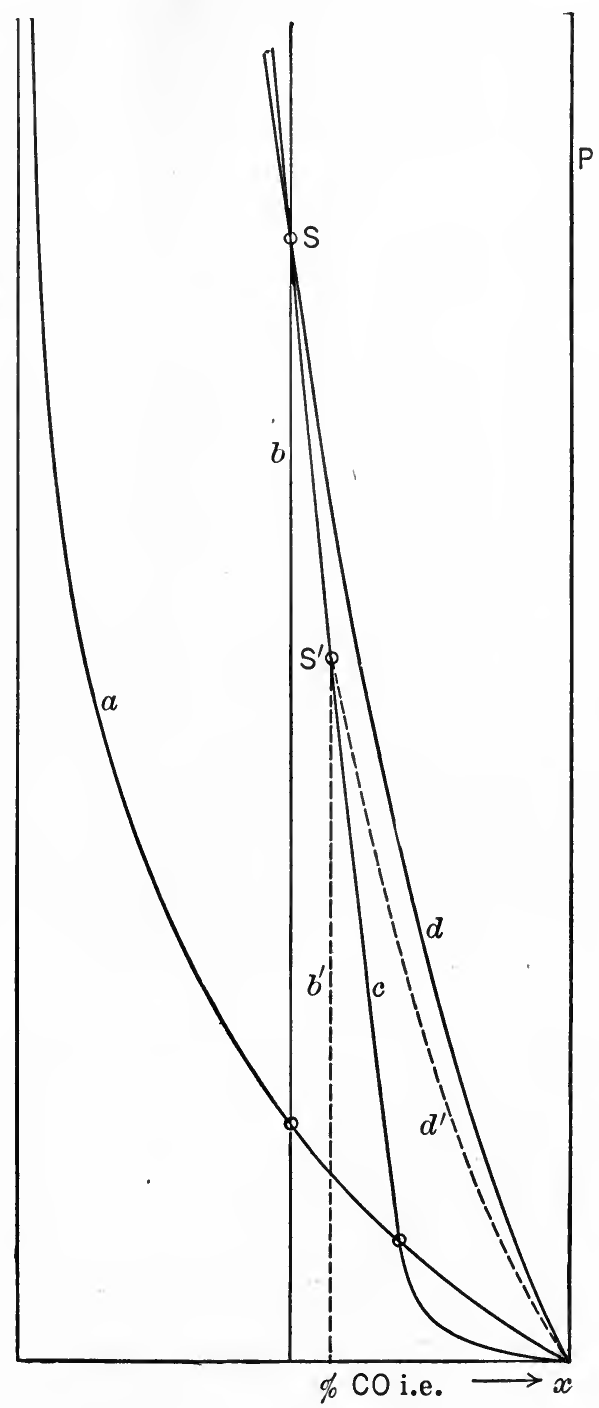

FIG. I03.

this way give us a knowledge of a magnitude that is of great practical importance. It makes it possible to give the condi- 
tions under which metallic iron is cemented by carbon monoxide.

The above-determined equilibrium point is not only the intersection for the curves of the bivariant system ( $\left.\mathrm{Fe}, \mathrm{FeO}, \mathrm{CO}, \mathrm{CO}_{2}\right)$ and $\left(\mathrm{Fe}_{3} \mathrm{C}, \mathrm{FeO}, \mathrm{CO}, \mathrm{CO}_{2}\right)$. Since in it three solid phases are in equilibrium with the gas, the equilibrium curve for the third possible combination $\left(\mathrm{Fe}_{3} \mathrm{C}, \mathrm{Fe}, \mathrm{CO}, \mathrm{CO}_{2}\right)$ must also pass through it. The equilibrium ${ }_{3} \mathrm{Fe}+{ }_{2} \mathrm{CO} \rightleftarrows \mathrm{Fe}_{3} \mathrm{C}+\mathrm{CO}_{2}$ also exists at the calculated point. This equilibrium is also bivariant since it consists of three components $(\mathrm{C}, \mathrm{Fe}, \mathrm{O})$ simultaneously present as three phases.

The equilibrium curve has, exactly as for the coexistence of carbon in contact with its gaseous oxide, the equation

$$
\mu=\frac{x^{2}}{I-x} P
$$

it is accordingly a cubic hyperbola. The constant $\mu$ is connected with the two constants $\eta$ and $\vartheta$ through a simple relation. For the two intersection points, we have

$$
P=\mu \frac{\mathrm{I}+\eta}{\eta^{2}}, \text { and } P=\vartheta \frac{\mathrm{I}+\eta}{\eta^{5}}
$$

From this follows:

For $65^{\circ} \vartheta=83,240$ and $\eta=\mathrm{I} .38 \mathrm{I}$, for $700^{\circ} \delta=384,000$ and $\eta=\mathrm{I} .50 \mathrm{C}$ hence

$$
\mu_{650^{\circ}}=\mathrm{I} 3600 ; \mu_{700^{\circ}}=\mathrm{II} 3,800 .
$$

From these values and the equation

$$
\mu=\frac{x^{2}}{\mathrm{I}-x} \cdot P,
$$

the composition of the gases can be calculated which are in equilibrium with iron and cementite at a determined pressure; they are

$$
x_{650}=0.96 \text {, and } x_{700}=0.99 \text {. }
$$


At the temperatures $650^{\circ}$ and $700^{\circ}$ accordingly a transformation of iron into cementite is only possible with such mixtures of $\mathrm{CO}$ and $\mathrm{CO}_{2}$ which contain more than 96 and 99 per cent $\mathrm{CO}$, respectively. The position of the cementation curve is shown in the isotherm for $650^{\circ}$ (see Fig. I02) and one can get from this the necessary $\mathrm{CO}$ concentration for carbide formation at other pressures. From the equilibrium diagram for $650^{\circ}$ (Fig. I02) we know further that ferrous oxide goes into cementite easier than the metal; 86 per cent being sufficient for that reaction.

In the previously considered cases pure cementite always results. One dare not draw the conclusion from these investigations that the conditions for cementation always require so high a content of monoxide. If the temperature allows of the formation of solid solutions between iron and carbon the relations are somewhat different. The influence of the solid solution formation on the $\mathrm{CO}$ concentration necessary for the cementation can also be seen from the schematic diagram (see Fig. I03).

In this diagram we recognize again our four curves for the bivariant equilibria:

$$
\begin{array}{ll}
\text { (A) }{ }_{2} \mathrm{CO} & \rightleftarrows \mathrm{C}+\mathrm{CO}_{2} \\
\text { (B) } & \mathrm{FeO}+\mathrm{CO} \rightleftarrows \mathrm{Fe}+\mathrm{CO}_{2} \\
\text { (C) }{ }_{3} \mathrm{FeO}+{ }_{5} \mathrm{CO} \rightleftarrows \mathrm{Fe}_{3} \mathrm{C}+{ }_{4} \mathrm{CO}_{2} \\
\text { (D) }{ }_{3} \mathrm{Fe}+{ }_{2} \mathrm{CO} \rightleftarrows \mathrm{Fe}_{3} \mathrm{C}+\mathrm{CO}_{2} .
\end{array}
$$

including their intersections. If some of the iron dissolves carbide so must the lines representing the equilibrium with metallic phases, the lines $b$ and the curve $d$ be displaced. The sense of this displacement is at once clear. Through the presence of the easily oxidized carbide, the solid solution, compared with the pure iron, is also increased in oxidizability; it requires for transformation into $\mathrm{FeO}$ even smaller $\mathrm{CO}_{2}$ concentrations than the pure metal; that is the line $b$ is displaced to the right. The result of this changed position is a sinking of the pressure value for the four-phase system. The pressure of the system (solid solution $\mathrm{FeO}, \mathrm{Fe}_{3} \mathrm{C}, \mathrm{CO}, \mathrm{CO}_{2}$ ) is smaller than that for the system (ferrite, $\mathrm{FeO}, \mathrm{Fe}_{3} \mathrm{C}, \mathrm{CO}, \mathrm{CO}_{2}$ ). Since the cementation curve 
for the solid solution must go through this point, it can be seen directly from the figure, that the cementation of solid solutions can take place with lower monoxide concentrations than that of pure iron. The cementation curve is pushed toward the left (the curve for the solid solution is dotted).

Since the curve $c$ is very steep relatively small displacements of $x$, respectively to $\eta$ represent large depressions of the intersection $A$. The ordinate equation

$$
P=\vartheta \frac{\mathrm{I}+\eta}{\eta^{5}}
$$

also holds for this point. $\vartheta$ retains its value since, in the equilibrium $c$ no solid solution phase appears.

How large this influence is, a rough calculation will show. We will assume that at a temperature of $700^{\circ}$ solid solution formation already takes place and that through this condition the equilibrium value $X$ for the oxidation of this solid solution is raised to 0.62 (compared to 0.60 for pure iron). Thereby $\eta$ increased from I.50-I.63. The value of $\vartheta$ is at this temperature 384,000 . From the above given equation we calculate for the equilibrium pressure of the solid solution with the simultaneous presence of cementite and $\mathrm{FeO}$, the value II 5.4 as compared to r66.3 atm. if we replace the solid solution with pure iron. The depression is accordingly ${ }_{5} \mathrm{I}$ atm. for the small concentration increase of $\mathrm{CO}$ (around 2 per cent). That the constant $\mu$ of the cementation equilibrium $\left(\mathrm{Fe}_{3} \mathrm{C}, \mathrm{Fe}\right.$, gas) changes with a displacement of $\eta$ is shown by the equation:

$$
\mu=\frac{\vartheta}{\eta^{3}} \text {. }
$$

Accordingly this change is relatively large for small deviations of the variable $\eta$, since $\mu$ is approximately proportional to the third power of $\eta$. It decreases with the above given change of $\eta$ from II 3,800 to 88,650 .

Beside the intersection $A$, the intersection of curves $a$ and $b$ is depressed by solid solution formation. Since the curve $a$ is flatter than the curve $d$, the influence is not so great as with $a$, 
but it is sufficiently large, that the pressure value, which is above atmospheric pressure for pure iron, is depressed below this value so that the equilibrium of the solid solution becomes conveniently

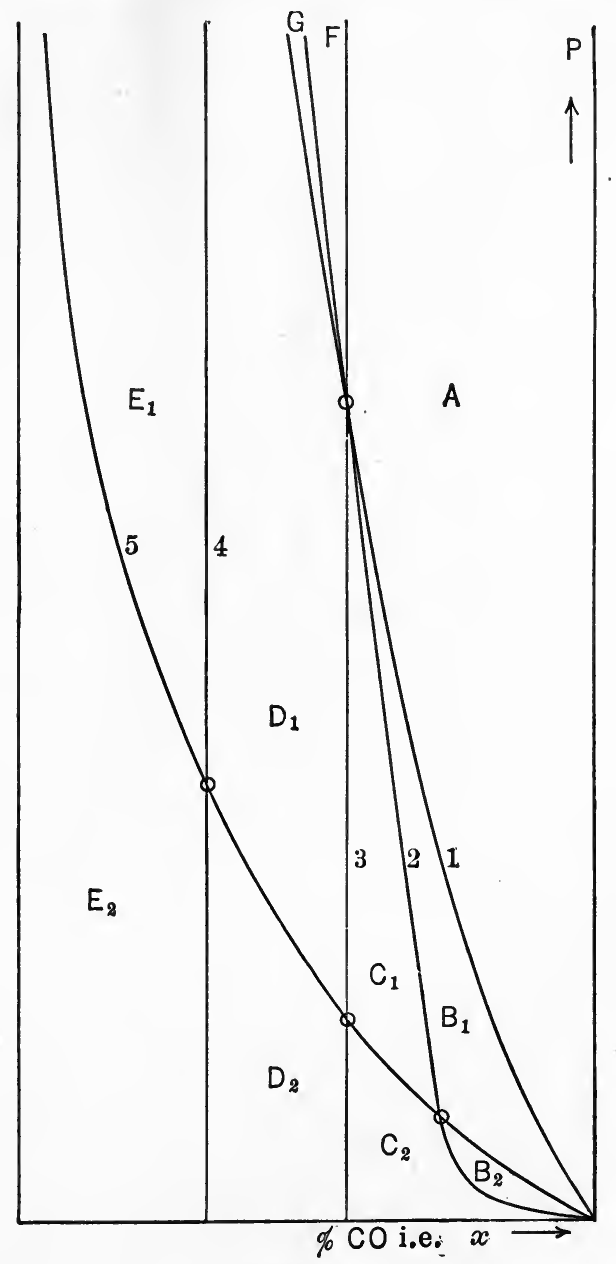

FIG. I04.

measurable. And this is not without practical importance, since we may orient ourselves experimentally concerning the dependence of the constant $\eta$ on the carbide content of the solid solution and from the determined relations follow the influence of the solid 
solution formation on the cementation process mathematically. Nothing further being necessary, than, after the occurrence of equilibrium between solid solution, ferrous oxide, carbon and the gas atmosphere, to determine the composition and pressure of the latter and to analyze the solid solution.

All these experimental data still fail to place us in a position to predict the direction of the displacement of the equilibrium and the reaction fields under the complex conditions for the formation of solid solutions such as can occur at high temperatures.

After this digression we return to the simple relation such as we have seen holds under $700^{\circ}$, we draw again a schematic diagram of the equilibrium curves and their intersections at constant temperature, considering, however, also the ferrous oxide (see Fig. 104).

We have, accordingly besides the representations of the equilibria

$$
\begin{aligned}
{ }_{2} \mathrm{CO} & \rightleftarrows \mathrm{C}+\mathrm{CO}_{2} \\
\mathrm{FeO}+\mathrm{CO} & \rightleftarrows \mathrm{Fe}+\mathrm{CO}_{2} \\
{ }_{3} \mathrm{FeO}+{ }_{5} \mathrm{CO} & \rightleftarrows \mathrm{Fe}_{3} \mathrm{C}+{ }_{4} \mathrm{CO}_{2} \\
{ }_{3} \mathrm{Fe}+{ }_{2} \mathrm{CO} & \rightleftarrows \mathrm{Fe}_{3} \mathrm{C}+\mathrm{CO}_{2}
\end{aligned}
$$

also that for

$$
\mathrm{Fe}_{3} \mathrm{O}_{4}+\mathrm{CO} \rightleftarrows{ }_{3} \mathrm{FeO}+\mathrm{CO}_{2}
$$

These five curves divide our diagram, the $X, P$ plane into twelve fields, in which the following reactions go on:

Field $A$

$$
\begin{aligned}
& \text { I. }{ }_{3} \mathrm{Fe}+{ }_{2} \mathrm{CO}=\mathrm{Fe}_{3} \mathrm{C}+\mathrm{CO}_{2} \\
& \text { 2. }{ }_{3} \mathrm{FeO}+{ }_{5} \mathrm{CO}=\mathrm{Fe}_{3} \mathrm{C}+{ }_{4} \mathrm{CO}_{2} \\
& \text { 3. } \mathrm{FeO}+\mathrm{CO}=\mathrm{Fe}+\mathrm{CO}_{2} \\
& \text { 4. } \mathrm{Fe}_{3} \mathrm{O}_{4}+\mathrm{CO}=3 \mathrm{FeO}+\mathrm{CO}_{2} \\
& \text { 5. }{ }_{2} \mathrm{CO}=\mathrm{C}+\mathrm{CO}_{2}
\end{aligned}
$$


Field $B_{1}$

I. $\mathrm{Fe}_{3} \mathrm{C}+\mathrm{CO}_{2}={ }_{3} \mathrm{Fe}+{ }_{2} \mathrm{CO}$

2. ${ }_{3} \mathrm{FeO}+{ }_{5} \mathrm{CO}=\mathrm{Fe}_{34} \mathrm{CO}_{2}$

3. $\mathrm{Fe}+\mathrm{CO}=\mathrm{Fe}+\mathrm{CO}_{2}$

4. $\mathrm{Fe}_{3} \mathrm{O}_{4} \mathrm{CO}={ }_{3} \mathrm{FeO}+\mathrm{CO}_{2}$ ${ }_{2} \mathrm{CO}=\mathrm{C}+\mathrm{CO}_{2}$

Field $C_{1}$

Field $B_{2}$

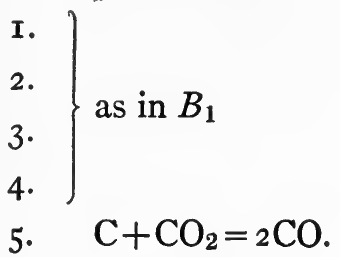

Field $C_{2}$

I. $\mathrm{Fe}_{3} \mathrm{C}+\mathrm{CO}_{2}={ }_{3} \mathrm{Fe}+{ }_{2} \mathrm{CO}$

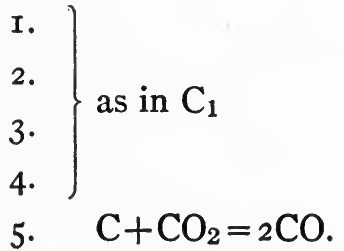

Field $D_{1}$

I. $\mathrm{Fe}_{3} \mathrm{C}+\mathrm{CO}_{2}={ }_{3} \mathrm{Fe}+{ }_{2} \mathrm{CO}$

2. $\mathrm{Fe}_{3} \mathrm{C}+{ }_{4} \mathrm{CO}_{2}={ }_{3} \mathrm{FeO}+{ }_{5} \mathrm{CO}$

3. $\mathrm{Fe}+\mathrm{CO}_{2}=\mathrm{FeO}+\mathrm{CO}$

4. $\mathrm{Fe}_{3} \mathrm{O}_{4}+\mathrm{CO}={ }_{3} \mathrm{FeO}+\mathrm{CO}_{2}$

5 .

$$
{ }_{2} \mathrm{CO}=\mathrm{C}+\mathrm{CO}_{2}
$$

Field $E_{1}$

I. $\mathrm{Fe}_{3} \mathrm{C}+\mathrm{CO}_{2}={ }_{3} \mathrm{Fe}+{ }_{2} \mathrm{CO}$

2. $\mathrm{Fe}_{3} \mathrm{C}+{ }_{4} \mathrm{CO}_{2}={ }_{3} \mathrm{FeO}+{ }_{5} \mathrm{CO}$

3. $\mathrm{Fe}+\mathrm{CO}_{2}=\mathrm{FeO}+\mathrm{CO}$

4. ${ }_{3} \mathrm{FeO}+\mathrm{CO}_{2}=\mathrm{Fe}_{3} \mathrm{O}_{4}+\mathrm{CO}$

5 .

$$
{ }_{2} \mathrm{CO}=\mathrm{C}+\mathrm{CO}_{2}
$$

Field $D_{2}$

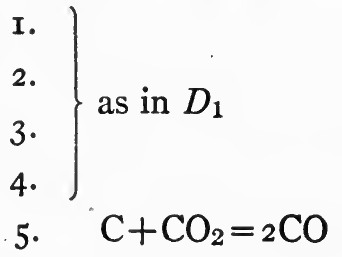

Field $E_{2}$

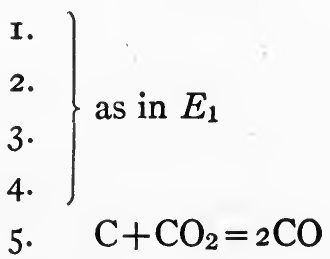

Field $F$

I. $3 \mathrm{Fe}+{ }_{2} \mathrm{CO}=\mathrm{Fe}_{3} \mathrm{C}+\mathrm{CO}_{2}$

2. ${ }_{3} \mathrm{FeO}+{ }_{5} \mathrm{CO}=\mathrm{Fe}_{3} \mathrm{C}+{ }_{4} \mathrm{CO}_{2}$

3. $\mathrm{Fe}+\mathrm{CO}_{2}=\mathrm{FeO}+\mathrm{CO}$

4. $\mathrm{Fe}_{3} \mathrm{O}_{4}+\mathrm{CO}={ }_{3} \mathrm{FeO}+\mathrm{CO}_{2}$

5 .

${ }_{2} \mathrm{CO}=\mathrm{C}+\mathrm{CO}_{2}$ 
Field $G$

I. $3 \mathrm{Fe}+2 \mathrm{CO}=\mathrm{Fe}_{3} \mathrm{C}+\mathrm{CO}_{2}$

2. $\mathrm{Fe}_{3} \mathrm{C}+{ }_{4} \mathrm{CO}_{2}={ }_{3} \mathrm{FeO}+{ }_{5} \mathrm{CO}$

3. $\mathrm{Fe}+\mathrm{CO}_{2}=\mathrm{FeO}+\mathrm{CO}$

4. $\mathrm{Fe}_{3} \mathrm{O}_{4}+\mathrm{CO}={ }_{3} \mathrm{FeO}+\mathrm{CO}_{2}$

5 .

$$
{ }_{2} \mathrm{CO}=\mathrm{C}+\mathrm{CO}_{2}
$$

Field $H$

$$
\begin{array}{rlrl}
\text { I. } & { }_{3} \mathrm{Fe}+{ }_{2} \mathrm{CO} & =\mathrm{Fe}_{3} \mathrm{C}+\mathrm{CO}_{2} \\
\text { 2. } \mathrm{Fe}_{3} \mathrm{C}+{ }_{5} \mathrm{CO}_{2} & ={ }_{3} \mathrm{FeO}+{ }_{4} \mathrm{CO}_{2} \\
\text { 3. } \mathrm{Fe}_{2} \mathrm{CO}_{2} & =\mathrm{FeO}+\mathrm{CO} \\
\text { 4. } & { }_{3} \mathrm{FeO}+\mathrm{CO}_{2} & =\mathrm{Fe}_{3} \mathrm{O}_{4}+\mathrm{CO} \\
\text { 5. } & { }_{2} \mathrm{CO} & =\mathrm{C}+\mathrm{CO}_{2}
\end{array}
$$

As end products of the reaction also occur: Cementite, together with carbon in fields $A$ and $F$, metallic iron with carbon in fields $B_{1}$ and $C_{1}$, without simultaneous precipitation of carbon in $B_{2}$ and $C_{2}$.

Ferrous oxide with carbon in fields $D_{1}$ and $G$.

Ferrous oxide without carbon in field $D_{2}$.

Ferrosoferric oxide with carbon in fields $E_{1}$ and $H$.

Ferrosoferric oxide without carbon in field $E_{2}$.

We can accordingly, at the same temperature obtain any of the four solid substances as the stable phase by simple variations of pressure and composition of the gas phase.

By raising the temperature all fields suffer deformation, all curve constants increase, as a result, the curvature changes and displacements occur toward the right. If we think now of all isotherms as vertical to a temperature axis of a space model with the coordinate axes, $T, P$, and $X$, so we have a geometrical representation of the whole theory of the blast furnace.

We will now study one important conclusion which our diagram brings out. It so happens that the cementite-as a phase -in opposition to the other solid products is only stable in such fields as the $\mathrm{CO}$ is labile and is subject to decomposition 
into $\mathrm{CO}_{2}+\mathrm{C}$. From this it arises that the cementite is not formed from carbon and metal, that the only cementing agent by which one can reach a direct formation of carbide is $\mathrm{CO}$. It can, however, be formed by the action of carbon on ferrous oxide (in $B$ ). It is, however, labile here.

However, the solid carbon can also act as cementing agent if it is not in the formation of pure cementite as a separate phase, but in the formation of a solid solution of this substance with metallic iron. Suppose that the prevailing temperature for the formation of solid solution falls inside of field $C_{2}$, the field in which at temperature less than $770^{\circ}$, metallic iron is the only stable solid phase. At this temperature reaction I in the above given table is no longer unidirectional, but is reversible for a large interval of $X$. We must replace it with the equation

$$
\mathrm{Fe}_{3} \mathrm{C}+\mathrm{CO}_{2} \rightleftarrows{ }_{3} \mathrm{Fe}+{ }_{2} \mathrm{CO},
$$

in which the carbide belongs to the same phase as the metal.

If we remember the Mass Law, we see that the composition of the solid solution is dependent on the pressure and composition of the gas atmosphere.

That is also the case for the reaction.

$$
\mathrm{FeO}+\mathrm{CO} \rightleftarrows \mathrm{Fe}\left(\mathrm{Fe}_{3} \mathrm{C} \text { containing }\right)+\mathrm{CO}_{2} \text {. }
$$

The fields $F$ and $G$ which on account of the high pressure values are not observable with iron deserve a few further words. The mutual relations of metal, carbide and oxide in the presence of gas can be made clear with other metals, especially with manganese.

Practical experience has taught that by the reduction of manganese oxide with carbon and carbon monoxide a carbonfree metal never results but always a carbide. We might draw the conclusion from this that the oxide is more easily reduced to the carbide than to the metal, which would be the case at point $A$ if the CO concentration necessary for cementation were smaller than that required for reduction. 
The equilibrium pressure occurring with manganese is very small. Carbon monoxide is, up to over $1000^{\circ}$, easily and completely absorbed by metallic manganese with strong heat evolution. At a temperature of $1200^{\circ}$ the equilibrium pressure reaches a measurable value. This relation can be easily understood from our earlier theoretical considerations, since with manganese we have a metal which is much less noble than iron and as a consequence possesses a larger value for the reduction constant $\eta$. What holds for $\eta$ holds also for $\vartheta$, the constant which gives the conditions for the reduction of the oxide to the carbide. The result of increase of $\eta$ and $\vartheta$ is the strong decrease

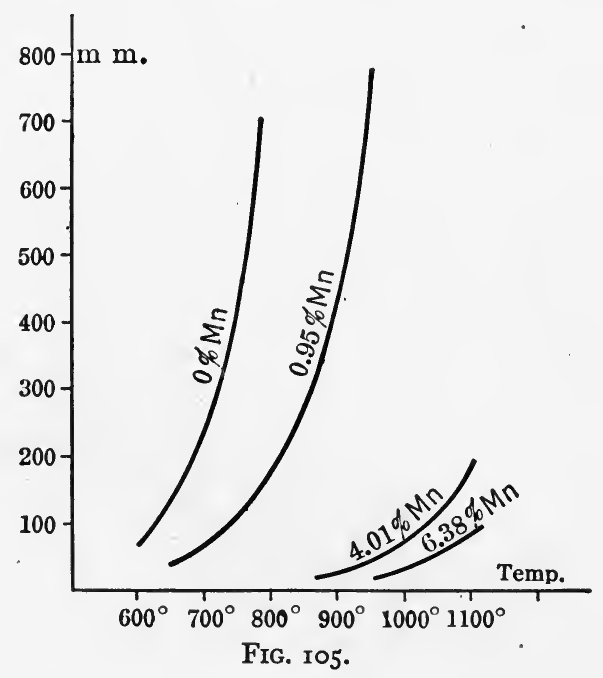

of the equilibrium pressure for the systems. Metal oxide, carbon (amorphous) gas, and carbide oxide, carbon (amorphous) gas.

This influence makes itself felt in the action of $\mathrm{CO}$ on solid solutions of iron and manganese as well as those of iron and manganese cementite. Small manganese contents cause, as the observations show, great decrease in the equilibrium pressure. In the following table the results of one experiment are given, which has been taken from the observations of Schenck and Semiller on the action of $\mathrm{CO}$ on manganese containing pig iron. 
From the numerical values and still better from the graphical representation (Fig. 105) the influence of the manganese content on the equilibrium pressure for the presence of the solid phases, cementite, oxide, amorphous carbide can be seen. For comparison the values for manganese free iron cementite are given.

COMPOSITION OF MANGANESE CONTAINING PIG IRON

\begin{tabular}{c|c|c|c}
\hline Preparation. & Mn, Per Cent. & Fe, Per Cent. & C, Per Cent. \\
\cline { 2 - 3 } I & 0.95 & 96.6 & 2.15 \\
II & 4.0 I & 93.0 & 2.99 \\
II I & 6.38 & 93.2 & I.32 \\
\hline
\end{tabular}

\begin{tabular}{|c|c|c|c|c|c|c|c|}
\hline \multicolumn{2}{|c|}{$\begin{array}{c}\text { Cementite, Manganese } \\
\text { Free }\end{array}$} & \multicolumn{2}{|c|}{ Preparation I. } & \multicolumn{2}{|c|}{ Preparation II. } & \multicolumn{2}{|c|}{ Preparation III. } \\
\hline $\begin{array}{l}\text { Temp. in } \\
\text { Degrees. }\end{array}$ & $\begin{array}{l}\text { Pressure, } \\
\text { Mm. }\end{array}$ & $\begin{array}{l}\text { Temp. in } \\
\text { Deg. }\end{array}$ & $\begin{array}{l}\text { Pressure, } \\
\text { Mm. }\end{array}$ & $\begin{array}{l}\text { Temp., } \\
\text { Deg. }\end{array}$ & $\begin{array}{l}\text { Pressure, } \\
\text { Mm. }\end{array}$ & $\begin{array}{c}\text { Temp., } \\
\text { Deg., }\end{array}$ & $\begin{array}{l}\text { Pressure, } \\
\text { Mm. }\end{array}$ \\
\hline $\begin{array}{l}634 \\
672 \\
691 \\
722 \\
734 \\
774 \\
779\end{array}$ & $\begin{array}{r}83 \\
131 \\
195 \\
298 \\
341 \\
562 \\
657\end{array}$ & $\begin{array}{c}629 \\
679 \\
\ldots \ldots \\
\\
730 \\
751 \\
\\
820 \\
849 \\
880 \\
900 \\
938 \\
959\end{array}$ & $\begin{array}{r}86 \\
101 \\
180 \\
217 \\
349 \\
396 \\
617 \\
802\end{array}$ & $\begin{array}{c}853 \\
911 \\
\ldots \ldots \ldots \\
965 \\
1010 \\
1088 \\
1103\end{array}$ & $\begin{array}{c}\text { I7 } \\
28 \\
\ldots \ldots \\
46 \\
74 \\
162 \\
\\
170\end{array}$ & $\begin{array}{r}943 \\
956 \\
981 \\
\text { 103I } \\
1086 \\
\text { 1093 } \\
\text { I I 10 }\end{array}$ & $\begin{array}{l}15 \\
20 \\
20 \\
34 \\
62 \\
68 \\
96\end{array}$ \\
\hline
\end{tabular}

If we also distort the results by the formation of ferritecementite solid solution, we obtain a picture, at least qualitative, of the influence on the equilibrium of the presence of manganese.

According to our previous consideration we would expect that the reduction of the metallic oxide by carbon and $\mathrm{CO}$ would be easier the more noble the metal and coordinately the 
greater the field $B_{2}$ of our diagram. We should encounter accordingly very little danger of falling into a field where the $\mathrm{CO}_{2}$ concentration is so high that the metal present is oxidized.

The experience of practice and the laboratory show us now that one is bitterly deceived in these expectations. Nickel oxide, as well as tin oxide, are vainly subjected to conditions, which with iron oxide would produce the metal without difficulty. To obtain an energetic reaction much higher temperatures must be used than are necessary according to the position of the equilibrium pressure, which with noble metals is already many atmospheres at relatively low temperatures.

We have heretofore left entirely out of consideration a factor which is of essential meaning for an energetic reaction, namely: the reaction velocity, the velocity with which a chemical process approaches the equilibrium. Even with the oxides of noble metals, the reduction with carbon is only feasible if the reaction velocity is not too small.

The resistance, which is opposed to an energetic completion of the reaction is in many cases due to the physical condition of the oxide. With one and the same substance, we can meet different degrees of reaction energy, if it has received different previous treatment. Strongly ignited sintered masses are much more inert than finely pulverized porous preparations. The surface is the essential factor on which the reaction velocity depends.

A second factor is the temperature and indeed the velocity increases with the temperature under all conditions. Of this fact use has long been made in practice. The reduction of $\mathrm{NiO}$, which at $600^{\circ}$ goes only very slowly, is conveniently carried on $100^{\circ}$ higher provided the oxide and the reducing agent are intimately mixed. There must be considered for the reduction of oxides, beside the equilibrium ratio also sufficiently great reaction velocity. In many cases it is easier to obtain a base metal from its oxide than a noble one, if the latter oxide shows inertness toward the reducing agent. 


\section{The Mond Nickel Process.}

We dare not close our considerations of the action of $\mathrm{CO}$ on the oxides and metals without mentioning a remarkable reaction, which is of interest to the metallurgist and has been made by Mond to play an important rôle in the production of nickel.

Iron and nickel, have, at temperatures slightly removed from room temperature, the peculiarity of adding $\mathrm{CO}$ and forming with it the remarkable compounds- $\mathrm{Fe}(\mathrm{CO})_{7}, \mathrm{Fe}(\mathrm{CO})_{5}$, $\mathrm{Ni}(\mathrm{CO})_{4}$.

The most important of these is nickel carbonyl $\mathrm{Ni}(\mathrm{CO})_{4}$. Concerning its formation and existence conditions, Mittach * has made thorough investigations. Nickel-carbonyl is a water clear, very volatile liquid which boils at $40^{\circ}$ and at higher temperatures decomposes easily into the components from which it was formed. The ease of formation on the one hand and the decomposition on the other can be demonstrated by a simple experiment. If we fill a glass tube, drawn to a point on both ends, with the vapor of nickel-carbonyl and place it, after the ends have been sealed, in a boiling water-bath, after a time we observe the precipitation of a nickel mirror. If then the tube be taken out and allowed to lie a few days at room temperature, the mirror disappears again, with re-formation of nickel-carbonyl vapor. We are accordingly dealing with a reversible reaction, which can be expressed by the symbol

$$
\mathrm{Ni}+{ }_{4} \mathrm{CO} \rightleftarrows \mathrm{Ni}(\mathrm{CO})_{4} \text {. }
$$

As previously, we can deduce the equilibrium conditions from the mass law. They are

$$
\frac{\mathrm{C}^{4} \mathrm{CO} \cdot \mathrm{C}_{\mathrm{N} 1}}{\mathrm{C}_{\mathrm{N} 1}(\mathrm{co})_{4}}=K
$$

We have, so long as the nickel-carbonyl is gaseous, a twocomponent system with two phases; it is accordingly bivariant

* Z. Physik. Chem., 40, I (I902). 
and dependent on the pressure and temperature. The equation of the isotherm is as one can easily derive.

$$
\frac{x^{4} \cdot P^{3}}{\mathrm{I}-x}=K
$$

which gives us the relation between the pressure and the composition of the gas phase. The higher the pressure the greater the amount of the nickel-carbonyl vapor in it.

\begin{tabular}{c|c||c|c}
\hline $\begin{array}{c}\text { Temperature in } \\
\text { Degrees. }\end{array}$ & $\log K$. & $\begin{array}{c}\text { Temperature in } \\
\text { Degrees. }\end{array}$ & $\log K$. \\
\cline { 2 - 3 } II.3 & 2.719 & 62.0 & 5.575 \\
16.1 & 3.04. & 70.4 & 5.948 \\
29.8 & 3.812 & 80.0 & 6.443 \\
35.9 & 4.199 & 90.0 & 6.859 \\
50.2 & 4.925 & 99.3 & 7.178 \\
\hline
\end{tabular}

It is sufficient to have the values for $K$ or its logarithm for a series of temperatures between ro and $100^{\circ}$. From

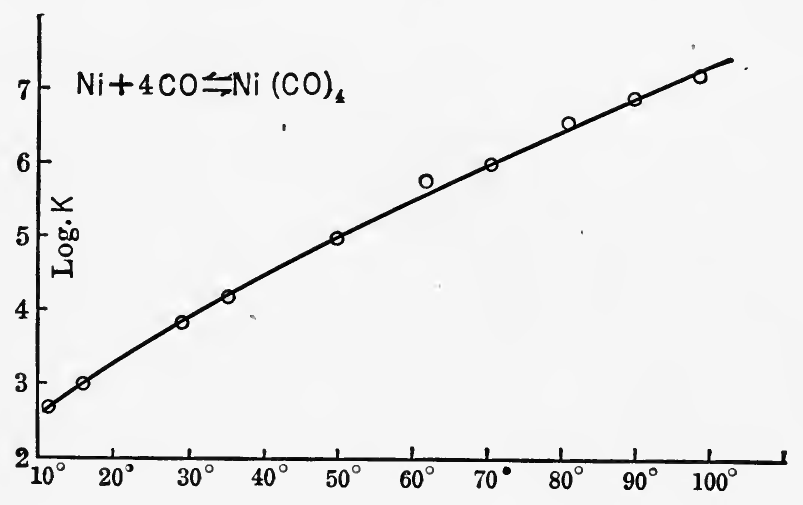

Fig. ro6.

these we can calculate the composition of the gas for every other temperature. For an illustration of the displacement of the equilibrium with the temperature, see Fig. ro6. It shows that as the amount of $\mathrm{CO}$ in the gas mixture increases with rising temperature, that of nickel-carbonyl decreases. 
The constants vary somewhat with the condition of the metallic nickel present, and the value for the finely divided metal is higher than for the compact, an analogy to the fact that small crystals show a greater solubility than large.

The velocity of the formation is influenced by a large number of factors. That increasing pressure, that is, raising the $\mathrm{CO}$ concentration, is favorable to the reaction is a result of the mass law and that fine division of the nickel also aids the reaction can be understood from our earlier experience. It is remarkable, however, that traces of foreign substances, for example of oxygen, cause very great variations from the norrnal run. They work directly as "poison" for the nickel and destroy its combining ability. It would be going too far here to follow this influence further.

Our problem, the action of carbon and carbon-monoxide on the ores and metals, and the study of the occurring equilibbrium phenomena is now disposed of, and we now understand the factors on which the oxidation reduction and cementation depend. We will now turn to another field, application of theory. to the chemical processes which are important in the smelting of sulfide ores. 


\section{CHAPTER VI}

\section{THE REACTIONS OF SULFIDES}

WHILE for the preparation of iron only oxide ores come into consideration, the principal amount of the other practically important metals are obtained from the sulfides. This holds especially for copper, lead, zinc, and mercury.

A thorough knowledge of the relations of the metallic sulfides to the metals on the one hand, and to the oxides on the other, is therefore essential if we would specify the conditions under which the reactions, which are used in practice for the transformation of sulfides to the metal, run in the desired direction. It is a well-known fact that at high temperatures the sulfides undergo a dissociation into their elements or into sulfur and sulfur-poorer sulfides. From some, for example, the iron sulfide $\mathrm{FeS}_{2}$, the sulfur can be directly distilled. What now are the kinds of dissociation phenomena concerned, and are the relations exactly as with the dissociation of the oxides.

The reaction

$$
\mathrm{MeS} \rightleftarrows \mathrm{Me}+\mathrm{S},
$$

is characterized by a definite dissociation tension, dependent on the temperature which with the above-mentioned iron sulfide amounts to over one atmosphere at the distillation temperature.

Naturally, the occurrence of the definite dissociation pressure is connected with the condition, that two solid phases must be simultaneously present. Due to the frequently observed miscibility between metals and sulfides, the mixtures consist in many cases of a single phase, a solid or liquid solution and 
it depends entirely on the concentration of these solutions whether at the same temperature, the sulfur tension is great or small.

The experimental material concerning the sulfur tension of sulfides is extraordinarily sparse. There is still difference of opinion as to the series which gives the sulfides, according to the magnitude of their tension.

The reason for this is the experimental difficulty encountered in handling the problem, and the great influence of mutual solubility which the various authors have not taken sufficiently into consideration.

That the difference of the dissociation magnitude for different sulfides in some cases must be very large, may be concluded from the possibility of the so-called precipitation process. This metallurgical process consists in heating the sulfide of a valuable metal with iron, whereby the metal is set free and the sulfur combined with the iron. Many uses are made of this reaction; for example, the mercury out of cinnabar and the antimony out of stibnite are precipitated. In some cases lead has even been obtained from galena by this method. Iron sulfide may also give up sulfur even in the liquid state by the addition of manganese or ferromanganese, to the melt. This desulfurization process which is used in practice would not be possible if the affinity of manganese for sulfur were not considerably greater than that of iron.

This "precipitation process" has its exact analogy in the reduction of oxides of noble metals by less noble, which has been treated in the fourth chapter. Also in this case, reaction takes place if the dissociation tension of the desulfurized sulfide, is greater than that corresponding to the sulfide of the metal used.

However, the relations are not so simple as with the oxides. A series which gives the ease of desulfurization of the single sulfides is extraordinarily difficult to arrange. That this difficulty is principally due to the solubility of the metals in the sulfides we have already mentioned. It is further increased since the mutual solubility of the sulfides themselves is very 
considerable even in the solid state. I need recall only that in the complex diagram of the nickel matte, the solid solutions between nickel sulfide and iron sulfide play an important rôle. Further it is no rarity for the sulfides to go into chemical compounds with each other as we also recall from the nickel matte. The degree of the desulfurization reached will under conditions be dependent on the relative amounts of the sulfide and the desulfurizing metals that enter into the reaction.

If we would become clear concerning the yield of the metal to be expected, we must investigate first the equilibrium diagram of the concerned ternary systems. Only in rare cases does the reaction take place without matte formation, the desulfurization being generally only partial.

We have now, in desulfurization by iron, at least one method by which the dissociation tension of the original sulfide can be considerably depressed and thereby the energy of desulfurization essentially raised. This means is an addition of $\mathrm{Na}_{2} \mathrm{~S}$ or $\mathrm{CaS}$ to the liquid melt. These substances form with iron sulfide complex sulfides, so-called sulfurets, whose sulfur tension is considerably smaller than even that of the iron sulfide. This has the added advantage that the sulfide dissolved in the metal bath is increased, not to mention the change of physical properties which is very favorable. The sulfuret melt is considerably lighter and more liquid than that of the matte, it separates much better from the regulus and can be separated very readily from it after cooling. The limitation of the usefulness of this modification of the precipitation process is naturally that the sulfide to be desulfurized may form stable complex compounds with alkali sulfides. The latter appears to be the case with lead sulfide, where the experience of practice shows that addition of alkali sulfide influences the precipitation process adversely.

We recognize from this that it is difficult and not sufficiently reliable to arrive at an orientation of the relative affinities of the metals for sulfur, by means of decomposition of the sulfides with metals. We will therefore experiment in another way to get consistency, at least in some cases. 
We saw with the oxides that a conclusion concerning the affinity of metals for oxygen could be drawn, if the equilibrium between metal oxide, water vapor and hydrogen is known. In an entirely similar way a conclusion concerning the affinity of the metals for sulfur may be drawn from measurements of the equilibrium.

$$
\mathrm{MeS}+\mathrm{H}_{2} \rightleftarrows \mathrm{Me}+\mathrm{H}_{2} \mathrm{~S} \text {. }
$$

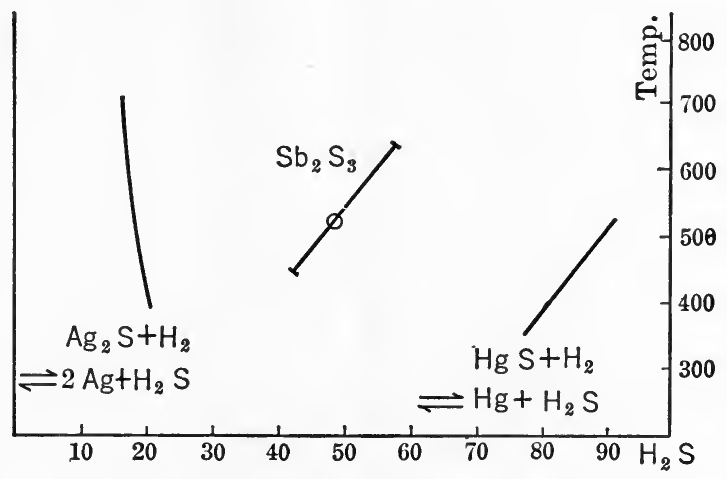

Fig. 107.

Such measurements have been made for several sulfides by Pelabon.* His results are given in the following table and the graphic representation in Fig. I07:

\begin{tabular}{|c|c|c|c|c|c|}
\hline \multicolumn{2}{|c|}{$\mathrm{Ag}_{2} \mathrm{~S}+\mathrm{H}_{2} \rightleftarrows \mathrm{Ag}_{2}+\mathrm{H}_{2} \mathrm{~S}$} & \multicolumn{2}{|c|}{$\mathrm{HgS}+\mathrm{H}_{2} \rightleftarrows \mathrm{Hg}+\mathrm{H}_{2} \mathrm{~S}}$. & \multicolumn{2}{|c|}{$\mathrm{Sb}_{2} \mathrm{~S}_{3}+{ }_{3} \mathrm{H}_{2} \rightleftarrows \mathrm{Sb}_{2}+{ }_{3} \mathrm{H}_{2} \mathrm{~S}}$. \\
\hline $\begin{array}{l}\text { Temp. in } \\
\text { Degrees. }\end{array}$ & $\begin{array}{c}\mathrm{H}_{2} \mathrm{~S} \\
\text { Per Cent. }\end{array}$ & $\begin{array}{l}\text { Temp. in } \\
\text { Degrees. }\end{array}$ & $\begin{array}{c}\mathrm{H}_{2} \mathrm{~S}, \\
\text { Per Cent. }\end{array}$ & $\begin{array}{l}\text { Temp. in } \\
\text { Degrees. }\end{array}$ & $\mathrm{H}_{2} \mathrm{~S}$, Fer Cent. \\
\hline 360 & 21.02 & 360 & 78.67 & & \\
\hline 440 & I9. 85 & 440 & 85.26 & 440 & $44 \cdot 3$ two solid \\
\hline 520 & 18.60 & 520 & 92.10 & 510 & $48.6\}$ phases \\
\hline 615 & I 7.00 & $\ldots \ldots \ldots$ & $\ldots \ldots \ldots$ & 555 & $5^{1.8}$ \\
\hline 710 & 16.03 & $\ldots \ldots \ldots$ & $\ldots \ldots \ldots$ & $\begin{array}{l}610 \\
625\end{array}$ & $\left.\begin{array}{l}56.01 \\
56.9\end{array}\right\} \begin{array}{c}\text { two liquod } \\
\text { phases }\end{array}$ \\
\hline
\end{tabular}

We have also here to deal with the measurements of incomplete equilibria and reversible reactions. We find a definite * Ann. Chim. Phys. (7), 25, 365 (1902). 
equilibrium relation of the two gases depending only on the temperature, so long as sulfide and metal are present as two solid or liquid phases. The latter possibility is met, as we have seen in chapter 3 , rather frequently in systems of sulfides and metals. Such a case of limited miscibility in the liquid state is the antimony-antimony sulfide equilibrium in the abo-ve table.

The percentage of hydrogen sulfide in the equilibrium mixture of gases, as we see from our examples, decreases with temperature (e.g., with silver) or as with mercury and antimony increases. The direction of the temperature change of the equilibrium will according to the rules of chemical thermo-dynamics, be conditioned on the thermo-chemistry of the decomposition. That side of the reaction will be favored by rising temperature which is formed with heat absorption.

The stability of silver sulfide accordingly increases with rising temperature, the affinity for sulfur increases. With mercury and antimony the reverse is true, an increase in temperature favoring a precipitation of the elementary metals.

To be sure the equilibrium constants may only be used as a correct measure of the affinity of sulfur for metal, if the metal and sulfide exist as phases in the pure state. If one or the other, or both of the "Bodenkorper" consist of solutions, the hydrogen sulfide content of the gas phase shows us only the tendency of the sulfide-richer phase to go over to a sulfidepoorer.

If the sulfide and metal dissolve completely in one another the hydrogen sulfide content of the gas atmosphere depends entirely on the mixture relations of the two substances in the solution. If we investigate solutions of increasing sulfide content at constant temperature, the hydrogen sulfide concentration in the gas increases in the same direction; it is first constant when the solution becomes saturated with sulfide. These relations may be readily followed with the system bismuth-bismuth sulfide, as has been shown by Pelabon. It lends itself particularly to graphic representation (see Fig. 108).

At $600^{\circ}$ we have complete miscibility, at $440^{\circ}$ the curve goes upward with increasing sulfide content and at a determined 
place, namely, the limit of solubility, it becomes a straight line. From this point on the hydrogen sulfide content is constant.

From all these facts we may conclude, that the possibility of determining the affinity of metals for sulfur from the equilibrium atio of a hydrogen-hydrogen sulfide atmosphere, which is in contact with a metal and its sulfide, is very limited.

The precipitation process for obtaining metals from their sulfides is only used in practice in special cases. The process of reduction after previous roasting is much more general.

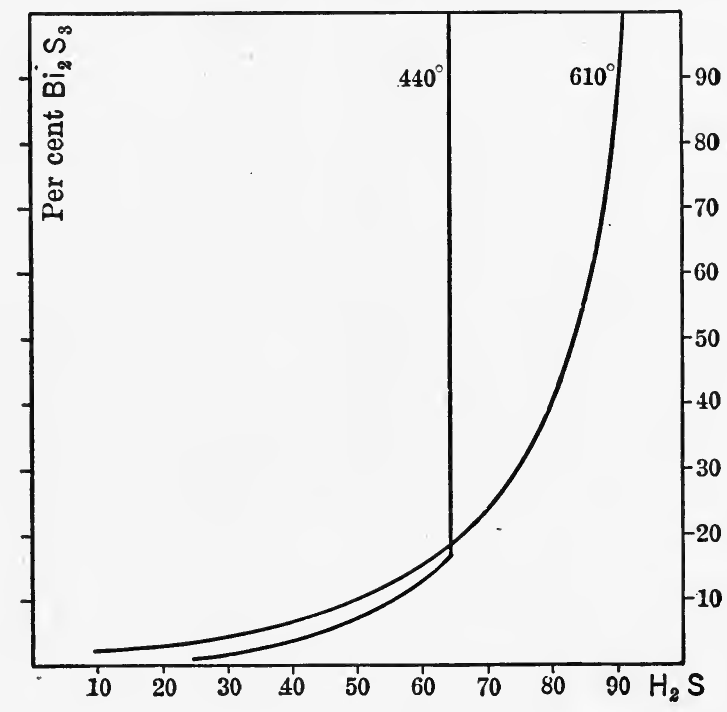

FIG. 108.

By the roasting of sulfides is understood, their oxidation by atmospheric oxygen, a reaction which can be generally represented by the equation

$$
2 \mathrm{MeS}+{ }_{3} \mathrm{O}_{2}=2 \mathrm{MeO}+{ }_{2} \mathrm{SO}_{2} \text {. }
$$

(Me indicating any bivalent metal).

The reverse of this reaction has never been observed. There occurs, however, sometimes in place of the oxide, other oxidation products, under some conditions sulfate is formed. The sulfatizing roast plays a rôle, for example, in the Ziervogel 
process which consists in roasting the argentiferous copper matte so that the silver; but not the accompanying iron and copper, is changed to sulfate, so that by leaching the silver goes into solution, which is then precipitated by copper, washed, pressed and melted in a crucible. The copper and iron remain as oxides in the residue. There is also no difficulty in changing copper sulfide to sulfate and one observes in the Ziervogel process always the formation of copper sulfate as well as iron and silver sulfate. By heating to higher temperatures it decomposes as does the iron sulfate, while the silver sulfate remains unchanged.

We now come to the question: "Under what conditions does the sulfide go on roasting to oxide, and under what conditions to sulfate?" Frequently the result of the roasting depends on the temperature and the composition of the gas phase which is over the material to be roasted.

From analytical practice we know that by strong heating the sulfates of the heavy metals are decomposed and that thereby sulfur trioxide as well as sulfur dioxide and oxygen are formed. This reaction has also technical importance, or rather it has had, since on it depends the old method for the preparation of fuming sulfuric acid and sulfur trioxide, in which iron sulfate was heated in retorts and the evolved vapor condensed in prolongs which contained a small amount of water.

The decomposition of the sulfate is a dissociation process which can be represented by the equation

$$
\mathrm{MeSO}_{4} \rightleftarrows \mathrm{MeO}+\mathrm{SO}_{3} \text {. }
$$

We may conclude on the basis of the phase rule, that a definite sulfur trioxide pressure exists for every temperature. If a sulfate is heated in a previously evacuated vessel, connected with a manometer, at a constant temperature, a definite pressure results. Since a number of metal oxides favor the decomposition of sulfur trioxide into sulfur dioxide and oxygen, these gaseous substances are found in the dissociation products of the sulfate and raise the dissociation pressure. This does not interfere, however, if we heat them with platinum gauze so that 
the equilibrium between the two oxides of sulfur and oxygen can take place. The resulting gas pressure allows us to calculate the partial pressure of $\mathrm{SO}_{3}$ and from that the $\mathrm{SO}_{3}$ tension of the sulfate. The observed pressure is equal to the sum of the partial pressures of the separate gases present.

$$
P=p \mathrm{So}_{3}+p \mathrm{SO}_{2}+p \mathrm{o}_{2}
$$

and since the number of molecules of oxygen that result from the decomposition of the trioxide is half as great as that of the trioxide, so it follows

$$
P=\mathrm{PSO}_{3}+\frac{3}{2} \mathrm{pso}_{2} \text {. }
$$

Recently Keppeler,* and L. Wöhler, Plüddemann and P. Wöhler $\dagger$ have made observations concerning the tension of sulfates and measured the values of $P$ for a series of metallic sulfates.

The equilibrium between $\mathrm{SO}_{3}, \mathrm{SO}_{2}$, and $\mathrm{O}$, has been rather completely investigated by Knietsch, $\ddagger$ Bodlander, $\S$ and further by Bodenstein and Pohl.\| The equilibrium conditions for the reversible reaction are

$$
\begin{gathered}
{ }_{2} \mathrm{SO}_{3} \rightleftarrows{ }_{2} \mathrm{SO}_{2}+\mathrm{O}_{2}, \\
K=\frac{\mathrm{C}^{2} \mathrm{SO}_{2} \cdot \mathrm{C}_{\mathrm{O}_{2}}}{\mathrm{C}^{2}{ }_{\mathrm{SO}_{3}}}
\end{gathered}
$$

The magnitude for the constant $K$ as measured for different temperatures by Bodenstein and Pohl are given in the following table:

\begin{tabular}{c|c||c|c}
\hline $\begin{array}{c}\text { Temperature in } \\
\text { Degrees. }\end{array}$ & $K$. & $\begin{array}{c}\text { Temperature in } \\
\text { Degrees. }\end{array}$ & $K$. \\
\hline 528 & I.55.10-5 & 727 & $3 \cdot 45 \cdot 10-3$ \\
579 & $7 \cdot 55 \cdot 10-5$ & 789 & I.26.10-2 \\
627 & $3 \cdot 16 \cdot 10-4$ & 832 & $2.80 .10-2$ \\
680 & I.12.10-3 & 897 & $8.16 .10-2$ \\
\hline
\end{tabular}

*Z. angew. Chem., 21, 532 (I908).

‡ Ber., 344059 (r90r).
$†$ Ber., 41, 703 (1908).

§ Z. Elektrochem., 9, 787 (I903).

|| Z. Elektrochem., 11, 373 (1905). 
TENSION $P$ ACCORDING TO L. WÖHLER, PLÜDDEMANN AND P. WÖHLER

\begin{tabular}{c|c||c|c}
\hline Temp. in Degrees. & Pressure in $\mathrm{Mm}$. & Temp. in Degrees. & Pressure in $\mathrm{Mm}$. \\
\cline { 1 - 2 } $\mathrm{Fe}_{2}\left(\mathrm{SO}_{4}\right) \rightleftarrows \mathrm{Fe}_{2} \mathrm{O}_{3}+{ }_{3} \mathrm{SO}_{3}\left(\mathrm{SO}_{2}, \mathrm{O}_{2}\right)$. & $\mathrm{Al}_{2}\left(\mathrm{SO}_{4}\right)_{3 .} \rightleftarrows \mathrm{Al}_{2} \mathrm{O}_{3}+{ }_{3} \mathrm{SO}_{3}\left(\mathrm{SO}_{2}, \mathrm{O}_{2}\right)$. \\
\hline & & & \\
553 & 23 & 572 & 28 \\
570 & 33 & $62 \mathrm{I}$ & $5 \mathrm{I}$ \\
592 & 35 & $68 \mathrm{I}$ & 120 \\
614 & 70 & 702 & 180 \\
634 & $\mathrm{II}$ & 720 & $26 \mathrm{I}$ \\
650 & $\mathrm{I} 49$ & $73 \mathrm{I}$ & 356 \\
660 & $\mathrm{I} 82$ & 742 & 480 \\
680 & 286 & 748 & 692 \\
$690^{\circ}$ & 401 & & \\
699 & 560 & & \\
707 & 715 & & \\
\hline
\end{tabular}

\begin{tabular}{|c|c|c|c|}
\hline \multicolumn{2}{|c|}{${ }_{2} \mathrm{CuSO}_{4} \rightleftarrows{ }_{2} \mathrm{CuO} \cdot \mathrm{SO}_{3}+\mathrm{SO}_{3}\left(\mathrm{SO}_{2} \mathrm{O}_{2}\right)$} & \multicolumn{2}{|c|}{${ }_{2} \mathrm{CuO} . \mathrm{SO}_{2} . \rightleftarrows{ }_{2} \mathrm{CuO}+\mathrm{SO}_{3}\left(\mathrm{SO}_{2}, \mathrm{O}_{2}\right)$. } \\
\hline 546 & 43 & 600 & 62 \\
\hline $5^{88}$ & 55 & 653 & 98 \\
\hline 615 & 700 & 686 & I 23 \\
\hline 642 & 98 & 705 & 139 \\
\hline 665 & 130 & 728 & I 73 \\
\hline 700 & 233 & 745 & 209 \\
\hline 714 & 324 & 775 & 298 \\
\hline 725 & 460 & 805 & 542 \\
\hline
\end{tabular}

\begin{tabular}{|c|c|}
\hline Temp. in Degrees. & Pressure in $\mathrm{Mm}$. \\
\hline $\mathrm{ZnSO}_{4} . \rightleftarrows \mathrm{ZnO}+\mathrm{SO}_{3}\left(\mathrm{SO}_{2}, \mathrm{O}_{2}\right)$ \\
\hline 675 & 5 \\
690 & 6 \\
720 & 24 \\
750 & 61 \\
775 & 112 \\
800 & 189 \\
\hline
\end{tabular}


From the plotting of $\log K$ the values for the intermediate temperatures can be obtained. (Fig. Iog.)

If we rearrange the equilibrium conditions somewhat we obtain

$$
\mathrm{C}^{2}{ }_{\mathrm{sO}_{3}}=\frac{\mathrm{C}^{2} \mathrm{sO}_{2} \cdot \mathrm{C}_{\mathrm{O}_{2}}}{K}
$$

i.e.,

$$
\mathrm{C}_{\mathrm{SO}_{3}}=\mathrm{C}_{\mathrm{SO}_{2}} \sqrt{\frac{\mathrm{C}_{\mathrm{O}_{2}}}{K}}
$$

If we designate the $\mathrm{SO}_{3}$ concentration corresponding to the dissociation tension by $\mathrm{CsO}_{3}$, the equilibrium between the solid

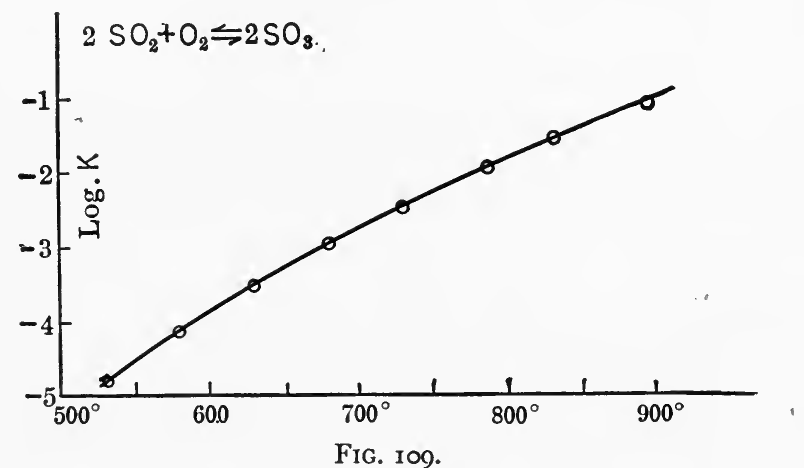

products, metal sulfate, and oxide and the gases $\mathrm{SO}_{3}, \mathrm{SO}_{2}$, and $\mathrm{O}_{2}$ requires,

$$
\mathrm{C}_{\mathrm{SO}_{3}}=\mathrm{C}_{\mathrm{SO}_{2}} \cdot \sqrt{\frac{\mathrm{C}_{\mathrm{O}_{2}}}{K}}
$$

If the expression on the right is greater the oxide changes to sulfate, if it is smaller the sulfate decomposes.

The same conditions also hold for the roasting process. By roasting an atmosphere is obtained, which contains $\mathrm{SO}_{2}$ and the unused oxygen. . If we designate the concentrations with $\mathrm{CsO}_{2}$ and $\mathrm{Co}_{2}$, the conditions for the formation of oxide are

$$
\mathrm{C}_{\mathrm{SO}_{2}} \cdot \sqrt{\frac{\mathrm{C}_{\mathrm{O}_{2}}}{K}}>\mathrm{C}_{\mathrm{SO}_{3}} \cdot
$$


The conditions for the sulfatizing roast are:

$$
\mathrm{C}_{\mathrm{SO}_{2}} \sqrt{\frac{\mathrm{C}_{\mathrm{O}_{2}}}{K}}<\mathrm{C}_{\mathrm{SO}_{3}} \text {. }
$$

It is frequently more convenient to use the partial pressure of the gases, in place of the concentrations, these are obtained, expressed in atmospheres (which, however, are easily converted into millimeters, by multiplying by 760 ) by the general gas equation:

$$
p=c . R . T .
$$

The roast reactions are of the form

$$
\begin{gathered}
p s o_{2} \cdot \sqrt{\frac{p o_{2}}{R \cdot T \cdot K .}}>p s o_{3} \text { (oxidizing) } \\
\cdot p s o_{2} \cdot \sqrt{\frac{p o_{2}}{R \cdot T \cdot K .}}<p s o_{3} \text { (sulfatizing). }
\end{gathered}
$$

where $R=0.082 \mathrm{I}$, the general gas constant.

The partial pressures of $\mathrm{SO}_{3}$ for single important sulfates

\begin{tabular}{|c|c|c|c|c|}
\hline \multirow{2}{*}{$\begin{array}{c}\text { Temperature in } \\
\text { Degrees. }\end{array}$} & \multicolumn{4}{|c|}{$p \mathrm{SO}_{3}$ in Millimeters for the System. } \\
\hline & $\mathrm{Fe}_{2}\left(\mathrm{SO}_{4}\right)_{3}: \mathrm{Fe}_{2} \mathrm{O}_{3}$ & $\begin{array}{c}\mathrm{CuSO}_{4} ; \\
(\mathrm{CuO})_{2} \mathrm{SO}_{8} .\end{array}$ & $\begin{array}{c}\left(\mathrm{CuO}_{2} \mathrm{SO}_{3}:\right. \\
\mathrm{CuO} .\end{array}$ & $\mathrm{ZnSO}_{4} \mathrm{ZnO}$. \\
\hline $55^{\circ}$ & I 2 & 27 & & \\
\hline 600 & 22.5 & 29 & 29 & \\
\hline 650 & $6 \mathrm{r} \cdot 5$ & 40 & 33 & \\
\hline 700 & 244 & 99 & 35 & I \\
\hline 750 & $\ldots \ldots \ldots \ldots$ & $\ldots \ldots \ldots \ldots$ & 52 & 8.7 \\
\hline 800 & $\ldots \ldots \ldots \ldots$ & $\ldots \ldots \ldots \ldots$ & 104 & 28.5 \\
\hline
\end{tabular}
can be calculated from the above given observations of $\mathrm{L}$. Wöhler, and his co-workers, and are given in the following table.

$\mathrm{SO}_{3}$-TENSION OF SULFATES

In special cases the roasting process can be carried on so that the metal results directly. This very remarkable reaction plays an important role in the smelting of copper and lead. The metal is due to a reaction of the roasting products with 
the still unattacked sulfide. We designate this reaction commonly as the "Roasting Reaction." The chemical process for the formation of blister copper out of copper sulfide of the copper matte can be represented by the following reactions:

$$
\begin{aligned}
\mathrm{Cu}_{2} \mathrm{~S}+{ }_{2} \mathrm{CuO} & ={ }_{4} \mathrm{Cu}+\mathrm{SO}_{2}, \\
\mathrm{Cu}_{2} \mathrm{~S}+{ }_{2} \mathrm{Cu}_{2} \mathrm{O} & =6 \mathrm{Cu}+\mathrm{SO}_{2}, \\
\mathrm{Cu}_{2} \mathrm{~S}+\mathrm{CuSO}_{4} & ={ }_{3} \mathrm{Cu}+{ }_{2} \mathrm{SO}_{2} .
\end{aligned}
$$

And for the lead " roast reactions "* the process is commonly formulated

$$
\begin{aligned}
\mathrm{PbS}+\mathrm{PbSO}_{4} & ={ }_{2} \mathrm{~Pb}+{ }_{2} \mathrm{SO}_{2}, \\
\mathrm{Pbs}+{ }_{2} \mathrm{PbO} & ={ }_{3} \mathrm{~Pb}+\mathrm{SO}_{2} .
\end{aligned}
$$

These reactions appear very simple. It has, however, been found that the reactions between the factors can under some conditions go in other directions. One of these deviations is of practical importance in the Huntington and Heberlein lead smelting process. From lead sulfate and lead sulfide, lead oxide is formed according to the equation:

$$
\mathrm{PbS}+{ }_{3} \mathrm{PbSO}_{4}={ }_{4} \mathrm{PbO}+{ }_{4} \mathrm{SO}_{2} .
$$

The conditions are still further complicated by the condition that metallic lead absorbs $\mathrm{SO}_{2}$ at high temperatures as Jenkins and Smith have found, and that these reactions give different kinds of products, oxide, sulfate and sulfide.

All the conditions indicate that the named reactions are reversible, and that measurable chemical equilibria occur. This assumption has proved entirely correct and we are now able to give the conditions under which the various reactions go on. We will now show by an example how the laws of chemical equilibria are used for practical questions.

The phase rule is first used to determine the kind of the equilibrium. We have systems in which there are three com-

\footnotetext{
*For a consideration of the lead "roast reactions," see Ber., 40, 2i85 (I907)
} 
ponents, lead, sulfur, and oxygen. Beside the gas, sulfur dioxide, we may expect as separate solid or liquid phases, metallic lead, lead sulfide, lead oxide and lead sulfide.

Whether beside these still others as basic sulfates are possible needs a special investigation, whose results we will consider further.

If we would orient ourselves concerning such complex reaction systems it is best to first investigate the univariant equilibria. Since a gas phase is present in our system, it corresponds to a definite pressure dependent only on the temperature. For the occurrence of a univariant equilibrium in a three-component system the simultaneous presence of four phases is required, that is, three solid or liquid phases beside the gas phase. If the three solid or liquid phases be heated to a high temperature, gas is evolved and the reactions are stopped at a definite pressure if observable equilibria occur.

The four solid or liquid phases which we know can be combined in four combinations of three and so we obtain three possible univariant equilibria. These must be first investigated as to whether they give measurable pressure values. The possible combinations are the following:

(I) $\mathrm{PbSO}_{4}, \mathrm{PbS}, \mathrm{Pb}$, Gas.

(2) $\mathrm{PbO}, \mathrm{PbS}, \mathrm{Pb}$, Gas.

(3) $\mathrm{PbSO}, \mathrm{PbO}, \mathrm{PbS}$, Gas.

(4) $\mathrm{PbSO}, \mathrm{PbO}, \mathrm{Pb}$, Gas.

It has been shown that measurable equilibria occur in the first two. Especially in the first, the equilibrium pressure is arrived at quickly and sharply, and is independent of the direction from which it is approached. The gas evolution by heating a mixture of lead sulfide and lead sulfate in the presence of some metal comes to a halt at the same $\mathrm{SO}_{2}$ tension as the absorption of the gas by metallic lead in the presence of sulfide and sulfate.

The reaction between sulfide and sulfate begins to go appreciably at $550^{\circ}$. At this temperature, the evolution of $\mathrm{SO}_{2}$ is perceptible. At $600^{\circ}$ measurable pressures are reached, which 
grow rapidly with rising temperature so that by about $725^{\circ}$ the pressure of the atmosphere is reached.

Sulfide and oxide do not react so easily, it is first possible to ascertain traces of $\mathrm{SO}_{2}$ at $650-660^{\circ}$. The following table shows the equilibrium pressure:

\begin{tabular}{|c|c|c|c|}
\hline \multicolumn{2}{|c|}{ I. $\mathrm{PbS}+\mathrm{PbSO}_{4 .} \rightleftarrows{ }_{2} \mathrm{~Pb}+2 \mathrm{SO}_{2}$} & \multicolumn{2}{|c|}{ II. $\mathrm{PbS}+2 \mathrm{PbO} . \rightleftarrows \mathrm{Pb}+\mathrm{SO}_{2}$. } \\
\hline Temp. in Degrees. & Pressure in $\mathrm{Mm}$. & Temp. in Degrees. & Pressure in $\mathrm{Mm}$. \\
\hline 600 & 39 & 692 & 6 \\
\hline 615 & 61 & 712 & I4 \\
\hline 635 & 98 & 733 & 23 \\
\hline 665 & 201 & 751 & 39 \\
\hline 695 & 402 & 776 & 60 \\
\hline 713 & 590 & 800 & 99 \\
\hline 723 & 735 & 824 & 276 \\
\hline
\end{tabular}

If the second reaction is not carried above $800^{\circ}$ it appears reversible. By falling temperature and the absorption of $\mathrm{SO}_{2}$, we arrive again at the pressure values which had been found for the reaction between oxide and sulfide.

If the solid mass is heated very hot and then quickly cooled to the given temperature it does not return to the original condition. We obtain after the first absorption of sulfur dioxide, final values for the pressure which are far higher than those given above. These phenomena cannot be dependent on a slow attainment of the equilibrium from this side, since we obtain it, also if we remove the gas with a mercury pump and allow the solid substances to evolve new sulfur dioxide.

The position of this value in respect to the above given, can be seen from the graphic representation. (See Fig. I Io.) It gives the new curve which lies between those for the systems sulfate, sulfide, metal, gas and oxide, sulfide, metal, gas. What substance has been formed by the high heating and quenching, cannot be said from these considerations, this question requires a special investigation. We can only assume that at high temperature the lead oxide goes over to the liquid state and 
that by long heating it forms sulfate, by action of the $\mathrm{SO}_{2}$. Out of this sulfate containing melt we may precipitate by cooling different kinds of products, there may, as a single possibility, be solid solution or compounds between oxide and sulfate present in the solid phase and the variation of the gas evolution may be due to these.

These we can only decide by investigation of the crystallization diagram of the system lead oxide-lead sulfate. The

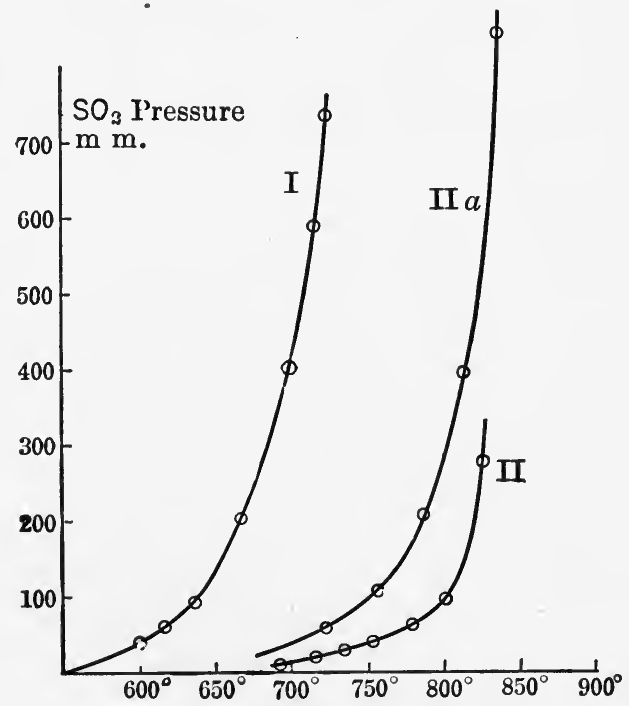

FIG. I IO.

equilibrium diagram of this pair of components is shown in Fig. III. From this the remarkable fact is apparent that there are a number of compounds between lead sulfate and lead oxide. Two of them are recognized by maxima in the crystallization curve. They are the two basic sulfates $\mathrm{PbO} \cdot \mathrm{PbSO}_{4}$ and ${ }_{2} \mathrm{PbO} \cdot \mathrm{PbSO}_{4}$. Beside these there is still a third compound, ${ }_{3} \mathrm{PbO} \cdot \mathrm{PbSO}_{4}$, whose maximum is not, however, to be observed, since it decomposes before it is reached.

The position of the melting point for the components and their compounds are as follows:

$\mathrm{PbSO}_{4} \ldots \ldots \ldots \mathrm{I}_{100^{\circ}}$

PbO......... $882^{\circ}$
$\mathrm{PbSO}_{4} \cdot \mathrm{PbO} \ldots . .966^{\circ}$

$\mathrm{PbSO}_{4} \cdot 2 \mathrm{PbO} \ldots . .95^{\circ}$ 
The compound $\mathrm{PbSO}_{4} \cdot 3 \mathrm{PbO}$ decomposes above $880^{\circ}$ into the compound $\mathrm{PbSO}_{4} \cdot 2 \mathrm{PbO}$ and melt.

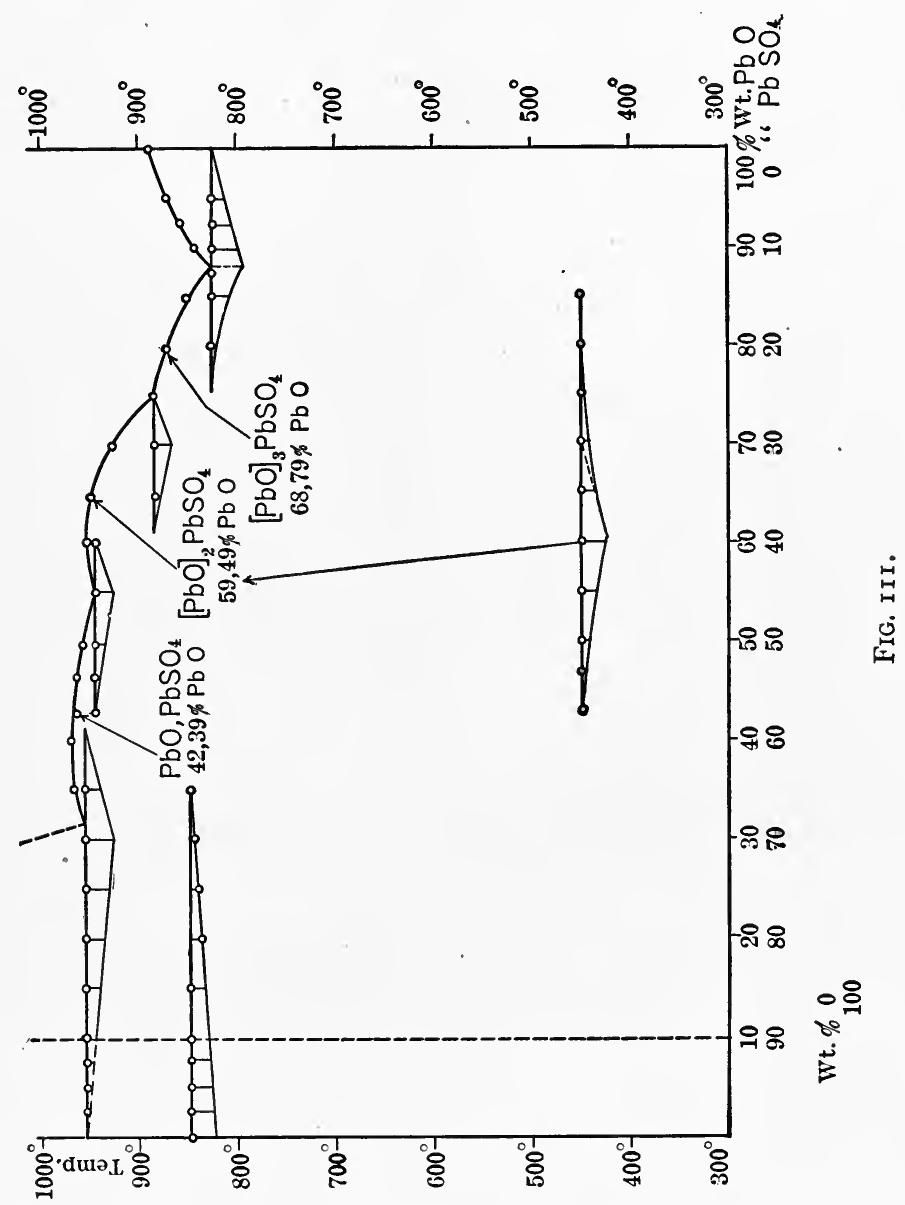

Eutectic points are present in three cases:

$\mathrm{PbO}-\mathrm{PbSO}_{4} \cdot 3 \mathrm{PbO}$ at $820^{\circ}$ and 87 per cent $\mathrm{PbO}$. $\mathrm{PbSO}_{4} \cdot{ }_{2} \mathrm{PbO}-\mathrm{PbSO}_{4} \cdot \mathrm{PbO}$ at $940^{\circ}$ and 553 per cent $\mathrm{PbO}$. $\mathrm{PbSO}_{4} \cdot \mathrm{PbO}-\mathrm{PbSO}_{4}$ at $95^{\circ}$ and 30 per cent $\mathrm{PbO}$.

Besides these there occur two horizontals in the diagram which correspond to transitions in the solid state. The one 
at $845^{\circ}$ corresponds to a transition of the pure lead sulfate while the second at $45^{\circ}$ corresponds to a rearrangement of the compound $\mathrm{PbSO}_{4} \cdot{ }_{2} \mathrm{PbO}$. This rearrangement is reversible. It shows a halt-point with both rising and falling temperature. Whether this is a change of modification or the chemical reaction

$$
{ }_{2} \mathrm{PbSO}_{4} \cdot{ }_{2} \mathrm{PbO} \rightleftarrows \mathrm{PbSO}_{4} \cdot \mathrm{PbO}+\mathrm{PbSO}_{4} \cdot{ }_{3} \mathrm{PbO}
$$

cannot be decided easily and for our special purpose it makes no difference.

The temperature field of $55^{\circ}-900^{\circ}$ is the only one of importance to us, inside of this we have to do with three solid phases due to the fact that three basic sulfates of lead exist. We may conclude from this test that the raised sulfur dioxide tension which occurs with mixtures of oxide, sulfide and metal, previously heated to melting is due to the presence of these basic sulfates and indeed it turns out that the deviation is conditioned by the formation of $\mathrm{PbSO}_{4} \cdot \mathrm{PbO}$ and that the curve represents the equilibrium.

$$
{ }_{2}\left(\mathrm{PbSO}_{4} \cdot \mathrm{PbO}\right)+{ }_{3} \mathrm{PbS} \rightleftarrows 7{ }_{7} \mathrm{~Pb}+{ }_{5} \mathrm{SO}_{2} .
$$

The formation of this basic sulfate can be easily understood. The action of $\mathrm{SO}_{2}$ on molten lead oxide is under all conditions to form sulfate. If we allow such a melt to crystallize we obtain a eutectic which consists of basic sulfates. For the greatest sulfur dioxide tension, that substance is necessary which with sulfide will develop the highest pressure and that is naturally the sulfate-richest substance.

The pressure value and curves for the other basic salts must be obtained by special experiments. A glance at the diagram shows us that to procure the melts which would allow us to measure the $\mathrm{SO}_{2}$ tension of the equilibrium system, basic salt, sulfide, metal, gas, would require special preparations. The measurements must always be carried out at temperatures not exceeding $830^{\circ}$. 
The Structure Constituents Present in the Solid Mass.

I. $\mathrm{PbSO}_{4} \cdot 3 \mathrm{PbO}$ with $\mathrm{PbO}$

2. $\mathrm{PbSO}_{4} \cdot{ }_{2} \mathrm{PbO}$ with $\mathrm{PbSO}_{4} \cdot{ }_{3} \mathrm{PbO}$

3. $\mathrm{PbSO}_{4} \cdot \mathrm{PbO}$ with $\mathrm{PbSO}_{4} \cdot{ }_{2} \mathrm{PbO}$

4. $\mathrm{PbSO}_{4}$ with $\mathrm{PbSO}_{4} \mathrm{PbO}$
The Composition of the Melts, $\mathrm{PbSO}_{4}$, Per cent.

25

25-39

$39-60$

60

For every basic salt we would expect a curve which represents the equilibrium between each of these salts, sulfide metal and gas.

Masses, formed by melting oxide and sulfate, in the ratio, which No. 3 of the given table represents, are rich in the basic sulfate $\mathrm{PbSO}_{4} \cdot \mathrm{PbO}$ and quickly reach equilibrium with sulfide, metal and $\mathrm{SO}_{2}$ and a definite $\mathrm{SO}_{2}$ tension is obtained which increases with rising temperature. With the oxide rich melts in which the other basic sulphates are contained equilibrium is reached only with difficulty and the position of their corresponding equilibrium curves is uncertain, we are therefore limited in our considerations to the normal basic sulfate. The dependence of the $\mathrm{SO}_{2}$ tension on the temperature is given in the following table:

\begin{tabular}{c|c||c|c}
\hline $\begin{array}{c}\text { Temperature in } \\
\text { Degrees. }\end{array}$ & Pressure in Mm. & $\begin{array}{c}\text { Temperature in } \\
\text { Degrees. }\end{array}$ & Prcssure in Mm. \\
\cline { 1 - 3 } $68 \mathrm{I}$ & $\mathrm{I6}$ & 780 & 217 \\
$7 \mathrm{I} 6$ & 42 & 795 & 306 \\
$74 \mathrm{I}$ & $8 \mathrm{I}$ & 810 & 440 \\
759 & $\mathrm{I30}$ & $82 \mathrm{I}$ & 548 \\
770 & $\mathrm{I84}$ & 830 & 710 \\
\hline
\end{tabular}

If we compare these values with those of the system II $a$ Fig. Iro, we see that these fall completely together with the curve for the basic sulphate. By the action of $\mathrm{SO}_{2}$ on lead oxide during the cooling basic sulfate has formed.

We obtain accordingly three equilibrium curves (if those for the di- and tri-basic sulfates were known there would be, in all, five) their comparative position is shown in Fig. II 2. 
These curves divide the coordinate plane into four different fields, inside of these, different possible reactions take place and different end products remain. The following table gives

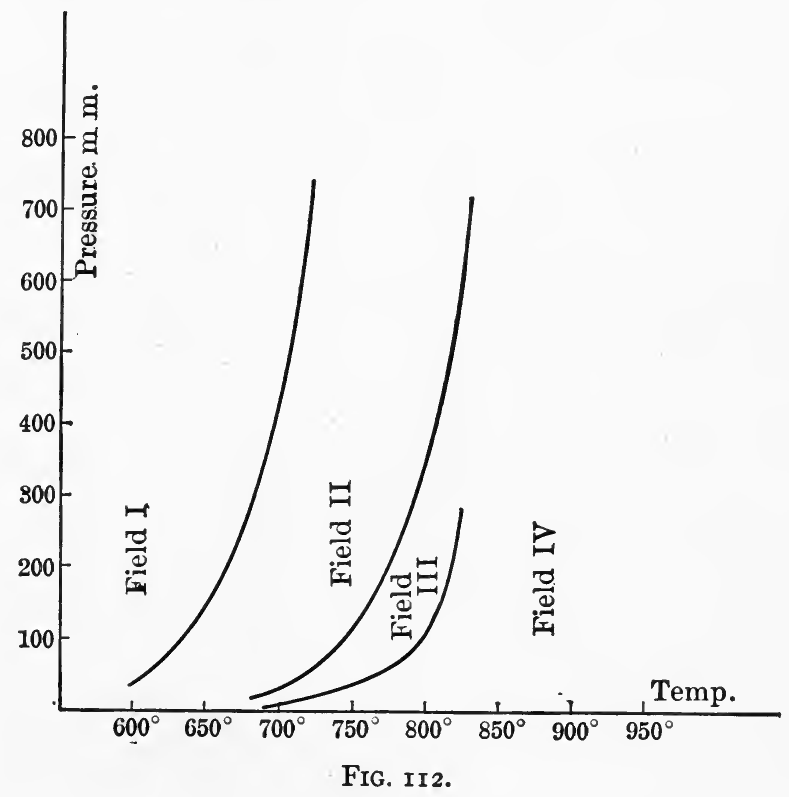

us a general view of the reaction system, the stable solid products are in heavy type:

Field I.
(a) $2 \mathrm{~Pb}+2 \mathrm{SO}_{2}$
$=\mathrm{PbSO}_{4}+\mathrm{PbS}$,
(b) $7 \mathrm{~Pb}+{ }_{5} \mathrm{SO}_{2}$
$=2\left(\mathrm{PbSO}_{4} \cdot \mathrm{PbO}\right)+{ }_{3} \mathrm{PbS}$,
(c) ${ }_{3} \mathrm{~Pb}+\mathrm{SO}_{2}$
$=2 \mathrm{PbO}+\mathrm{PbS}$.

Field II.
(a) $\mathrm{PbSO}_{4}+\mathrm{PbS}$
$=2 \mathrm{~Pb}+2 \mathrm{SO}_{2}$,
(b) $7 \mathrm{~Pb}+{ }_{5} \mathrm{SO}_{2}$
$=2\left(\mathrm{PbSO}_{4} \cdot \mathrm{PbO}\right)+{ }_{3} \mathrm{PbS}$,
(c) ${ }_{3} \mathrm{~Pb}+\mathrm{SO}_{2}$
$=2 \mathrm{PbO}+\mathrm{PbS}$.

Field III.
(a) $\mathrm{PbSO}_{4}+\mathrm{PbS}$
$={ }_{2} \mathrm{PbO}+\mathrm{PbS}$,
(b) $\left({ }_{2} \mathrm{PbSO}_{4} \cdot \mathrm{PbO}\right)+{ }_{3} \mathrm{PbS}={ }_{7} \mathrm{~Pb}+{ }_{5} \mathrm{SO}_{2}$,
(c) ${ }_{3} \mathrm{~Pb}+\mathrm{SO}_{2}$
$=2 \mathrm{PbO}+\mathrm{PbS}$. 
Field IV.
(a) $\mathrm{PbSO}_{4}+\mathrm{PbS}$
$={ }_{2} \mathrm{~Pb}+2 \mathrm{SO}_{2}$,
(b) $2\left(\mathrm{PbSO}_{4} \cdot \mathrm{PbO}\right)+{ }_{3} \mathrm{PbS}=7 \mathrm{~Pb}+5 \mathrm{SO}_{2}$,
(c) $2 \mathrm{PbO}+\mathrm{PbS}$
$={ }_{3} \mathrm{~Pb}+\mathrm{SO}_{2}$.

In Field I sulfate and sulfide do not react with each other, in Field II the basic sulfate does not act on the lead sulfide and in Field III oxide and sulfide are compatible.

It can now be easily shown that the action of sulfur dioxide on lead oxide always gives these stable products. Out of Eqs. $a$ and $b$ of Field I it follows by elimination of the metal

$$
{ }_{4} \mathrm{SO}_{2}+{ }_{4} \mathrm{PbO}={ }_{3} \mathrm{PbSO}_{4}+\mathrm{PbS} .
$$

The same end products are left by the basic sulfate with $\mathrm{SO}_{2}$.

In Field II one obtains the basic sulfate by the action of sulfur dioxide on sulfate, as well as on oxide, and in Field III, the reaction takes place to which one ascribes the principal rôle in the Huntington and Heberlein process:

$$
\mathrm{PbS}+{ }_{3} \mathrm{PbSO}_{4}={ }_{4} \mathrm{PbO}+{ }_{4} \mathrm{SO}_{2} \text {. }
$$

The stable products always result.

It is easiest to reach the most stable state by the action of sulfur dioxide on the metal. The progress of the reaction with time can be followed very conveniently by means of a manometer and further there is the possibility by variation of the gas pressure and temperature to start from every point in the field.

The experiments on the reaction of metallic lead with $\mathrm{SO}_{2}$ in Field I are easily understood. Their results are shown in Fig. Ir3. Metallic lead absorbs $\mathrm{SO}_{2}$; if we observe a closed volume of this gas in contact with lead at constant temperature, we notice a decrease of the gas pressure to a constant value which represents the equilibrium of sulfate with sulfide and metal. The values $653^{\circ}$ : IOI mm., $690^{\circ}: 240 \mathrm{~mm}$., fall exactly with the sulfate curve, observed from the other direction.

If the experiments be continued still further so would a further decrease in pressure occur after a time, especially if the sulfate undergoes rearrangement to basic sulfate by tran- 
sitions in the solid phase. When the next curve is reached, the pressure would remain again constant for a time. Also this

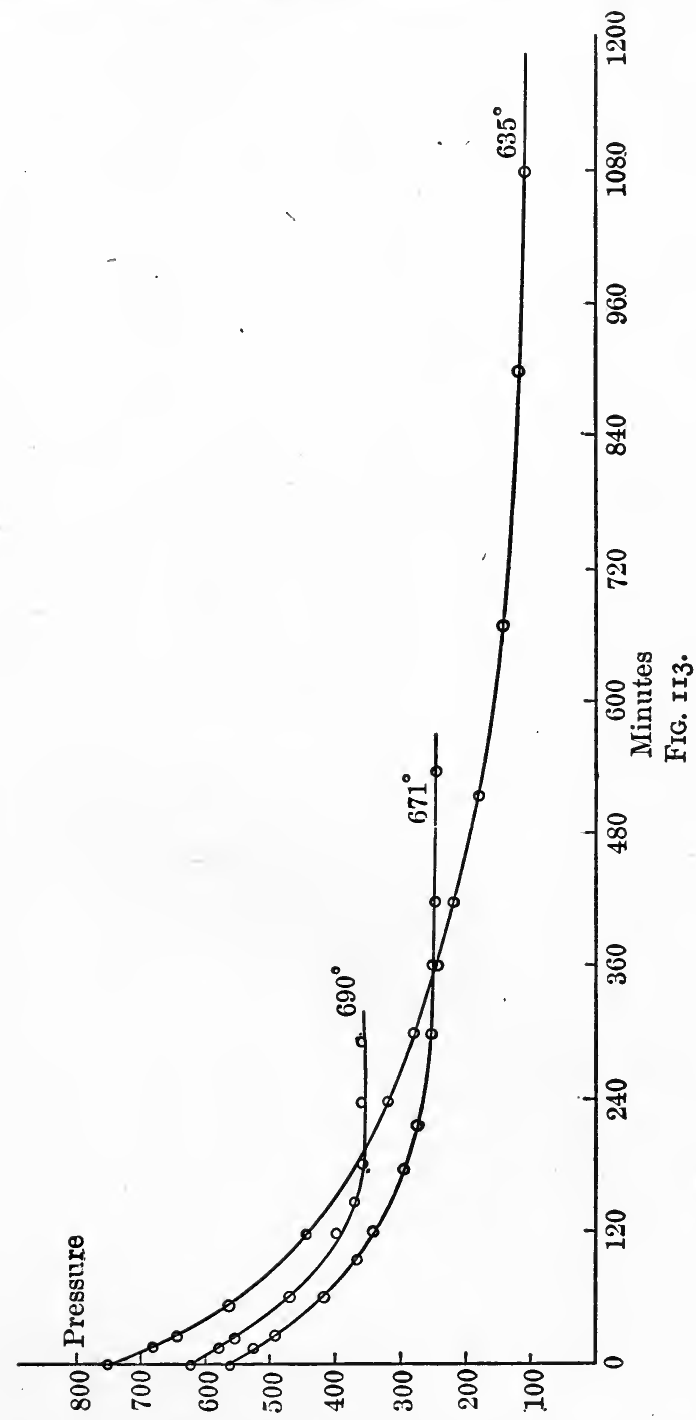

arrest is finally passed and if the amount of lead reacting is very large the pressure sinks to very small values. Such a complete experiment would require considerable time; it would, 
however, be excellent to determine the position of the resulting equilibrium at the considered temperature. Reactions which are connected with the evolution and absorption of gases are best investigated at different temperatures by the surveying of the reaction isotherms and from the position of the pressure halt-points, the equilibrium diagram is constructed in an entirely similar way as we put one together for solidificatior and transition processes from the temperature halt-points.

Since we have not a complete absorption diagram at our disposal we will have to be content with single sections of such. A closed volume of $\mathrm{SO}_{2}$ shows in the presence of lead, which has previously been treated with lead sulfide at $800^{\circ}$, the following change of gas pressure with time:

\begin{tabular}{|c|c|c|c|c|c|}
\hline $\begin{array}{l}\text { Time in } \\
\text { Minutes. }\end{array}$ & $\begin{array}{l}\text { Pressure in } \\
\mathrm{Mm} \text {. }\end{array}$ & $\begin{array}{l}\text { Time in } \\
\text { Minutes. }\end{array}$ & $\begin{array}{l}\text { Pressure in } \\
\mathrm{Mm} \text {. }\end{array}$ & $\begin{array}{l}\text { Time in } \\
\text { Minutes. }\end{array}$ & $\begin{array}{l}\text { Pressure in } \\
\text { Mm. }\end{array}$ \\
\hline 0 & 745 & 96 & r 35 & I32 & I 25 \\
\hline 22 & 559 & 102 & I34 & I92 & I IO \\
\hline 24 & 403 & 108 & 132 & 228 & 100 \\
\hline 42 & $25 \mathrm{I}$ & I I 4 & I3I & & \\
\hline 72 & I56 & I 20 & I 29 & & \\
\hline 84 & 142 & I 26 & $x_{30}$ & 465 & 40 \\
\hline
\end{tabular}

The halt-point lies inside of the Field III, somewhat above the value which the pure oxide shows at $800^{\circ}$, it belongs accordingly to the oxide rich basic salt, probably, however, the lead is still not sufficiently saturated with sulfide.

In all the above treated equilibria the metal phase consists not of pure but of sulfide saturated lead. If the sulfide amount present does not reach saturation equilibrium may be obtained; this is, however, not a univariant but a divariant system, and the $\mathrm{SO}_{2}$ pressure depends on the sulfide concentration of the lead bath.

In Field IV equilibrium curves do not exist and it is more remarkable that we find a halt-point there, as the experiment represented in Fig. II4, shows. At $880^{\circ}$ is shown a retardation in the decrease at a pressure of $90 \mathrm{~mm}$., at $940^{\circ}$ in the interval $470 \mathrm{~mm} .-430^{\prime} \mathrm{mm}$. It is certainly not to be treated as a univari- 
ant equilibrium. There is formed on the upper surface of the . metal, first a relatively concentrated solution of sulfide in metal which, due to its lower specific gravity, floats on the surface. This, in contact with lead oxide, gives a sulfur dioxide tension which remains till the concentration of the solution is decreased by diffusion into the lower layers and since the diffusion equalization requires some time, the retardation is easily understood. Also in Field 4, the reaction

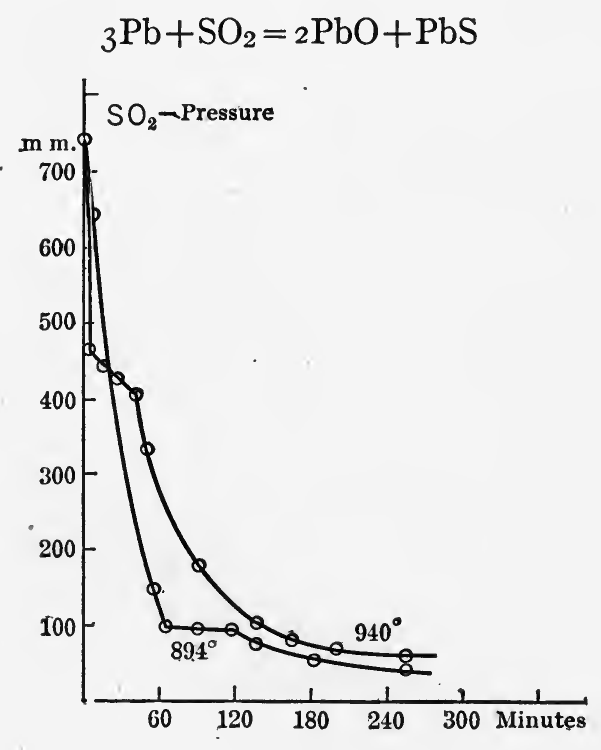

FIG. II4.

can take place, this is true, however, only so long as the solution is not saturated. At the high temperature, it is further to be considered that one no longer has a solid oxide or sulfate phase, but a liquid solution of sulfate in oxide whose concentration depends on the external conditions. In any case we see that to get an understanding of so great a multiplicity of phenomena, as the reactions between the components of the ternary system, lead-sulfur-oxygen show, the consideration of the solubility of the sulfide in the metal and the miscibility of oxide and sulfate in the molten state is absolutely necessary. 



\section{NAME INDEX}

Allen, H. S., 35

Arrhenius, S., 42

Bancroft, W. D., I34

Barus, C., 5

Bauer, I16, I18, I I9, I 20, I26

Baur, I62

Benedicks, 84, 85, 96

Berzelius, I

Bijl, 6o

Bodenstein, 2 I 2

Bodländer, 212

Bornemann, I22, I 25

Börnstein, 9, 10, 4I

Boudouard, I68

Bredig, 40

Broniewski, I6

Burgess, I I, 15

Byers, 37

Bunsen, R., I8I

Carpenter, 84

Chamberlain, 9

Charpy, I6, 65, 69

Chretien, I 6

Cohen, I3, I7, I8

Crow, 15

Darrin, 37

Davy, I

Day, I Io, II3

Dean, R. S., 35

Desch, I I

Dewar, 13

Diesselhorst, $24,78,80$
Drude, 23, 24, 25, 26, 28, 30, 32, 33, 34, 78,8 o, 8 I

Ewen, 9

Fabre du Faure, I8I

Falcke, 162, 177. 185

Faraday, 22

Findlay, 134

Foerster, 84

Franklin, 37

Franz, 23, 26, 77

Friedrich, II4, I I 5, I I 8, I23, I24, I28

Getman, I7

Gibbs, 134, I35

Glaesner, I62

Goerens, 87, 88, 89, 90, 91, 92, 93, 94, $95,96,97,99,100,102,103,104$, 105

Goldschmidt, 149

Goubau, 8

Graham, 8o

Grenet, I6

Grunchant, I 6

Grüneisen, 78

Guertler, 9, I 7, 74, 75, 107, I33

Guldberg, I 52

Hagen, 29

Hanke, 37

Heberlein, 216, 224

Heller, I69, I 77

Henning, 157

Heræus, 57, 180

Heusler, 62 
Heycock, 45, 53

Heyn, 54, 84, IIo, II2, II3, II6, II8, I I 9 , I 20 , I 26

van't Hoff, 45,156

Holborn, I10, II3, I 57

Humphrey, I6, 84

Huntington, 216, 224

Houghton, 9

Jäger, 24, 78, 80

Jenkins, 216

Johnston, 4, 5

v. Jüptner, I43

Kahlbaum, 4

Keppler, 2 I 2

Kinder, 15, 20

Knietsch, 2 I 2

Koessler, 37

Krafft, 6, 28

Kurbatoff, 95

Landolt, 9, Io, 4I

Langmuir, I., 8, 35

Lea, Carey, 39

LeChatelier, I6, 54, 74, 84, I40, 145, I 47, I 5 I, I $52,154,158,164$

Lehman, I8

Leroux, I I4, I I 5, I I 8

Levin, 60

Lewis, I4 I, I43, I68

Lichtenberg, 68

Liebenow, 77

Lorenz, 40

Löwenstein, I 56

Maey, 70

Martens, 54

Matthiesen, 74

Meyer, G., 4I

Meyer, V., 5

Meyerhoffer, 9, 10, 4I

Mittasch, 202

Moissan, 4

Murray, 9

Mond, 202

Nernst, 21, I43, I 55, I 58, I69

Neville, 45, 53
Newton, 68

Nichols, 37

Osmond, 84, Io9

Parkes, 47

Pattison, 52

Pelabon, II6, I4I, 208, 209

Peltier, 77

Petersen, 106

Pluddemann, 212

Poggendorff, 18r

Pohl, 21 2

Preuner, I 59

Puluj, 80

Puschin, 72

Ramsay, 43, 44

Randall, I68

Rathke, 84

Rayleigh, 77

Reinganum, 22

Rhead, I64

Richards, T. W., I35

Roberts-Austen, 4I, 84

Romanoff, 47

Röntgen, I 24

Roozeboom, 5I, 84

Roschdestwensky, 3 I

Rosenhain, I6, 84

Roth, 4

Rubens, 29

Rudolphi, I3 I

Schaum, I3

Scheele, 140

Schenck, I69, I 70, I77

Schule, F. A., 77

Schuster, 30

Semiller, 177

Siedler, 4

Smith, 216

Smits, I69

Sorby, 54

Spring, 47

Ssaposhnikow, 68, 69

Stahl, 143, I49

Stansfield, 84 
Stas, 3

Stead, I 27, I 28

Tammann, 45, 54, 57, 63, I07, I2I, I3I, I33

Thomson, J. J., 23

Thomson, W., 20

Treitschke, I2I

Turner, 9

Waage, I52

Warburg, 6 v. Wartenberg, $155,160,6$ Wheeler, 164

Wiedemann, G., 23, 26, 77

Winkler, I

Wöhler, I

Wöhler, L., 21 2, I48, I4 I

Wöhler, P., 2I

Wood, 68

Wüst, 84,85 , 103, I06

Zeemann, 3I

Ziervogel, 2 I I

Zimmermann, I 70 



\section{SUBJECT INDEX}

Absorption of dyes, 28

metals, 28

Alloys between sulfides, I 23

binary, 49

coincident melting, 60

density of, 70

electrical resistance of, 73

freezing point of, 44

hardness maxima in, 69

heat conductivity of, 77

low melting, 68

magnetic, 62

maximum melting, 60

microscopic examination of, 55

minimum melting, 60

of metals with metallic compounds, 82

sulfides, I I 4

potential of, 72

relation of physical properties to structure of, 68

segregation in, 52

structure of, 53

temperature coefficient of electrical conductivity of, 75

ternary, 64

Aluminum sulfate, sulfur trioxide tension of, $2 \mathrm{I} 3$

Analysis of blast furnace gases, 182

graphite and amorphous carbon, I 78

Aniline dyes, absorption of, 28

luster of, 27

Antimony-antimony sulfide, II 5

explosive, 17

-manganese, 62 sulfide-hydrogen, 208

Arsenic-alloys, I 25

-copper, 129

-iron, I 29

-lead, I 29

-nickel, I3I 
Arsenic-silver, 129

-zinc, 129

Austenite, 95, 96, 97, I0r

Barium peroxide- barium oxide, 146

Blast furnace processes, I80

gas, 182

Bearing metals, 69

Binary alloys, 49

Bismuth-antimony, $5^{8}$

-bismuth sulfide, 209

-lead-tin, 65

-zinc, 47

Boiling points of metals, 4

Cadmium-mercury, $6 \dot{1}$

-zinc, $49,55,56$

Calcium plumbate-plumbite, 147

Carbon-iron, 83

-precipitation of, in iron-carbon alloys, 98

Carbon monoxide, catalysis of $37,164,166,270$

-iron, I 73

-iron oxide, $\mathrm{I} 62$

reduction by, 159

—zinc oxide, I60

Catalysis and passivity, 37

of carbon monoxide, 37, I64, I66, I70

Cementite, $85,87,88,89$

$$
\text { -iron, } 85
$$

Charge on one electron, 25

Chromium-tungsten steel, Io8

influence of, on iron carbon alloys, 104

steel, ro8, ro9

Coefficient of absorption, 28

temperature, of conductivity, 3 I

Coincident melting alloys, 60

Colloidal solutions, aqueous, 39

solid or molten, 40

Colored metals, 34

Color of metal vapors, 6

Cooling curves, ro

Component, 135

Compounds, intermetallic, 60, 6I, 63

with metallic properties, 82

Conductivity, 2I

relation between heat and electrical, 23

Constantan, 76, 77, 8I 
Copper-antimony, 74

-arsenic, 129

- copper oxide, I ro

-copper-sulfide, I I6 matte, 123

- silicon, 132

-silver, 5 I

Critical solution temperature, 47

Crystal growth, 20

Crystallization diagrams, of solid solutions, $57,58,59$

compounds, 6 I

Decomposition of oxides by heat, 148

Degrees of freedom, I35

Density - change in transition of tin $\mathrm{I} 4$

change on melting, 9

of alloys, 70

of explosive antimony, I 7

Desulfurization with iron, 207

Diffusion of metals, 4I

Distillation of metals, 3

Elastic limit, 68

Electrical conductivity of solutions, 2I

gases, 22

metals, 22

properties of metals, 2I

Electromagnetic theory of light, 29

Electrons, concentration of, in metals, 30

normality of, in metals, $3 \mathrm{I}$

Electron theory, 22

Enantiotropy, 18

Equivalent weight of electrons, 24

Faraday's law, 22

Ferrite, 91, 92, 93

Form changes, 32

Frauenhoffer lines, 7

Freezing point depression, 45

Fusion, heat of, 9

of alloys, 44

Gases, blast furnace, 182

Gold-nickel, 60

-platinum, 57, 59

- silver, 58

-sodium, 54

Goldschmidt process, I49 
Graphical representation of three component systems, 66

Graphite and amorphous carbon, analysis of, 178

-iron, Ior

Hardness of alloys, 69

Heat conductivity, 23

conductivity of alloys, 77

of transition, 18

specific, ratio of at constant pressure and at const. vol., 6

of fusion, 9 , ro

- decomposition of oxides by, 148

Heræus process, 57

Heusler's alloys, 62

van't Hoff's equation, 156

Hysteresis, 108

Index of refraction of metals, 28

Iron-arsenic, 129 carbide, $\mathrm{I}_{5} \mathrm{I}$

-carbon, I5I

- carbon monoxide, 173

-iron sulfide, I 20

magnetism of, 16

modifications of, 15,83

oxide-carbon, 177

oxide-hydrogen, 159

passivity of, 34

-phosphorus, 127

- silicon, $\mathrm{I}_{42}$

sulfate, sulfur trioxide tension of, 213

transition points of, I5

volume change of, transition, I5

Kinetic theory, 24

Kish, 98

Kurbatoff reagent, 95

Law of mass action, $\mathbf{I}^{2}$

Wiedemann and Franz, 28

Faraday's, 22

LeChatelier's principle, I5I

Light absorption, 27

reflection, 27

Lead-arsenic, 129

-bismuth-tin, 65

-bismuth-zinc, 47

-lead sulîde, i 44 
Lead-sulfate basic, 222

- sulfur-oxygen, 218

Luster metallic, 21, 28

Magnetism and passivity, 35, 36, 37

of iron, 16

Magnetic alloys, 62

Manganese-antimony, 62

-effect on cementation of iron, I98

-effect on steel, 106

Manganin, 76, 77, 8I

Martensite, 90, 9I, 96

Mass Law, 152

Mattes, I 23

Melting points-definition of, 7 of metals, 8

Mercury-oxygen, I4 I

-cadmium, 6I

- sulfide-hydrogen, 208

Metallic luster, 28 solutions, 39

Metal-oxide-oxygen, I40

Metals, reduction by, 149

Miscibility of metals, 46,57

Molecular weights of dissolved metals, 44 .

Monatomic state of metal vapors, 5, 6

Mond nickel process, 203

Monotropy, 18

Nickel-arsenic, I30

-gold, 6I

- nickel sulfide, 122

- silicon, I33

-steel, 108, 109

Normality of electrons in metals, 3 I

Newton's metal, 68

Oxygen tension, I4I

of metal oxides, 143

Brin's methods for, 146

Optical constants of metals, 21, 27, 28

Osmotic pressure, 42

Oxides, alloys of metals with, I ro

Palladium-oxygen, 144

Parkes process, 47

Passivity, 37, 36, 35, 34

Pattison process, 52 
Perlite, 93, 94, 95

Permeability and passivity, 35

Pest, the tin, I2

Phase Rule, I33-138, 140, 150

Phosphorus alloys, 125

-copper, 126

-iron, 126

Potential of alloys, 72

Polymorphy, II

Precipitation process, 207

Radiographs of gold--sodium alloys, 54

Ratio of heat conductivity to electrical conductivity, 24

Rates of reaction, 20I

Reactions of sulfides, 205

Reagent, Kurbatoff's, 95

Reduction by gases, 149

$\mathrm{CO}, \mathrm{I} 59$

$\mathrm{H}, \mathrm{I} 5 \mathrm{O}$

metals, 149

Reflection, light, 27

constant, 28

Resistance, electrical, of alloys, 73

Roast, sulfatizing, 2 10, 2 I I

Roasting process, 210

reactions, 216

Röntgen rays in the investigation of alloy structure, $5^{8}$

Segregation in alloys, $5^{2}$

Silicides, I $3 \mathbf{I}$

Silicon-copper, 142 effect on steel, ro6

-iron, 132

- nickel, r33

Silver-copper, $5^{\mathrm{I}}$

-oxygen, I I3, I4I

- silver sulfide, I 8

-lead, $5 \mathrm{I}$

Speiss, I 29

sulfide-hydrogen, 208

Solidification curve of binary alloys, I49

Solutions, metallic, 39

colloidal, 39,40

solid, crystallization diagrams of, $57,58,59$

electrical conductivity of, $2 \mathrm{r}$

Sorbite, 95

vapor pressure of metallic, 42

Steel, chromium, 108, I09 
Steel, high speed, i ro

tungsten, 108

chromium tungsten, 108

nickel. 108, 109

Sulfatizing roast, 2 Io, 2 I I

Sulfides, alloys between, I 23

of metals and, I 44

reactions of, 205

Sulfates, sulfur trioxide tension of, 2I3, 2I4

Sulfurets, 207

Sulfur tensions, 206

trioxide, dissociation of, $2 \mathrm{I} 2$

Supercooling, 7, 8, I I

Temperature coefficient of conductivity, $3 \mathrm{I}, 75$

eutectic, $5^{\text {I }}$

Ternary alloys, 64

Tension, oxygen, I4I

sulfur trioxide,

Tin pest, $\mathrm{I} 2$

- bismuth-lead, 65

gray, I 2

Transition points, 20

of iron, 15

of tin, 14

of metals, I 7

Transition, volume change of, I5

heat of, 18

density change of, I4

Troostite, 95, 96

Tungsten steel, I08

Vapor density of metals, 6

pressure of metals, 5 metallic solutions, 42

Vapors, color of metal, 6

monatomic state of metal, 5,6

Viscosity of gas, 3 I

Water vapor, dissociation of, 155

Woods metal, 67

$\mathrm{X}$-rays in the investigation of alloy structure, 53

$$
\begin{aligned}
& \text { Zinc-bismuth-lead, } 47 \\
& \text { - cadmium, } 49,55,56 \\
& \text { - arsenic, I } 29 \\
& \text { oxide-carbon monoxide, } 160
\end{aligned}
$$

Ziervogel process, 2 IO 










THIS BOOK IS DUE ON THE LAST DATE STAMPED BELOW

AN INITIAL FINE OF 25 CENTS WILL BE ASSESSED FOR FAILURE TO RETURN THIS BOOK ON THE DATE DUE. THE PENALTY WILL INCREASE TO 50 CENTS ON THE FOURTH DAY AND TO \$1.00 ON THE SEVENTH DAY OVERDUE.

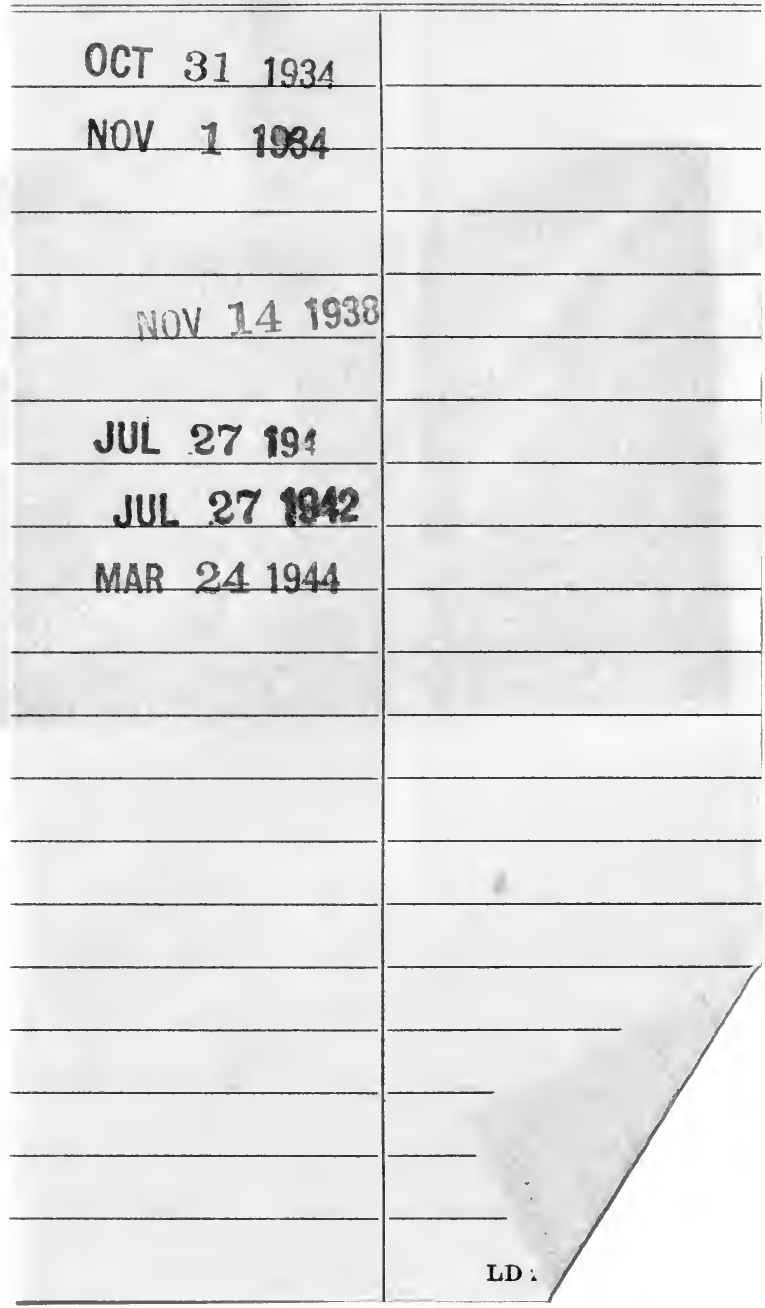


YC 21726

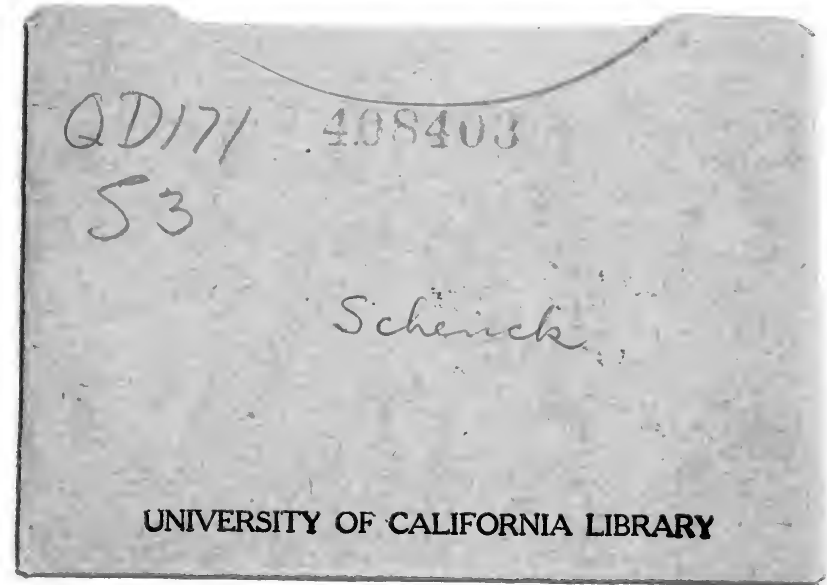


